GUILHERME TODT CARDOSO DE FARO

Versão Original

\title{
AVALIAÇÃO DE SISTEMAS DE RECURSOS HÍDRICOS COMPLEXOS POR MEIO DE INDICADORES DE DESEMPENHO
}



GUILHERME TODT CARDOSO DE FARO

Versão Original

\section{AVALIAÇÃO DE SISTEMAS DE RECURSOS HÍDRICOS COMPLEXOS POR MEIO DE INDICADORES DE DESEMPENHO}

Dissertação apresentada à Escola Politécnica da Universidade de São Paulo para obtenção do título de Mestre em Ciências

Área de concentração:

Engenharia Hidráulica Sanitária

Orientador: Prof. Dr. Joaquin Ignácio Bonnecarrère Garcia

São Paulo 
Autorizo a reprodução e divulgação total ou parcial deste trabalho, por qualquer meio convencional ou eletrônico, para fins de estudo e pesquisa, desde que citada a fonte.

\section{Catalogação-na-publicação}

Faro, Guilherme Todt Cardoso de

Avaliação de sistemas de recursos hídricos complexos por meio de indicadores de desempenho / G. T. C. Faro -- São Paulo, 2020.

$183 \mathrm{p}$.

Dissertação (Mestrado) - Escola Politécnica da Universidade de São Paulo. Departamento de Engenharia de Hidráulica e Ambiental.

1.Gerenciamento de recursos hídricos 2.Indicadores de desempenho 3.Apoio à tomada de decisão I.Universidade de São Paulo. Escola Politécnica. Departamento de Engenharia de Hidráulica e Ambiental II.t. 


\section{AGRADECIMENTOS}

A realização deste trabalho não seria possível sem o apoio de inúmeras pessoas que não só me incentivaram nas dificuldades do dia a dia, mas também deram valiosas contribuições que me permitiram chegar a este momento de conclusão de uma etapa. Registro aqui agradecimentos a alguns desses nomes.

Primeiramente a Deus, meu guia, meu farol.

À Equipe do LabSid, pelo aprendizado diário e pelos meses de convivência. Em especial a Cristiano, Alexandre e Pedro, pelas contribuições diretas na condução deste trabalho.

Aos colegas da pós-graduação, pelo companheirismo e parceria.

Ao professor Rubem, pelo apoio paciente nos meses iniciais do programa e, principalmente, por ter plantado a semente que deu origem a este trabalho.

À professora Mônica e ao professor Arisvaldo, pelas valiosas contribuições da qualificação.

À Sabesp, pelo compartilhamento de informações e dados utilizados no desenvolvimento deste trabalho.

Ao meu orientador, professor Joaquin, pela amizade desenvolvida durante todo este caminho, pelos conhecimentos compartilhados, paciência e dedicação inesgotáveis.

Ao meu tio e padrinho, Luiz Gabriel, pela referência e incentivo constantes.

Ao meu avô Todt, pelas ligações semanais sempre saudosas e zelosas "E o mestrado, filho, vai bem?"

Aos meus pais, Virgílio e Ana Luiza, pelo carinho e apoio sempre presentes.

À Amanda e Arthur, pelo amor compreensivo e, acima de tudo, por terem sido o meu esteio forte destes últimos meses árduos de trabalho. 



\section{RESUMO}

O atual panorama da gestão de recursos hídricos impõe aos gestores e tomadores de decisão a complexa tarefa de ter que lidar com inúmeros desafios do ponto de vista do atendimento às múltiplas demandas e interesses que cercam a gestão da água. As pressões sobre os sistemas de recursos hídricos, principalmente associadas aos avanços do desenvolvimento econômico da sociedade, delimitam um novo contexto para as atividades de planejamento e gestão. Somados ainda os riscos e incertezas associados ao comportamento das variáveis hidrológicas que afetam direta e indiretamente os sistemas de recursos hídricos, urge o desenvolvimento e consolidação de ferramentas que apoiem os gestores nesta desafiadora tarefa de garantir o uso sustentável do recurso para todas as partes interessadas. Sobre este pano de fundo, o presente trabalho teve como objetivo a avaliação de um sistema de recursos hídricos altamente complexo, o Sistema Integrado Metropolitano (SIM), responsável pelo abastecimento de água da Região Metropolitana de São Paulo (RMSP), por meio de indicadores de desempenho (Confiabilidade, Resiliência e Vulnerabilidade) e Índices de Sustentabilidade. A avaliação proposta foi desenvolvida frente a diferentes cenários de operação do SIM, considerando desde a inclusão de obras de segurança hídrica, planejadas no âmbito da Crise Hídrica de 2014-2015, até a integração efetiva do sistema através de pontos de demanda compartilhada entre os sistemas produtores do SIM. Pretendeu-se analisar detalhadamente os ganhos e perdas de desempenho provocados por diferentes arranjos estruturais da rede, com foco principal na discussão dos impactos de desempenho gerados nas condições insatisfatórias de operação do sistema, procurando, assim, contribuir para o incremento das bases técnicas nos processos de tomada de decisão referentes à gestão de sistemas de recursos hídricos complexos, influenciados por múltiplas demandas e interesses, neste novo contexto em constante transformação.

Palavras-chave: Gerenciamento de recursos hídricos, indicadores de desempenho, índices de sustentabilidade, suporte à tomada de decisão, Sistema Integrado Metropolitano. 


\begin{abstract}
The present water management framework imposes upon managers and decision makers the complex task of dealing with numerous challenges in terms of addressing multiple demands and interests surrounding water management. The pressure on water resources systems, mainly associated with the society's economic development, sets a new framework for planning and management activities. Furthermore, considering the risks and uncertainties associated with hydrological variables behavior that directly and indirectly affect water resources systems, there is an urgent need to develop and consolidate new tools to support managers in this challenging task of ensuring the sustainable water use for all stakeholders. In this context, this work aimed to evaluate a highly complex water resources system, the Metropolitan Integrated System (SIM), responsible for São Paulo Metropolitan Region water supply (RMSP), through performance indicators (Reliability, Resilience and Vulnerability) and Sustainability Indexes. The assessment was developed under different operation scenarios, considering the addition of water safety works, planned in the 2014-2015 Water Crisis scope, and the effective system integration through shared demand points among SIM's water producing systems. The purpose was to analyze in detail the performance gains and losses caused by different network structural arrangements, with the main focus on discussing the performance impacts of unsatisfactory system operation conditions, thus, aiming to contribute to the increase of technical bases in decision making processes related to complex water resources systems management, influenced by multiple demands and interests, in this new and ever-changing framework.
\end{abstract}

Key-words: Water resource management, performance indicators, sustainability indexes, decision-making support, Metropolitan Integrated System. 


\section{LISTA DE FIGURAS}

Figura 1: Representação das interações entre os subsistemas de gestão e entre eles e o meio ambiente circunvizinho (Adaptado de Loucks e Van Beek, 2005). 10

Figura 2: Estrutura geral do processo de planejamento de recursos hídricos (Adaptado de KARAMOUZ et al., 2003).

Figura 3: Representação gráfica de duas séries de dados sujeitas a critérios de "valor limite" para definição de falhas (Adaptado de HASHIMOTO, STEDINGER e LOUCKS, 1982)

Figura 4: Distinção entre os modelos de simulação e otimização (Adaptado de Loucks e Van Beek, 2005) .27

Figura 5: Layout do Modelo SSD AcquaNet e arranjo geral de uma rede simulada, com representações de reservatórios, nós e demandas

Figura 6: Estrutura geral do modelo de avaliação de desempenho de sistemas de recursos hídricos. 32

Figura 7: Capacidade de armazenamento (útil) dos sistemas produtores de água da Região Metropolitana de São Paulo (RMSP).

Figura 8: Vazões outorgadas de produção das ETA's dos sistemas produtores de água da RMSP. .37

Figura 9: Arranjo geral do Sistema Integrado Metropolitano (SIM). 39

Figura 10: Localização das áreas / pontos de demanda consuntiva - Sistemas Alto Tietê e Rio Claro (Fonte: Sabesp/Encibra, 2017). .53

Figura 11: Localização das áreas / pontos de demanda consuntiva - Sistema Cantareira (Fonte: Sabesp/Encibra, 2017).

Figura 12: Localização das áreas / pontos de demanda consuntiva - Sistemas Guarapiranga e Rio Grande (Fonte: Sabesp/Encibra, 2017). .55

Figura 13: Localização das áreas / pontos de demanda consuntiva - Sistema Cotia (Fonte: Sabesp/Encibra, 2017) .56

Figura 14: Representação esquemática das demandas compartilhadas - Rede Integrada (Cenário 3) 65

Figura 15: Rede do Sistema Integrado Metropolitano (Cenário 1). .70

Figura 16: Rede do Sistema Integrado Metropolitano (Cenário 2). .71

Figura 17: Rede integrada do Sistema Integrado Metropolitano (Cenário 3). .72 
Figura 18: Fluxograma de entrada e saída de dados do modelo de avaliação de desempenho.

Figura 19: Tela inicial de "Entrada de Dados" do modelo de avaliação de desempenho.

Figura 20: Tela de cálculo dos indicadores de desempenho (Confiabilidade, Resiliência e Vulnerabilidade) e Índice de Sustentabilidade. .78

Figura 21: Resumo dos indicadores de desempenho e índice global de sustentabilidade para o Sistema Alto Tietê. Comparação Cenários 1 e 2 . .82 Figura 22: Vazões fornecidas e Vazão-meta no ponto de demanda "ETA Taiaçupeba" nos Cenários 1 e 2.

Figura 23: Acompanhamento dos indicadores de desempenho no ponto de demanda "ETA Taiaçupeba". Comparação entre os Cenários 1 e 2.

Figura 24: Volumes armazenados e Volume-meta para o Sistema Alto Tietê nos Cenários 1 e 2 .

Figura 25: Acompanhamento dos indicadores de desempenho para os reservatórios do Sistema Alto Tietê. Comparação entre os Cenários 1 e 2

Figura 26: Curvas de permanência dos dados de vazão da reversão do Rio Guaió e transposição do Rio Grande.

Figura 27: Acompanhamento do Índice de Sustentabilidade global do Sistema Alto Tietê. Comparação entre os Cenários 1 e 2 .

Figura 28: Resumo dos indicadores de desempenho e índice global de sustentabilidade para o Sistema Cantareira. Comparação Cenários 1 e 2. .88

Figura 29: Vazões fornecidas e Vazão-meta no ponto de demanda "ETA Guaraú" nos Cenários 1 e 2 .

Figura 30: Acompanhamento dos indicadores de desempenho no ponto de demanda "ETA Guaraú". Comparação entre os Cenários 1 e 2 . 90

Figura 31: Volumes armazenados e Volume-meta para o Sistema Cantareira nos Cenários 1 e 2.

Figura 32: Curva de permanência dos dados de vazão da interligação Jaguari Atibainha.

Figura 33: Acompanhamento dos indicadores de desempenho para os reservatórios do Sistema Cantareira. Comparação entre os Cenários 1 e 2.

Figura 34: Acompanhamento do Índice de Sustentabilidade global do Sistema Cantareira. Comparação entre os Cenários 1 e 2. 
Figura 35: Resumo dos indicadores de desempenho e índice global de sustentabilidade para o Sistema Rio Claro. Comparação Cenários 1 e 2................94 Figura 36: Vazões fornecidas e Vazão-meta no ponto de demanda "ETA Casa Grande" nos Cenários 1 e 2.

Figura 37: Acompanhamento dos indicadores de desempenho no ponto de demanda "ETA Casa Grande". Comparação entre os Cenários 1 e 2. 95

Figura 38: Volumes armazenados e Volume-meta para o Sistema Rio Claro nos Cenários 1 e 2 . 96

Figura 39: Acompanhamento dos indicadores de desempenho para os reservatórios do Sistema Rio Claro. Comparação entre os Cenários 1 e 2 . .97 Figura 40: Acompanhamento do Índice de Sustentabilidade global do Sistema Rio Claro. Comparação entre os Cenários 1 e 2. 98

Figura 41: Resumo dos indicadores de desempenho e índice global de sustentabilidade para o Sistema Rio Grande. Comparação Cenários 1 e 2. 99

Figura 42: Curva de permanência dos dados de vazão da transferência do Rio Pequeno.

Figura 43: Volumes armazenados e Volume-meta para o Sistema Rio Claro nos Cenários 1 e 2. 100

Figura 44: Acompanhamento dos indicadores de desempenho para o reservatório Rio Grande. Comparação entre os Cenários 1 e 2. 101

Figura 45: Acompanhamento do Índice de Sustentabilidade global do Sistema Rio Grande. Comparação entre os Cenários 1 e 2 . 101

Figura 46: Resumo dos indicadores de desempenho e índice global de sustentabilidade para o Sistema Integrado Metropolitano. Comparação Cenários 1 e 2 . 102

Figura 47: Somatório das vazões fornecidas e vazão-meta para o total das ETA's do Sistema Integrado Metropolitano nos Cenários 1 e 2 103

Figura 48: Acompanhamento dos indicadores de desempenho para o fornecimento global de água das ETA's do Sistema Integrado Metropolitano. Comparação entre os Cenários 1 e 2. 104

Figura 49: Volumes armazenados totais e Volume-meta para o Sistema Integrado Metropolitano nos Cenários 1 e 2 105 
Figura 50: Acompanhamento dos indicadores de desempenho para o armazenamento global dos reservatórios do Sistema Integrado Metropolitano. Comparação entre os Cenários 1 e 2.

Figura 51: Acompanhamento do Índice de Sustentabilidade global do Sistema Integrado Metropolitano. Comparação entre os Cenários 1 e 2. ............................107 Figura 52: Resumo dos indicadores de desempenho e índice global de sustentabilidade para o Sistema Alto Tietê. Comparação Cenários 2 e 3. 110 Figura 53: Curvas de permanência das vazões de interligação do Sistema Alto Tietê.

Figura 54: Volumes armazenados e Volume-meta para o Sistema Alto Tietê nos Cenários 2 e 3.

Figura 55: Acompanhamento dos indicadores de desempenho para os reservatórios do Sistema Alto Tietê. Comparação entre os Cenários 2 e 3 112 Figura 56: Acompanhamento do Índice de Sustentabilidade global do Sistema Alto Tietê. Comparação entre os Cenários 2 e 3.

Figura 57: Resumo dos indicadores de desempenho e índice global de sustentabilidade para o Sistema Cotia. Comparação Cenários 2 e 3. 114

Figura 58: Curvas de permanência das vazões de interligação do Sistema Cotia.. 115 Figura 59: Vazões fornecidas e Vazão-meta no ponto de demanda "ETA Alto Cotia" nos Cenários 2 e 3. 115

Figura 60: Acompanhamento dos indicadores de desempenho no ponto de demanda "ETA Alto Cotia". Comparação entre os Cenários 2 e 3 116 Figura 61: Volumes armazenados e Volume-meta para o Sistema Cotia nos Cenários 2 e 3

Figura 62: Acompanhamento dos indicadores de desempenho para os reservatórios do Sistema Cotia. Comparação entre os Cenários 2 e 3.

Figura 63: Acompanhamento do Índice de Sustentabilidade global do Sistema Cotia. Comparação entre os Cenários 2 e 3.

Figura 64: Resumo dos indicadores de desempenho e índice global de sustentabilidade para o Sistema Cantareira. Comparação Cenários 2 e 3. 119

Figura 65: Curvas de permanência das vazões de interligação do Sistema Cantareira.

Figura 66: Vazões fornecidas e Vazão-meta no ponto de demanda "ETA Guaraú" nos Cenários 2 e 3. 
Figura 67: Acompanhamento dos indicadores de desempenho no ponto de demanda "ETA Guaraú". Comparação entre os Cenários 2 e 3.

Figura 68: Volumes armazenados e Volume-meta para o Sistema Cotia nos Cenários 2 e 3 .

Figura 69: Acompanhamento dos indicadores de desempenho para os reservatórios do Sistema Cantareira. Comparação entre os Cenários 2 e 3. 122

Figura 70: Acompanhamento do Índice de Sustentabilidade global do Sistema Cantareira. Comparação entre os Cenários 2 e 3. 123

Figura 71: Resumo dos indicadores de desempenho e índice global de sustentabilidade para o Sistema Guarapiranga. Comparação Cenários 2 e 3........124 Figura 72: Curvas de permanência das vazões de interligação do Sistema Guarapiranga. 125

Figura 73: Vazões fornecidas e Vazão-meta no ponto de demanda "ETA ABV" nos Cenários 2 e 3. 125

Figura 74: Acompanhamento dos indicadores de desempenho no ponto de demanda "ETA ABV". Comparação entre os Cenários 2 e 3. 126

Figura 75: Volumes armazenados e Volume-meta para o Sistema Guarapiranga nos Cenários 2 e 3.

Figura 76: Acompanhamento dos indicadores de desempenho para os reservatórios do Sistema Guarapiranga. Comparação entre os Cenários 2 e 3. 128

Figura 77: Acompanhamento do Índice de Sustentabilidade global do Sistema Guarapiranga. Comparação entre os Cenários 2 e 3. 129

Figura 78: Resumo dos indicadores de desempenho e índice global de sustentabilidade para o Sistema Rio Claro. Comparação Cenários 2 e 3. 130

Figura 79: Curvas de permanência das vazões de interligação do Sistema Rio Claro.

Figura 80: Vazões fornecidas e Vazão-meta no ponto de demanda "ETA Casa Grande" nos Cenários 2 e 3. 131

Figura 81: Acompanhamento dos indicadores de desempenho no ponto de demanda "ETA Casa Grande". Comparação entre os Cenários 2 e 3. 132

Figura 82: Volumes armazenados e Volume-meta para o Sistema Rio Claro nos Cenários 2 e 3. 133

Figura 83: Acompanhamento dos indicadores de desempenho para os reservatórios do Sistema Rio Claro. Comparação entre os Cenários 2 e 3 
Figura 84: Acompanhamento do Índice de Sustentabilidade global do Sistema Rio Claro. Comparação entre os Cenários 2 e 3.

Figura 85: Resumo dos indicadores de desempenho e índice global de sustentabilidade para o Sistema Rio Grande. Comparação Cenários 2 e 3. 136

Figura 86: Curvas de permanência das vazões de interligação do Sistema Rio Grande.

Figura 87: Vazões fornecidas e Vazão-meta no ponto de demanda "ETA Ribeirão da Estiva" nos Cenários 2 e 3.

Figura 88: Acompanhamento dos indicadores de desempenho no ponto de demanda "ETA Ribeirão da Estiva". Comparação entre os Cenários 2 e 3.

Figura 89: Volumes armazenados e Volume-meta para o Sistema Rio Grande nos Cenários 2 e 3.

Figura 90: Acompanhamento dos indicadores de desempenho para os reservatórios do Sistema Rio Grande. Comparação entre os Cenários 2 e 3.

Figura 91: Acompanhamento do Índice de Sustentabilidade global do Sistema Rio Grande. Comparação entre os Cenários 2 e 3.

Figura 92: Resumo dos indicadores de desempenho e índice global de sustentabilidade para o Sistema São Lourenço. Comparação Cenários 2 e 3........142 Figura 93: Curvas de permanência das vazões de interligação do Sistema São Lourenço. 143

Figura 94: Resumo dos indicadores de desempenho e índice global de sustentabilidade para o Sistema Integrado Metropolitano. Comparação Cenários 2 e 3.

Figura 95: Somatório das vazões fornecidas e vazão-meta para o total das ETA's do Sistema Integrado Metropolitano nos Cenários 2 e 3. 144

Figura 96: Acompanhamento dos indicadores de desempenho para o fornecimento global de água das ETA's do Sistema Integrado Metropolitano. Comparação entre os Cenários 2 e 3.

Figura 97: Volumes armazenados totais e Volume-meta para o Sistema Integrado Metropolitano nos Cenários 2 e 3.

Figura 98: Acompanhamento dos indicadores de desempenho para o armazenamento global dos reservatórios do Sistema Integrado Metropolitano. Comparação entre os Cenários 2 e 3. 
Figura 99: Acompanhamento do Índice de Sustentabilidade global do Sistema Integrado Metropolitano. Comparação entre os Cenários 2 e 3..............................148 Figura 100: Resumo dos indicadores de desempenho e índice global de sustentabilidade para o Sistema Integrado Metropolitano. Comparação Cenários 1, 2 e 3.

Figura 101: Acompanhamento do Índice de Sustentabilidade global do Sistema Integrado Metropolitano. Comparação entre os Cenários 1, 2 e 3. 151 Figura 102: Correlação dos resultados de Confiabilidade e Resiliência, calculados em dezembro/18, para os sistemas produtores do SIM nos 3 (três) cenários de simulação.

Figura 103: Correlação dos resultados de Confiabilidade e Vulnerabilidade, calculados em dezembro/18, para os sistemas produtores do SIM nos 3 (três) cenários de simulação. 153

Figura 104: Correlação dos resultados de Resiliência e Vulnerabilidade, calculados em dezembro/18, para os sistemas produtores do SIM nos 3 (três) cenários de simulação. 154

Figura 105: Curvas de permanência das vazões fornecidas na ETA Guaraú (Sistema Cantareira) nos Cenários 1, 2 e 3. 155 


\section{LISTA DE TABELAS}

Tabela 1: Sistemas produtores de água integrantes do SIM (Fonte: SSD3 Sabesp). .36

Tabela 2: Pontos de interesse cujas séries de vazões naturais foram utilizadas para montagem das redes do Sistema Integrado Metropolitano (SIM).

Tabela 3: Resumo das principais informações das Outorgas de uso da água dos sistemas componentes do SIM.

Tabela 4: Faixas de operação e vazões requeridas, de acordo com a Outorga do Sistema Cantareira.

Tabela 5: Vazões mínimas de restrição a jusante dos barramentos e em localidades específicas (SABESP/ENCIBRA, 2017).

Tabela 6: Vazões mínimas de restrição $\left(\mathrm{m}^{3} / \mathrm{s}\right)$ de acordo com as Resoluções da ANA -Bacia do Rio Paraíba do Sul.

Tabela 7: Demandas $\left(\mathrm{m}^{3} / \mathrm{s}\right)$ consuntivas para o Ano-base 2045, segundo áreas de agrupamento e tipos de uso (Fonte: Sabesp/Encibra, 2017).

Tabela 8: Descrição dos novos aportes e obras de ampliação de capacidade dos sistemas considerados nas simulações deste trabalho (Fonte: Sabesp/Encibra, 2017).

Tabela 9: Resumo das principais características dos cenários de simulação do Sistema Integrado Metropolitano (SIM).

Tabela 10: Descrição das prioridades, por tipo de elemento, das redes de simulação nos Cenários 1,2 e 3.

Tabela 11: Demandas requeridas (metas de atendimento) nas ETA's dos sistemas produtores nos Cenários 1 e 2 .

Tabela 12: Volumes-meta nos sistemas produtores do SIM nos Cenários 1, 2 e 3. .64 Tabela 13: Matriz de transferência de vazões $\left(\mathrm{m}^{3} / \mathrm{s}\right)$ entre os sistemas produtores do SIM. 68

Tabela 14: Demandas exclusivas e compartilhadas dos sistemas produtores no Cenário 3. 69

Tabela 15: Pesos de cada sistema produtor para o cálculo do Índice de Sustentabilidade Ponderado do SIM. 
Tabela 16: Matriz de Interligação do Sistema Integrado Metropolitano - Resultados (Cenário 3) 


\section{LISTA DE ABREVIATURAS}

ANA: Agência Nacional de Águas

AT: Alto Tietê

CO: Cotia

CT: Cantareira

DAEE: Departamento de Água e Energia Elétrica do Estado de São Paulo GP: Guarapiranga

IS: Índice de Sustentabilidade

ISP: Índice de Sustentabilidade Ponderado

LabSid: Laboratório de Sistemas de Suporte a Decisões

PCJ: Piracicaba, Capivari e Jundiaí

PDAA: Plano Diretor de Abastecimento de Água

RC: Rio Claro

RG: Rio Grande

RMSP: Região Metropolitana de São Paulo

SABESP: Companhia de Saneamento Básico do Estado de São Paulo

SIM: Sistema Integrado Metropolitano

SL: São Lourenço

SSD: Sistema de Suporte à Decisão 


\section{SUMÁRIO}

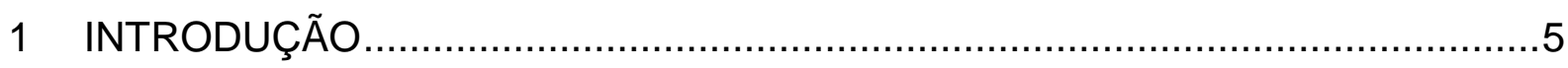

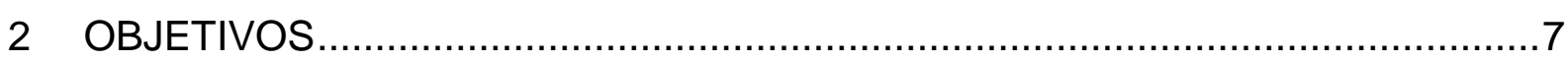

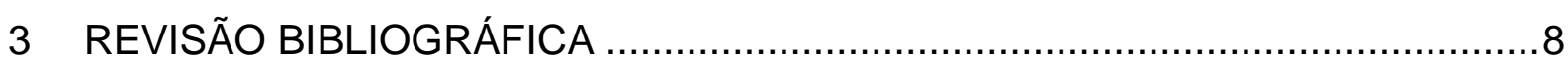

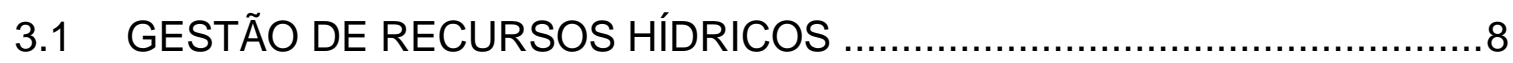

3.2 ANÁLISE DE DESEMPENHO EM RECURSOS HÍDRICOS ...................15

3.3 MODELOS PARA GESTÃO DE RECURSOS HÍDRICOS .......................25

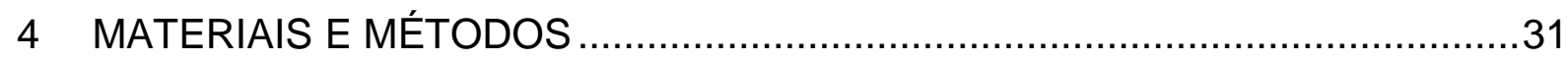

4.1 DEFINIÇÃO DA ESTRUTURA DO MODELO DE AVALIAÇÃO DE

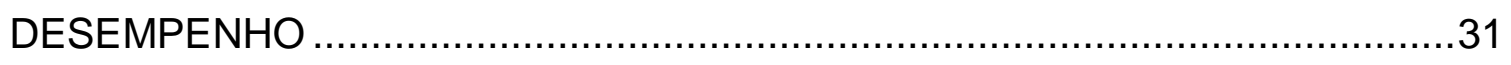

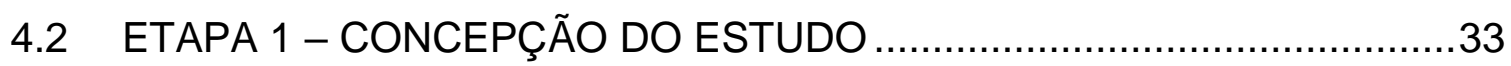

4.3 ETAPA 2 - LEVANTAMENTO DE DADOS E INFORMAÇÕES ................34

4.3.1 O SISTEMA INTEGRADO METROPOLITANO (SIM) E A REGIÃO

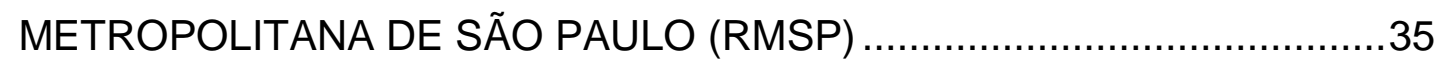

4.3.2 DADOS DE VAZÃO NATURAL.............................................. 40

4.3.3 OUTORGAS E REGRAS DE OPERAÇÃO DO SISTEMAS

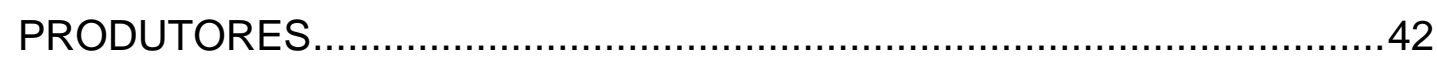

4.3.4 DEMANDAS DE USOS CONSUNTIVOS .....................................52

4.3.5 OBRAS DE INCREMENTO DA SEGURANÇA HÍDRICA ...............60

4.4 ETAPA 3 - SIMULAÇÃO DOS CENÁRIOS DE OPERAÇÃO....................61

4.5 ETAPA 4 - AVALIAÇÃO DE DESEMPENHO .........................................73

4.6 ETAPA 5 - ANÁLISE DE RESULTADOS E CONCLUSÕES....................79

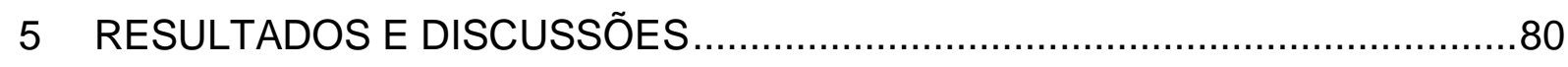

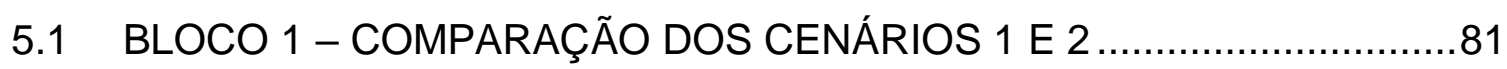

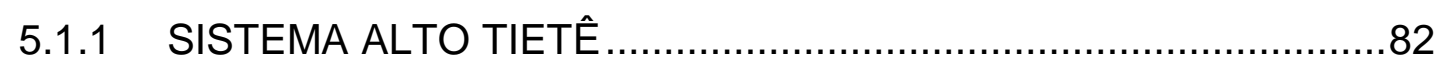

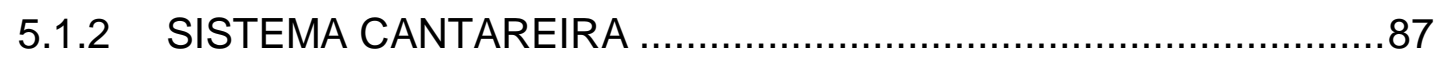

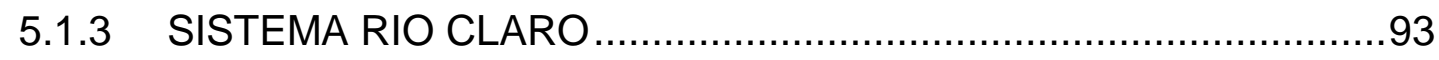

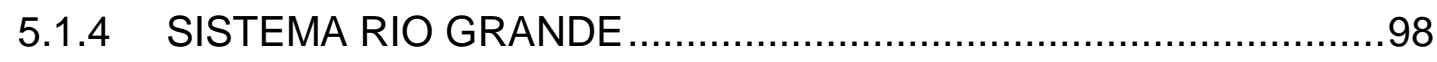

5.1.5 SISTEMA INTEGRADO METROPOLITANO ….........................102

5.2 BLOCO 2 - COMPARAÇÃO DOS CENÁRIOS 2 E 3 ….........................107

5.2.1 SISTEMA ALTO TIETÊ..........................................................110

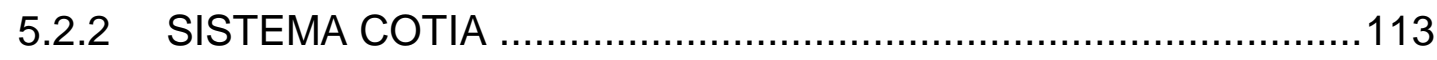

5.2.3 SISTEMA CANTAREIRA ...................................................118 
5.2.4 SISTEMA GUARAPIRANGA ...............................................123

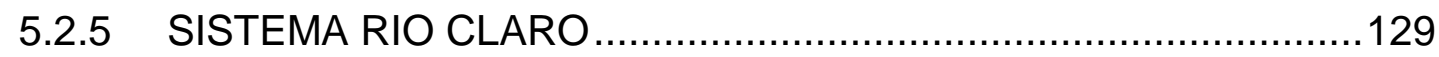

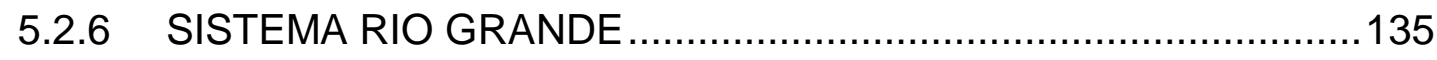

5.2.7 SISTEMA SÃO LOURENÇO ................................................ 141

5.2.8 SISTEMA INTEGRADO METROPOLITANO …..........................143

5.3 BLOCO 3 - DESEMPENHO GLOBAL DO SIM NOS CENÁRIOS 1, 2 E 3 148

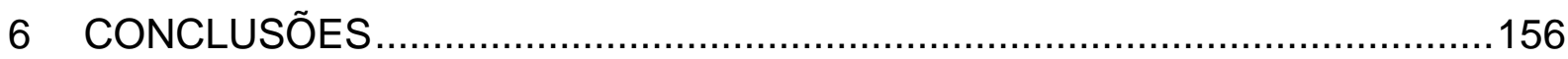

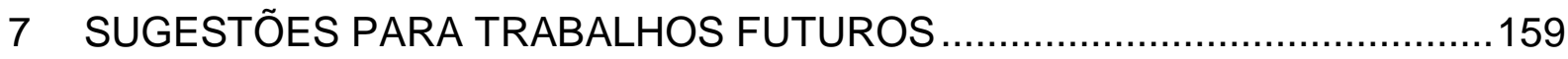

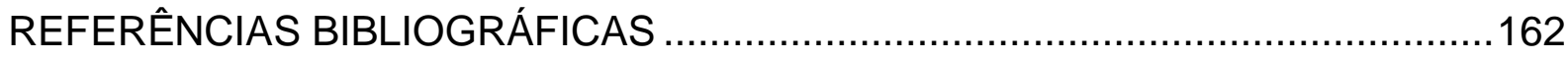




\section{INTRODUÇÃO}

Ao longo dos séculos, recursos hídricos superficiais e subterrâneos têm sido a fonte de água para o consumo agrícola, industrial e de abastecimento urbano. Os rios permitem a geração de energia hidrelétrica, além do transporte de carga entre portos situados às suas margens. Soma-se ainda o uso recreativo da água, e suas funções à biodiversidade e aos habitats naturais, entre outros.

Os recursos hídricos são bens de relevante valor para a promoção do bemestar de uma sociedade. A água é bem de consumo final ou intermediário na quase totalidade das atividades humanas. Em muitas regiões, entretanto, os recursos hídricos não são suficientes para atenderem as demandas de consumo, nem mesmo para necessidades básicas como água potável, nem para prover e manter ecossistemas naturais, tornado assim compreensível que, com o aumento da intensidade e variedades de uso desta água, ocorram conflitos entre os usuários (LOUCKS e VAN BEEK, 2005) (TUCCl et al., 2012).

Também segundo Karamouz et al. (2003), as crescentes demandas por água, os altos padrões de uso, a depleção das reservas hídricas de qualidade elevada, e a excessiva poluição causada por ações antrópicas na expansão da agricultura e produção industrial têm causado intensos conflitos sócio-políticos em torno dos recursos hídricos. Apesar dos ganhos em relação à qualidade da população em geral, o progresso também tem causado considerável destruição do meio ambiente em uma magnitude que não pôde ser prevista.

Neste contexto de pressões e transformações, a questão que deve ser indagada é como que nas próximas décadas que estão por vir, a sociedade pode manter seu desenvolvimento de forma econômica e ecologicamente sustentável (KARAMOUZ et al, 2003). Segundo estes autores, a resposta para este questionamento não pode ser dada sem se considerar uma visão de futuro e o planejamento de estruturas ambientalmente responsáveis e sensíveis aos principais elementos físicos do meio ambiente: ar, água e solo. Destes elementos, a água merece uma especial importância.

Loucks e Van Beek (2005) complementam ainda delineando que, para que se garanta de forma adequada, eficiente e sustentável o suprimento, em quantidade e qualidade, de água tanto para uso humano quanto dos ecossistemas naturais, o planejamento, desenvolvimento e gestão dos sistemas de recursos hídricos devem 
endereçar os fatores causais socioeconômicos, tais como educação inadequada, pressões da população e pobreza. O uso excessivo e ineficiente dos recursos hídricos, de fontes superficiais ou subterrâneas, e a poluição que lhes é causada afeta não só o meio ambiente, mas a sociedade diretamente (KARAMOUZ et al., 2003).

O planejamento dos recursos hídricos deve voltar-se para a sustentabilidade e traduzir-se em ações de conservação da água, prevenção da geração de resíduos e efluentes, melhoria na eficiência dos sistemas hídricos, melhoria na qualidade da água, uso eficiente e retirada de água dentro de limites estabelecidos, seja de fontes superficiais ou subterrâneas, e níveis de poluição compatíveis com a capacidade de assimilação dos cursos d'água. Em outras palavras, a chave encontra-se no adequado balanço entre as necessidades da sociedade, a habilidade de gerir os recursos naturais e as limitações impostas pelo meio ambiente (KARAMOUZ et al. 2003).

Lobato da Costa (2003) reforça ainda que o planejamento e a gestão dos recursos hídricos levantam, necessariamente, problemas de natureza inter-setorial e multidisciplinar. Sendo a água um recurso partilhado pelos mais diversos setores de atividade, esta não pode deixar de estar sujeita a um regime complexo de utilização e jurisdição que tem evoluído sucessivamente, estando atualmente voltada para a contextualização do uso do recurso hídrico, ou seja, sobre o conjunto integrado de condicionamentos ambientais, socioeconômicos e institucionais que envolvem e circunscrevem os usos e funções da água, e os processos de decisão a eles relacionados.

Assim, no âmbito do gerenciamento dos recursos hídricos de um sistema produtor de água, políticas eficientes e bem planejadas de gestão, bem como obras de incremento de segurança hídrica representam um passo extremamente significativo para a garantia da sustentabilidade dos recursos hídricos e o atendimento dos múltiplos interesses que os envolvem. A aferição do desempenho na gestão destes recursos através de indicadores, como Confiabilidade, Resiliência e Vulnerabilidade, representa, desta forma, um importante fator de auxílio à tomada de decisões na busca do atendimento aos múltiplos usos e diversas demandas. Neste sentido, o presente trabalho procura delimitar a linha base para a avaliação de desempenho de sistemas de recursos hídricos complexos e traçar os próximos passos na busca da consolidação de uma metodologia acessível que possa auxiliar os órgãos gestores na tomada de decisões voltadas ao uso sustentável e eficiente da água. 


\section{OBJETIVOS}

O presente trabalho tem como objetivo central a avaliação de desempenho de um sistema de recursos hídricos complexo, frente a diferentes cenários de operação, por meio da utilização dos indicadores de Confiabilidade, Resiliência e Vulnerabilidade, propostos por Hashimoto, Stedinger e Loucks (1982), e dos Índices de Sustentabilidade propostos por Sandoval-Solis, Mckinney e Loucks (2010).

Propõe-se avaliar detalhadamente os ganhos e perdas de desempenho provocados por diferentes arranjos estruturais de um sistema de recursos hídricos complexo, com foco principal na discussão dos impactos de desempenho gerados nas condições insatisfatórias de operação.

Pretende-se com este trabalho contribuir para o estabelecimento de mais uma ferramenta de suporte ao processo de tomada de decisão dos gestores de recursos hídricos, que se utiliza da aplicação de índices e indicadores compreensivos que permitem mensurar quantitativamente, de forma prática e objetiva, os eventuais benefícios e prejuízos de diversas alternativas de gestão e/ou engenharia, independentemente da complexidade do sistema avaliado. 


\section{REVISÃO BIBLIOGRÁFICA}

A presente seção tem como objetivo a apresentação do embasamento teórico que subsidia o desenvolvimento do trabalho. Para tanto, serão abordados os principais temas que contribuem para a estruturação do conhecimento que serve de base para o entendimento do trabalho desenvolvido nesta dissertação.

\subsection{GESTÃO DE RECURSOS HÍDRICOS}

Dentro da área de conhecimento que estuda os recursos hídricos, o termo gerenciamento pode ser definido como um subconjunto da governança dos recursos hídricos, conceito amplo e que implica a existência de conjuntos de sistemas políticos, sociais, econômicos e administrativos que afetam, direta ou indiretamente, a administração, o uso, consumo, os impactos, a preservação e os serviços, entre outros aspectos relativos a estes recursos.

O gerenciamento de recursos hídricos deve ser institucionalizado por meio de políticas e sistemas que definam, orientem e monitorem os papéis de governos, sociedade civil e setor privado, nas esferas regional, nacional e global (PORTO, 2012).

Apesar da Política Nacional de Recursos Hídricos do Brasil, instituída pela Lei № 9433/1997, definir a bacia hidrográfica como a unidade territorial para o planejamento e gestão dos recursos hídricos, o presente trabalho terá como foco a gestão de grandes sistemas produtores de água e, sendo assim, as bacias hidrográficas não estarão sob o foco principal do manejo, apesar de estarem obviamente incluídas no processo de avaliação global do estudo de caso.

De acordo com Karamouz et al. (2003), um sistema pode ser qualquer estrutura ou dispositivo, incluindo seus diferentes componentes interativos (reais ou abstratos), que gerem um determinado produto (saída), a partir de entradas específicas, em uma dada condição temporal. Ou seja, quando nos referimos aos ditos "sistemas de recursos hídricos", fazendo alusão à definição de "sistemas" feita por Karamouz et al. (2003) deve-se notar as seguintes características marcantes:

- Apresentam estrutura definida e organização;

- Sistemas refletem generalizações, abstrações, ou idealizações do plano real com diferentes níveis de complexidade; 
- Relações funcionais e estruturais existem entre os componentes do sistema;

- Os sistemas demonstram certo grau de integração;

- As relações das entradas e saídas e suas respectivas naturezas são importantes características dos sistemas.

Assim, os sistemas de recursos hídricos são definidos como estruturas ou volumes no espaço, com contornos definidos, que possui a água como entrada principal, a utiliza nas suas operações internas, e a tem como um de seus principais produtos (saídas) (CHOW, MAIDMENT e LARRY, 1988).

Segundo White, Mottershead e Harrison (1998), os sistemas de recursos hídricos são formados por diferentes elementos de duas dimensões distintas. Uma delas refere-se à dimensão física, química e biológica; enquanto a outra a dimensão cultural, com seus aspectos sociais, políticos, econômicos e tecnológicos que, em grande instância representam os interesses particulares e coletivos da sociedade.

Loucks e Van Beek (2005) apontam que, no panorama da gestão, o conceito de sistema integrado de recursos hídricos tem se desenvolvido desde os anos $80 \mathrm{em}$ resposta ao aumento das pressões nos sistemas de recursos hídricos causado pelo crescimento populacional e desenvolvimento socioeconômico. Em muitos países do mundo, os eventos recorrentes de escassez, a crescente ocorrência de conflitos pela água e deterioração de sua qualidade levaram uma mudança na orientação de suas políticas de gestão.

A gestão dos sistemas de recursos hídricos tem passado de uma conduta orientada apenas pela oferta de água, ou seja, determinada pelo quanto de água se tem a oferecer, para uma abordagem multi-setorial, transversal, que também reconhece a gestão das demandas como ponto-chave para a gestão, comumente chamada de gestão integrada de recursos hídricos (LOUCKS e VAN BEEK, 2005).

Segundo Tucci et al. (2012), uma forma eficiente de evitar e administrar conflitos pela água é a gestão integrada do uso, controle e conservação dos recursos hídricos. E isto envolve a consideração de uma grande diversidade de objetivos e interesses (econômicos, ambientais, sociais, etc.), usos (irrigação, geração de energia, abastecimento, etc.) e alternativas.

De acordo com Loucks e Van Beek (2005), a formação da base da gestão dos recursos hídricos envolve a influência e interação entre 3 subsistemas interdependentes: 
O subsistema natural dos rios (SNR), onde os processos físicos, químicos e biológicos ocorrem; o subsistema socioeconômico (SSE), que inclui as atividades humanas correlacionadas ao uso dos recursos hídricos, e; o subsistema administrativo-institucional (SAI), no qual os processos de tomada de decisão e de planejamento acontecem. A Figura 1, abaixo, representa esta integração que deve ser assumida como fundamental no âmbito da gestão dos recursos hídricos.

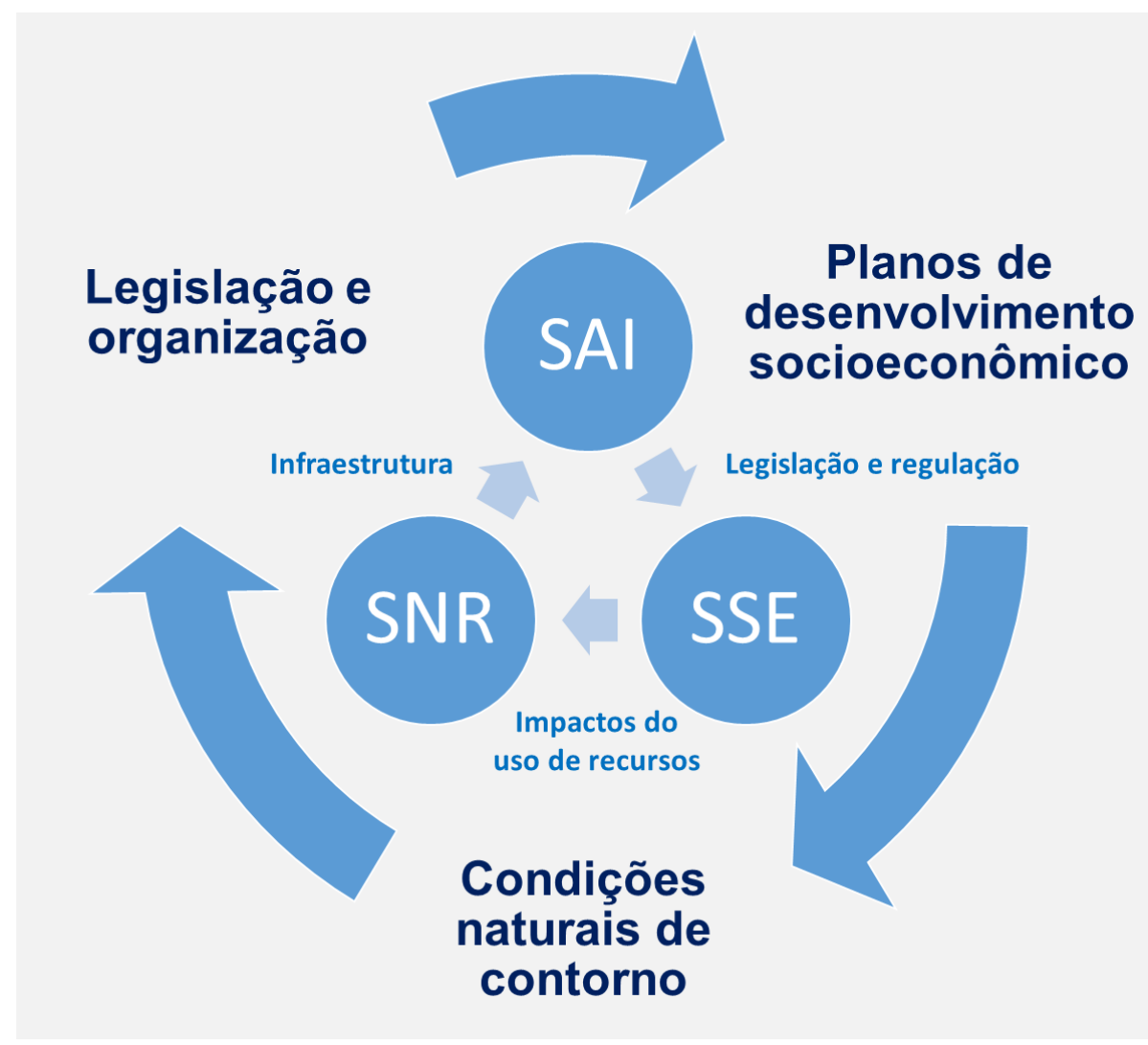

Figura 1: Representação das interações entre os subsistemas de gestão e entre eles e o meio ambiente circunvizinho (Adaptado de Loucks e Van Beek, 2005).

A falta de atenção em uma destas dimensões pode destruir o ganho de desempenho em qualquer um dos demais pilares.

As atividades humanas, entretanto, voltadas para a maximização dos benefícios obtidos juntos aos rios e suas áreas adjacentes têm se direcionado na contramão desta gestão integrada e sustentável, aumentado o potencial para geração de custos e degradação, principalmente durante períodos extremos de secas e cheias. A geração destes impactos é de natureza econômica, ambiental e social, e resultam basicamente do descompasso entre as expectativas e demandas da sociedade, e o quanto a natureza (meio ambiente) tem a oferecer (LOUCKS e VAN BEEK, 2005). 
Conforme definido por Loucks (1997), a sustentabilidade no âmbito dos sistemas de recursos hídricos refere-se à qualidade daqueles sistemas que são dimensionados e geridos da melhor e mais eficiente forma possível tanto para a atual quanto para as gerações que estão por vir. E para tanto, tais sistemas devem ser mais adaptativos, robustos e resilientes às incertezas e mudanças do futuro. A gestão e planejamento devem, portanto, garantir o uso sustentável dos recursos hídricos de forma ampla e abrangente, para atender os objetivos da sociedade, no presente e no futuro, assim como garantir a integridade das demandas ecológicas, ambientais e hidrológicas.

Ações voltadas para a redução da demanda de água em períodos de escassez, por exemplo, devem ser identificadas e implantadas antes que efetivamente os pontos consumidores tenham que sofrer as consequências de uma real escassez. De acordo com Loucks e Van Beek (2005), tal papel é de competência das autoridades institucionais, as quais devem implementar as medidas aplicáveis aos períodos secos a partir de determinados "gatilhos", ou indicadores, contribuindo assim para sustentabilidade daquele determinado sistema.

Assim como Karamouz et al. (2003), Loucks e Van Beek (2005) também apontam que a chave para a adequada gestão e planejamento dos recursos hídricos reside no fato de que tais recursos são finitos e há limites naturais para o quanto se pode utilizar / abstrair das fontes naturais, e para as cargas de poluição capazes de serem assimiladas. Deve-se considerar também certos "fatos hidrológicos", como, por exemplo, a assumpção de que vazões e volumes variam tanto no tempo quanto no espaço. Quando os limites são ultrapassados, via de regra, os benefícios do uso dos recursos hídricos começam a ser extintos.

Lobato da Costa (2003) também aborda que o núcleo central dos problemas envolvendo a água tem ligação estreita com a compatibilização entre necessidades e disponibilidades, no espaço e no tempo, em quantidade e qualidade.

Atualmente, apenas a identificação da forma como fazer esta compatibilização não é mais suficiente, e deve-se considerar também a maneira como a sociedade encara e valoriza (ou não) esta compatibilização. Esta realidade é influenciada por 3 (três) ordens de fatores distintas, porém sinérgicas (LOBATO DA COSTA, 2003).

Em primeiro lugar, estão os instrumentos tecnológicos e de gestão disponíveis, profundamente interligados com a problemática que se deseja solucionar. O segundo aspecto envolve tanto a natureza e a dinâmica específica dos agentes envolvidos, 
quanto os valores e atitudes que determinam seus comportamentos e escolhas. As formas concretas de utilização dos recursos hídricos dependem, então, das ações de diferentes usuários, de suas motivações, de sua cultura. Em terceiro lugar, encontramse os agentes de decisão e as estruturas administrativas e jurídicas, que enquadram e apoiam os processos decisórios e respaldam os mecanismos de execução, que também são um fator de grande importância, determinante para a formulação e resolução dos problemas em recursos hídricos.

Estes três fatores podem ser julgados suficientes para definir o contexto da utilização dos recursos hídricos, entretanto, a crescente integração com políticas mais gerais de gestão ambiental e a importância crescente dos aspectos socioeconômicos e institucionais envolvidos, levam a uma expansão da abordagem apresentada. É notória também a inter-relação destes 3 (três) fatores com as dimensões que formam a base da gestão dos recursos hídricos, apresentada por Loucks e Van Beek (2005).

Como se pode perceber, a água não é um simples recurso para satisfação de meras necessidades de utilização. É também suporte imprescindível para os ecossistemas, aos quais é atribuída cada vez mais importância (LOBATO DA COSTA, 2003).

Como os recursos hídricos, que são renováveis, porém finitos, podem ser melhor geridos e utilizados? Como isto pode ser atingido em um meio de suprimentos incertos e crescentes demandas e, consequentemente, de crescentes conflitos entre partes que possuem diferentes interesses e expectativas sobre a água? O propósito central da gestão e planejamento de recursos hídricos é endereçar e, se possível, responder adequadamente a estas questões. Os pontos delineados pelas perguntas acima possuem dimensões científica, técnica, político-institucional e social e, assim, também devem conter as estratégicas delineadas para a melhor e mais eficiente gestão de recursos hídricos (LOUCKS e VAN BEEK, 2005).

À medida em que as demandas aumentam, as variabilidades dos processos hidráulico-hidrológicos se tornam mais proeminentes e as interferências sobre os recursos hídricos se tornam mais volumosas e complexas, conforme apresentado, o manejo destes recursos passa a também exigir um novo grau de gestão e planejamento, não só com foco na maximização dos benefícios econômicos de seu uso e equidade na distribuição destes benefícios, mas também na consideração de objetivos ambientais e ecológicos. 
De acordo com Loucks e Van Beek (2005) as perguntas atuais no âmbito da gestão de recursos hídricos não são mais unidimensionais, como por exemplo: 'como se pode prover água de melhor qualidade para irrigação de uma determinada área na bacia?'. Mas sim, pluridimensionais. Atualmente, acrescenta-se a seguinte ponderação: 'E como as abstrações de água na bacia irão afetar os regimes quantitativos e qualitativos de água a jusante? E quais as consequências disto para os ecossistemas ripários e aquáticos?'.

Para se responder a tais questionamentos complexos, requisita-se a integração de uma grande variedade de ciências e tecnologias aos tomadores de decisão e instituições gestoras. Dentro desta aparente complexidade, é esperado que os mecanismos de gestão incorporem conhecimentos e equipes multi e interdisciplinares. A gestão de recursos hídricos consolida-se, assim, em uma atividade analítica e criativa, voltada aos seguintes aspectos principais:

- Formulação de princípios e diretrizes;

- Elaboração de documentos orientadores e normativos;

- Estruturação de sistemas gerenciais, e;

- Tomada de decisões.

Cujo objetivo final de promover o inventário, uso, controle e proteção dos recursos hídricos (TUCCl et al., 2012).

O planejamento de longo prazo dos sistemas de recursos hídricos requer que sejam considerados os usuários concorrentes pelo recurso naquele sistema, em conjunto com suas futuras condições de abastecimento e demanda. Neste contexto, a modelagem aplicada à gestão dos recursos hídricos insere-se como ferramenta altamente prestativa aos gestores e tomadores de decisão, responsáveis pela alocação eficiente do recurso (KARAMOUZ et al., 2003). De acordo com este autor, e conforme demonstrado na Figura 2, 5 (cinco) são as principais etapas do processo de planejamento de recursos hídricos:

1. Definição do problema e levantamento / processamento de dados;

2. Fase de modelagem;

3. Tomada de decisão;

4. Implantação / construção;

5. Monitoramento contínuo do sistema. 


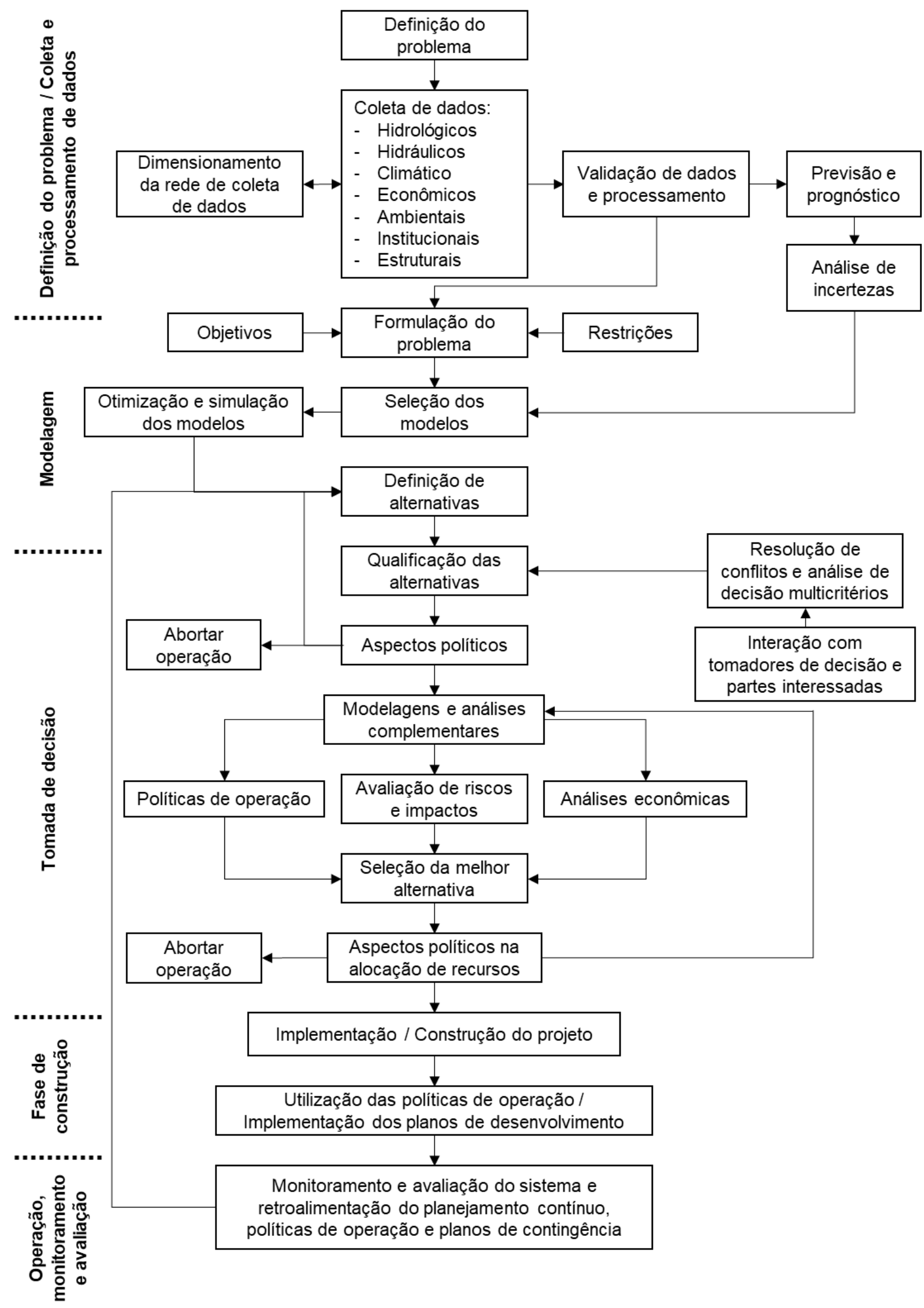

Figura 2: Estrutura geral do processo de planejamento de recursos hídricos (Adaptado de KARAMOUZ et al., 2003). 
O foco deste trabalho encontra-se na fase de "tomada de decisão". Nesta fase, a resolução dos conflitos associados à gestão da água e as técnicas de análise multicritério são utilizadas para a comparação de diferentes alternativas e definição da melhor decisão no cenário proposto.

As atividades de gestão e planejamento de recursos hídricos comumente são motivadas pela assumpção de que tanto existem problemas a serem solucionados, como oportunidades para se obterem maiores benefícios integrados do uso da água.

Neste contexto, as avaliações quantitativas de desempenho (performance) surgem como um importante ferramental para apoiar o processo de avaliação de benefícios e, assim, as múltiplas alternativas de planos e políticas de gestão (LOUCKS e VAN BEEK, 2005).

Os critérios de desempenho para avaliação dos sistemas de recursos hídricos têm evoluído ao longo do tempo, tendo se desenvolvido primariamente com o foco nos critérios de potabilidade das águas, no século passado, para o desenvolvimento econômico multiuso há meio século, para metas que agora podem incluir restauração e proteção de ecossistemas, percepção estética, questões recreativas e, mais recentemente, critérios de sustentabilidade (LOUCKS e GLADWELL, 1999).

\subsection{ANÁLISE DE DESEMPENHO EM RECURSOS HÍDRICOS}

Nos últimos anos, muitos índices e indicadores têm sido desenvolvidos para quantitativamente mensurar a fragilidade hídrica de regiões, bacias hidrográficas e sistemas produtores de água, bem como avaliar detalhadamente o risco hídrico, principalmente no contexto dos eventos de estresse ou escassez hídrica.

A mensuração objetiva de certos fenômenos e processos hidrológicos, entretanto, apresenta uma relativa dificuldade, uma vez que muitos são os critérios de avaliação, aparentemente de igual importância, quando se trata da abordagem das questões relacionados à gestão da água. A seleção destes critérios de avaliação pode ser tanto uma decisão de cunho político, quanto científico (BROWN e MATLOCK, 2011).

Segundo Siche et al. (2007), entende-se o termo índice como um valor numérico que representa a correta interpretação da realidade de um sistema, 
utilizando, em seu cálculo, bases científicas e métodos adequados. O valor obtido pode servir como instrumento de tomada de decisão, sendo, normalmente, composto por conjunto estruturado de indicadores e variáveis.

Dentre as diversas formas de se avaliar o desempenho de um determinado sistema de recursos hídricos, o presente trabalho se vale da utilização dos chamados critérios de performance ou indicadores de desempenho, sendo estes, medidas do quão eficientes determinados programas de gestão são em atender as demandas das partes interessadas (LOUCKS e VAN BEEK, 2005). Através destes indicadores, podese efetivamente avaliar o desempenho de um sistema ao longo do tempo, comparálo com outros sistemas, assim como avaliar políticas operacionais alternativas por meio da simulação de cenários hidrológicos (SANDOVAL-SOLIS, MCKINNEY e LOUCKS, 2010).

Muitas são as formas de se mensurar o desempeno de séries temporais de dados de forma a expressar os resultados de uma dada simulação. Médias aritméticas ponderadas, médias geométricas e variância podem ser alternativas viáveis, entretanto de forma geral, estas abordagens demonstram informações muito simples quando se avaliam processos complexos e dinâmicos, e assim, podem trazer dificuldades na interpretação de resultados (LOUCKS e VAN BEEK, 2005). Todos estes, entretanto, se avaliados isoladamente, não são os melhores indicadores de gestão quando o sistema em questão requer uma avaliação mais criteriosa de seus eventos de falha e as respectivas consequências (HASHIMOTO, STEDINGER e LOUCKS, 1982).

A Figura 3 a seguir, por exemplo, demonstra a inabilidade da média e variância, de forma isolada, definir quão severos e quão frequentes os períodos de baixo desempenho são. Os gráficos apresentam o acompanhamento de desempenho de dois sistemas genéricos. A média e variância são iguais para ambos os cenários, entretanto o desempenho do primeiro gráfico esteve abaixo do limite de falha em dois eventos, o que não aconteceu no segundo gráfico. 

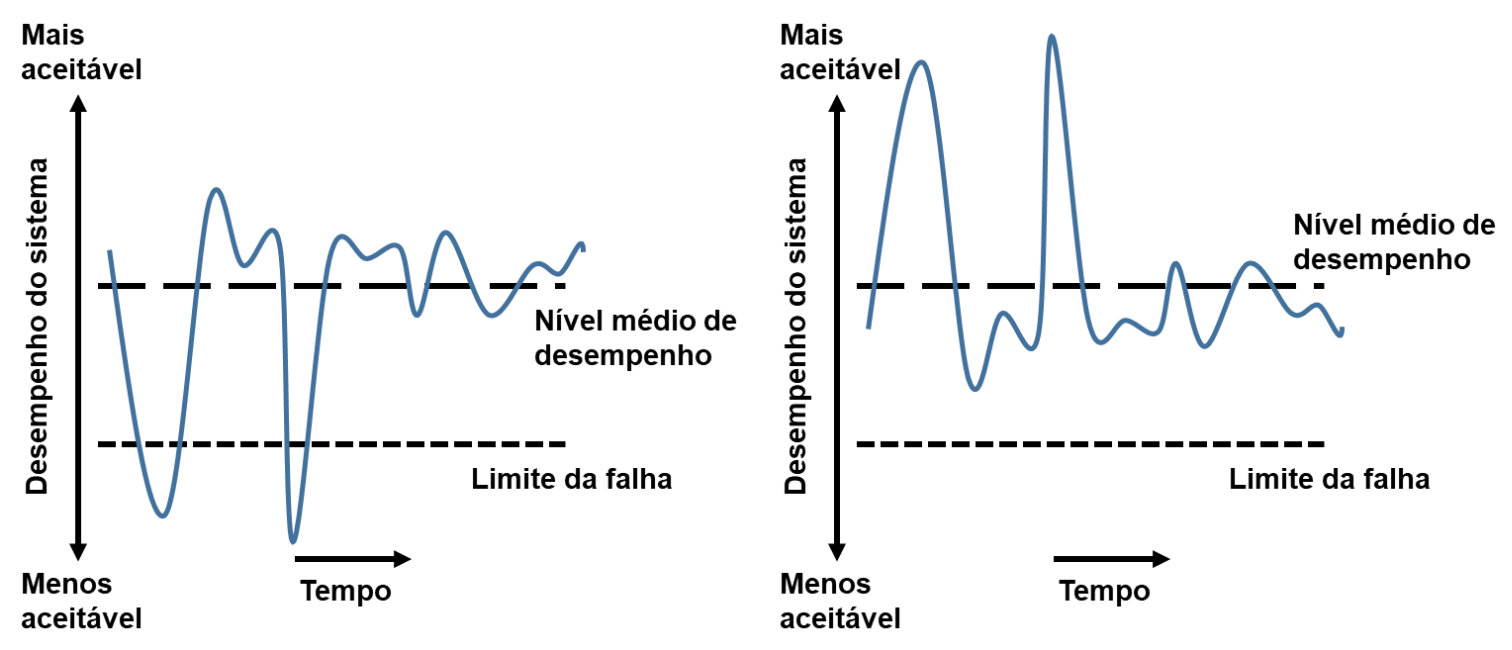

Figura 3: Representação gráfica de duas séries de dados sujeitas a critérios de "valor limite" para definição de falhas (Adaptado de HASHIMOTO, STEDINGER e LOUCKS, 1982).

Por outro lado, as características do comportamento das variáveis de um sistema podem ser avaliadas segundo as medidas de desempenho apresentadas inicialmente por Hashimoto, Stedinger e Loucks (1982), que consideram os seguintes pontos de vista:

- Qual a frequência que o sistema falha (Confiabilidade);

- Com qual rapidez o sistema se recupera de um estado insatisfatório, ou seja, de falha (Resiliência);

- Quão significativas são as consequências das falhas, uma vez que elas ocorrem (Vulnerabilidade).

Segundo Karamouz et al. (2003), a avaliação de desempenho de um sistema é o passo final da aplicação de modelos de simulação e de otimização, no âmbito do planejamento e gestão de recursos hídricos. Tendo em vista que, em última instância, o status operacional dos sistemas podem ser classificados em satisfatório ou insatisfatório (falha).

Em seu trabalho, Fowler; Kilsby e O'Connell (2003) utilizaram os critérios de desempenho de Hashimoto, Stedinger e Loucks (1982) para avaliar os impactos das mudanças e variabilidade climática sobre os recursos hídricos da região de Yorkshire, no norte do Inglaterra. A variabilidade climática, entendida como natural, foi avaliada segundo as influências das alterações do índice de Oscilação do Atlântico Norte (NOA), enquanto que os cenários de mudanças climáticas foram obtidos a partir do cenário UKCIP98 (moderado-severo), resultante do modelo climático HadCM2 GCM. Observou-se que, as mudanças climáticas tendem aumentar consideravelmente a 
vulnerabilidade dos sistemas recursos hídricos nesta região a eventos de seca, que se tornarão mais frequentes e severos. Nesta mesma linha, Asefa et al. (2014), utilizou-se dos critérios de performance para analisar as influências dos processos de mudanças climáticas sobre o Sistema Produtor de Água de Tampa Bay (Flórida) e, também, avaliar possíveis cenários de mitigação dos efeitos destas mudanças, na forma de estratégias adaptativas de operação.

Já Ajami, Hornberger e Sunding (2008) estudaram mais profundamente as características das incertezas hidrológicas e como se dá a sua propagação para a gestão de recursos hídricos. Para se avaliar os impactos destas incertezas, foram analisados os critérios de desempenho da simulação do Reservatório Shasta, situado na porção norte da bacia do Rio Sacramento (Califórnia), sob diferentes regras operativas. Verificou-se a sensibilidade dos 3 (três) critérios os cenários de operação propostos e analisadas as variações provocadas entre estes critérios, à medida em que se observavam mudanças na disponibilidade de água para suprimento das demandas.

Enquanto isto, o trabalho de Kjeldsen e Rosbjerg (2004) propôs a revisão dos conceitos de Confiabilidade, Resiliência e Vulnerabilidade propostos até então na literatura e uma análise mais aprofundada sobre quais as melhores combinações destes indicadores quando da avaliação de risco aplicada a sistemas de recursos hídricos. Para tanto, os critérios de desempenho foram investigados quanto ao comportamento monotônico (do inglês, monotonic behavior) e grau de sobreposição entre eles. Verificou-se uma forte correlação entre os critérios de Resiliência e Vulnerabilidade. No caso analisado, obtiveram-se os melhores resultados quando se procurava maximizar ambos os critérios, ou a Confiabilidade, em separado, mas não os 3 conjuntamente.

Simonovic e Arunkumar (2016), em seu trabalho, propuseram a introdução do conceito de Resiliência Dinâmica, que integra não só a mensuração da performance do sistema em um dado critério, mas também a sua capacidade adaptativa aos eventos de falhas, considerando as características específicas dos reservatórios, como: robustez, redundância, desenvoltura e celeridade (do inglês, Robustness, Redundancy, Resourcefulness, Rapidity). Segundo os autores, a Resiliência Dinâmica constitui uma importante ferramenta na seleção de medidas pró-ativas e reativasadaptativas como resposta de eventos de falhas na operação de sistemas de recursos hídricos de múltiplos usos, configurando-se em um indicador muito mais detalhado 
para avaliação de desempenho de sistemas do que as abordagens tradicionais de Resiliência, Vulnerabilidade e Confiabilidade.

No âmbito nacional, destaca-se o recente trabalho de Farias, Curi e Diniz (2017), que avaliaram o desempenho de cenários de distribuição de água, em termos de perdas hídricas. Neste trabalho, como modelo de alocação de água para simulação dos cenários estabelecidos, utilizou-se o modelo AcquaNet. Foram analisados 7 cenários de distribuição de água do Projeto de Integração do Rio São Francisco (PISF), e suas consequências sobre a bacia do Rio Paraíba. Para tanto, foram utilizados os critérios de Confiabilidade, Resiliência e Vulnerabilidade, além de critérios específicos sobre eficiência na operação de reservatórios. Com exceção do Cenário 1 (base), que não considerava as obras de transposição do PISF, os indicadores de desempenho dos demais 6 cenários assumiram todos seus valores máximos. Ou seja, não foram verificadas falhas no atendimento de demandas.

No Brasil, Paixão et al. (2002) também se utilizaram das medidas de desempenho para a avaliação e apoio à seleção de projetos de recursos hídricos no âmbito da bacia do Rio Curu, localizada no estado do Ceará. O trabalho propôs a avaliação, em escala progressiva temporal, dos resultados da construção de 3 reservatórios localizados na região. Em suas considerações, Paixão et al. (2002) discutiu brevemente os ganhos e perdas em cada um dos critérios a partir da entrada em operação dos reservatórios.

Também na bacia do Rio Curu, Junior e Lanna (2002) avaliaram o desempenho de diferentes regras operacionais do conjunto de 6 reservatórios de grande porte da região. Os objetivos principais do trabalho foram o diagnóstico do comportamento de um sistema de recursos hídricos existente, e a proposição de um método de otimização de suas regras operacionais. A metodologia utilizada provou-se uma opção adequada para análise de várias alternativas de formatação da regra operacional de um sistema de múltiplos reservatórios que atende a múltiplos usos.

Destaca-se ainda o trabalho de Peixoto e Mauad (2003), que apresentou a aplicação de um modelo de simulação computacional como ferramenta na análise do conflito de usos múltiplos da água. Foram calculados os indicadores de desempenho do sistema (confiabilidade, resiliência e vulnerabilidade) para os cenários considerados. O objetivo principal do trabalho foi analisar os conflitos gerados na bacia hidrográfica do Rio Sapucaí, com a implantação de três pequenas centrais hidrelétricas (PCHs). 
"Um sistema mais confiável é sempre melhor do que um sistema menos confiável? " Não necessariamente. Medidas de confiabilidade não dizem nada sobre a rapidez com que um sistema se recupera e retorna a um valor satisfatório (resiliência), nem indica quão ruim é um valor insatisfatório caso ele ocorra (vulnerabilidade). Um sistema que falha relativamente muitas vezes, mas em quantidades insignificantes e por curtos períodos, será muito preferível a um cuja confiabilidade é muito maior, mas onde, quando uma falha ocorre, é provável que seja muito mais grave. Análises como esta demonstram o grau de complexidade que envolve a avaliação destes fatores, a inter-relação e as possíveis "trocas" entre eles (LOUCKS e VAN BEEK, 2005).

Os critérios de desempenho foram desenvolvidos no intuito de prover informações que possam ser valorosas nos processos de planejamento e tomada de decisão em recursos hídricos. Planejadores e gerentes de sistemas de recursos hídricos e os numerosos outros participantes tipicamente envolvidos na tomada de decisão enfrentam um desafio quando é necessário selecionar uma das muitas alternativas, cada uma caracterizada por diferentes valores entre vários critérios de desempenho.

Conforme observado nos parágrafos anteriores, na literatura diversas são as abordagens sobre os conceitos de Confiabilidade, Resiliência e Vulnerabilidade. A seguir, apresentam-se os conceitos de definição de cada um dos indicadores de desempenho, conforme serão aplicados no presente trabalho.

\section{Confiabilidade}

A Confiabilidade de qualquer série temporal pode ser definida como o número de dados em um estado satisfatório dividido pelo total do número de dados na série temporal (LOUCKS e VAN BEEK, 2005). Este indicador é a medida do desempenho do sistema em atender a determinados valores esperados, como vazões requeridas ou um volume-meta de armazenamento, por exemplo.

A Confiabilidade consiste na probabilidade que nenhuma falha ocorra dentre de um certo período de tempo (KARAMOUZ et al., 2003). Assim a Confiabilidade é oposta ao conceito de risco, em que se expressa a probabilidade de falha do sistema. 
Karamouz et al. (2003) aponta que estas abordagens só podem ser utilizadas quando se dispõe de séries temporais longas o suficiente para a frequência de ocorrência de um determinado evento aproxime-se de sua probabilidade estatística.

Para cada período de tempo $t$, déficits $\mathrm{D}_{\mathrm{t}}^{\mathrm{i}}$ são positivos quando a demanda de água $X_{\text {meta }}$ é maior do que a vazão fornecida $X_{\text {fornecida }}$ para um determinado usuário $i$. Se a quantidade fornecida for igual à demanda, os déficits são iguais a zero.

$$
D_{t}^{i}=\left\{\begin{array}{c}
X_{\text {meta }, t}^{i}-X_{\text {fornecida }, t}^{i} \text { se } X_{\text {meta }, t}^{i}>X_{\text {fornecida }, t}^{i} \\
0 \text { se } X_{\text {meta }, t}^{i}=X_{\text {fornecida }, t}^{i}
\end{array}\right.
$$

A Confiabilidade, baseada no tempo, é considerada como a parcela de tempo em que as demandas de água são plenamente atendidas, ou seja, o número de vezes em que $D_{t}^{i}=0$, em relação ao número total de intervalos de tempo considerados $n$.

$$
C^{i}=\frac{N^{\mathrm{o}} \text { de vezes } D_{t}^{i}=0}{n}
$$

\section{Resiliência}

A Resiliência é a capacidade do sistema de retornar ao seu estado de condição satisfatória após uma determinada perturbação que o tenha levado à uma condição de falha (insatisfatória). É uma característica do sistema que se relaciona à capacidade de adaptação às mudanças (LOUCKS e VAN BEEK, 2005).

Em um contexto em que as condições climáticas globais não se apresentam mais estáveis, este critério pode ser considerado uma estatística que avalia a flexibilidade das políticas de gestão da água a se adaptarem a novas condições.

A Resiliência descreve o quão rápido um sistema se recupera de uma falha, uma vez que ela ocorre. A Resiliência também pode expressar uma medida da duração das condições insatisfatórias. Este indicador assume papel importante principalmente durante eventos de secas e cheias, já que os custos e impactos associados a estas condições são afetados justamente pela duração das condições insatisfatórias de operação (SANDOVAL-SOLIS, MCKINNEY e LOUCKS, 2010).

Sob a perspectiva temporal das falhas, o inverso da resiliência expressa a duração média das condições insatisfatórias. 
A Resiliência $R$ é a probabilidade de que o sistema saia de um estado insatisfatório (falha) e passe para um estado satisfatório (sucesso), considerando todas as vezes em que ocorreram falhas. Esta estatística avalia o grau de recuperação do sistema, uma vez que houve falha, e pode ser assim definida:

$$
R^{i}=\frac{N^{\mathrm{o}} \text { de vezes } D_{t}^{i}=0 \mid D_{t-1}^{i}>0}{N^{\mathrm{o}} \text { de vezes } D_{t}^{i}>0}
$$

Segundo Zongxue et al. (1998), a Resiliência pode ser considerada igual à 1,0 (valor máximo) quando não são verificadas condições de falha na série, o que indica que um determinado sistema sempre se mantém em um estado satisfatório de operação no período avaliado.

\section{Vulnerabilidade}

Vulnerabilidade é uma medida da extensão das diferenças entre um determinado valor limite (meta) e os valores insatisfatórios da série temporal. Segundo Kjeldsen e Rosbjerg (2004), no cálculo deste indicador, podem se utilizar valores médios esperados das falhas, máximo valor observado e, inclusive, a atribuição de uma probabilidade de excedência a um determinado valor-meta.

A Vulnerabilidade é o valor provável dos déficits, quando eles ocorrem. Essencialmente expressa a severidade das falhas. Pode ser expressa como o valor médio da falha (LOUCKS e VAN BEEK, 2005); a média dos déficits máximos de períodos contínuos de falhas (HASHIMOTO, STEDINGER e LOUCKS, 1982); ou mesmo a probabilidade de ser exceder um certo valor limite (MENDOZA et al. 1997).

Neste trabalho, será utilizada a metodologia de cálculo definida por SandovalSolis, Mckinney e Loucks (2010), que propõe utilização da Vulnerabilidade adimensional.

A Vulnerabilidade é a soma dos déficits $D^{i}$, dividida pelo número de vezes em que ocorreram os déficits $D_{t}^{i}>0$. A adimensionalização ocorre pela divisão deste valor (média dos déficits do período) pela demanda média $D A$ do usuário i considerado. 


$$
V^{i}=\frac{\sum_{t=0}^{t=n} D_{t}^{i} / N o \text { de vezes } D_{t}^{i}>0}{D A^{i}}
$$

\section{Análise de Desempenho Global}

O trabalho de Sandoval-Solis, Mckinney e Loucks (2010) apresenta a definição de um novo índice de sustentabilidade para análise de recursos hídricos, que compila as informações de critérios de performance ora descritos em um único valor. Propõese uma variação do índice de sustentabilidade inicialmente proposto por Loucks (1997), assim definido para um usuário de água genérico $i$ :

$$
I S^{i}=C^{i} * R^{i} *\left(1-V^{i}\right)
$$

Por outro lado, o "novo" índice é calculado como a média geométrica de $n$ critérios de desempenho $C P$, para um determinado usuário de água $i$.

$$
I S^{i}=\left[\prod_{m=1}^{M} C P_{m}^{i}\right]^{1 / M}
$$

Quando se utilizam os critérios de Confiabilidade, Resiliência e Vulnerabilidade, tem-se que o Índice de Sustentabilidade SI de Sandoval-Solis, Mckinney e Loucks (2010) fica assim definido:

$$
I S^{i}=\left[C^{i} * R^{i} *\left(1-V^{i}\right)\right]^{1 / 3}
$$

No trabalho de Sandoval-Solis, Mckinney e Loucks (2010), os autores avaliaram também a bacia do Rio Grande, uma bacia transfronteiriça, situada entre os Estados Unidos e o México, sob a ótica de como políticas de gestão impactam diferentes grupos de stakeholders da bacia. A utilização dos indicadores de desempenho permitiu a avaliação, comparação e identificação de políticas adaptativas que propiciaram ganhos em termos de gerenciamento de recursos hídricos, 
principalmente quando trocas entre certos critérios de desempenho foram necessárias. Nesse trabalho, a comparação entre os diversos usuários de água da bacia se deu por meio do Índice de Sustentabilidade Ponderado (ISP), que determina a sustentabilidade global de um determinado grupo $k$ através dos Índices de Sustentabilidade individuais de cada usuário $i$ e do peso relativo de cada um deles (W) nas demandas de água (DA) da bacia, seguindo a formulação abaixo:

$$
I S P^{k}=\sum_{i=1 \in k}^{i=j \in k} W^{i} * I S^{i}
$$

Tal que,

$$
W^{i}=\frac{D A^{i}}{D A^{k}}
$$

Sendo,

$$
D A^{k}=\sum_{i=1 \in k}^{i=j \in k} D A^{i}
$$

Zongxue et al. (1998), por sua vez, apresentou um índice de compilação diferente, chamado de Índice de Risco da Seca (DRI, em inglês) que se utiliza de uma média ponderada, cujos pesos devem ser pré-determinados pelo usuário, para a obtenção de um valor também derivado dos critérios de desempenho.

$$
D R I=w_{1} *(1-C)+w_{2} *(1-R)+w_{3} *(V)
$$

Em que,

$$
\sum_{i=1}^{3} w_{i}=1,0
$$

Em seu trabalho, Zongxue et al. (1998), utilizada como estudo de caso a operação do Sistema de Abastecimento de Água da cidade de Fukuoka (Japão), sob o ponto de vista da gestão de risco do gerenciamento de recursos hídricos regionais. 
Finalmente, a análise final do sistema deverá integrar seus diferentes componentes, de forma que a avaliação de desempenho seja feita do sistema como um todo, e não apenas de partes de sua estrutura. A gestão e planejamento integrados dos sistemas de recursos hídricos não deverão focar no desempenho dos componentes isolados dos sistemas, mas sim no desempenho do sistema como um todo (LOUCKS, 1997).

\subsection{MODELOS PARA GESTÃO DE RECURSOS HÍDRICOS}

Na modelagem de recursos hídricos, uma abordagem muito comum estabelece a análise dos sistemas de forma desagregada, componente por componente, como forma de avaliar isoladamente como cada parte do todo funciona. Nesta abordagem, chamada de reducionista, procura-se reduzir os fenômenos complexos a suas partes componentes e examiná-las em detalhe para então, posteriormente, organizá-las novamente em seu arranjo inicial e, assim, construir a compreensão do sistema completo (KARAMOUZ et al., 2003). Nesta abordagem, o remonte do sistema original pode constituir um problema. Karamouz et al. (2003) apontam que o processo de transferência de uma visão analítica para uma sintética pode ser mais objetivo quando se consideram as seguintes orientações:

- As interações entre os componentes e seu papel na composição do todo devem ser claramente definidas antes da segmentação. A compreensão destas interações é de fundamental importância tanto na avaliação individual de cada componente, quanto na análise do todo;

- As abordagens utilizadas na modelagem de cada componente devem ser consistentes;

- As terminologias e metodologias para definição e avaliação do desempenho de recursos hídricos devem ser compatíveis, de maneira que se possam tecer balizamentos entre as avaliações.

Em recursos hídricos, os modelos podem ser definidos como a representação de algum objeto, sistema ou processo, numa linguagem ou forma de fácil acesso ou uso, com o objetivo de melhor compreendê-lo e buscar suas respostas face a diferentes entradas (TUCCI et al., 1998). 
Os modelos podem ser classificados de acordo com algumas características específicas que consideram principalmente as seguintes abordagens:

Quanto à memória, os modelos podem possuir memória zero, infinita ou finita. Por este termo, entende-se como o espaço de tempo, no passado, durante o qual a entrada afeta o estado presente do sistema (DOOGE, 1973 apud. TUCCI et al., 1998). Em sistemas com memória zero, as entradas afetam somente no tempo em que elas ocorrem. A memória infinita existe quando o sistema depende de todo o seu passado. Já a memória finita, refere-se aos sistemas que dependem de suas entradas ocorridas dentro de período finito do passado (TUCCl et al., 1998).

Os modelos também podem ser classificados em lineares ou não-lineares. Quando as propriedades de superposição e homogeneidade são satisfeitas, um sistema pode ser considerado linear, de outra maneira, são considerados nãolineares.

Em relação à abordagem temporal, os modelos podem ser contínuos, quando os fenômenos modelados são contínuos no tempo, sendo assim, as saídas são produzidas continuamente. Ou discreto, quando as mudanças de estado se dão em intervalos discretos, e as saídas são geradas em intervalos finitos de tempo

Um modelo é agregado quando não leva em conta a variabilidade espacial, ou seja, não é sensível às mudanças no espaço. Ou considerado distribuído, quando varia de acordo com uma ou mais dimensões, por exemplo, se suas variáveis e parâmetros variam no tempo e no espaço (TUCCl et al., 1998) (KARAMOUZ et al., 2003).

Os modelos também podem ser classificados como determinísticos, quando as mesmas entradas, uma vez processadas, sempre geram as mesmas saídas. Ou estocásticos, em que um ou mais elementos tornam as relações entre entradas e saídas dependente de variáveis probabilísticas.

Os modelos podem possuir uma abordagem conceitual, quando possuem foco na modelagem dos fenômenos físicos do sistema, ou serem empíricos, quando focam na utilização de dados históricos dos diferentes componentes dos processos modelados (KARAMOUZ et al., 2003).

Em recursos hídricos, os modelos utilizados para avaliação dos sistemas e fenômenos hidrológicos podem ser divididos em basicamente dois grupos de modelos de acordo com seus métodos de modelagem e finalidades: os modelos de simulação e os modelos de otimização. 
Enquanto que os modelos de otimização buscam identificar as melhores variáveis de dimensionamento para um determinado projeto ou sistema. Ou seja, objetivam identificar as melhores soluções para o problema avaliado. Os modelos de simulação visam descrever o comportamento de um determinado sistema, procurando prognosticar as respostas a diferentes entradas, alternativas de arranjo e modificações de suas características, conforme demonstrado esquematicamente por Loucks e Van Beek (2005) na Figura 4 abaixo.

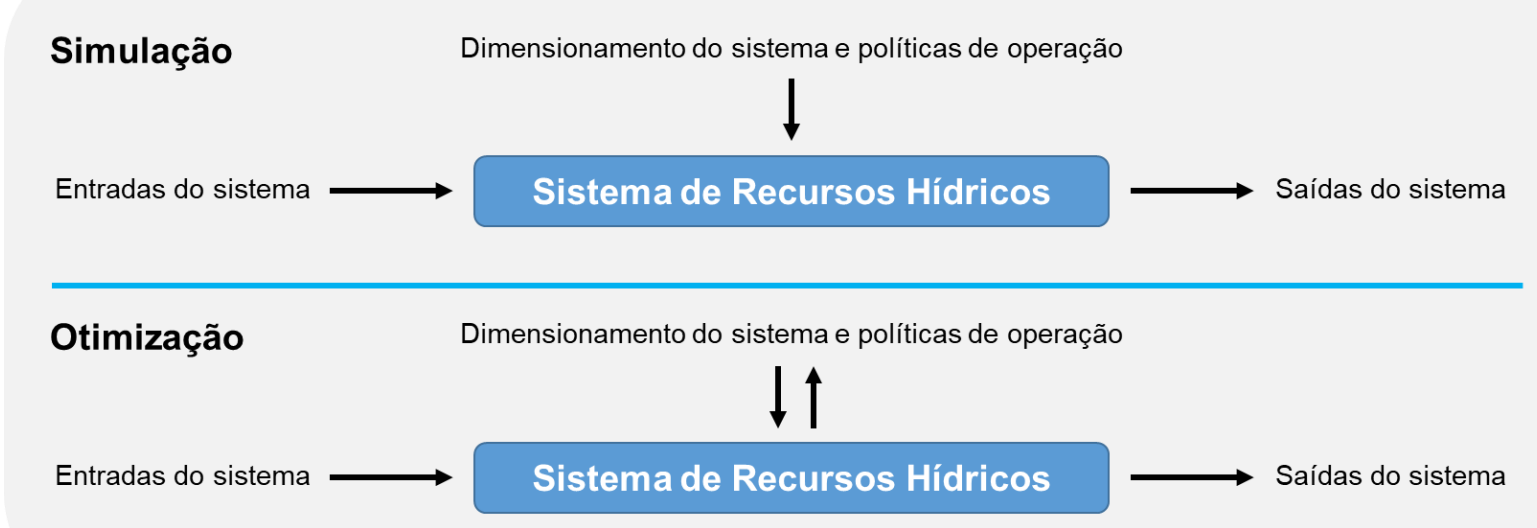

Figura 4: Distinção entre os modelos de simulação e otimização (Adaptado de Loucks e Van Beek, 2005).

Segundo Loucks e Van Beek (2005), os modelos de simulação endereçam basicamente a seguinte questão "o que acontecerá com o sistema se um determinado cenário for considerado ou uma determinada decisão for tomada? ". Nestes casos, os usuários necessitam especificar valores de dimensionamento e variáveis operacionais antes da simulação ser desempenhada, assim, os resultados deste processo podem apoiar os gestores nos processos de tomada de decisão, informando-os precisamente sobre possíveis impactos de suas decisões. Por outro lado, os modelos de otimização edificam-se basicamente sobre funções-objetivo de variáveis decisórias, conhecidas ou não, que necessitam ser maximizadas ou minimizadas. As soluções "ótimas" objetivam de maneira geral responder o seguinte questionamento "Como deveria estruturar-se / comportar-se um sistema para que uma determinada condição fosse alcançada?". 
No presente trabalho, fez-se a utilização de um modelo de alocação de água (modelo de simulação) para a geração dos dados de entrada para o modelo de cálculo de desempenho, desenvolvido no âmbito deste trabalho.

Como modelo de alocação de água, foi utilizado o modelo de rede de fluxo SSD AcquaNet. Segundo Porto e Azevedo (1997) os modelos de rede de fluxo são uma classe de modelos de simulação que contêm algoritmo de otimização. Estes modelos caracterizam-se pela representação de sistemas de recursos hídricos a partir de uma rede formada de nós e arcos. Os nós representam reservatórios, demandas, reversões, confluências e outros pontos do sistema. Por outro lado, os arcos são os elos de ligação entre os nós, representando trechos de rio, adutoras, canais e outras estruturas. O SSD AcquaNet foi escolhido devido principalmente à sua facilidade de uso. O mesmo se encontra disponível gratuitamente e é compatível com a disponibilidade de dados hidrológicos desta pesquisa.

Porto, Mello e Roberto (2006) relatam um breve histórico deste sistema, onde em sua fase inicial, o SSD AcquaNet foi inspirado em um modelo de rede de fluxo denominado ModSim, desenvolvido na Colorado State University pelo professor John Labadie (LABADIE, 1990 e 1998). Este modelo apresentou uma forma eficiente de resolver problemas complexos de rede de fluxo combinando simulação e otimização, de tal forma que acentua as vantagens de ambas as técnicas para a solução do problema de alocação da água.

O SSD AcquaNet funciona através de uma estrutura modular, na qual foram incorporados modelos matemáticos para analisar diferentes problemas relacionados ao aproveitamento de recursos hídricos. Atualmente, essa estrutura modular é constituída de um módulo base, denominado AcquaNet, e de módulos para obtenção da alocação de água, avaliação da qualidade da água, determinação de alocação de água para irrigação, produção de energia elétrica e consideração de valores econômicos nas decisões de alocação (PORTO e AZEVEDO, 1997).

O módulo de alocação de água, responsável pelo balanço hídrico, utiliza um algoritmo de otimização para minimizar o "custo" de alocação de água na rede e maximizar os benefícios associados ao seu uso. O algoritmo utilizado no modelo é o Out-of-Kilter (PORTO e AZEVEDO, 1997), que é uma variação de Método Simplex e utiliza a técnica primal-dual para minimizar o custo na rede de fluxo. O problema de otimização apresenta então a seguinte forma: 


$$
\min \sum_{i=1}^{N} \sum_{j=1}^{N} C_{i j} * Q_{i j}
$$

Sujeito ao balanço de massa em todos os nós j=1, ..., N - Rede Conservativa, isto é:

$$
\sum_{i \in I_{j}} q_{i j}-\sum_{k \in O_{j}} q_{i k}=0
$$

E às vazões mínimas e máximas em todos os arcos $(i, j)$, para todos $i, j=1, \ldots$, N, - Rede Capacitada, ou seja,

$$
I_{i j} \leq Q_{i j} \leq S_{i j}
$$

Sendo $\mathrm{Q}_{\mathrm{ij}}=$ vazão que transita do nó j; $\mathrm{C}_{\mathrm{ij}}=$ custo (prioridade) da unidade de vazão que transita entre os nós i e j, $\mathrm{N}$ = número total de nós de rede; $\mathrm{l}_{\mathrm{ij}}=$ limite inferior da vazão no arco ij; $S_{i j}=$ limite superior da vazão no arco ij e $l_{j}=$ conjunto de todos os nós com arcos que terminam no nó j; (i $\epsilon$ lj significa que todos os nós i sejam elementos do conjunto $\mathrm{I}_{\mathrm{j}}$ ) e $\mathrm{O}_{\mathrm{j}}=$ ao conjunto de todos os nós com os arcos que se originam no nó j.

A Figura 5 a seguir demonstra o layout do Modelo SSD AcquaNet e o arranjo geral de uma rede genérica simulada, com os elementos de reservatórios, nós e demandas. 


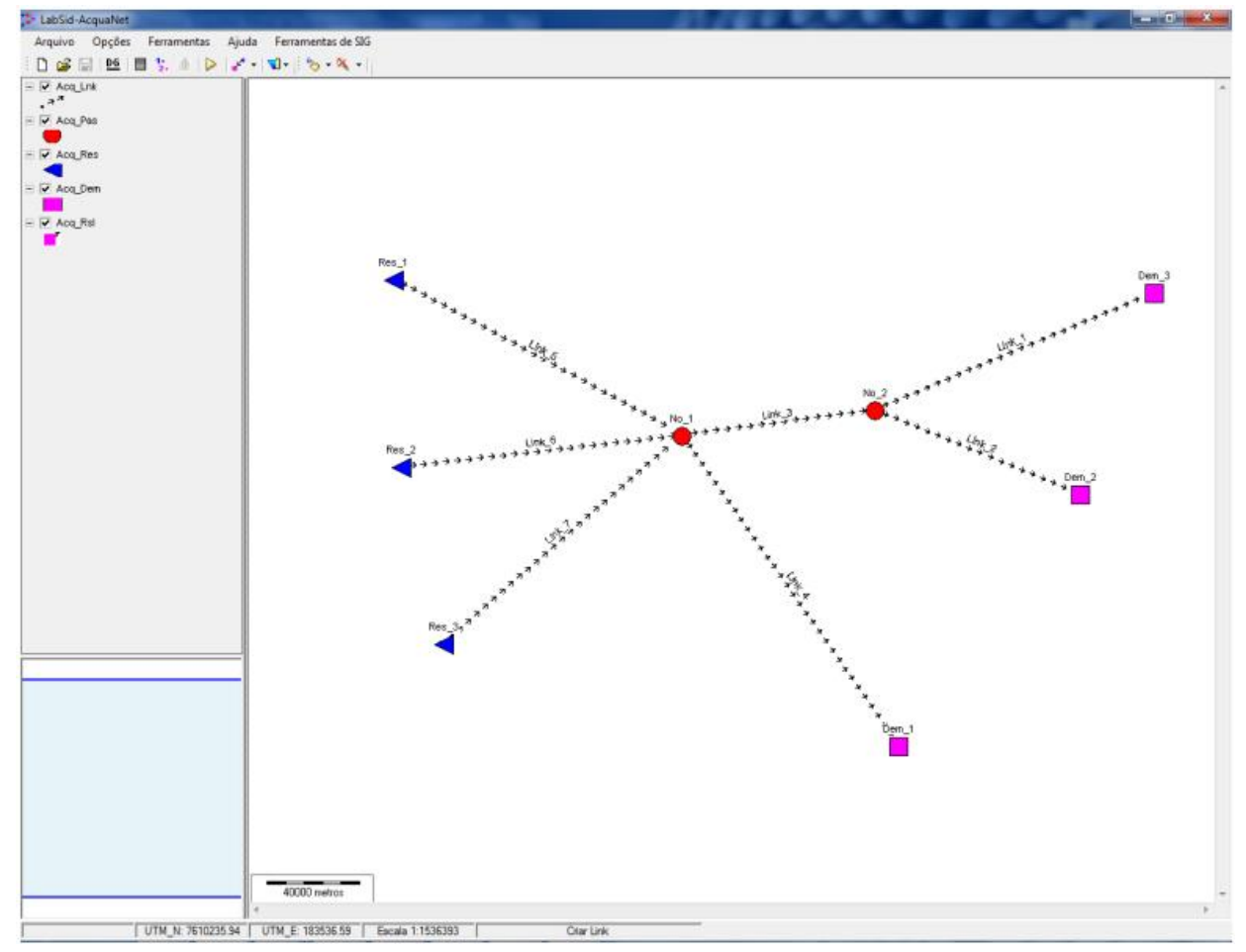

Figura 5: Layout do Modelo SSD AcquaNet e arranjo geral de uma rede simulada, com representações de reservatórios, nós e demandas (Fonte: Porto e Roberto, 2015).

Segundo o Manual do Programa, o SSD AcquaNet pode efetuar os cálculos de maneira sequencial no tempo (Simulação Contínua) ou estatisticamente (Planejamento Tático). Neste trabalho, foi utilizado o método de Simulação Contínua, no qual o valor mais importante é o número total de anos de simulação (NT). Neste método, o usuário deve fornecer séries de vazões afluentes mensais com duração igual a NT. O modelo irá efetuar os cálculos continuamente, para todos os anos existentes. Ao final do cálculo, os resultados serão fornecidos mensalmente para todos os anos (PORTO e ROBERTO, 2015).

As duas opções de cálculo existentes no AcquaNet são Estados Hidrológicos e Calibração. As diferenças entre estas duas opções estão na entrada de dados e na maneira como o modelo irá efetuar os cálculos. Na opção Estados Hidrológicos, o modelo considera o estado hidrológico (quantidade de água armazenada nos reservatórios) para determinar qual o valor de demanda, de volume meta e as prioridades que serão utilizadas no cálculo de cada um dos meses. Enquanto na opção Calibração, o modelo efetua os cálculos com os valores fornecidos sem considerar o estado atual do sistema (PORTO e ROBERTO, 2015). 


\section{MATERIAIS E MÉTODOS}

A presente seção abordará a metodologia utilizada na definição das etapas de trabalho para avaliação de desempenho de sistemas de recursos hídricos, conforme proposto nesta dissertação. Primeiramente será apresentado o fluxograma geral que delimita a estrutura global da metodologia de avaliação proposta. Na sequência, com o intuito de delinear claramente os passos de desenvolvimento do trabalho, cada etapa da metodologia será apresentada separadamente, de acordo com o agrupamento em 5 (cinco) etapas principais de execução.

\subsection{DEFINIÇÃO DA ESTRUTURA DO MODELO DE AVALIAÇÃO DE DESEMPENHO}

O fluxograma que descreve a estrutura do modelo de avaliação do desempenho de recursos hídricos seguido neste trabalho encontra-se apresentado na Figura 6, abaixo. Conforme pode ser observado, as atividades planejadas foram agrupadas em "macro-pacotes" de trabalho, seguindo critérios de afinidade de suas características e priorizando a segmentação do fluxo em 5 (cinco) grandes processos (etapas), de forma a facilitar a gestão das atividades necessárias ao desenvolvimento do modelo aqui proposto.

As 5 (cinco) etapas básicas estabelecidas neste trabalho para condução do processo de avaliação de desempenho de sistemas de recursos hídricos foram assim definidas:

- Etapa 1: Concepção do estudo;

- Etapa 2: Levantamento de dados e informações;

- Etapa 3: Simulação dos cenários de operação;

- Etapa 4: Avaliação de desempenho

- Etapa 5: Análise de resultados e conclusões. 


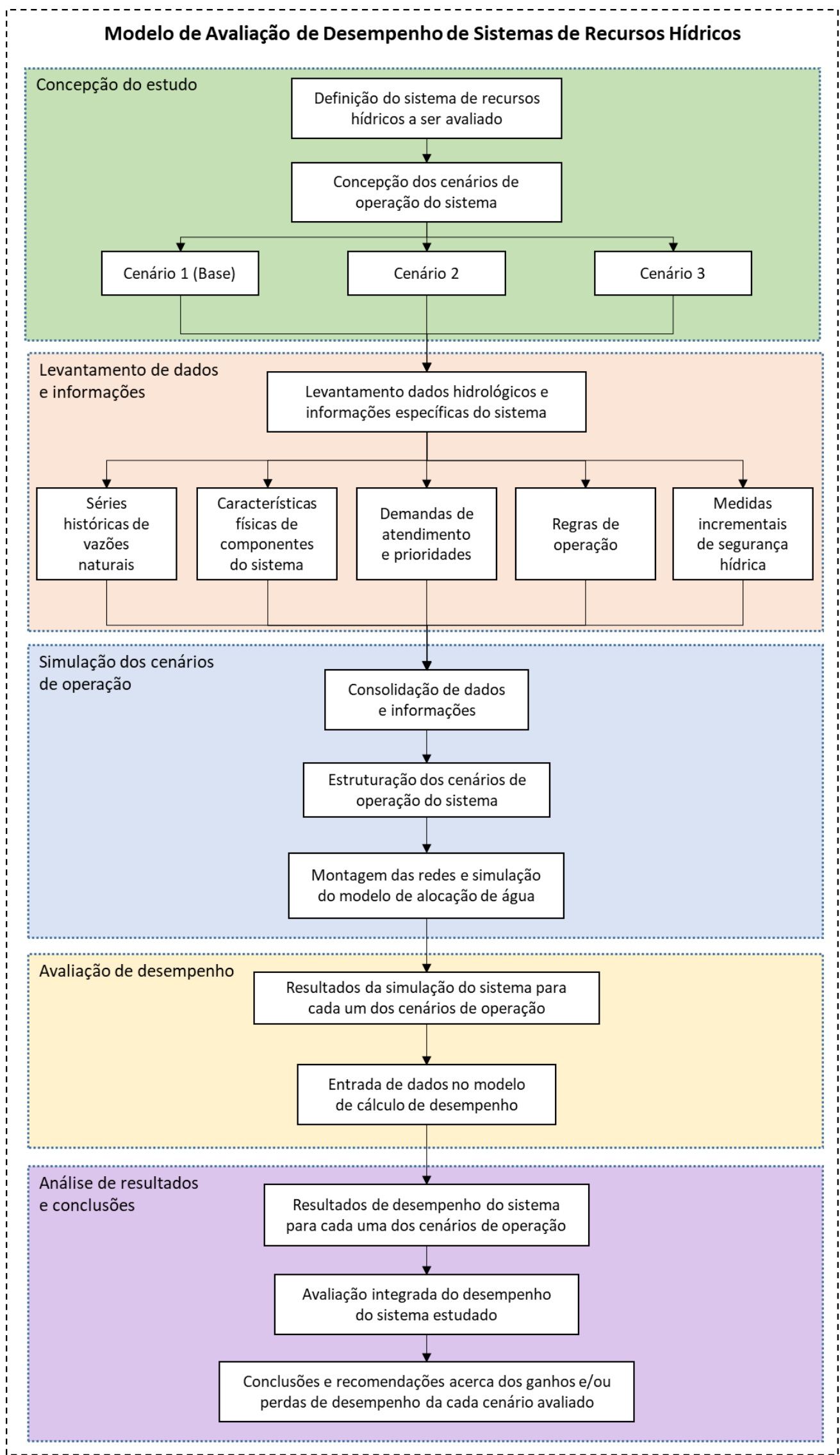

Figura 6: Estrutura geral do modelo de avaliação de desempenho de sistemas de recursos hídricos. 


\subsection{ETAPA 1 - CONCEPÇÃO DO ESTUDO}

Na etapa de concepção foi estabelecida a abordagem inicial da situação a ser estudada. Definiu-se o Sistema Integrado Metropolitano (SIM), responsável pelo abastecimento de água da Região Metropolitana de São Paulo (RMSP) como sistema de recursos hídricos a ser estudado por meio do processo de avaliação de desempenho de acordo com a metodologia proposta. O sistema foi escolhido devido à sua relevância no contexto da gestão de recursos hídricos no estado de São Paulo, bem como pela grande disponibilidade de dados acerca de seus componentes e séries de dados hidrológicos. A descrição do Sistema Integrado Metropolitano é apresentada mais adiante neste trabalho.

Nesta etapa, também foi realizada a concepção dos cenários de operação a serem estudados quanto ao seu desempenho, como forma de orientar a coleta de dados e informações da etapa seguinte.

Os 3 (três) cenários de operação do SIM propostos neste trabalho foram os seguintes:

- Cenário 1: Refere-se ao cenário básico, de diagnóstico, ou seja, a linhabase que serviu de comparação para os demais cenários. Neste cenário, concebeu-se a configuração "original" do SIM, ainda sem a implantação de medidas (obras) de incremento de segurança hídrica, com os 7 (sete) grandes sistemas produtores operando de forma isolada.

- Cenário 2: Este cenário foi concebido para representar a "nova" configuração do sistema após a implantação de medidas dimensionadas para incremento da segurança hídrica. Neste cenário, os sistemas produtores também foram simulados de forma isolada.

- Cenário 3: Neste cenário, além de considerar as medidas de incremento de segurança hídrica já acrescidas no cenário anterior, concebeu-se o SIM a partir de integração da rede por meio de pontos de demanda compartilhada entre os sistemas produtores.

Ressalta-se que, à princípio, não há restrições para a escolha do sistema a ser estudado no tocante aos critérios de desempenho. É importante, entretanto, que o sistema selecionado permita minimamente o estabelecimento de arranjos operacionais distintos, de forma a possibilitar a montagem de outros cenários 
hidrológicos, que não os atuais, para a análise de desempenho de múltiplas alternativas de gestão.

\subsection{ETAPA 2 - LEVANTAMENTO DE DADOS E INFORMAÇÕES}

Nesta etapa, foi realizado o levantamento dos dados e informações do Sistema Integrado Metropolitano (SIM) requeridos como "dados de entrada" no modelo de alocação de água - SSD AcquaNet.

O levantamento dos dados e informações do SIM identificou as diversas características e condições intervenientes que afetam (ou são afetadas) pela operação do sistema, de acordo com os seguintes grupos principais de dados e informações:

- Características físicas dos componentes do sistema - Topologia, volumes úteis de reservação, cotas máximas e mínimas, arranjo físico dos sistemas, interligação entre reservatórios, pontos de transferência de água;

- Demandas de atendimento e respectivas prioridades - Neste item, foram identificados os pontos de demanda de água (consuntivos e nãoconsuntivos) e suas respectivas vazões requeridas. Para cada ponto, foram estabelecidas as prioridades de atendimento em relação aos demais, ou seja, a hierarquia das prioridades que são atendidas sequencialmente pelos sistemas produtores de água;

- Regras de operação dos sistemas - Identificação dos critérios e regras operativas que regem a operação dos sistemas de recursos hídricos, estabelecidos por instrumentos de outorga ou mesmo por restrições técnicas de cada sistema, tais como: faixas de operação (volumes), critérios de transferências, vazões-meta em pontos de controle;

- Medidas de incremento de segurança hídrica - Identificação das obras implantadas no SIM durante e após a Crise Hídrica de 2014-2015, levantamento das contribuições geradas por estas obras e das novas configurações de rede resultantes.

Neste trabalho, destaca-se que foram utilizados dados hidrológicos com resolução mensal. Esta escolha reside no fato de que a avaliação de desempenho 
buscou inicialmente apresentar resultados no âmbito da gestão estratégica dos sistemas estudados, e não no plano tático-operacional, de forma que justificasse a escolha de resoluções temporais menores (horária, diária, por exemplo).

A seguir, apresentam-se as principais informações do Sistema Integrado Metropolitano (SIM) que subsidiaram a construção das redes de simulação do modelo de alocação de água. São, assim, apresentadas as principais características do SIM, sua área de competência de abastecimento, demandas, prioridades e demais fatores que regem a operação deste sistema.

\subsubsection{O SISTEMA INTEGRADO METROPOLITANO (SIM) E A REGIÃO METROPOLITANA DE SÃO PAULO (RMSP)}

A Região Metropolitana de São Paulo (RMSP) é a 4⿳亠丷a maior região metropolitana do mundo, contando com aproximadamente 20 milhões de habitantes. Em termos de disponibilidade de recursos hídricos, a situação da RMSP é dramática. A região possui uma disponibilidade hídrica de aproximadamente $201 \mathrm{~m}$ 3/hab./ano, extremamente baixa, comparável aos estados mais secos do Nordeste Brasileiro, como Paraíba e Pernambuco. Este fato ocorre muito por conta de que a RMSP se localiza em uma região de cabeceira de rios e constitui-se no maior aglomerado urbano do país (PORTO, 2003).

De acordo com a ANA (2017), a Região Metropolitana de São Paulo representa um dos casos mais emblemáticos no Brasil quando o assunto são as condições naturais desfavoráveis, em termos da disponibilidade hídrica local, para o abastecimento urbano e atendimento de outras demandas. Nestes casos, a disponibilidade precisa ser reforçada muitas vezes por obras de reservação e por transferências de vazões de bacias hidrográficas vizinhas, exigindo a operação de uma complexa infraestrutura para a garantia da oferta de água.

O abastecimento da RMSP se dá por meio de sistemas integrados, em que um conjunto de municípios compartilha o mesmo sistema de produção de água. Em grande parte, este abastecimento também é garantido pela transferência de vazões das bacias dos rios Piracicaba, Capivari e Jundiaí (PCJ) para o Alto Tietê por meio do Sistema Cantareira. 
O sistema integrado de abastecimento de água da Região Metropolitana de São Paulo, denominado de Sistema Integrado Metropolitano (SIM), conta basicamente com 7 (sete) sistemas produtores que juntos somam o montante de $1.903,5 \mathrm{hm}^{3}$ de Volume Útil (Tabela 1).

Tabela 1: Sistemas produtores de água integrantes do SIM (Fonte: SSD3 Sabesp).

\begin{tabular}{|c|c|c|c|}
\hline Sistemas & Reservatórios & A. Drenagem $\left(\mathrm{km}^{2}\right)$ & Volume Útil $\left(\mathrm{hm}^{3}\right)$ \\
\hline \multirow{6}{*}{ Alto Tietê } & Ponte Nova & 320,0 & 288,386 \\
\hline & Paraitinga & 182,0 & 36,893 \\
\hline & Biritiba & 75,0 & 34,800 \\
\hline & Dique Biritiba & 0,000 & 0,000 \\
\hline & Jundiaí & 122,0 & 74,100 \\
\hline & Taiaçupeba & 220,0 & 85,289 \\
\hline \multirow{3}{*}{ Cotia } & Pedro Breicht & 62,5 & 16,500 \\
\hline & Cachoeira da Graça & 107,0 & 0,080 \\
\hline & Isolina & 240,0 & 0,000 \\
\hline \multirow{4}{*}{ Cantareira } & Jaguari-Jacareí & 1230,0 & 808,044 \\
\hline & Cachoeira & 392,0 & 69,649 \\
\hline & Atibainha & 312,0 & 96,252 \\
\hline & Paiva Castro & 338,0 & 7,612 \\
\hline Guarapiranga & Guarapiranga & 631,0 & 171,190 \\
\hline Rio Claro & Ribeirão do Campo & 11,8 & 13,670 \\
\hline \multirow{2}{*}{ Rio Grande } & Rio Grande & 182,0 & 112,180 \\
\hline & Ribeirão da Estiva & 0,000 & 0,000 \\
\hline São Lourenço & São Lourenço & 951,0 & 88,820 \\
\hline
\end{tabular}

Dentre os 7 (sete) sistemas produtores de água, o Sistema Cantareira destacase como o que apresenta a maior capacidade de armazenamento de água, respondendo por aproximadamente $52 \%$ do volume total de reservação do Sistema Integrado Metropolitano (SIM), conforme pode ser observado na Figura 7, a seguir. 


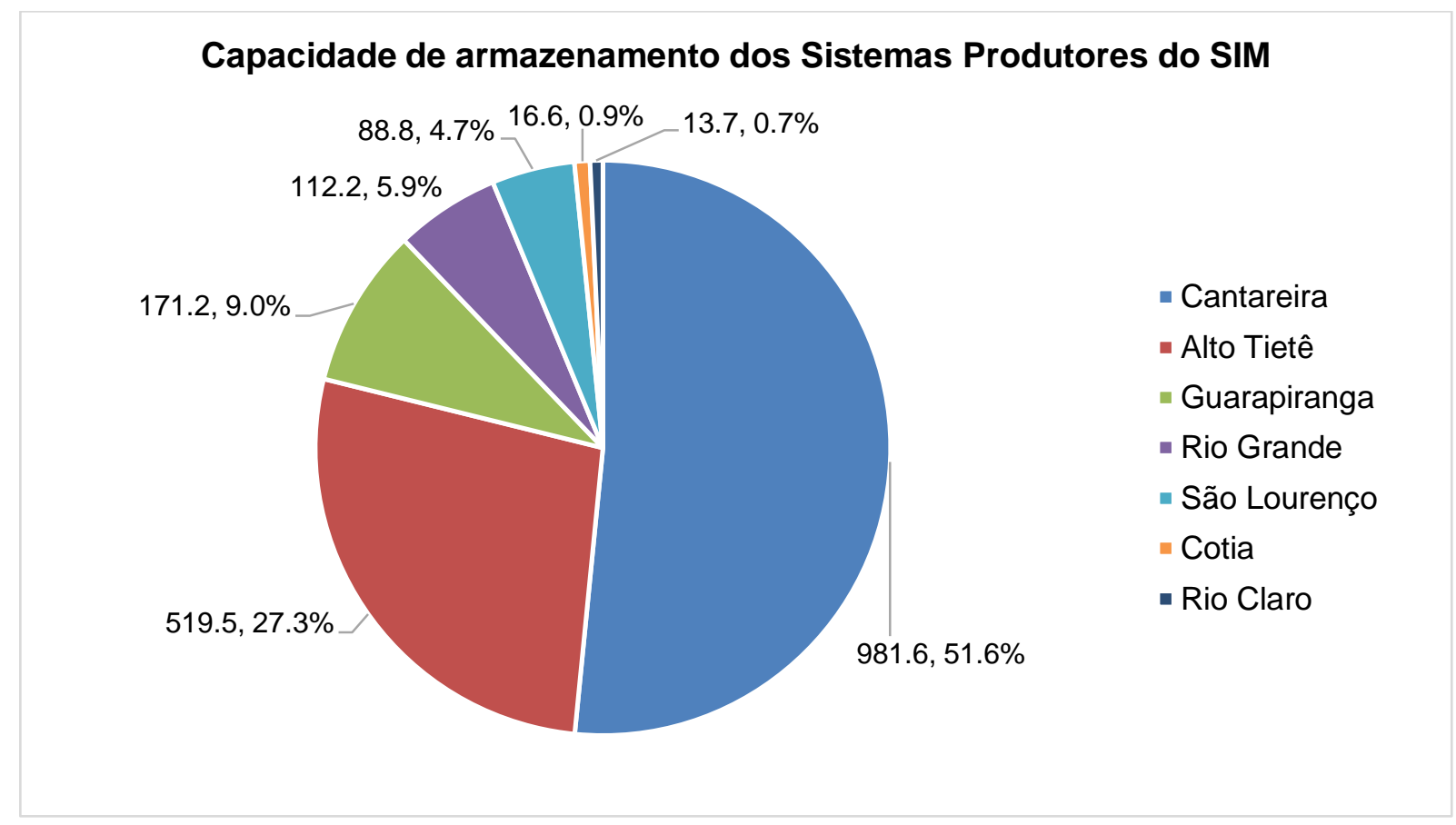

Figura 7: Capacidade de armazenamento (útil) dos sistemas produtores de água da Região Metropolitana de São Paulo (RMSP).

A capacidade nominal de tratamento das Estações de Tratamento de Água (ETA's) de cada sistema representa a seguinte contribuição no total de água produzido para atendimento à RMSP (Figura 8):

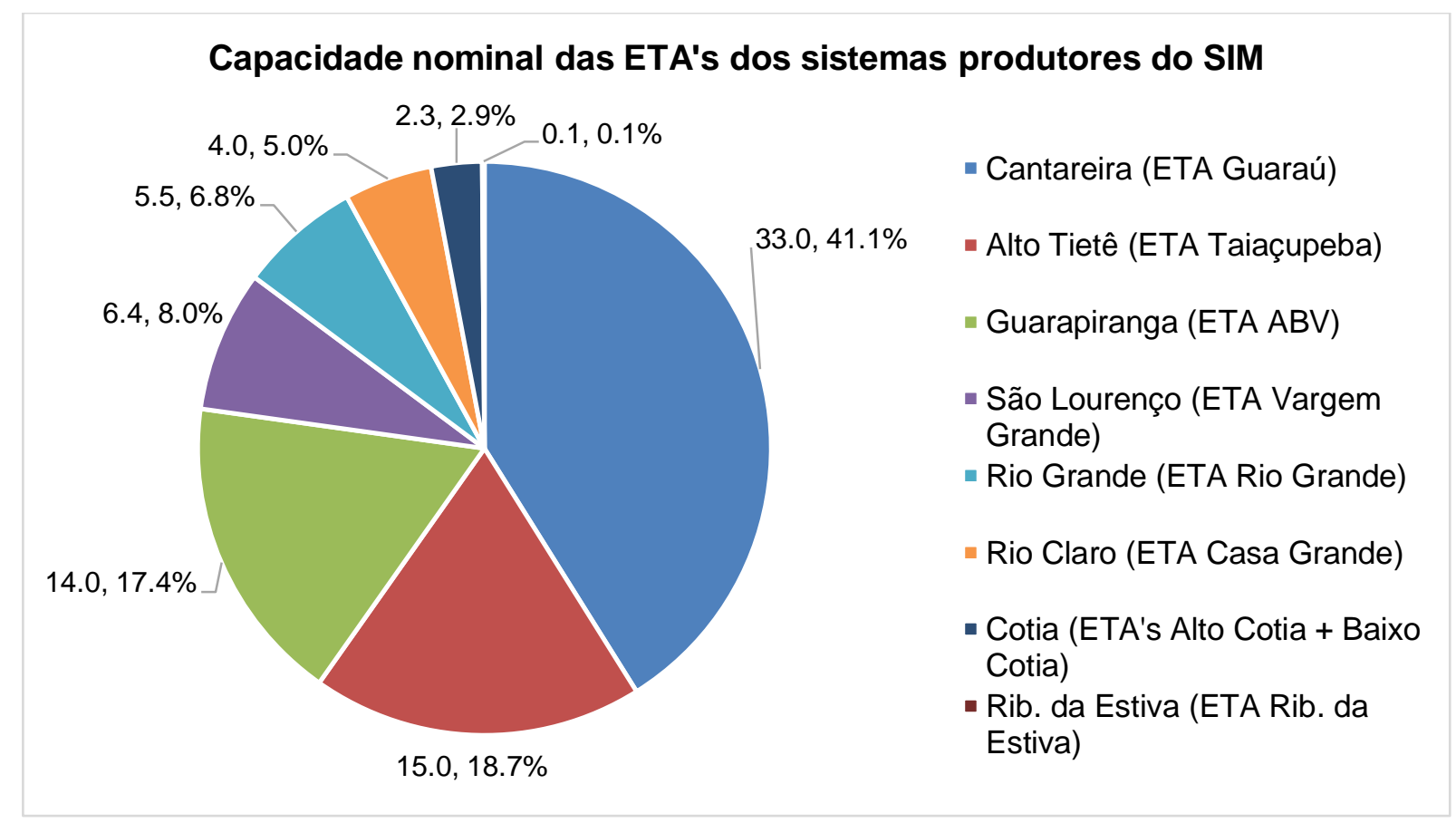

Figura 8: Vazões outorgadas de produção das ETA's dos sistemas produtores de água da RMSP. 
Como se observa na Figura 8, acima, além de responder pela maior parte da capacidade de armazenamento, o Sistema Cantareira também possui a Estação de Tratamento de Água com o maior valor de produção outorgada do SIM. A ETA Guaraú responde por $41 \%$ da capacidade total de produção do SIM, com um valor máximo de produção de 33,0 m³.s.

A Figura 9 a seguir demonstra o arranjo geral dos sistemas produtores de água componentes do Sistema Integrado Metropolitano (SIM). 


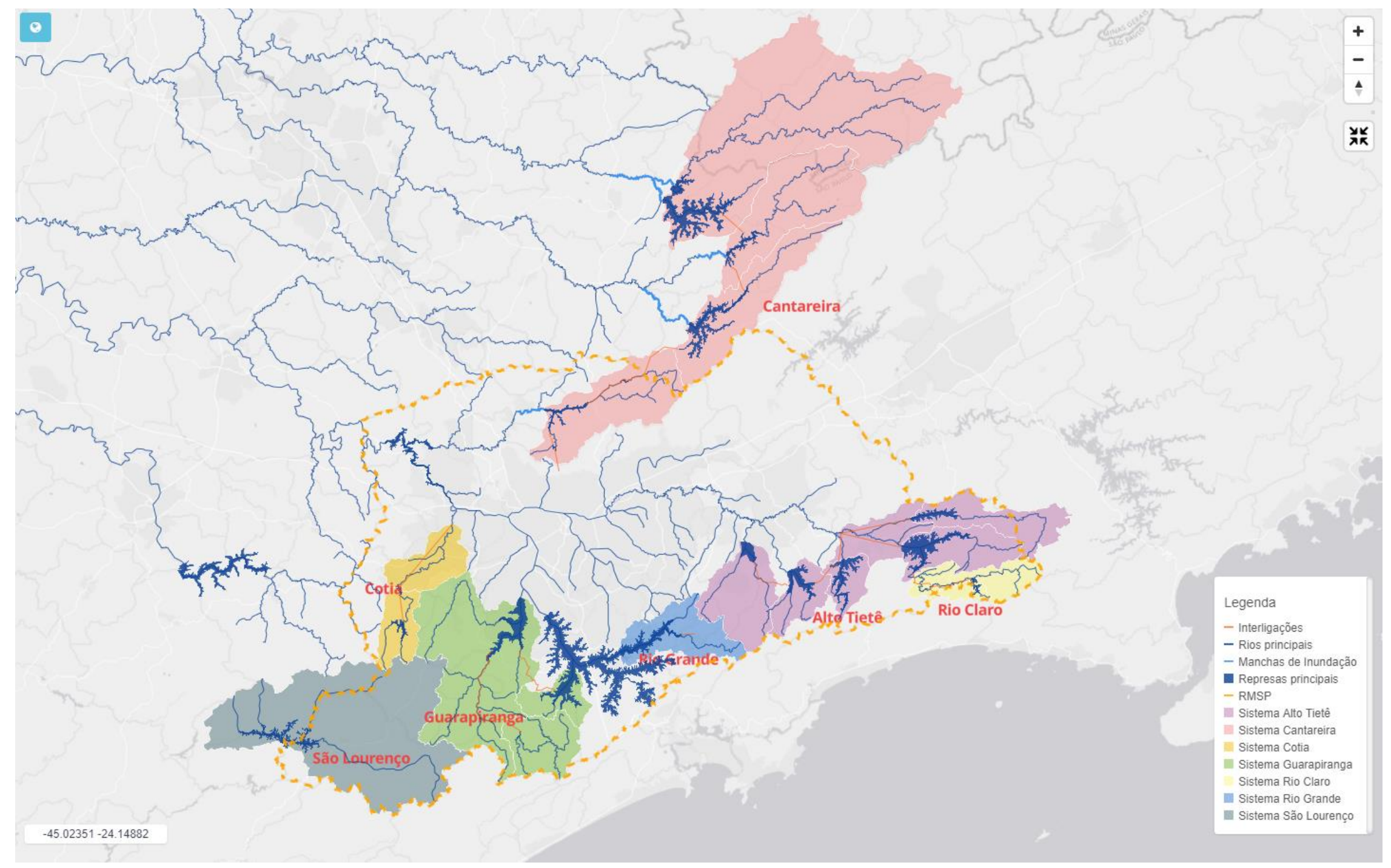

Figura 9: Arranjo geral do Sistema Integrado Metropolitano (SIM). 


\subsubsection{DADOS DE VAZÃO NATURAL}

Os dados de vazões naturais para construção da rede do Sistema Integrado Metropolitano (SIM) foram obtidos junto à Companhia de Saneamento Básico do Estado de São Paulo (Sabesp), de 2 (duas) fontes de dados principais:

- De 1930 a 2015, do banco de dados para elaboração do Relatório Final - Volume II "Avaliação da Disponibilidade Hídrica dos Mananciais para Utilização no SIM”, componente do Plano Diretor de Abastecimento de Água - PDAA Sabesp 2017, e;

- De 2016 a 2018, do banco de dados da Companhia, disponibilizado através da Plataforma do Sistema de Suporte à Decisão da Sabesp, o SSD 3 Sabesp.

Conforme já mencionado, os dados utilizados possuem resolução mensal. As séries utilizadas possuem extensão total de 89 anos, se estendendo de janeiro/1930 a dezembro/2018.

Foram levantadas as séries de vazões naturais para todos os reservatórios componentes do Sistema Integrado Metropolitano (SIM), bem como para outras localidades, conforme apresentação na Tabela 2, a seguir.

As séries de dados foram arquivadas em meio eletrônico (planilhas Excel) para posterior inserção no modelo de alocação de água - SSD AcquaNet.

Tabela 2: Pontos de interesse cujas séries de vazões naturais foram utilizadas para montagem das redes do Sistema Integrado Metropolitano (SIM).

\begin{tabular}{|l|l|c|}
\hline \multicolumn{1}{|c|}{ Sistema } & \multicolumn{1}{|c|}{ Barragem / Localidade } & $\begin{array}{c}\text { Vazão Média } \\
\left(\mathbf{m}^{\mathbf{3} / \mathbf{s}} \mathbf{)}\right.\end{array}$ \\
\hline \multirow{5}{*}{ Alto Tietê } & Biritiba & 1,93 \\
\cline { 2 - 3 } & Jundiaí & 2,34 \\
\cline { 2 - 3 } & Paraitinga & 2,48 \\
\cline { 2 - 3 } & Ponte Nova & 3,00 \\
\cline { 2 - 3 } & Taiaçupeba & 4,60 \\
\cline { 2 - 3 } & Estação Elevatória de Água Bruta de Biritiba (EEABB) & 1,41 \\
\cline { 2 - 3 } & Jusante Foz do Rio Biritiba-Mirim & 1,21 \\
\cline { 2 - 3 } & Jusante Foz do Rio Jundiaí & 4,74 \\
\cline { 2 - 3 } & Jusante Foz do Rio Taiaçupeba-Açu & 0,46 \\
\cline { 2 - 3 } & Captação Guaió & 1,18 \\
\hline \multirow{4}{*}{ Cotia } & Pedro Breicht & 1,09 \\
\cline { 2 - 3 } & Cachoeira da Graça & 0,68 \\
\hline
\end{tabular}




\begin{tabular}{|l|l|c|}
\hline \multicolumn{1}{|c|}{ Sistema } & \multicolumn{1}{|c|}{ Barragem / Localidade } & $\begin{array}{c}\text { Vazão Média } \\
\left(\mathbf{m}^{3} \mathbf{s} \mathbf{)}\right.\end{array}$ \\
\hline \multirow{5}{*}{ Cantareira } & Isolina & 3,04 \\
\hline & Jaguari/Jacareí & 24,43 \\
\cline { 2 - 3 } & Cachoeira & 8,14 \\
\cline { 2 - 3 } & Atibainha & 5,82 \\
\cline { 2 - 3 } & Paiva Castro & 4,18 \\
\cline { 2 - 3 } & Posto Atibaia & 8,31 \\
\cline { 2 - 3 } & Posto Valinhos & 12,00 \\
\cline { 2 - 3 } & Posto Buenópolis & 10,55 \\
\hline \multirow{5}{*}{ Guarapiranga } & Guarapiranga & 12,17 \\
\cline { 2 - 3 } & Captação Capivari & 7,08 \\
\cline { 2 - 3 } & Braço Taquacetuba & 1,85 \\
\hline \multirow{5}{*}{ Rio Claro } & Ribeirão do Campo & 0,82 \\
\cline { 2 - 3 } & Captação Poço Preto & 2,95 \\
\cline { 2 - 3 } & Captação Km 76 & 1,64 \\
\cline { 2 - 3 } & Captação Guaratuba & 2,05 \\
\hline \multirow{5}{*}{ Rio Grande } & Rio Grande & 6,24 \\
\cline { 2 - 3 } & Captação Ribeirão da Estiva & 0,53 \\
\cline { 2 - 3 } & Rio Pequeno & 1,50 \\
\hline São Lourenço & UHE Cachoeira do França & 22,00 \\
\hline \multirow{5}{*}{ Baíba do Sul } & Paraibuna & 67,74 \\
\cline { 2 - 3 } & Santa Branca & 79,15 \\
\cline { 2 - 3 } & Jaguari & 27,41 \\
\cline { 2 - 3 } & Funil & 224,41 \\
\cline { 2 - 3 } & Santa Cecília & \\
\hline \multirow{5}{*}{} & & 290,30 \\
\hline
\end{tabular}

Destaca-se que as séries de vazões naturais apresentadas acima referem-se apenas às bacias de contribuição de cada ponto de interesse específico, já descontadas das contribuições naturais das bacias situadas a montante.

Como pode ser visto na Tabela 2, também foi necessário o levantamento dos dados de vazões naturais dos reservatórios bacia do Paraíba do Sul: Paraibuna, Santa Branca, Jaguari (CESP), Funil e Santa Cecília. Apesar de não serem alvo da avaliação de desempenho deste trabalho, os dados da bacia do Paraíba do Sul foram necessários para construção e simulação verossímil dos Cenários 2 e 3, que consideraram a inclusão da obra de interligação Jaguari - Atibainha.

Especificamente os dados do período de 2016 a 2018 foram obtidos diretamente no banco de dados da Agência Nacional da Água - Sistema de Acompanhamento de Reservatórios (SAR), disponível no sítio eletrônico da agência (ANA, 2019). 


\subsubsection{OUTORGAS E REGRAS DE OPERAÇÃO DO SISTEMAS PRODUTORES}

No Brasil, a gestão da alocação de água para atendimento de qualquer que seja a demanda é regulada pela chamada Outorga de Direito de Uso da Água, que compõe um dos instrumentos de gestão para implementação da Política Nacional de Recursos Hídricos. O instrumento da Outorga tem como função a regulamentação que estabelece o controle das demandas, lançamentos, disponibilidade hídrica (quantitativa e qualitativa) da bacia hidrográfica, bem como a garantia do direito ao acesso à água (GARCIA, 2011).

Além da estipulação dos limites máximos de captação de um determinado corpo hídrico, os instrumentos das Outorgas estipulam ainda condições e regras específicas que devem ser atendidas na operação de um determinado sistema, por exemplo, níveis máximos e mínimos de armazenamento, vazões máximas e mínimas a jusante de reservatórios, entre outras.

Nesta etapa, foram levantadas todas as Outorgas pertinentes aos sistemas produtores do SIM, de forma a identificar as regras operacionais específicas de cada sistema para a montagem das redes no modelo de alocação de água.

As principais informações acerca das Outorgas dos sistemas produtores de água componentes do SIM são apresentadas na Tabela 3 a seguir. 
Tabela 3: Resumo das principais informações das Outorgas de uso da água dos sistemas componentes do SIM.

\begin{tabular}{|c|c|c|c|}
\hline Sistema & Documento & Emissão & Vazões Outorgadas \\
\hline Alto Tietê & $\begin{array}{l}\text { Portaria DAEE no } \\
\text { 350/2014 }\end{array}$ & $11 / 02 / 2014$ & $\begin{array}{c}15 \mathrm{~m}^{3} / \mathrm{s} \text { no Reservatório } \\
\text { Taiaçupeba; } 9 \mathrm{~m}^{3} / \mathrm{s} \text { nos Rios } \\
\text { Tietê e Biritiba-Mirim (reversão } \\
\text { p/ Reservatório Biritiba) }\end{array}$ \\
\hline Rio Claro & $\begin{array}{l}\text { Portaria DAEE no } \\
2792 / 2014\end{array}$ & $17 / 11 / 2014$ & $\begin{array}{c}2,5 \mathrm{~m}^{3} / \mathrm{s} \text { do afluente do Rio } \\
\text { Claro; } 1,5 \mathrm{~m}^{3} / \mathrm{s} \text { do Rio Claro; } \\
1,0 \mathrm{~m}^{3} / \mathrm{s} \mathrm{da} \text { Represa Ribeirão } \\
\text { do Campo; } 0,5 \mathrm{~m}^{3} / \mathrm{s} \text { do Rio } \\
\text { Guaratuba }\end{array}$ \\
\hline Cantareira & $\begin{array}{c}\text { Resolução Conjunta } \\
\text { ANA/DAEE no 926/2017 }\end{array}$ & $29 / 05 / 2017$ & $\begin{array}{l}\text { Até } 33,0 \mathrm{~m}^{3} / \mathrm{s} \text { na Estação } \\
\text { Elevatória Santa Inês (EESI) }\end{array}$ \\
\hline Guarapiranga & $\begin{array}{l}\text { Portaria DAEE no } \\
2104 / 2010\end{array}$ & $\begin{array}{l}\text { 16/09/2010 (Reti- } \\
\text { ratificada em } \\
01 / 07 / 2015)\end{array}$ & $\begin{array}{l}14 \text { m³/s no Reservatório } \\
\text { Guarapiranga; } 2,19 \text { m³/s no } \\
\text { braço do Rio Taquacetuba } \\
\text { (reversão p/ Guarapiranga) }\end{array}$ \\
\hline Rio Grande & $\begin{array}{l}\text { Portaria DAEE no } \\
2443 / 2017\end{array}$ & 02/08/2017 & $\begin{array}{c}5,5 \mathrm{~m}^{3} / \mathrm{s} \text { do Rio Grande / } \\
\text { Jurubatuba }\end{array}$ \\
\hline $\begin{array}{l}\text { Ribeirão da } \\
\text { Estiva (Sistema } \\
\text { Rio Grande) }\end{array}$ & $\begin{array}{l}\text { Portaria DAEE no } \\
3373 / 2018\end{array}$ & $26 / 06 / 2018$ & $0,1 \mathrm{~m}^{3} / \mathrm{s}$ do Ribeirão da Estiva \\
\hline $\begin{array}{l}\text { Alto Cotia } \\
\text { (Sistema Cotia) }\end{array}$ & $\begin{array}{c}\text { Portaria DAEE no } \\
588 / 2017\end{array}$ & $22 / 02 / 2017$ & $\begin{array}{l}\text { 1,25 m³/s no Rio Cotia } \\
\text { (Barragem da Graça) }\end{array}$ \\
\hline $\begin{array}{l}\text { Baixo Cotia } \\
\text { (Sistema Cotia) }\end{array}$ & $\begin{array}{l}\text { Portaria DAEE no } \\
3975 / 2016\end{array}$ & $21 / 12 / 2016$ & 1,05 m³/s no Rio Cotia \\
\hline São Lourenço & $\begin{array}{l}\text { Portaria DAEE no } \\
3062 / 2017\end{array}$ & $21 / 09 / 2017$ & $\begin{array}{c}6,4 \mathrm{~m}^{3} / \mathrm{s} \text { (média diária) no } \\
\text { Reservatório da UHE } \\
\text { Cachoeira do França }\end{array}$ \\
\hline
\end{tabular}

$\mathrm{Na}$ sequência, são descritas individualmente as regras de atendimento e condições de operação de cada sistema de acordo com diretrizes e premissas preconizadas nos documentos de Outorga apresentados acima.

Ao final desta seção, são apresentadas as tabelas com a compilação dos dados de vazões mínimas de restrição em pontos específicos da rede (Tabela 5 e 6).

\subsubsection{SISTEMA ALTO TIETÉ}

As condições descritas a seguir foram definidas pelas Portaria $n^{\circ} 350$ 11/02/2014 do Departamento de Águas e Energia Elétrica do Estado de São Paulo (DAEE):

- Demanda de 15,00 m³/s na ETA Taiaçupeba; 
- Operação da Estação Elevatória do Biritiba com 9,00 m³/s;

- Vazão mínima na seção do rio Tietê a jusante da foz do rio Biritiba igual a $3,00 \mathrm{~m}^{3} / \mathrm{s}$;

- Vazão mínima na seção do rio Tietê a jusante da foz do rio Taiaçupeba igual a $4,00 \mathrm{~m}^{3} / \mathrm{s}$;

- Represa Paraitinga:

- Vazão mínima de jusante igual a $0,50 \mathrm{~m}^{3} / \mathrm{s}$;

- Vazão máxima de jusante (válida de 01 de novembro a 30 de abril) igual a $7,00 \mathrm{~m}^{3} / \mathrm{s}$;

- Nível máximo operacional (válido de 01 de novembro a 30 de abril) igual a 767,70 m;

- Nível máximo normal igual a 768,76 m.

- Represa Ponte Nova:

- Vazão mínima de jusante igual a $0,30 \mathrm{~m}^{3} / \mathrm{s}$;

- Vazão máxima de jusante (válida de 01 de novembro a 30 de abril) igual a $12,00 \mathrm{~m}^{3} / \mathrm{s}$;

- Nível máximo operacional (válido de 01 de novembro a 30 de abril) igual a 769,60 m;

- Nível máximo normal igual a 769,94 m;

- Total das descargas simultâneas das represas Paraitinga e Ponte Nova não deve ser superior a 15,00 m³/s.

- Represa Biritiba:

- Vazão mínima de jusante igual a $0,30 \mathrm{~m}^{3} / \mathrm{s}$;

- Vazão máxima de jusante (válida de 01 de novembro a 30 de abril) igual a $0,60 \mathrm{~m}^{3} / \mathrm{s}$;

- Nível máximo operacional (válido de 01 de novembro a 30 de abril) igual a $757,30 \mathrm{~m}$;

- Nível máximo normal igual a 757,54 m.

- Represa Jundiaí:

○ Vazão mínima de jusante igual a $0,10 \mathrm{~m}^{3} / \mathrm{s}$;

- Vazão máxima de jusante (válida de 01 de novembro a 30 de abril) igual a $2,00 \mathrm{~m}^{3} / \mathrm{s}$; 
- Nível máximo operacional (válido de 01 de novembro a 30 de abril) igual a $754,25 \mathrm{~m}$;

- Nível máximo normal igual a 754,50 m.

- Represa Taiaçupeba:

○ Vazão mínima de jusante igual a $0,70 \mathrm{~m}^{3} / \mathrm{s}$;

- Vazão máxima de jusante (válida de 01 de novembro a 30 de abril) igual a $7,00 \mathrm{~m}^{3} / \mathrm{s}$;

- Nível máximo operacional (válido de 01 de novembro a 30 de abril) igual a 746,80 m;

○ Nível máximo normal igual a 747,21 m.

\subsubsection{SISTEMA COTIA}

As condições de operação do Sistema Cotia se encontram detalhadas abaixo, segundo as Portarias DAEE nํ58/2017 e no 3975/2016:

- Demanda de $1,20 \mathrm{~m}^{3} / \mathrm{s}$ na ETA Alto Cotia;

- Manter a jusante do barramento vazão mínima natural;

- Demanda de $0,90 \mathrm{~m}^{3} / \mathrm{s}$ na ETA Baixo Cotia.

\subsubsection{SISTEMA CANTAREIRA}

A Outorga do Sistema Cantareira foi definida na Resolução Conjunta ANA/DAEE o 926/2017. De acordo com a Outorga, a operação do sistema observa a condição de armazenamento dos reservatórios e o período hidrológico do ano, buscando a racionalização do uso dos recursos hídricos e o atendimento ao uso múltiplo das águas. Para fins de operação do Sistema, foram definidos dois períodos hidrológicos: Período Úmido - de 1ํ de dezembro de um ano a 31 de maio do ano seguinte; e Período Seco - de $1^{\circ}$ de junho a 30 de novembro do mesmo ano.

De acordo com a outorga, o Sistema Cantareira deverá operar segundo "Faixas de Operação", que correspondem a uma faixa percentual do volume útil do sistema equivalente e é definida no início de cada mês. A cada "Faixa de Operação", estão 
associadas vazões que deverão ser atendidas em determinados pontos de interesse definidos na resolução, conforme Tabela 4, abaixo.

As vazões dos Postos de Controle poderão sofrer variação momentânea desde que respeitada a vazão mínima média diária de $10,0 \mathrm{~m}^{3} / \mathrm{s}$ em Valinhos, de 2,0 m³/s em Buenópolis e de 2,0 m³/s em Atibaia.

No Período Seco, nas Faixas 1, 2, 3 e 4 (Normal, Atenção, Alerta e Restrição), deve ser garantida uma vazão média, no período de $1^{\circ}$ de junho a 30 de novembro, de $10,0 \mathrm{~m}^{3} / \mathrm{s}$, equivalente a um volume de $158,1 \mathrm{hm}^{3}$, a ser liberada do Sistema Cantareira para as Bacias PCJ. Na Faixa 5 (Especial), mantem-se a vazão mínima média diária de 10,0 m³/s no posto de controle Captação de Valinhos, no rio Atibaia, e de $2,0 \mathrm{~m}^{3} / \mathrm{s}$ no posto de controle de Buenópolis, no rio Jaguari.

São definidas ainda as seguintes vazões mínimas instantâneas a serem liberadas a jusante do Cantareira independentemente da Faixa de Operação do sistema e do período do ano:

- Descarga mínima para jusante do reservatório Paiva Castro no rio Juqueri: $0,10 \mathrm{~m}^{3} / \mathrm{s}$;

- Descarga mínima para jusante dos reservatórios Jaguari/Jacareí no rio Jaguari: $0,25 \mathrm{~m}^{3} / \mathrm{s}, \mathrm{e}$;

- Descarga mínima para jusante dos reservatórios Cachoeira/Atibainha no rio Atibaia: $0,25 \mathrm{~m}^{3} / \mathrm{s}$.

As vazões bombeadas do reservatório de Jaguari, na bacia do Paraíba do Sul, são acrescidas aos limites máximos de retiradas à RMSP quando o Sistema Cantareira estiver operando nas faixas 2, 3 e 4. Na faixa 5 (especial) a alocação das vazões bombeadas é definida pelos órgãos gestores visando aumentar a segurança hídrica do sistema.

No período úmido as liberações das vazões para as Bacias PCJ são estabelecidas pelo DAEE e comunicadas à SABESP e aos Comitês PCJ. No período Seco as vazões liberadas são determinadas pelos Comitês PCJ através de comunicado ao DAEE que por sua vez comunica a SABESP. A manobra dos descarregadores deve ser realizada pela SABESP até as $8 \mathrm{~h}$ do dia seguinte ao recebimento do comunicado. 
Tabela 4: Faixas de operação e vazões requeridas, de acordo com a Outorga do Sistema Cantareira.

\begin{tabular}{|c|c|c|c|c|c|c|c|c|}
\hline \multirow{2}{*}{$\begin{array}{l}\text { Faixas de } \\
\text { Operação }\end{array}$} & \multirow{2}{*}{ Intervalos } & \multirow{2}{*}{$\begin{array}{l}\text { V. Limite Sup. } \\
\left(\mathrm{hm}^{3}\right)\end{array}$} & \multirow{2}{*}{$\begin{array}{l}\text { V. Limite Inf. } \\
\left(\mathrm{hm}^{3}\right)\end{array}$} & \multirow{2}{*}{ Status } & \multicolumn{4}{|c|}{ Vazões Requeridas (m³/s) } \\
\hline & & & & & ESI & PC Atibaia & PC Valinhos & PC Buenóp. \\
\hline Faixa 1 & Acima $60 \%$ & 981,56 & 588,95 & Normal & 33,0 & 3,0 & 12,0 & 2,5 \\
\hline Faixa 2 & $60-40 \%$ & 588,95 & 392,62 & Atenção & 31,0 & 3,0 & 12,0 & 2,5 \\
\hline Faixa 3 & $40-30 \%$ & 392,62 & 294,47 & Alerta & 27,0 & 2,5 & 11,0 & 2,0 \\
\hline Faixa 4 & $30-20 \%$ & 294,47 & 196,31 & Restrição & 23,0 & 2,5 & 11,0 & 2,0 \\
\hline Faixa 5 & Abaixo $20 \%$ & 196,31 & 0 & Especial & 15,5 & 2,0 & 10,0 & 2,0 \\
\hline
\end{tabular}




\subsubsection{SISTEMA GUARAPIRANGA}

As condições de operação do Sistema Guarapiranga se encontram detalhadas a seguir, segundo a Portaria DAEE no 2104/2010, Reti-ratificada em 01/07/2015:

- Demanda de $14,00 \mathrm{~m}^{3} / \mathrm{s}$ na ETA ABV;

- Transferência de 2,19 m³/s da represa Billings - Braço Taquacetuba para a represa Guarapiranga;

\subsubsection{SISTEMA RIO CLARO}

As condições descritas a seguir foram definidas pelas Portaria $n^{\circ} 2792$ 17/11/2014 do Departamento de Águas e Energia Elétrica do Estado de São Paulo (DAEE):

- Demanda de 4,00 m³/s na ETA Casa Grande;

- Vazões máximas de captação de $2,5 \mathrm{~m}^{3} / \mathrm{s}$ do afluente do Rio Claro; 1,5 $\mathrm{m}^{3} / \mathrm{s}$ do Rio Claro, e; 1,0 m³/s da Represa Ribeirão do Campo;

- Reversão do rio Guaratuba operando com capacidade máxima de 0,50 $\mathrm{m}^{3} / \mathrm{s}$;

- Manter a jusante do barramento vazão mínima natural.

\subsubsection{SISTEMA RIO GRANDE}

As condições de operação do Sistema Rio Grande se encontram detalhadas a seguir, segundo as Portarias DAEE no 2443/2017 e no 3373/2018:

- Demanda de $5,50 \mathrm{~m}^{3} / \mathrm{s}$ na ETA Rio Grande;

- Manter a jusante do barramento vazão mínima natural;

- Demanda de 0,10 m³/s na ETA Ribeirão da Estiva. 


\subsubsection{SISTEMA SÃO LOURENÇO}

- Demanda de 6,40 m³/s na ETA Vargem Grande;

- Descarga mínima de $50 \%$ da $Q_{7,10}$ para jusante da barragem;

- Cota mínima do nível do reservatório de 630 metros. 
Tabela 5: Vazões mínimas de restrição a jusante dos barramentos e em localidades específicas (SABESP/ENCIBRA, 2017).

\begin{tabular}{|c|c|c|}
\hline Sistemas & Barramento / Localidade & Qmín $\left(m^{3} / s\right)$ \\
\hline \multirow{8}{*}{ Alto Tietê } & Paraitinga & 0,500 \\
\hline & Ponte Nova & 0,300 \\
\hline & Biritiba & 0,300 \\
\hline & Jundiaí & 0,100 \\
\hline & Taiaçupeba & 0,700 \\
\hline & Jusante foz do rio Biritiba & 3,000 \\
\hline & Jusante foz do rio Taiaçupeba & 4,000 \\
\hline & Rio Guaió & 0,119 \\
\hline \multirow{3}{*}{ Cotia } & Jusante Pedro Breicht & 0,000 \\
\hline & Jusante Cachoeira da Graça & 0,158 \\
\hline & Jusante Isolina & 0,000 \\
\hline \multirow{7}{*}{ Cantareira } & Jusante do Res. Jaguari/Jacareí no Rio Jaguari & 0,250 \\
\hline & Jusante do Res. Cachoeira/Atibainha no Rio Atibaia & 0,250 \\
\hline & Posto Contr. Capitação Valinhos (Período Úmido) & 10,000 \\
\hline & Posto Contr. Buenópolis (Período Úmido) & 2,000 \\
\hline & Posto Contr. Atibaia (Período Úmido) & 2,000 \\
\hline & Bacias do PCJ (Período Seco) & 10,000 \\
\hline & Jusante do Res. Paiva Castro no Rio Juqueri & 0,100 \\
\hline \multirow{2}{*}{ Guarapiranga } & Guarapiranga & 0,000 \\
\hline & Rio Capivari & 0,143 \\
\hline \multirow{2}{*}{ Rio Claro } & Ribeirão do Campo & 0,000 \\
\hline & Rio Guaratuba & 0,146 \\
\hline \multirow{3}{*}{ Rio Grande } & Rio Grande & 0,000 \\
\hline & Ribeirão da Estiva & 0,027 \\
\hline & Rio Pequeno & 0,000 \\
\hline São Lourenço & Jusante da Cachoeira do França & 3,230 \\
\hline
\end{tabular}


Tabela 6: Vazões mínimas de restrição ( $\left.\mathrm{m}^{3} / \mathrm{s}\right)$ de acordo com as Resoluções da ANA -Bacia do Rio Paraíba do Sul.

\begin{tabular}{|l|c|c|c|c|c|c|}
\hline \multicolumn{1}{|c|}{ Resolução ANA } & Período & Paraibuna & Santa Branca & Jaguari & Funil & Santa Cecília \\
\hline № $211-26 / 05 / 2003$ & Outubro/1930 - Maio/2014 & 30 & 40 & 10 & 80 & 190 \\
\hline № $700-27 / 05 / 2014$ & Junho/2014 - Julho/2014 & 30 & 40 & 10 & 80 & 173 \\
\hline № $1038-16 / 07 / 2014$ & Agosto/14 & 30 & 40 & 10 & 80 & 165 \\
\hline № $1309-29 / 08 / 2014$ & Setembro/2014 - Dezembro/2014 & 30 & 40 & 10 & 80 & 160 \\
\hline № 2051-23/12/2014 & Janeiro/15 & 30 & 40 & 10 & 80 & 140 \\
\hline № $86-30 / 01 / 2015$ & Fevereiro/15 & 30 & 34 & 7 & 80 & 140 \\
\hline № 145-27/02/2015 & Março/15 & 30 & 34 & 4 & 70 & 110 \\
\hline № 205-23/03/2015 & Abril/2015 - Setembro/2015 & 25 & 30 & 4 & 70 & 110 \\
\hline
\end{tabular}




\subsubsection{DEMANDAS DE USOS CONSUNTIVOS}

Neste item, apresentam-se as demandas consuntivas utilizadas na construção dos cenários simulados no modelo de alocação de água.

As informações sobre das demandas de cada sistema produtor foram obtidas do Relatório Final - Volume II "Avaliação da Disponibilidade Hídrica dos Mananciais para Utilização no SIM", componente do Plano Diretor de Abastecimento de Água PDAA Sabesp 2017.

Para cada um dos sistemas produtores do SIM, foram levantadas as demandas de uso consuntivo projetadas para o Ano-Base 2045. Com a única exceção das demandas da bacia hidrográfica do rio Paraíba do Sul, que tem como base o ano de 2040.

Optou-se pelo uso destas demandas e não das demandas do Ano-Base 2013, também disponíveis no PDAA Sabesp 2017, com o objetivo de provocar um maior estresse na operação dos sistemas produtores, uma vez que as demandas consuntivas Ano-Base 2045 são aproximadamente $26 \%$ superiores às demandas do Ano-Base 2013.

De acordo com a Sabesp/Encibra (2017), as séries de vazões naturais calculadas para os sistemas produtores foram obtidas por balanço hídrico nos reservatórios de cada sistema e, portanto, já incluem algumas captações e lançamentos. Assim, para as demandas do horizonte de 2045, foram consideradas apenas as outorgas que não estão incluídas no cálculo das séries de vazões operadas pelos reservatórios.

As Figura 10 a 13 apresentam as localizações dos pontos de demanda, bem como as áreas de agrupamento que foram selecionadas para auxílio na compilação dos dados. 


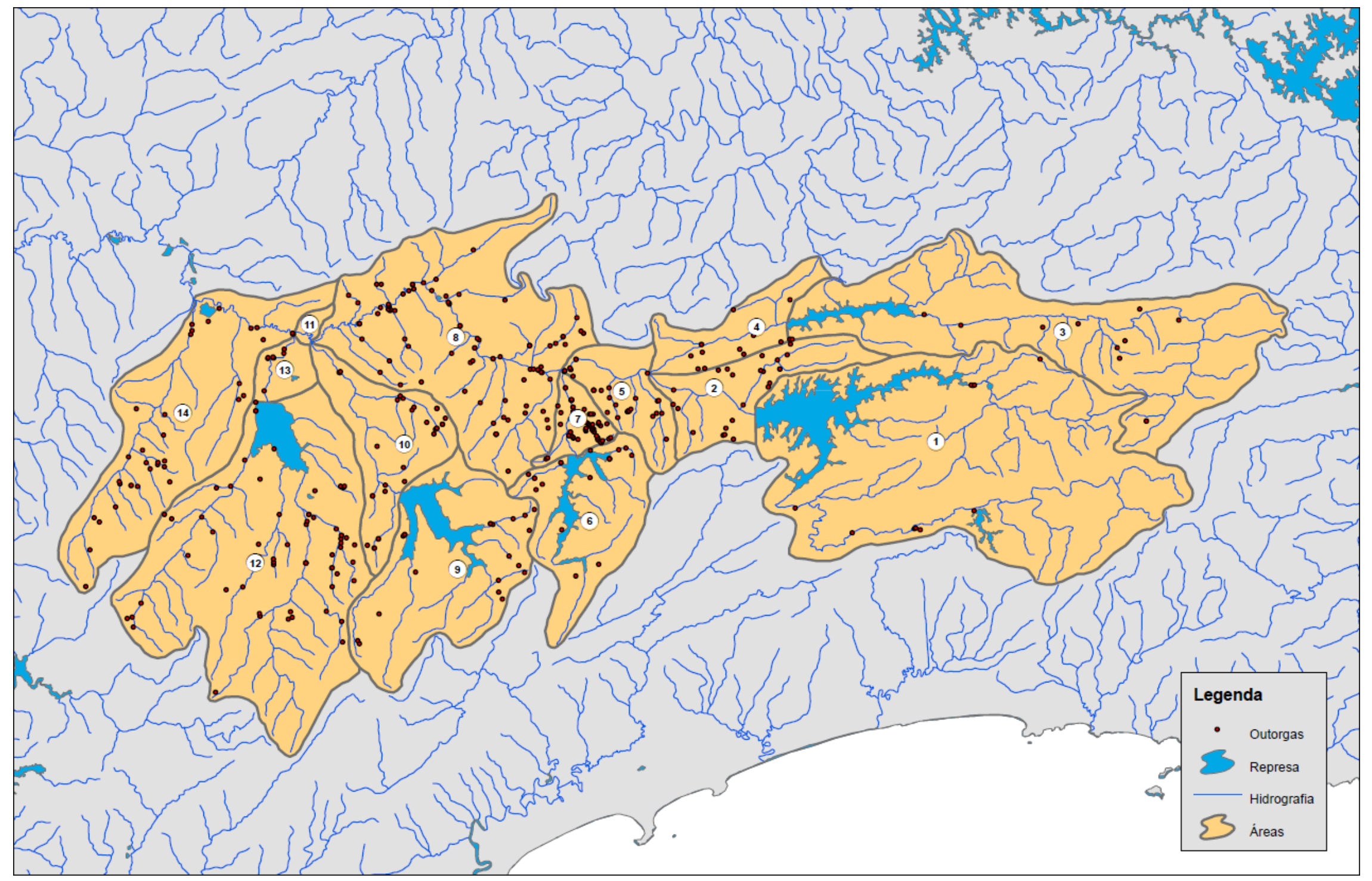

Figura 10: Localização das áreas / pontos de demanda consuntiva - Sistemas Alto Tietê e Rio Claro (Fonte: Sabesp/Encibra, 2017). 


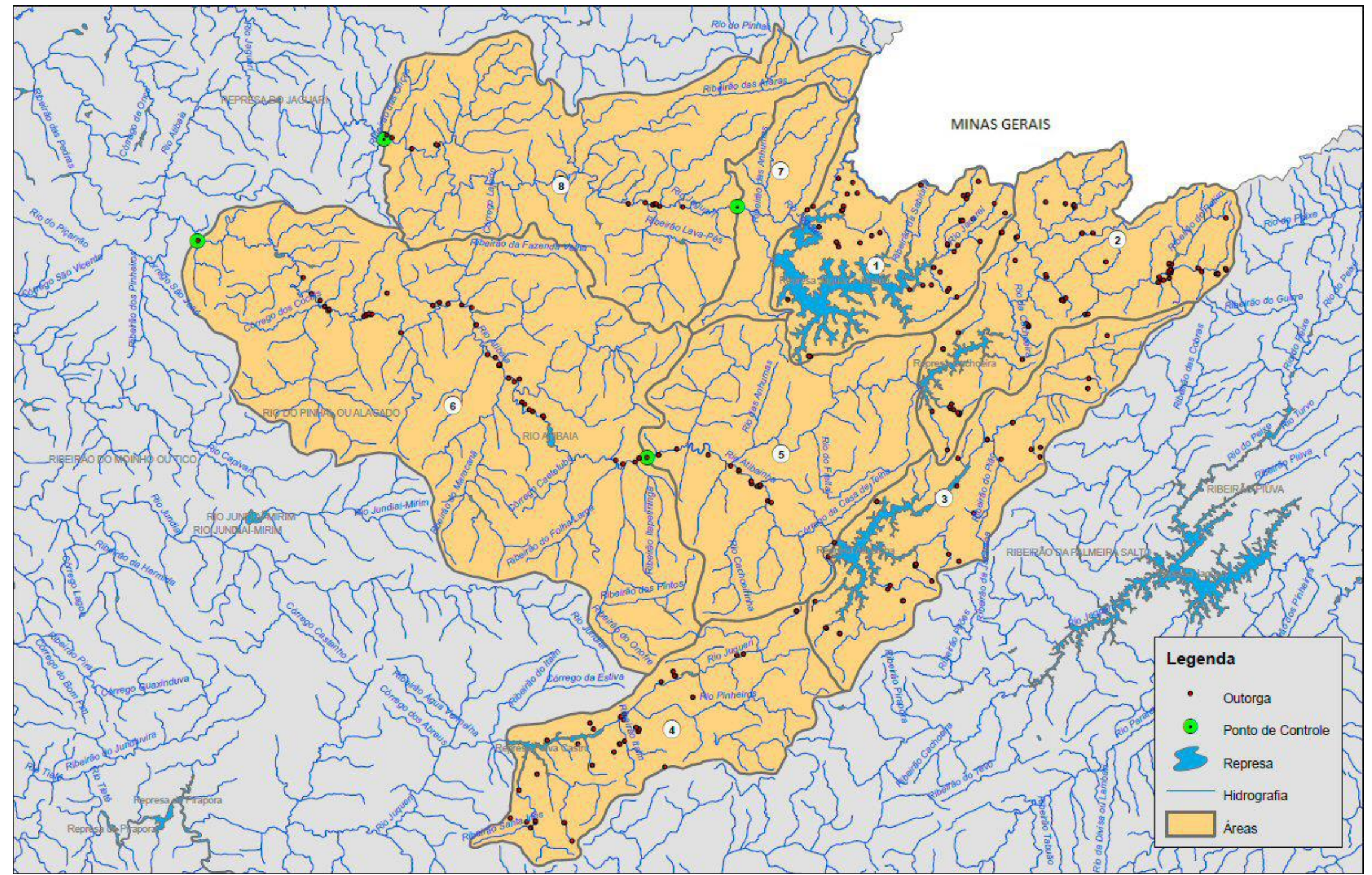

Figura 11: Localização das áreas / pontos de demanda consuntiva - Sistema Cantareira (Fonte: Sabesp/Encibra, 2017). 


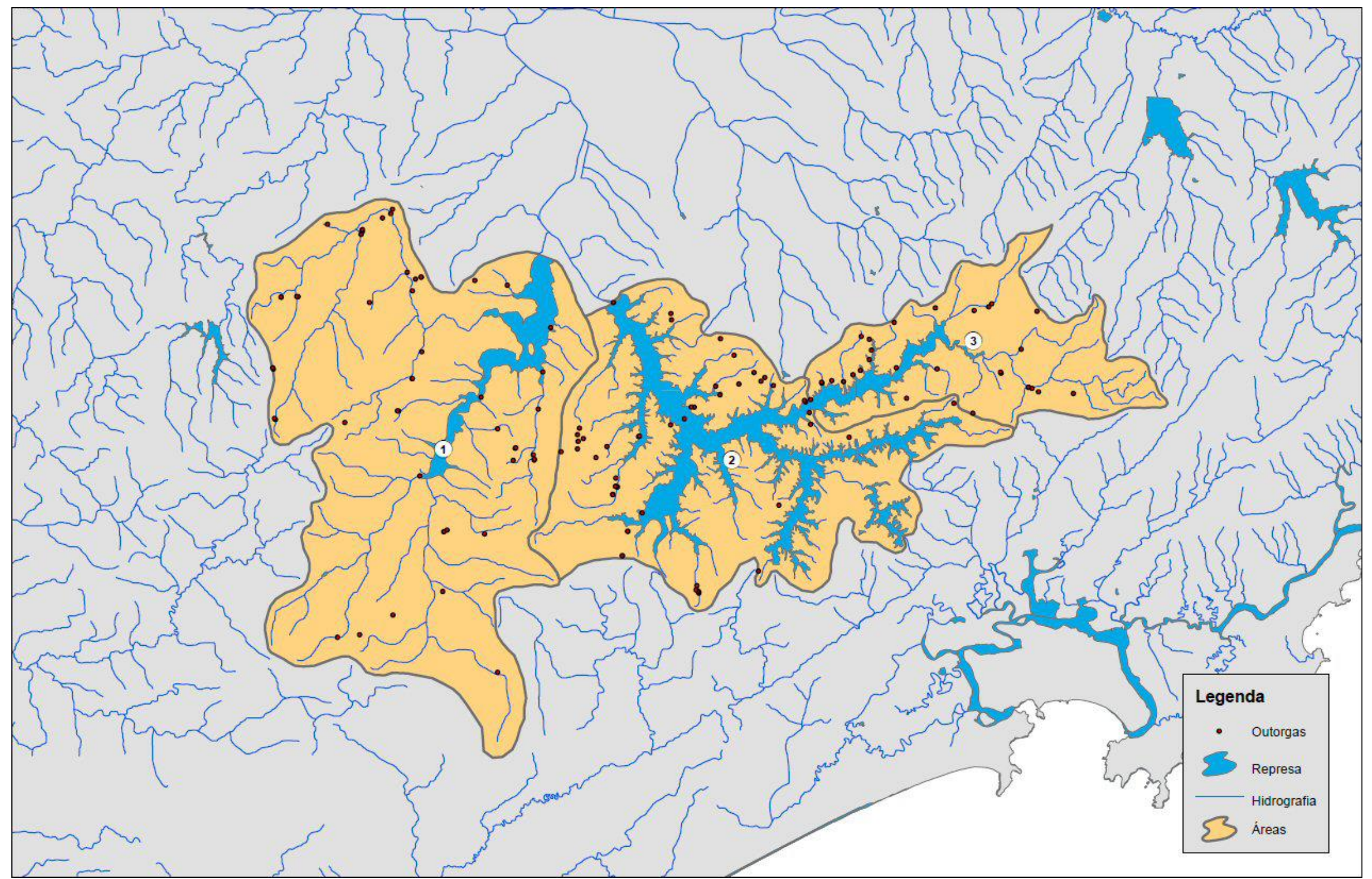

Figura 12: Localização das áreas / pontos de demanda consuntiva - Sistemas Guarapiranga e Rio Grande (Fonte: Sabesp/Encibra, 2017). 


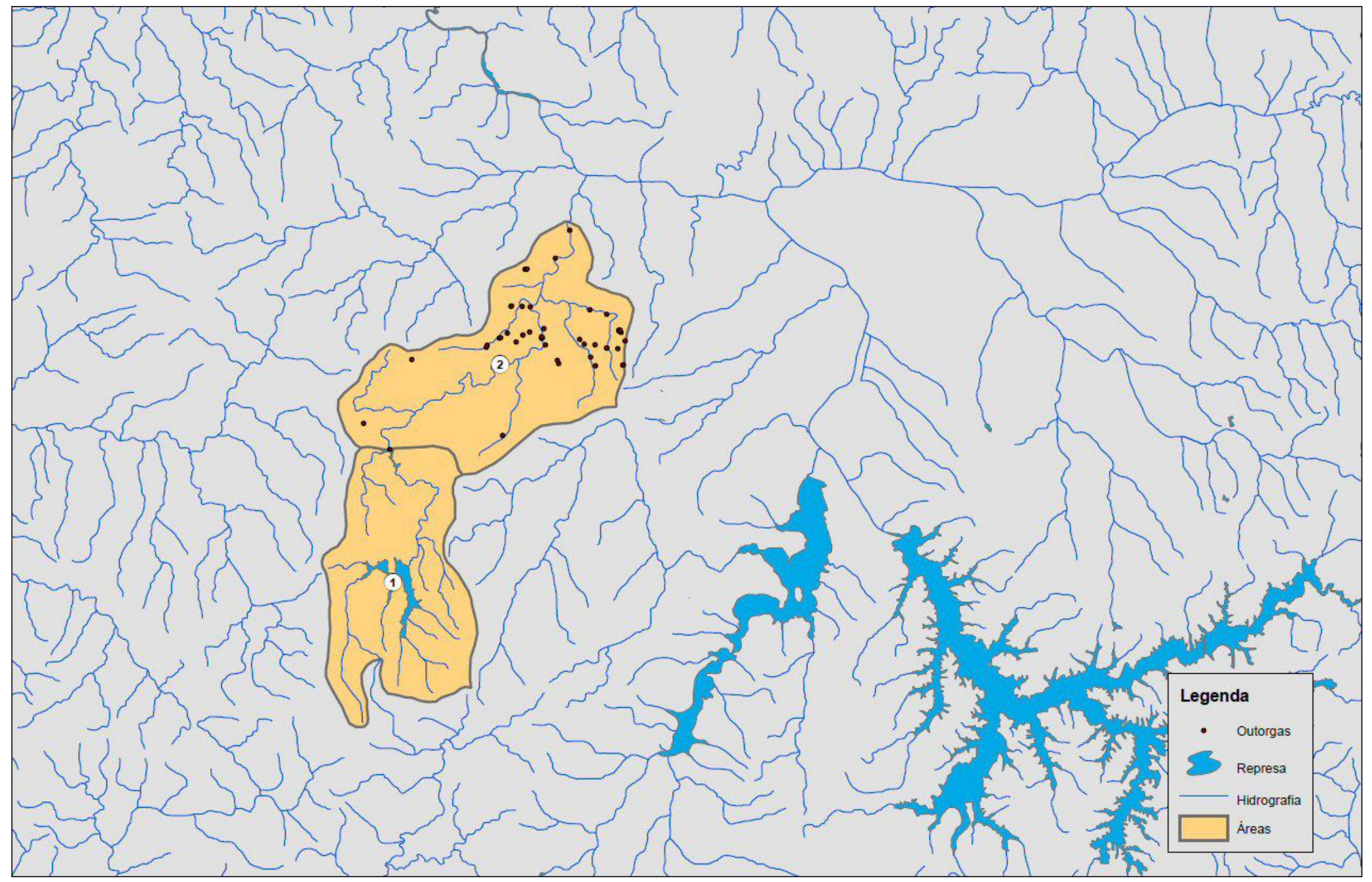

Figura 13: Localização das áreas / pontos de demanda consuntiva - Sistema Cotia (Fonte: Sabesp/Encibra, 2017). 
As demandas para o Ano-Base 2045 são apresentadas na Tabela 7 a seguir. Note-se que as demandas se encontram separadas em 4 tipos de uso: abastecimento público, industrial, energia e irrigação (linhas horizontais). E também separadas por áreas de agrupamento (colunas verticais). 
Tabela 7: Demandas ( $\left.\mathrm{m}^{3} / \mathrm{s}\right)$ consuntivas para o Ano-base 2045, segundo áreas de agrupamento e tipos de uso (Fonte: Sabesp/Encibra, 2017).

\begin{tabular}{|c|c|c|c|c|c|c|c|c|c|c|c|c|c|c|c|c|c|}
\hline Sistemas & Tipo de Uso & $1 \mathrm{~A}$ & 1 & 2 & 3 & 4 & 5 & 6 & 7 & 8 & 9 & 10 & 11 & 12 & 13 & 14 & Total \\
\hline \multirow{5}{*}{$\begin{array}{l}\text { Alto Tietê e } \\
\text { Rio Claro }\end{array}$} & Capt. Total & - & 0,005 & 0,159 & 0,001 & 0,025 & 0,126 & 0,011 & 0,820 & 1,798 & 0,003 & 0,059 & - & 0,033 & 0,728 & 1,400 & 5,168 \\
\hline & Ab. Público & - & 0,005 & 0,125 & 0,000 & 0,000 & 0,000 & 0,000 & 0,000 & 1,468 & 0,000 & 0,000 & - & 0,000 & 0,000 & 0,000 & 1,598 \\
\hline & Energia & - & 0,000 & 0,000 & 0,000 & 0,000 & 0,000 & 0,000 & 0,000 & 0,000 & 0,000 & 0,000 & - & 0,000 & 0,000 & 0,000 & 0,000 \\
\hline & Industrial & - & 0,000 & 0,000 & 0,000 & 0,000 & 0,001 & 0,000 & 0,000 & 0,235 & 0,000 & 0,014 & - & 0,002 & 0,728 & 1,400 & 2,380 \\
\hline & Irrigante & - & 0,000 & 0,034 & 0,001 & 0,025 & 0,125 & 0,011 & 0,820 & 0,095 & 0,003 & 0,045 & - & 0,031 & 0,000 & 0,000 & 1,190 \\
\hline \multirow{4}{*}{ Cantareira } & Capt. Total & 0,269 & 0,010 & 0,014 & 0,015 & 0,125 & 0,874 & 2,624 & - & 0,855 & - & - & - & - & - & - & 4,786 \\
\hline & Ab. Público & 0,006 & 0,004 & 0,004 & 0,010 & 0,107 & 0,859 & 2,295 & - & 0,754 & - & - & - & - & - & - & 4,039 \\
\hline & Industrial & 0,000 & 0,001 & 0,000 & 0,004 & 0,018 & 0,015 & 0,233 & - & 0,101 & - & - & - & - & - & - & 0,372 \\
\hline & Irrigante & 0,263 & 0,005 & 0,010 & 0,001 & 0,000 & 0,000 & 0,096 & - & 0,000 & - & - & - & - & - & - & 0,375 \\
\hline \multirow{5}{*}{$\begin{array}{l}\text { Guarapiranga } \\
\text { e Rio Grande }\end{array}$} & Capt. Total & - & 0,034 & 0,180 & 0,028 & - & - & - & - & - & - & - & - & - & - & - & 0,242 \\
\hline & Ab. Público & - & 0,006 & 0,000 & 0,000 & - & - & - & - & - & - & - & - & - & - & - & 0,006 \\
\hline & Energia & - & 0,000 & 0,000 & 0,000 & - & - & - & - & - & - & - & - & - & - & - & 0,000 \\
\hline & Industrial & - & 0,025 & 0,078 & 0,028 & - & - & - & - & - & - & - & - & - & - & - & 0,131 \\
\hline & Irrigante & - & 0,003 & 0,102 & 0,000 & - & - & - & - & - & - & - & - & - & - & - & 0,105 \\
\hline \multirow{6}{*}{$\begin{array}{l}\text { Alto e Baixo } \\
\text { Cotia }\end{array}$} & Capt. Total & - & 0,000 & 0,005 & - & - & - & - & - & - & - & - & - & - & - & - & 0,005 \\
\hline & Ab. Público & - & 0,000 & 0,000 & - & - & - & - & - & - & - & - & - & - & - & - & 0,000 \\
\hline & Industrial & - & 0,000 & 0,005 & - & - & - & - & - & - & - & - & - & - & - & - & 0,005 \\
\hline & Irrigante & - & 0,000 & 0,000 & - & - & - & - & - & - & - & - & - & - & - & - & 0,000 \\
\hline & Capt. Total & - & 0,452 & 0,22 & 5,186 & 0,465 & 0,552 & 15,442 & - & - & - & - & - & - & - & - & 22,317 \\
\hline & Ab. Urbano & - & 0,212 & 0,144 & 3,409 & 0,036 & 0,001 & 5,451 & 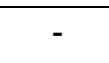 & - & - & - & - & - & - & - & 9,253 \\
\hline
\end{tabular}




\begin{tabular}{|c|c|c|c|c|c|c|c|c|c|c|c|c|c|c|c|c|c|}
\hline Sistemas & Tipo de Uso & 1A & 1 & 2 & 3 & 4 & 5 & 6 & 7 & 8 & 9 & 10 & 11 & 12 & 13 & 14 & Total \\
\hline \multirow{3}{*}{$\begin{array}{l}\text { Bacia do Rio } \\
\text { Paraíba do } \\
\text { Sul }\end{array}$} & Industrial & - & 0,02 & 0,034 & 1,707 & 0,217 & 0,499 & 1,887 & - & - & - & - & - & - & - & - & 4,364 \\
\hline & Irrigação & - & 0,003 & 0,005 & 0,001 & 0,024 & 0,000 & 7,205 & - & - & - & - & - & - & - & - & 7,238 \\
\hline & Outros & - & 0,217 & 0,037 & 0,069 & 0,188 & 0,052 & 0,899 & - & - & - & - & - & - & - & - & 1,462 \\
\hline
\end{tabular}




\subsubsection{OBRAS DE INCREMENTO DA SEGURANÇA HÍDRICA}

As informações acerca das obras de incremento de segurança hídrica do Sistema Integrado Metropolitano (SIM) foram obtidas do Relatório Final - Volume II "Avaliação da Disponibilidade Hídrica dos Mananciais para Utilização no SIM", componente do Plano Diretor de Abastecimento de Água - PDAA Sabesp 2017.

$\mathrm{Na}$ Tabela 8 a seguir encontram-se descritas as obras selecionadas para aplicação no presente trabalho. Estas obras e medidas foram pontadas pela Sabesp como estratégias necessárias para ganho de segurança hídrica do Sistema Integrado Metropolitano (SIM), principalmente após os eventos da Crise Hídrica de 2014-2015.

Além de descritas no PDAA Sabesp 2017, acima mencionado, estas medidas foram inicialmente apresentadas no documento chamado Relatório "Crise Hídrica, Estratégias e Soluções da Sabesp, 2015", também de autoria da Companhia de Saneamento Básico do Estado de São Paulo (SABESP, 2015).

A escolha destas medidas para a construção dos Cenários de Simulação 2 e 3 considerou principalmente o fato de que estas foram efetivamente as obras de segurança hídrica implementadas pela Companhia durante e após os eventos da Crise de 2014-2015, e que atualmente se mantém em operação.

Tabela 8: Descrição dos novos aportes e obras de ampliação de capacidade dos sistemas considerados nas simulações deste trabalho (Fonte: Sabesp/Encibra, 2017).

\begin{tabular}{|c|c|}
\hline Sistema & Descrição das Medidas \\
\hline Alto Tietê & $\begin{array}{l}\text { - Reversão do rio Guaió para a represa Taiaçupeba, com capacidade } \\
\text { máxima de } 1,2 \mathrm{~m} 3 / \mathrm{s} \text {; } \\
\text { - Transposição do Rio Grande (Sistema Rio Grande) para a represa } \\
\text { Taiaçupeba (Sistema Alto Tietê), com capacidade máxima de } 3,0 \text { m³/s. }\end{array}$ \\
\hline Cantareira & $\begin{array}{l}\text { - Interligação do reservatório Jaguari - bacia do rio Paraíba do Sul com o } \\
\text { reservatório Atibainha - Sistema Cantareira. Essa interligação foi } \\
\text { simulada como uma transferência constante de } 5,13 \mathrm{~m}^{3} / \mathrm{s} \text { do } \\
\text { reservatório Jaguari para o reservatório Atibainha. }\end{array}$ \\
\hline Rio Grande & $\begin{array}{l}\text { - Transposição do Rio Grande (Sistema Rio Grande) para a represa } \\
\text { Taiaçupeba (Sistema Alto Tietê), com capacidade máxima de 3,0 m³/s. } \\
\text { - Transferência do Braço do Rio Pequeno para o Rio Grande, com } \\
\text { capacidade máxima de } 4,0 \mathrm{~m} 3 / \mathrm{s} \text {. }\end{array}$ \\
\hline
\end{tabular}




\subsection{ETAPA 3 - SIMULAÇÃO DOS CENÁRIOS DE OPERAÇÃO}

Na Etapa de Simulação dos Cenários, o primeiro passo refere-se à organização e consolidação dos dados levantados na etapa anterior, de forma que estes possam estar adaptados ao formato de entrada no modelo de alocação de água.

Para a simulação dos cenários de operação do Sistema Integrado Metropolitano (SIM) foi utilizado o Sistema de Suporte a Decisões LabSid AcquaNet 2013, desenvolvido no Laboratório de Sistemas de Suporte a Decisões da Escola Politécnica da USP - LabSid.

Conforme já mencionado neste trabalho, o SSD LabSid AcquaNet 2013 faz a alocação da água para diversos pontos da bacia procurando atender as demandas de cada ponto de acordo com prioridades previamente fixadas pelo usuário. O SSD AcquaNet é composto por vários módulos e, neste trabalho, foi utilizado o módulo de Alocação. As principais informações necessárias ao funcionamento do modelo são:

- Topologia do sistema;

- Séries de vazões médias mensais naturais em pontos de interesse;

- Características físicas dos componentes do sistema (reservatórios, canais, obras de condução de água, estações de bombeamento, etc.);

- Prioridades estabelecidas pelo usuário para as demandas e os volumes dos reservatórios.

Como resultado o SSD AcquaNet fornece o grau de atendimento às diversas demandas, quantifica os eventuais déficits e apresenta os valores destas e de outras variáveis, como volume dos reservatórios, por exemplo, em termos absolutos ao longo do tempo ou em termos estatísticos na forma de curvas de permanência.

Em todos os sistemas analisados foram utilizadas séries de vazões médias mensais com início em janeiro de 1930 e término em dezembro de 2018.

Os Cenários de operação do SIM, analisados neste trabalho, foram assim estruturados (Tabela 9): 
Tabela 9: Resumo das principais características dos cenários de simulação do Sistema Integrado Metropolitano (SIM).

\begin{tabular}{|c|c|c|c|}
\hline Especificação & Cenário 1 & Cenário 2 & Cenário 3 \\
\hline Tempo de simulação & 89 anos & 89 anos & 89 anos \\
\hline Período & $1930-2018$ & $1930-2018$ & $1930-2018$ \\
\hline Tipo de simulação & Simulação Contínua & Simulação Contínua & Simulação Contínua \\
\hline Opção de cálculo & Estados Hidrológicos & Estados Hidrológicos & Estados Hidrológicos \\
\hline Dados hidrológicos & $\begin{array}{c}\text { Dados históricos de } \\
\text { vazões naturais dos } \\
\text { sistemas componentes } \\
\text { do SIM }\end{array}$ & $\begin{array}{c}\text { Dados históricos de } \\
\text { vazões naturais dos } \\
\text { sistemas componentes } \\
\text { do SIM }\end{array}$ & $\begin{array}{c}\text { Dados históricos de } \\
\text { vazões naturais dos } \\
\text { sistemas componentes } \\
\text { do SIM }\end{array}$ \\
\hline Demandas & $\begin{array}{l}\text { Demandas referentes } \\
\text { ao ano-base } 2045\end{array}$ & $\begin{array}{l}\text { Demandas referentes } \\
\text { ao ano-base } 2045\end{array}$ & $\begin{array}{l}\text { Demandas referentes } \\
\text { ao ano-base } 2045\end{array}$ \\
\hline Configuração da rede & $\begin{array}{c}\text { Utilização da } \\
\text { configuração original } \\
\text { do SIM. Não foram } \\
\text { considerados os novos } \\
\text { aportes de água no } \\
\text { sistema }\end{array}$ & $\begin{array}{l}\text { Configuração do SIM } \\
\text { atualizada pela } \\
\text { inserção das obras de } \\
\text { novos aportes de água }\end{array}$ & $\begin{array}{l}\text { Configuração do SIM } \\
\text { atualizada pela } \\
\text { inserção das obras de } \\
\text { novos aportes de água } \\
\text { + Integração da rede } \\
\text { por meio do } \\
\text { compartilhamento de } \\
\text { demandas } \\
\end{array}$ \\
\hline $\begin{array}{l}\text { Modelo de Alocação } \\
\text { de Água }\end{array}$ & $\begin{array}{l}\text { LabSid AcquaNet } \\
2013\end{array}$ & $\begin{array}{l}\text { LabSid AcquaNet } \\
2013\end{array}$ & $\begin{array}{l}\text { LabSid AcquaNet } \\
2013\end{array}$ \\
\hline
\end{tabular}

A rede do Sistema Integrado Metropolitano (SIM) utilizada para a simulação dos cenários acima descritos foi desenvolvida pelo autor do trabalho com o apoio da equipe do Laboratório de Sistemas de Suporte a Decisões da Escola Politécnica da USP - LabSid. A configuração desta rede encontra-se apresentada nas Figura 15, Figura 16 e Figura 17.

Para os 3 (três) Cenários de Simulação, as prioridades dos elementos da rede foram mantidas iguais, conforme apresentado na Tabela 10 abaixo. 
Tabela 10: Descrição das prioridades, por tipo de elemento, das redes de simulação nos Cenários 1, 2 e 3.

\begin{tabular}{|c|c|}
\hline Elemento & Prioridade \\
\hline Demandas de Vazões Mínimas & 1 \\
\hline Demandas Consuntivas dos Sistemas & 5 \\
\hline Pontos de Controle (Sistema Cantareira) & 15 \\
\hline Demandas das ETA's & 20 \\
\hline Reservatórios & 50 \\
\hline Vertimentos dos Reservatórios & 80 \\
\hline Dreno (elemento fictício da rede) & 99 \\
\hline
\end{tabular}

As metas de atendimento para as demandas das ETA's de cada sistema produtor do SIM foi definida em $90 \%$ da vazão outorgada para captação dos sistemas. Tendo em vista que uma das premissas-base para a simulação da rede do SIM foi o atendimento às vazões máximas de retiradas dos reservatórios, definidas nos instrumentos de Outorga, a vazão de $90 \%$ da Outorga foi estabelecida como forma de tentar provocar um estresse significativo na operação dos sistemas produtores e, por conseguinte, a ocorrência de falhas de atendimento, assim como permitir uma flexibilidade operacional de $10 \%$ para que cada sistema ainda pudesse compartilhar água para o atendimento dos pontos de demanda compartilhada (Cenário 3).

No tocante às metas de reservação de água, definiu-se o valor de $80 \%$ do volume máximo de cada sistema produtor, considerando o conjunto de todos os seus reservatórios, como se estes fossem um único reservatório-equivalente. $\mathrm{O}$ valor de 80\% tomou como referência a Faixa 1 (Normal) de operação do Sistema Cantareira, determinada em sua respectiva Outorga, quando a reservação do sistema se situa entre 60 e 100\%. Utilizou-se o valor de $80 \%$ como o valor intermediário de referência desta faixa para representar uma condição satisfatória de armazenamento para os reservatórios dos sistemas do SIM.

$\mathrm{Na}$ Tabela 11 abaixo apresentam-se as vazões-metas para as ETA's dos sistemas produtores do SIM para os Cenários 1 e 2 de Simulação. Os dados referentes ao Cenário 3 são apresentados mais adiante nesta mesma seção. 
Tabela 11: Demandas requeridas (metas de atendimento) nas ETA's dos sistemas produtores nos Cenários 1 e 2.

\begin{tabular}{|c|c|c|c|}
\hline Sistema & ETA & $\begin{array}{c}\text { Vazão Outorgada } \\
\left(\mathrm{m}^{3} / \mathrm{s}\right)\end{array}$ & $\begin{array}{c}\text { Demanda Requerida } \\
\left(\mathrm{m}^{3} / \mathrm{s}\right)\end{array}$ \\
\hline Alto Tietê & Taiaçupeba & 15,000 & 13,500 \\
\hline \multirow{2}{*}{ Cotia } & Alto Cotia & 1,250 & 1,125 \\
\hline & Baixo Cotia & 1,050 & 0,945 \\
\hline Cantareira & Guaraú & 33,000 & 29,700 \\
\hline Guarapiranga & ABV & 14,000 & 12,600 \\
\hline Rio Claro & Casa Grande & 4,000 & 3,600 \\
\hline \multirow{2}{*}{ Rio Grande } & Rio Grande & 5,500 & 4,950 \\
\hline & Ribeirão da Estiva & 0,100 & 0,090 \\
\hline São Lourenço & Vargem Grande & 6,400 & 5,760 \\
\hline
\end{tabular}

Na Tabela 12 a seguir são apresentados os volumes-meta de reservação dos sistemas produtores do SIM, para os 3 (três) Cenários de Simulação, que foram utilizados como referência para avaliação das condições satisfatórias e insatisfatórias de armazenamento.

Tabela 12: Volumes-meta nos sistemas produtores do SIM nos Cenários 1, 2 e 3.

\begin{tabular}{|c|c|c|}
\hline Sistema & Volume máximo $\mathbf{( h m}^{\mathbf{3}} \mathbf{)}$ & Volume-meta $\mathbf{( \mathbf { h m } ^ { \mathbf { 3 } } )}$ \\
\hline Alto Tietê & 639,802 & 511,842 \\
\hline Cotia & 17,590 & 14,072 \\
\hline Cantareira & 1492,450 & 1193,960 \\
\hline Guarapiranga & 190,120 & 152,096 \\
\hline Rio Claro & 13,810 & 11,048 \\
\hline Rio Grande & 115,010 & 92,008 \\
\hline São Lourenço & 134,290 & 107,432 \\
\hline
\end{tabular}

Para explicar como funcionou o compartilhamento de demandas da rede integrada simulada no Cenário 3, utiliza-se o exemplo a seguir (Figura 14).

Considerando o Sistema genérico $X$ e demais Sistemas adjacentes $A$ (Sist $A$ ), B (SistB), C (SistC) e D (SistD). 


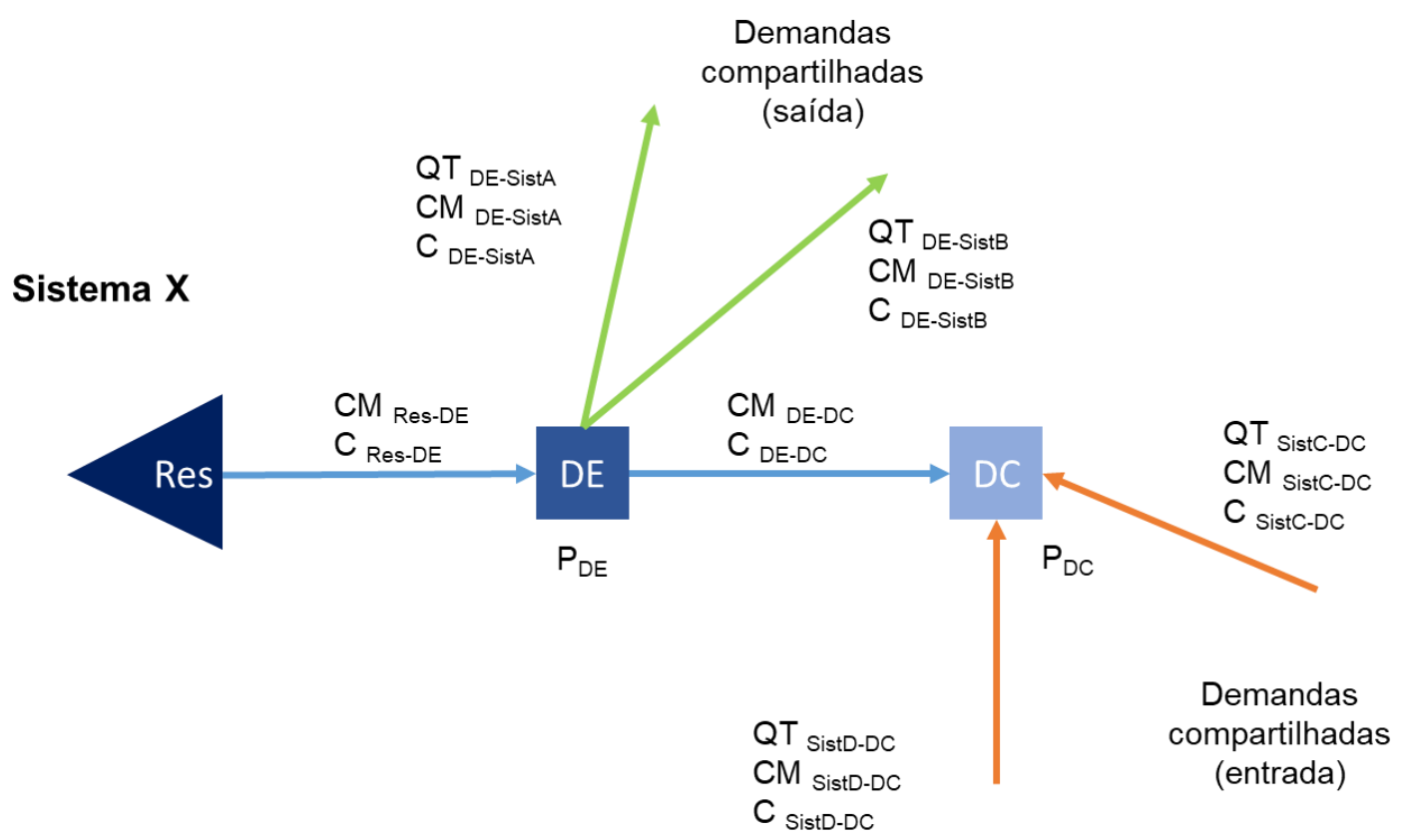

Figura 14: Representação esquemática das demandas compartilhadas - Rede Integrada (Cenário 3)

Sendo, QT = Vazão de transferência entre Sistemas; $C M$ = Capacidade máxima do link; $C=$ Custo do link; $D E=$ Demanda exclusiva do Sistema $X ; D C=$ Demanda compartilhada do Sistema X; $\mathrm{P}=$ Prioridade de atendimento; Res = Reservatório do Sistema X.

Considera-se a prioridade de atendimento $(\mathrm{P})$ entre as demandas exclusiva (DE) e compartilhada (DC) iguais.

$$
P_{D E}=P_{D C}
$$

Tem-se que o custo $(\mathrm{C})$ de transferência de água dentro do próprio Sistema $\mathrm{X}$ é menor que o custo do compartilhamento de demandas, de entrada ou saída, ou seja:

$$
C_{R e s-D E}=C_{D E-D C}<C_{D E-S i s t A}=C_{D E-S i s t B}=C_{S i s t C-D C}=C_{S i s t D-D C}
$$

A demanda total a ser atendida pelo Sistema X é o somatório entre a demanda exclusiva (DE) e a demanda compartilhada (DC). 
Sendo a demanda compartilhada (DC) o somatório total das vazões de transferência (QT) que os demais sistemas podem ofertar ao Sistema X.

$$
D C=Q T_{S i s t C-D C}+Q T_{S i s t D-D C}
$$

Os links de entrada e saída das demandas compartilhadas possuem capacidades máximas $(\mathrm{CM})$ iguais às suas respectivas vazões de transferência $(\mathrm{QT})$, ou seja:

$$
\begin{aligned}
& C M_{D E-S i s t A}=Q T_{D E-S i s t A} \\
& C M_{D E-S i s t B}=Q T_{D E-S i s t B} \\
& C M_{\text {SistC-DC }}=Q T_{\text {SistC-DC }} \\
& C M_{\text {SistD-DC }}=Q T_{\text {SistD-DC }}
\end{aligned}
$$

O link de ligação entre o reservatório (Res) e demanda exclusiva do Sistema $X$ (DE) é restrito pelo valor da Outorga de captação do Sistema X, ou seja:

$$
C M_{\text {Res-DE }}=\text { Vazão Outorgada Sistema X }
$$

Sendo a Demanda Total X definida em 90\% da Vazão Outorgada do Sistema $X$, temos que a demanda exclusiva (DE) do Sistema $X$ fica definida como:

$$
D E=(90 \% * \text { Vazão Outorgada Sistema } X)-D C
$$

Para as simulações da rede integrada do Sistema Integrado Metropolitano (Cenário 3), as vazões de transferência entre os sistemas produtores do SIM foram definidas tendo como base o Relatório Parcial RP06C "Estudo de Modelagem Hídrica das Transferências entre os Sistemas Produtores para o Sistema Integrado - SIM", parte do Plano Diretor de Abastecimento de Água - PDAA Sabesp 2017 (SABESP/ENCIBRA, 2017).

A partir dos dados apresentados neste relatório, foram feitas algumas atualizações nos valores das vazões em alinhamento e com o apoio da equipe técnica 
da Sabesp, de forma a se obter a seguinte Matriz de Transferência utilizada neste trabalho: 
Tabela 13: Matriz de transferência de vazões $\left(\mathrm{m}^{3} / \mathrm{s}\right)$ entre os sistemas produtores do SIM.

\begin{tabular}{|c|c|c|c|c|c|c|c|c|c|c|}
\hline \multirow{2}{*}{ Origem } & \multicolumn{9}{|c|}{ Destino } & \multirow{2}{*}{ Total } \\
\hline & Cantareira & Alto Tietê & Guarapiranga & S. Lourenço & Rio Grande & Rib. Estiva & Rio Claro & Alto Cotia & Baixo Cotia & \\
\hline Cantareira & & 4,82 & 6,62 & 2,45 & & & 0,93 & & 0,23 & 15,05 \\
\hline Alto Tietê & 3,2 & & & & & & 1,44 & & & 4,64 \\
\hline Guarapiranga & 5,62 & & & & & & & 0,15 & & 5,77 \\
\hline São Lourenço & 2,45 & & & & & & & 0,43 & & 2,88 \\
\hline Rio Grande & & & & & & & 0,39 & & 0,86 & 1,25 \\
\hline Rib. Estiva & & & & & & & & & & 0 \\
\hline Rio Claro & 0,93 & 0,75 & & & 0,74 & 0,05 & & & & 2,47 \\
\hline Alto Cotia & & & 0,15 & 0,43 & & & & & & 0,58 \\
\hline Baixo Cotia & 0,23 & & & 0,86 & & & & & & 1,09 \\
\hline Total & 12,43 & 5,57 & 6,77 & 3,74 & 0,74 & 0,05 & 2,76 & 0,58 & 1,09 & \\
\hline
\end{tabular}


A partir do exposto, tem-se que as vazões requeridas (demandas) nas ETA's dos sistemas produtores no Cenário 3 ficaram assim definidas:

Tabela 14: Demandas exclusivas e compartilhadas dos sistemas produtores no Cenário 3.

\begin{tabular}{|c|c|c|c|}
\hline Sistema & ETA & $\begin{array}{c}\text { Demanda Exclusiva } \\
\left(\mathbf{m}^{\mathbf{3}} \mathbf{s}\right)\end{array}$ & $\begin{array}{c}\text { Demanda } \\
\text { Compartilhada }\left(\mathbf{m}^{\mathbf{3}} \mathbf{s}\right)\end{array}$ \\
\hline Alto Tietê & Taiaçupeba & 7,930 & 5,570 \\
\hline \multirow{2}{*}{ Cotia } & Alto Cotia & 0,545 & 0,580 \\
\cline { 2 - 4 } & Baixo Cotia & 0,000 & 0,945 \\
\hline \multirow{2}{*}{ Cantareira } & Guaraú & 17,270 & 12,430 \\
\hline Guarapiranga & ABV & 5,830 & 6,770 \\
\hline Rio Claro & Casa Grande & 0,840 & 2,760 \\
\hline \multirow{2}{*}{ Rio Grande } & Rio Grande & 4,210 & 0,740 \\
\cline { 2 - 4 } & Ribeirão da Estiva & 0,040 & 0,050 \\
\hline \multirow{2}{*}{ São Lourenço } & Vargem Grande & 2,020 & 3,740 \\
\hline
\end{tabular}

A seguir nas Figura 15, Figura 16 eFigura 17 apresentam-se as configurações finais das redes do Sistema Integrado Metropolitano (SIM) desenvolvidas neste trabalho. 


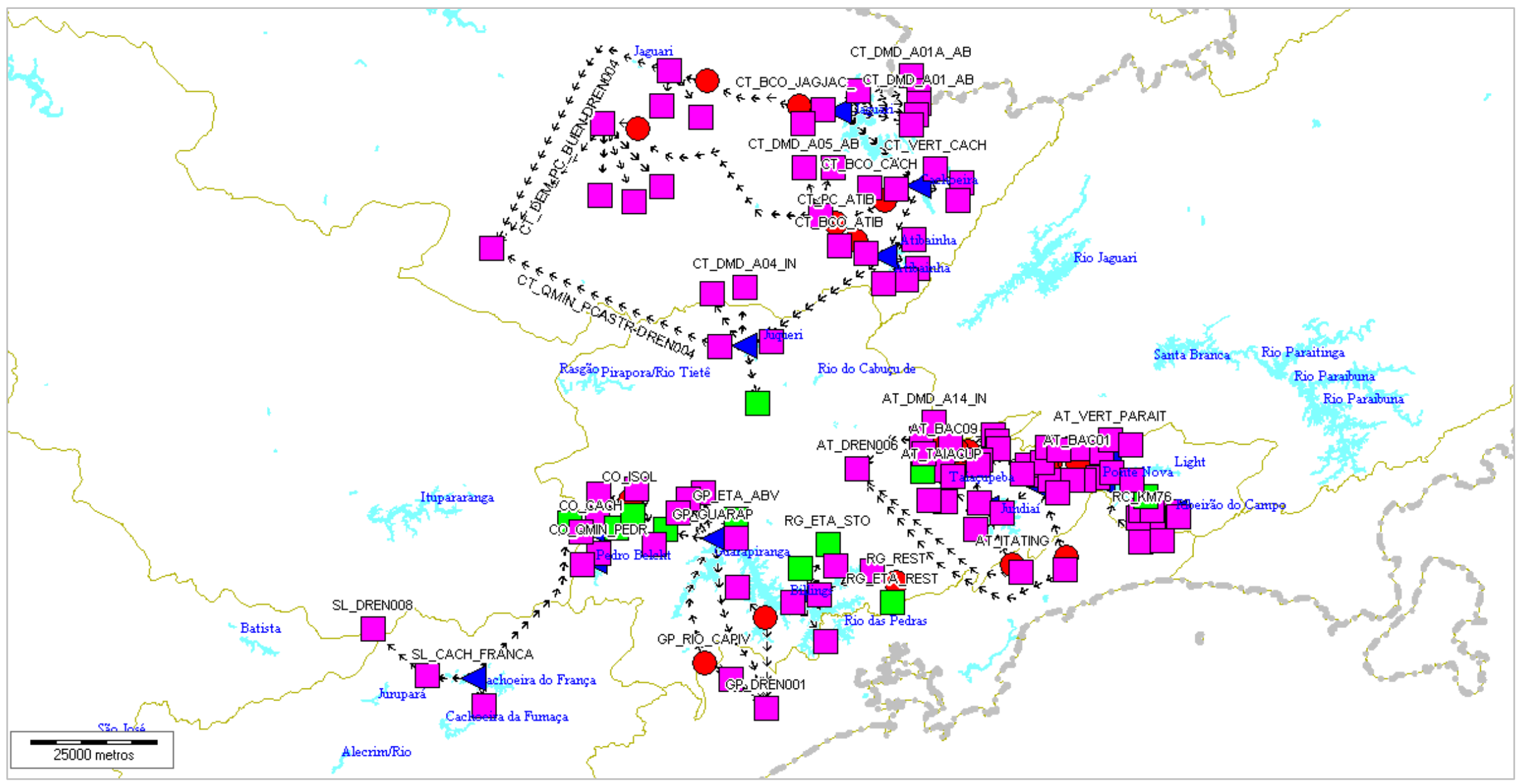

Figura 15: Rede do Sistema Integrado Metropolitano (Cenário 1). 


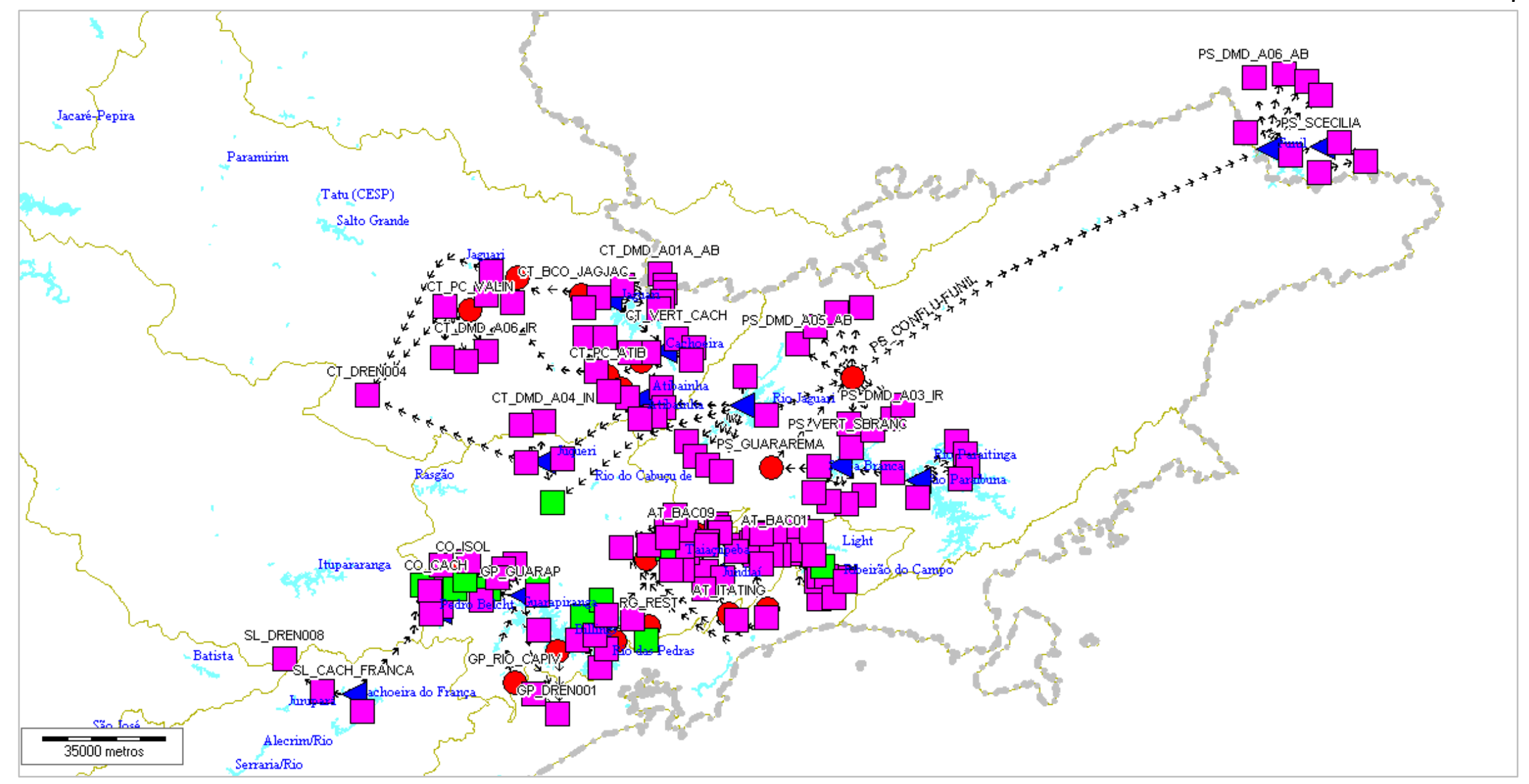

Figura 16: Rede do Sistema Integrado Metropolitano (Cenário 2). 


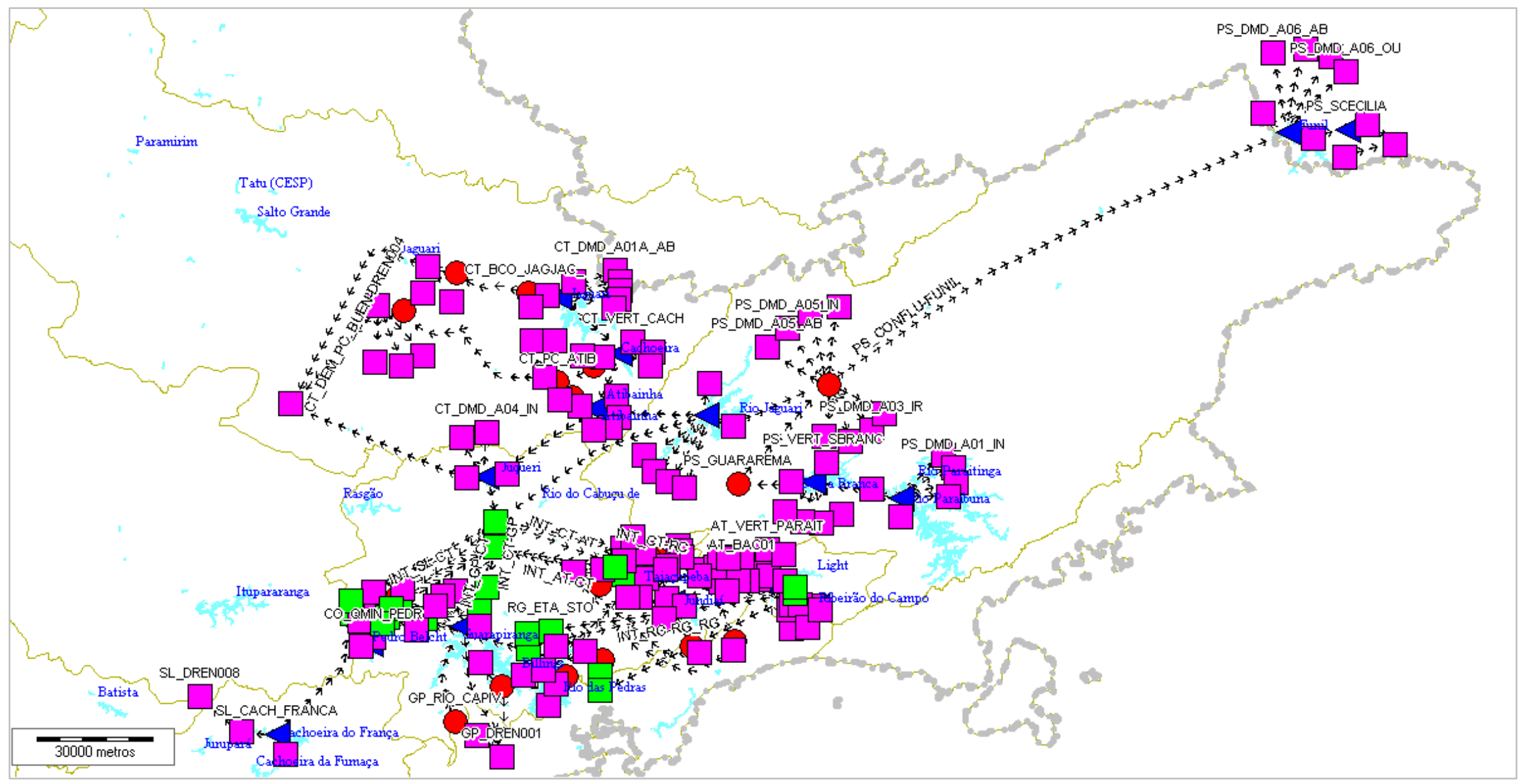

Figura 17: Rede integrada do Sistema Integrado Metropolitano (Cenário 3). 


\subsection{ETAPA 4 - AVALIAÇÃO DE DESEMPENHO}

A partir dos resultados obtidos da simulação dos 3 (três) Cenários descritos na etapa anterior, a Etapa 4 determina a Avaliação de Desempenho do sistema frente às configurações propostas. Nesta etapa, os resultados obtidos do modelo de alocação de água foram aplicados ao modelo de avaliação do desempenho para determinação dos indicadores de Confiabilidade, Resiliência e Vulnerabilidade (HASHIMOTO, STEDINGER e LOUCKS, 1982), e Índice de Sustentabilidade (SANDOVAL-SOLIS, MCKINNEY e LOUCKS, 2011). O modelo determinou a análise de eficiência quanto ao atendimento às demandas requeridas nas Estações de Tratamento de Água, bem como aos volumes-meta de reservação nos sistemas produtores de água pertencentes ao Sistema Integrado Metropolitano.

O modelo de avaliação de desempenho foi implementado em planilha eletrônica (Excel). Conforme mencionado, o objetivo deste modelo foi de calcular os indicadores de desempenho do SIM a partir dos resultados gerados pelo modelode alocação de água - SSD AcquaNet.

Os resultados de desempenho do SIM foram obtidos a partir de fórmulas que consideram um agrupamento estatístico sobre o sucesso ou fracasso no atendimento de determinadas condições previamente definidas pelo usuário.

Para o processamento dos indicadores de desempenho (Confiabilidade, Resiliência e Vulnerabilidade) e Índice de Sustentabilidade, o modelo de avaliação de desempenho utilizou fundamentalmente os seguintes resultados do modelo de alocação de água, para os 3 (três) Cenários de Simulação:

- "Vazões Fornecidas" e "Demanda Necessária" em cada um dos pontos de demanda representativos das principais Estações de Tratamento de Água (ETA's);

- "Volumes Finais" armazenados e "Volumes-Meta" dos reservatórios de cada um dos sistemas produtores.

A Figura 18 a seguir representa esquematicamente este processo: 


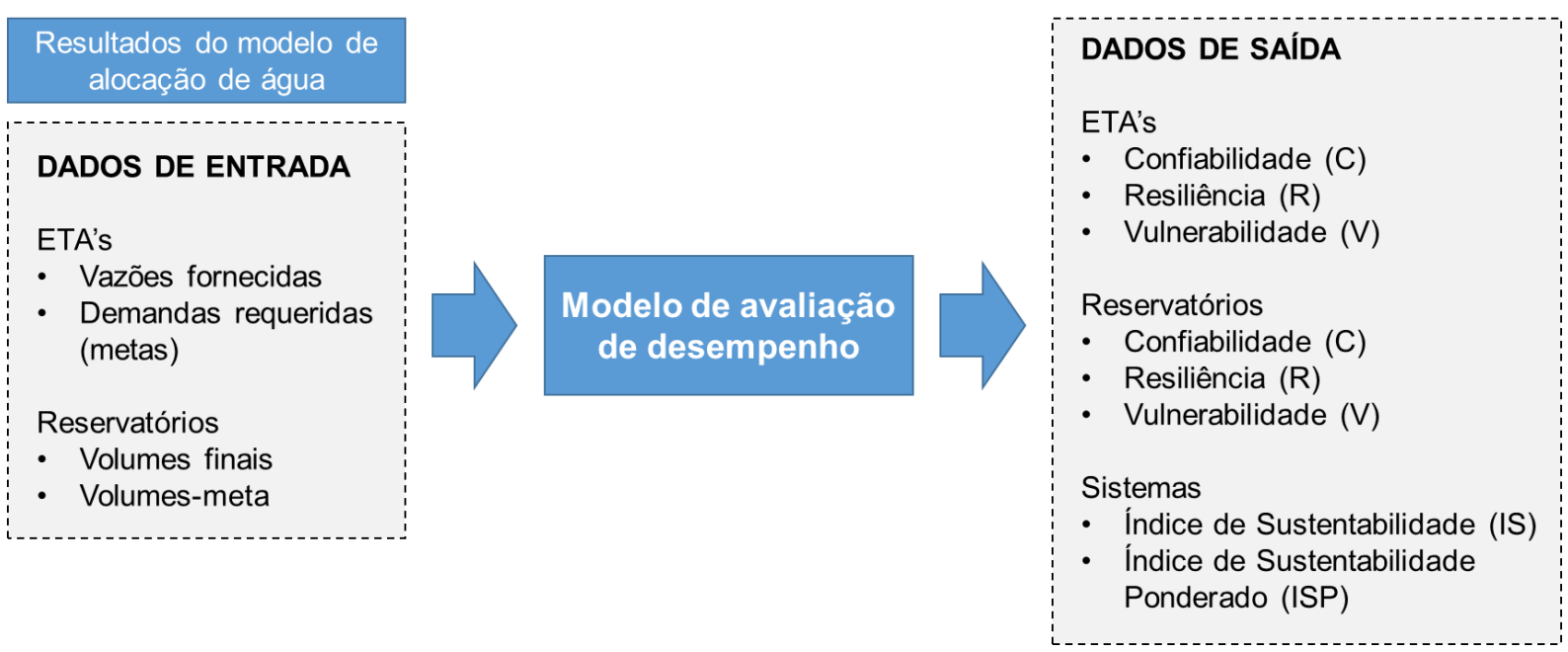

Figura 18: Fluxograma de entrada e saída de dados do modelo de avaliação de desempenho.

Especificamente para o Cenário 3, que simulou a operação do Sistema Integrado Metropolitano (SIM) na rede integrada por pontos de demanda compartilhada, também foram extraídos do SSD AcquaNet os dados de "Vazões Transferidas" entre os sistemas produtores. Estes resultados não foram diretamente utilizados no modelo de avaliação de desempenho, entretanto, foram utilizados para no contexto da análise global dos resultados, conforme será apresentado na seção 6 .

Para cada passo de tempo mensal, o modelo avalia a ocorrência de eventos satisfatórios (sucesso) ou insatisfatórios (falha) nos fornecimentos de água das ETA's e nos armazenamentos dos reservatórios. O processamento do cálculo dos indicadores de desempenho (Confiabilidade, Resiliência e Vulnerabilidade) e Índice de Sustentabilidade ocorre mensalmente. $O$ valor característico do desempenho de cada sistema produtor, para cada indicador, é dado como o último valor calculado da série, ou seja, em dezembro/2018.

Especificamente para a avaliação global do desempenho do Sistema Integrado Metropolitano como um todo, também se estabelece o cálculo do Índice de Sustentabilidade Ponderado (ISP), considerando a representatividade relativa de cada sistema produtor no contexto global de abastecimento do SIM.

O cálculo dos índices e indicadores no modelo de avaliação de desempenho desenvolvido neste trabalho obedece às seguintes formulações:

Para cada passo de tempo mensal ( $\mathrm{t}$ ), os déficits são positivos quando as metas de vazão de fornecimento $\left(Q_{\text {meta }}\right)$ ou metas de volume armazenado ( $\left.V_{\text {meta }}\right)$ são maiores do que a vazão fornecida (Qfornecida) em uma determinada ETA ou maiores 
que volume ao final do mês $\left(\mathrm{V}_{\text {final }}\right)$ para um determinado reservatório ou conjunto de reservatórios. Se a vazão fornecida ou o volume forem iguais às suas respectivas metas, os déficits são iguais a zero.

$$
\begin{aligned}
& D_{t}^{E T A}=\left\{\begin{array}{c}
Q_{\text {meta }, t}^{E T A}-Q_{\text {fornecida }, t}^{E T A} \text { se } Q_{\text {meta }, t}^{E T A}>Q_{\text {fornecida }, t}^{E T A} \\
0 \text { se } Q_{\text {meta }, t}^{E T A}=Q_{\text {fornecida }, t}^{E T A}
\end{array}\right. \\
& D_{t}^{\text {Res }}=\left\{\begin{array}{c}
V_{\text {meta }, t}^{\text {Res }}-V_{\text {final }, t}^{\text {Res }} \text { se } V_{\text {meta }, t}^{\text {Res }}>V_{\text {final }, t}^{\text {Res }} \\
0 \text { se } V_{\text {meta }, t}^{\text {Res }}=V_{\text {final }, t}^{\text {Res }}
\end{array}\right.
\end{aligned}
$$

Sendo $n$ o número total de meses da amostra, os valores de Confiabilidade (C), Resiliência (R) e Vulnerabilidade (V), para ETA's e Reservatórios, foram calculados pelas seguintes equações:

$$
\begin{gathered}
C_{t}^{E T A}=\frac{N \text { o de vezes } D_{t}^{E T A}=0}{n} \\
C_{t}^{\text {Res }}=\frac{N^{\mathrm{o}} \text { de vezes } D_{t}^{\text {Res }}=0}{n} \\
R_{t}^{E T A}=\frac{N^{\mathrm{o}} \text { de vezes } D_{t}^{\text {ETA }}=0 \mid D_{t-1}^{E T A}>0}{N^{\mathrm{o}} \text { de vezes } D_{t}^{E T A}>0} \\
R_{t}^{\text {Res }}=\frac{N^{\mathrm{o}} \text { de vezes } D_{t}^{\text {Res }}=0 \mid D_{t-1}^{\text {Res }}>0}{N^{\mathrm{o}} \text { de vezes } D_{t}^{\text {Res }}>0} \\
V_{t}^{\text {ETA }}=\frac{\sum_{t=0}^{t=n} D_{t}^{\text {ETA }} / N^{\mathrm{o}} \text { de vezes } D_{t}^{E T A}>0}{D A^{E T A}}
\end{gathered}
$$

Sendo DA = Demanda de água na ETA (meta de fornecimento).

$$
V_{t}^{\text {Res }}=\frac{\sum_{t=0}^{t=n} D_{t}^{\text {Res }} / N \text { o de vezes } D_{t}^{\text {Res }}>0}{V M^{\text {Res }}}
$$


Em que, $\mathrm{VM}=$ Volume-meta de reservação de água no reservatório ou conjunto de reservatórios.

Para cada sistema produtor (Sist), o cálculo do Índice de Sustentabilidade (IS) ficou assim definido:

$$
I S_{t}^{\text {Sist }}=\left[C_{t}^{E T A} * R_{t}^{E T A} *\left(1-V_{t}^{E T A}\right) * C_{t}^{\text {Res }} * R_{t}^{\text {Res }} *\left(1-V_{t}^{\text {Res }}\right)\right]^{1 / 6}
$$

Para os sistemas produtores com 2 (duas) ETA's, como por exemplo, o Sistema Cotia, os indicadores de desempenho de ambas as ETA's entram na equação, aumentando assim o número de produtos para 9 (nove).

O Índice de Sustentabilidade Ponderado (ISP) para o Sistema Integrado Metropolitano (SIM) foi calculado a partir da equação abaixo.

$$
\begin{aligned}
I S P^{S I M} & =\left(W^{A T} * I S_{t}^{A T}\right)+\left(W^{C O} * I S_{t}^{C O}\right)+\left(W^{C T} * I S_{t}^{C T}\right) \\
& +\left(W^{G P} * I S_{t}^{G P}\right)+\left(W^{R C} * I S_{t}^{R C}\right)+\left(W^{R G} * I S_{t}^{R G}\right) \\
& +\left(W^{S L} * I S_{t}^{S L}\right)
\end{aligned}
$$

Em que a ponderação (W) foi determinada pela divisão das demandas das ETA's de cada sistema produtor pela demanda total do SIM. A Tabela 15 a seguir apresenta os pesos calculados para cada sistema.

Tabela 15: Pesos de cada sistema produtor para o cálculo do Índice de Sustentabilidade Ponderado do SIM.

\begin{tabular}{|l|c|c|}
\hline \multicolumn{1}{|c|}{ Sistema } & Variável & Pesos \\
\hline Alto Tietê & W $^{\mathrm{AT}}$ & 0,187 \\
\hline Cotia & W $^{\mathrm{CO}}$ & 0,029 \\
\hline Cantareira & $\mathrm{W}^{\mathrm{CT}}$ & 0,411 \\
\hline Guarapiranga & $\mathrm{W}^{\mathrm{GP}}$ & 0,174 \\
\hline Rio Claro & $\mathrm{W}^{\mathrm{RC}}$ & 0,050 \\
\hline Rio Grande & $\mathrm{W}^{\mathrm{RG}}$ & 0,070 \\
\hline São Lourenço & $\mathrm{W}^{\mathrm{SL}}$ & 0,080 \\
\hline
\end{tabular}

A seguir, as Figura 19 e Figura 20 apresentam as interfaces do modelo de cálculo de desempenho desenvolvido e utilizado no presente trabalho. 
固日の・c-

1. Modelo_Rel_Res_Vul (para o texto).xlsx - Excel

ARQUIVO PÁGINA INICIAL INSERIR LAYOUTDA PÁGINA FÓRMULAS DADOS REVISÃO EXIBIÇÃO DESENVOLVEDOR

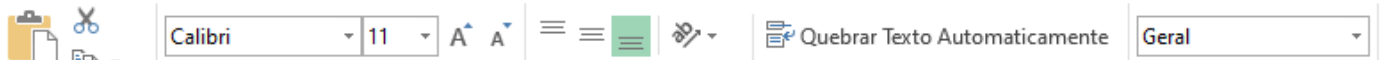

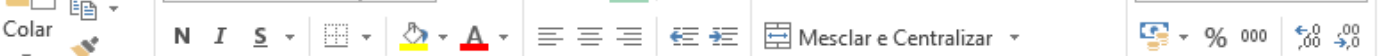

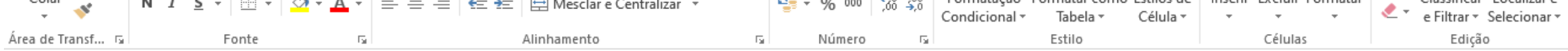

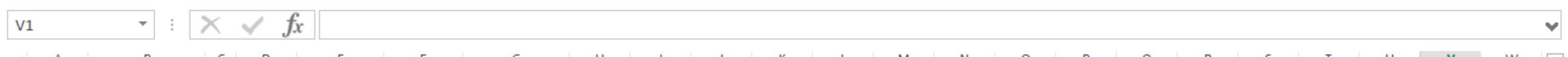

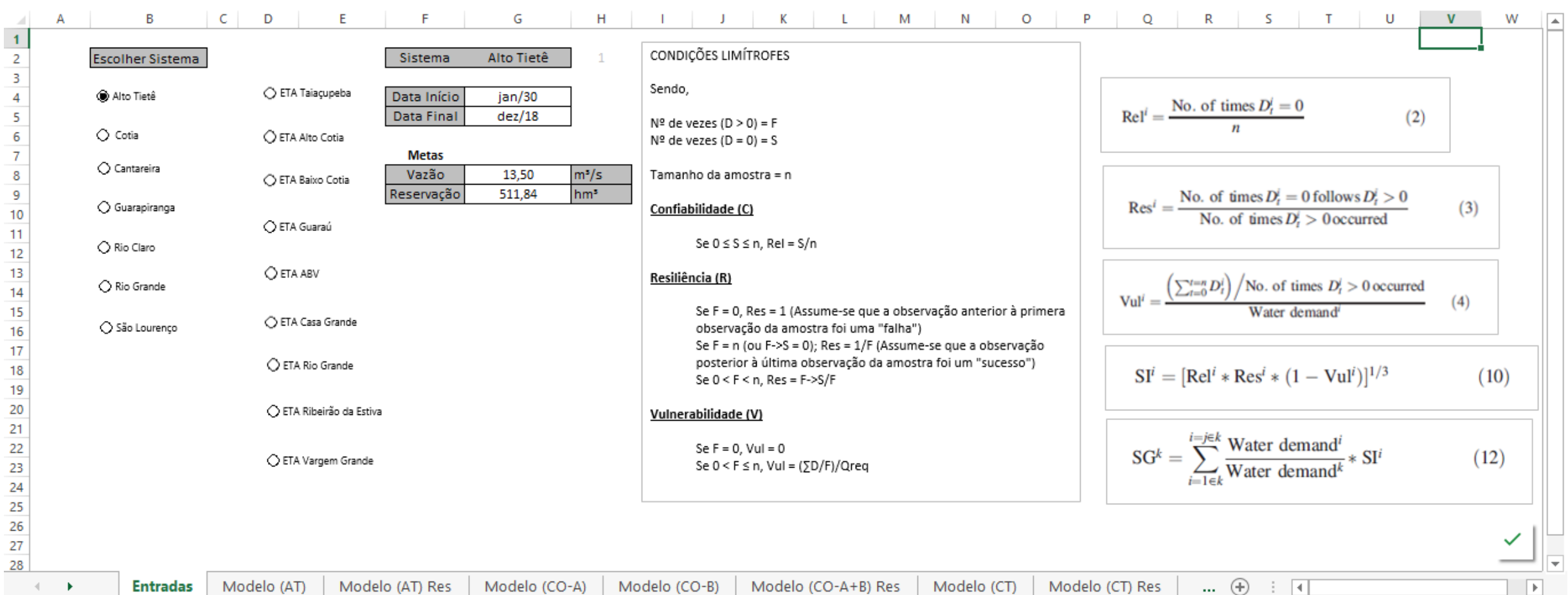

Figura 19: Tela inicial de "Entrada de Dados" do modelo de avaliação de desempenho. 


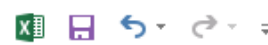

1. Modelo_Rel_Res_Vul (para o texto).xlsx - Excel

ARQUIVO PÁGINA INICIAL INSERIR LAYOUTDA PÁGINA FóRMULAS DADOS REVISÃO EXIBIÇÃO DESENVOLVEDOR

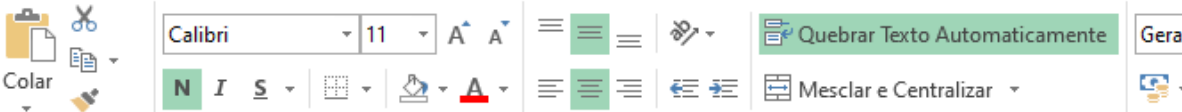

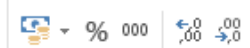
Área de Transf... $\sqrt{x}$
Alinhamento
Número Condicional r Tarmatar como Estilos de

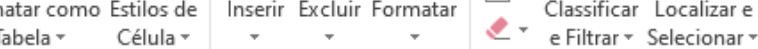

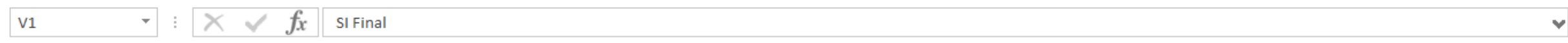

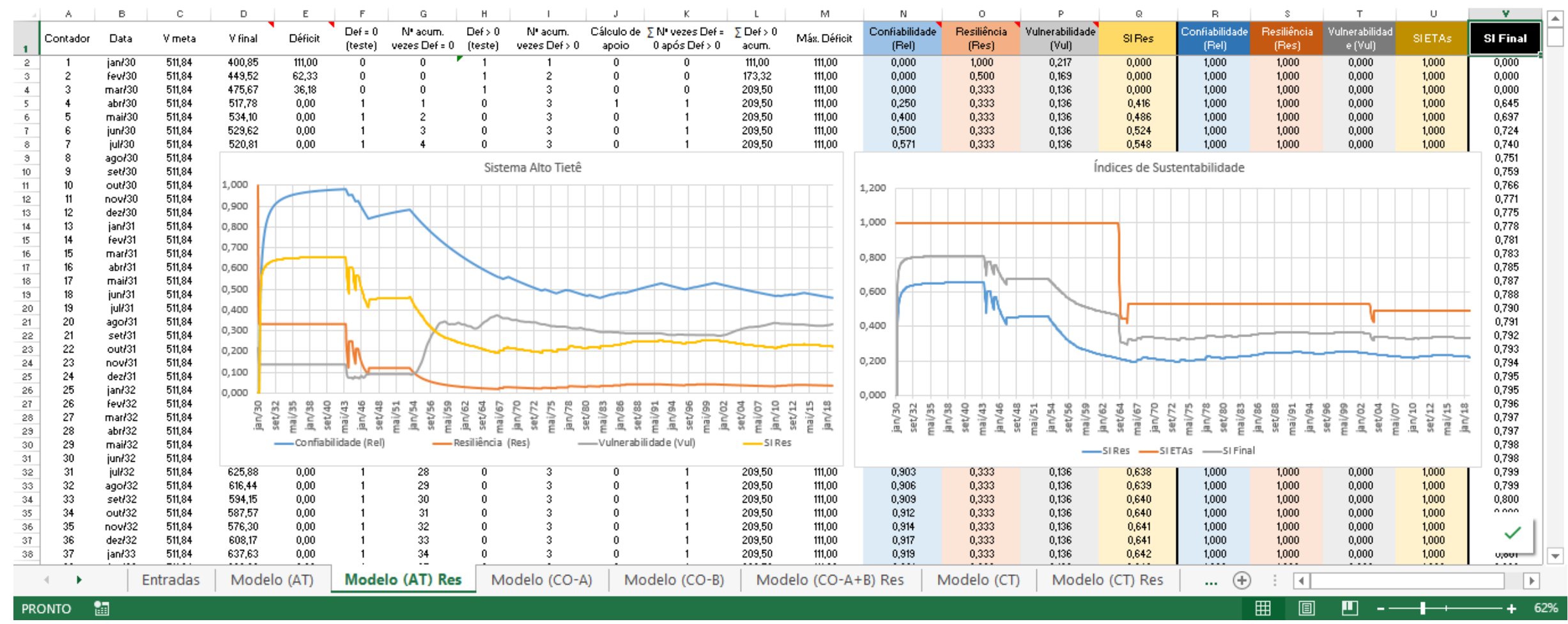

Figura 20: Tela de cálculo dos indicadores de desempenho (Confiabilidade, Resiliência e Vulnerabilidade) e Índice de Sustentabilidade. 


\subsection{ETAPA 5 - ANÁLISE DE RESULTADOS E CONCLUSÕES}

Nesta Etapa, realizou-se a análise dos resultados gerados nas etapas anteriores e a discussão comparativa dos resultados de desempenho de cada Cenário de Simulação.

O conteúdo da Etapa 5 - Análise de Resultados e Conclusões refere-se justamente às seções 6 (Resultados e Discussões) e 7 (Conclusões) do presente trabalho que se encontram apresentadas adiante. 


\section{RESULTADOS E DISCUSSÕES}

Os resultados obtidos do modelo de cálculo de desempenho são apresentados nesta seção. Os resultados das simulações das redes do estudo de caso foram utilizados como dados de entrada do modelo de cálculo de desempenho. Conforme mencionado anteriormente, para cada um dos cenários analisados, o modelo utilizou como dados de entrada os seguintes resultados gerados pelas simulações do programa AcquaNet:

- "Vazões Fornecidas" e "Demanda Necessária" em cada um dos pontos de demanda representativos das principais Estações de Tratamento de Água (ETA's) de cada um dos Sistemas Produtores de água do Sistema Integrado Metropolitano;

- "Volumes Finais" armazenados e "Volumes-Meta" dos reservatórios de cada um dos Sistemas Produtores de água do Sistema Integrado Metropolitano.

Especificamente para o Cenário 3, que simulou a operação do Sistema Integrado Metropolitano em uma rede integrada por pontos de demanda compartilhada, também foram analisados os dados de "Vazões Transferidas" entre os sistemas produtores para composição da análise de resultados.

Os resultados apresentados nesta seção estão organizados em 3 blocos de avaliação. Nestes blocos, os resultados do modelo de desempenho são apresentados de forma comparativa, da seguinte forma:

- Bloco 1: comparação dos resultados dos Cenários 1 e 2;

- Bloco 2: comparação dos resultados dos Cenários 2 e 3;

- Bloco 3: avaliação global resultados nos Cenários 1, 2 e 3 para o Sistema Integrado Metropolitano.

Os resultados foram assim organizados no intuito de demonstrar os efetivos ganhos / perdas de desempenho entre os cenários de simulação de forma lógica e escalonada, conforme será explicado no início de cada uma das seções abaixo.

A apresentação dos resultados em cada bloco será feita por sistema produtor de água e, ao final, serão apresentados os resultados do Sistema Integrado Metropolitano (SIM) de maneira global. Para cada sistema produtor de água, os resultados de desempenho encontram-se apresentados sob 3 pontos de vista: i) 
ETA's - Atendimento às demandas-meta estabelecidas para as Estações de Tratamento de Água, com a apresentação dos critérios de desempenho (Confiabilidade, Resiliência e Vulnerabilidade) isoladamente; ii) Reservatórios Atendimento aos volumes-meta dos reservatórios de cada sistema produtor, também com a apresentação dos critérios de desempenho (confiabilidade, resiliência e vulnerabilidade) de forma separada, e; iii) Global - Desempenho global do sistema, com a apresentação dos indicadores de sustentabilidade (IS) de cada sistema produtor, que compilam em um único índice os resultados dos 3 critérios de desempenho.

Quando da apresentação dos resultados para as Estações de Tratamento de Água, como forma de auxiliar na avaliação do comportamento dos indicadores de desempenho, também serão apresentadas as "vazões fornecidas" em cada mês ao longo da série, bem como os valores das “demandas-meta' de cada sistema. De maneira similar, para avaliação conjunta dos resultados de armazenamento (reservatórios) dos sistemas produtores, também serão apresentados dos dados de "volume" ao final de cada mês, bem como os "volumes-meta" de cada sistema.

Ainda sob o ponto de vista do armazenamento de água, destaca-se que a avaliação do desempenho dos reservatórios foi realizada considerando os "reservatórios-equivalentes" de cada sistema produtor, ou seja, avaliou-se o armazenamento de água em cada sistema de maneira global, considerando os reservatórios de cada sistema (quando há mais de um), como um único sistema interligado, e não como reservatórios isolados.

\subsection{BLOCO 1 - COMPARAÇÃO DOS CENÁRIOS 1 E 2}

A comparação entre os Cenários 1 e 2 demonstra os resultados gerados individualmente para os sistemas que foram beneficiados pelas obras de segurança hídrica, implementadas no âmbito da crise hídrica da Região Metropolitana de São Paulo entre os anos de 2014 e 2015. Conforme demonstrado na seção 6, no estudo de caso analisado neste trabalho, foi verificado o desempenho das seguintes obras: interligação Jaguari-Atibainha, reversão do Rio Guaió para o Reservatório Taiaçupeba, transposição Rio Grande para o Reservatório Taiaçupeba e transferência do Braço do Rio Pequeno para o Rio Grande. 
Os sistemas produtores de água que não são impactados diretamente pelas obras supracitadas não terão seus resultados de desempenho reportados nas subseções baixo, uma vez que não há diferenças entre seus estados de desempenho entre os Cenário 1 e 2, são eles: Sistema Guarapiranga, Sistema Cotia e Sistema São Lourenço. O desempenho destes sistemas será analisado detalhadamente no Bloco 2 de resultados, seção 7.2 .

\subsubsection{SISTEMA ALTO TIETÊ}

O Sistema Alto Tietê se beneficiou de 2 importantes obras que trouxeram novos aportes de água para o sistema: reversão do Rio Guaió para o Reservatório Taiaçupeba e transposição Rio Grande para o Reservatório Taiaçupeba, conforme se verifica no resumo dos resultados de desempenho apresentado na Figura 21 . As especificidades de cada um destes resultados serão discutidas na continuidade desta seção.

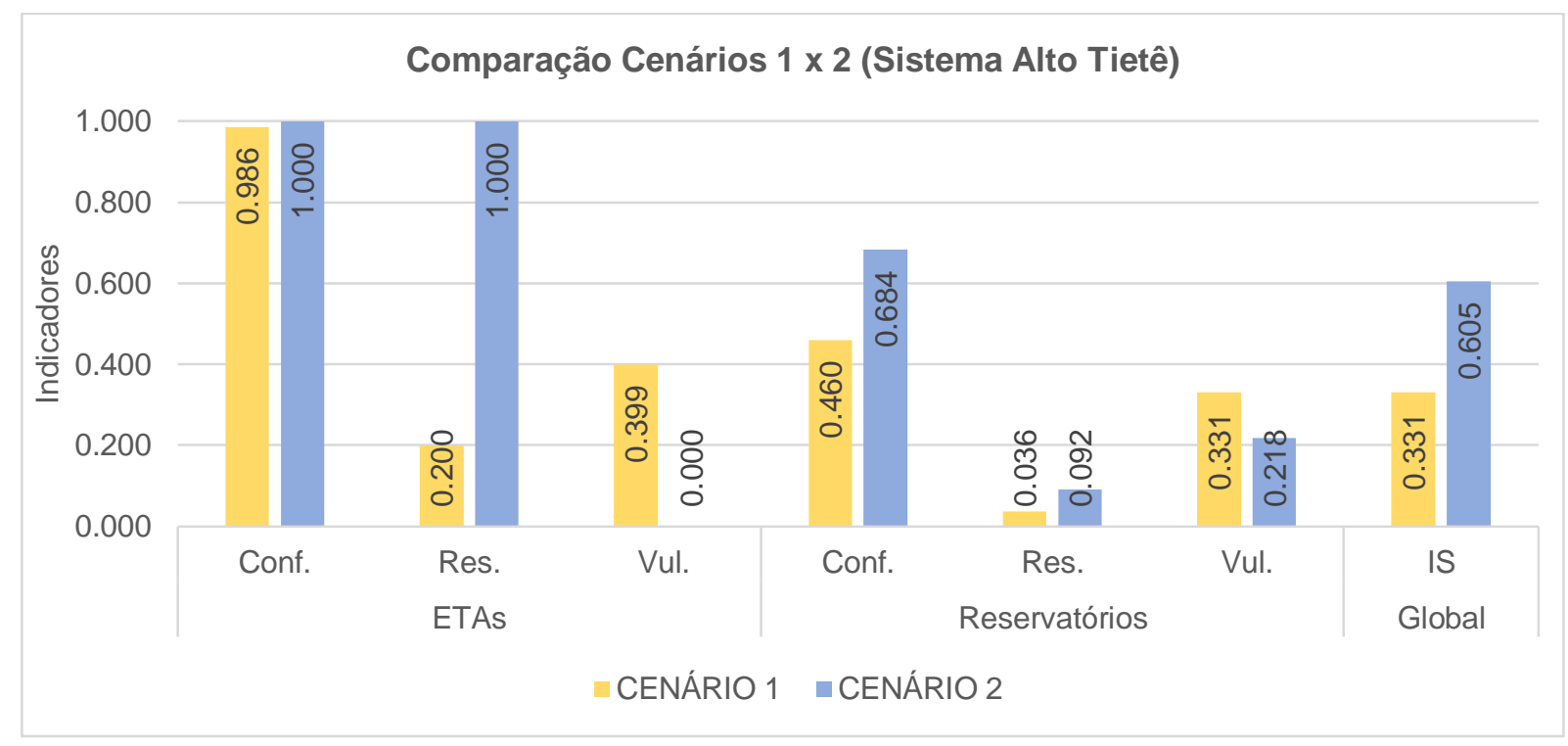

Figura 21: Resumo dos indicadores de desempenho e índice global de sustentabilidade para o Sistema Alto Tietê. Comparação Cenários 1 e 2.

A Figura 22 a seguir demonstra os resultados do fornecimento de água na ETA Taiaçupeba nos Cenários 1 e 2. 


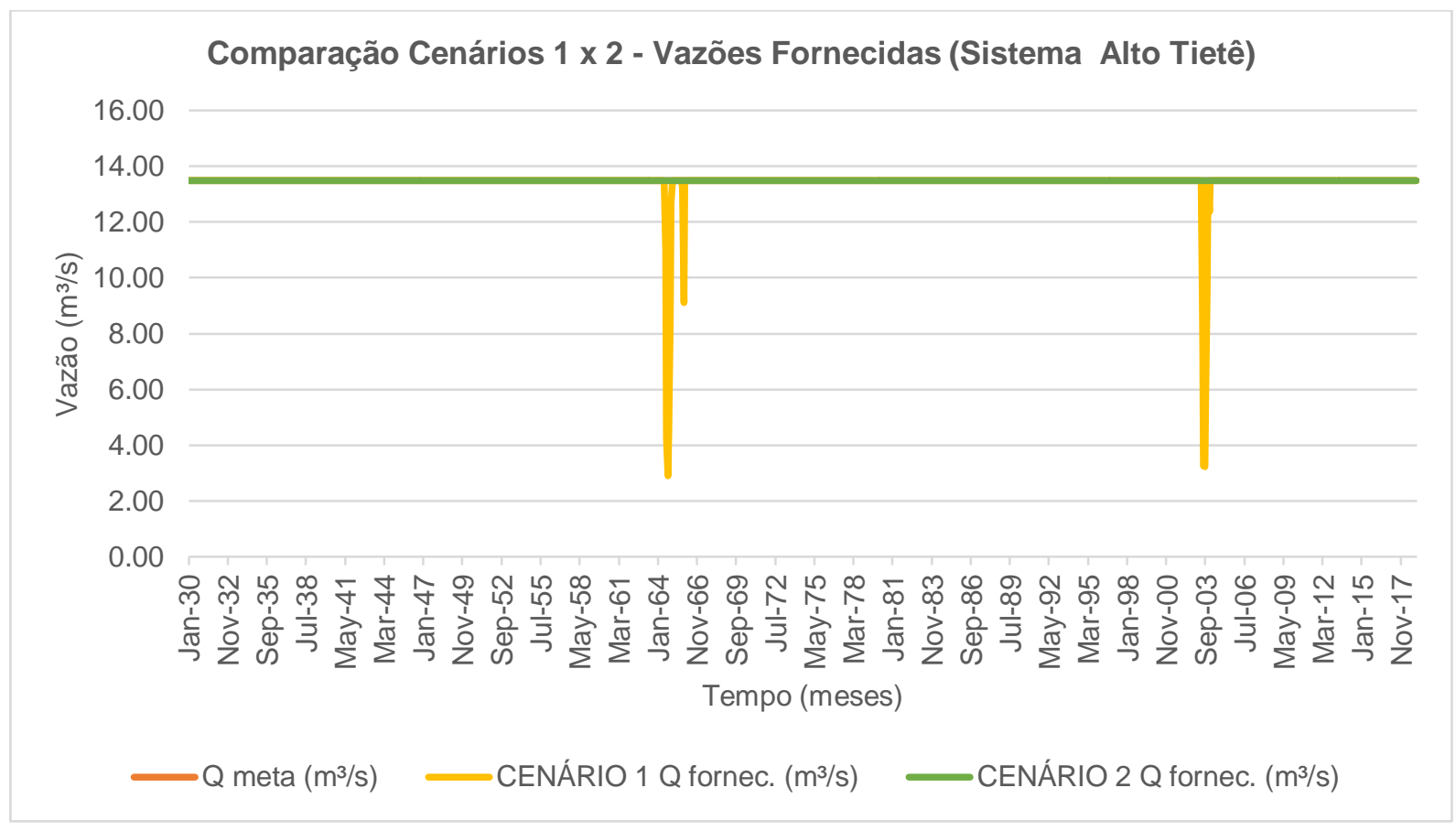

Figura 22: Vazões fornecidas e Vazão-meta no ponto de demanda "ETA Taiaçupeba" nos Cenários 1 e 2.

O acompanhamento dos indicadores de desempenho para o ponto de demanda "ETA Taiaçupeba" é apresentado na Figura 23 abaixo. Como se pode verificar, as falhas de fornecimento ocorridas no Cenário 1, notadamente nos anos de 1964, 1965 e 2003, provocaram a perda de desempenho constatada neste Cenário. Apesar de não impactar significativamente a Confiabilidade ao final da série, que ficou em 0,986, as falhas impactaram de forma determinante os indicadores de Resiliência e Vulnerabilidade do sistema. Em dezembro/2018, a Resiliência foi de 0,200, enquanto a Vulnerabilidade, 0,399. Ou seja, o sistema em média necessitou de 5 meses para se recuperar de uma condição insatisfatório de abastecimento, enquanto que cada uma das falhas observadas teve magnitude de aproximadamente $40 \%$ da vazão requerida de abastecimento.

Como se observa na Figura 22, a ETA Taiaçupeba não apresentou falhas de abastecimento no Cenário 2, fazendo com que os 3 indicadores de desempenho atingissem seus valores máximos teóricos: Confiabilidade $=1,000$; Resiliência $=1,000$ e Vulnerabilidade $=0,000$. Esta condição, entretanto, deve ser avaliada com ressalvas, conforme será melhor discutido mais adiante neste trabalho. 


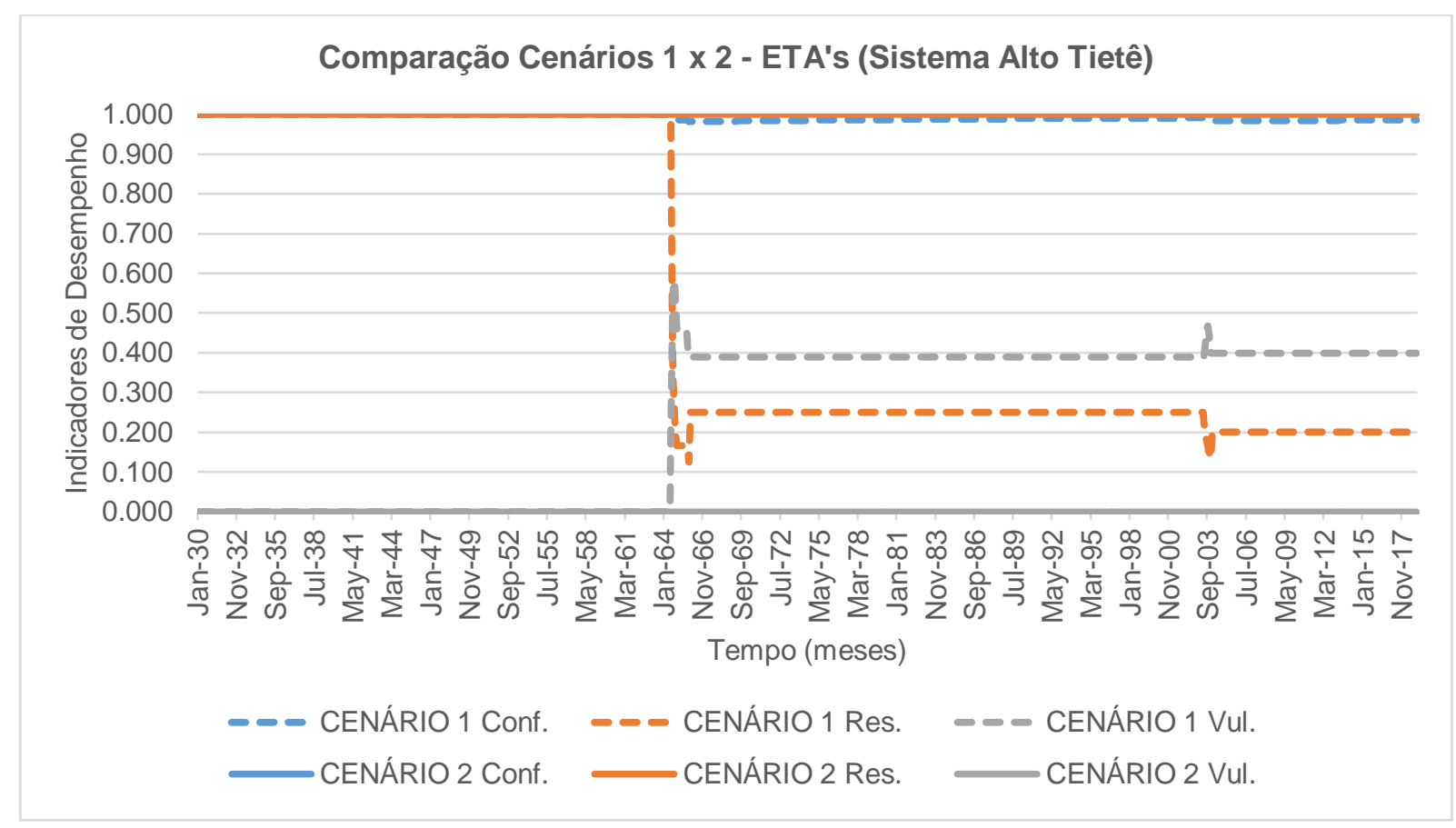

Figura 23: Acompanhamento dos indicadores de desempenho no ponto de demanda "ETA Taiaçupeba". Comparação entre os Cenários 1 e 2.

O acompanhamento dos dados de volume armazenado no Sistema Alto Tietê é apresentado na Figura 24. No gráfico é possível verificar que esta variável se comporta de forma mais instável ao longo do tempo, diferentemente dos dados de vazão fornecida. Os aportes resultantes das obras de segurança hídrica fizeram com que os reservatórios do Sistema Alto Tietê apresentassem maiores volumes de água armazenada no Cenário 2 em comparação ao Cenário 1, resultando assim em ganhos de desempenho para os 3 (três) indicadores, conforme demonstrado na Figura 25. Os volumes armazenamentos no Cenário 2 foram em média 17,0\% superiores aos do sistema sem as obras de reversão do Rio Guaió e transposição do Rio Grande (Cenário 1). 


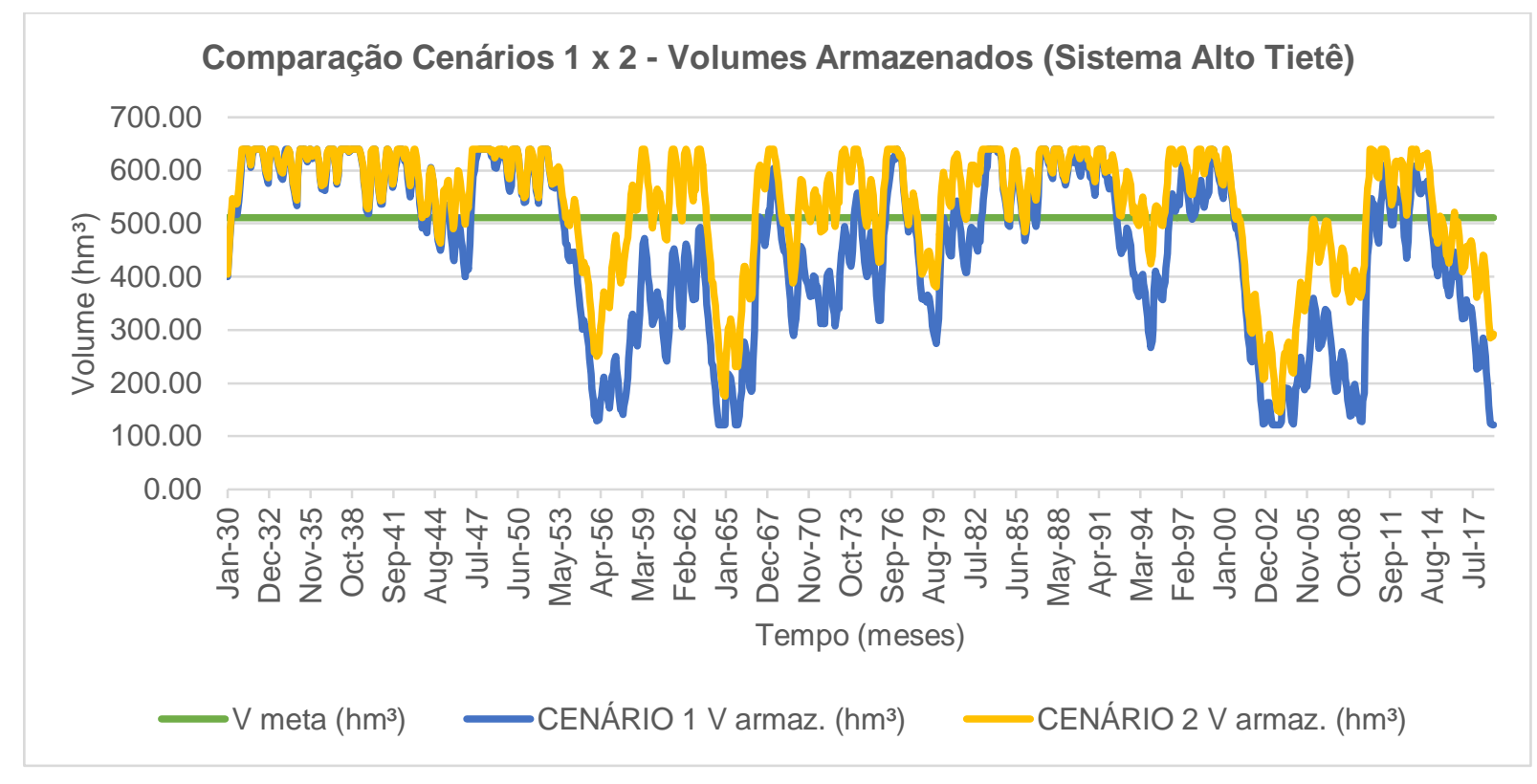

Figura 24: Volumes armazenados e Volume-meta para o Sistema Alto Tietê nos Cenários 1 e 2.

Conforme se observa na Figura 25 abaixo, o Sistema Alto Tietê apresentou ganhos de desempenho nos 3 indicadores analisados. A Confiabilidade sofreu incremento de $48,7 \%$, subindo de 0,460 no Cenário 1 para 0,684 no Cenário 2 . Apesar do ganho ocorrido no critério de Resiliência, saindo de 0,036 para 0,092, este indicador ainda se manteve em patamares baixos, principalmente devido os sucessivos meses de condição insatisfatória que os reservatórios do Alto Tietê apresentaram entre os anos de 1954 e 1958. As baixas vazões naturais afluentes ao sistema durante a crise hídrica de 1954-1955 desencadearam estes eventos.

Os reservatórios do Sistema Alto Tietê demonstraram ganhos em termos do critério de Vulnerabilidade, ou seja, a Vulnerabilidade sofreu uma redução de 0,331 no Cenário 1 para 0,218 no Cenário 2. Na prática, isto quis dizer que o houve uma redução de $34,1 \%$ da magnitude média das falhas verificadas em termos de armazenamento de água no sistema. 


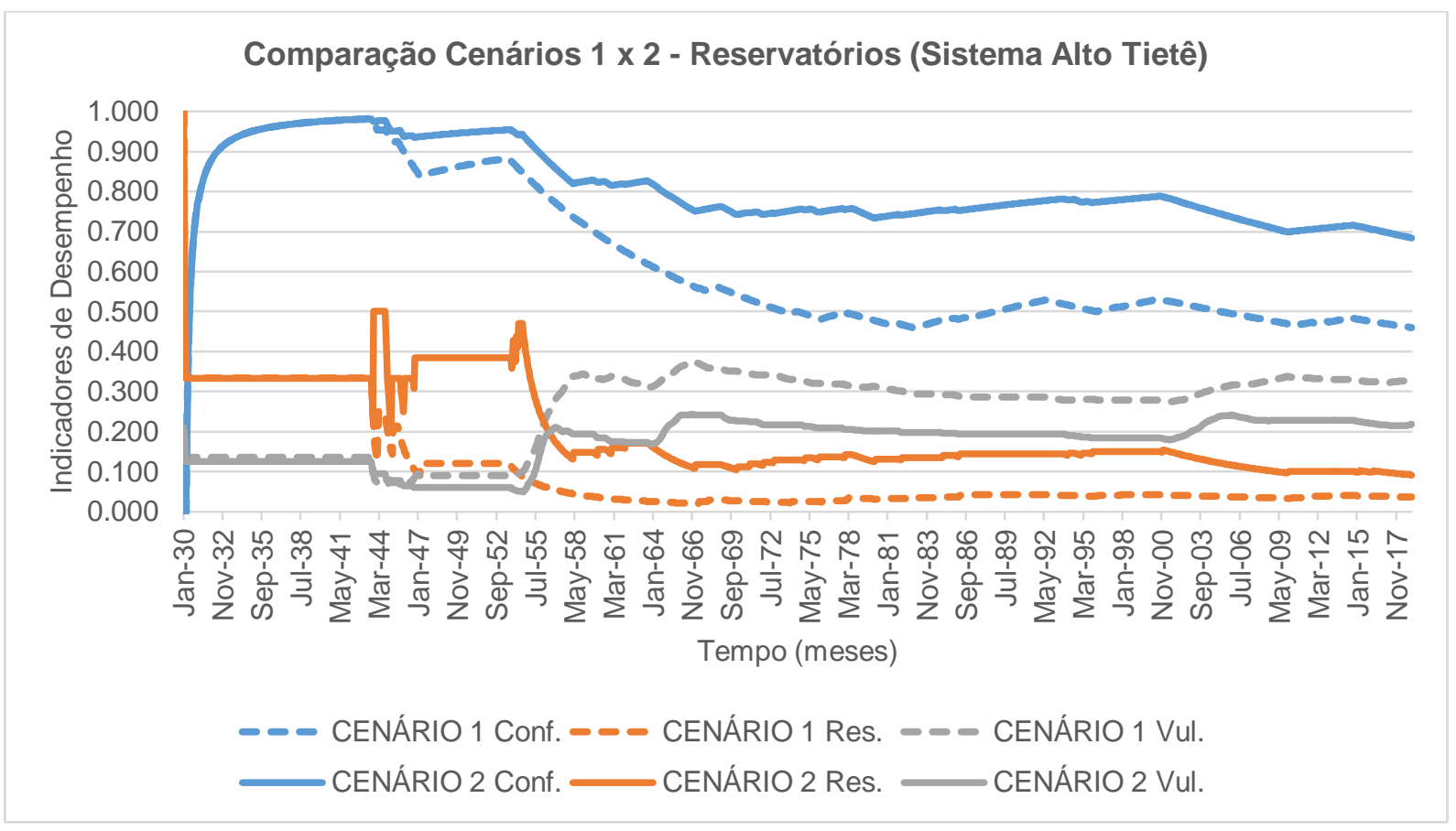

Figura 25: Acompanhamento dos indicadores de desempenho para os reservatórios do Sistema Alto Tietê. Comparação entre os Cenários 1 e 2.

Como comentado, os novos aportes de água no Sistema Alto Tietê fizeram com que o desempenho global do sistema no Cenário 2 fosse superior ao verificado no Cenário 1. A Figura 26 abaixo demonstra as curvas de permanência das novas vazões afluentes ao reservatório Taiaçupeba, que resultaram no acréscimo de desempenho.

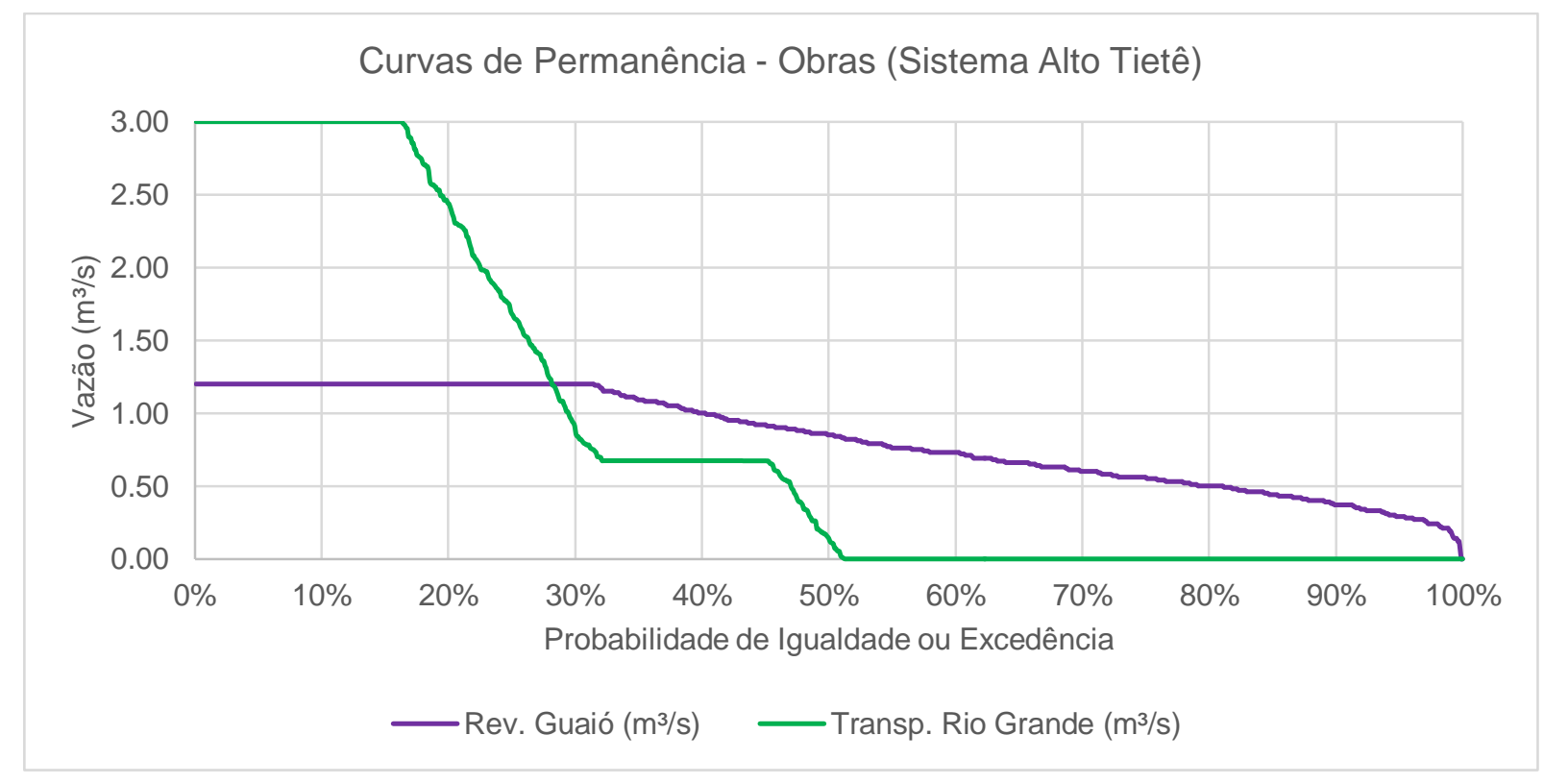

Figura 26: Curvas de permanência dos dados de vazão da reversão do Rio Guaió e transposição do Rio Grande. 
Ao longo da série, a reversão do Rio Guaió aportou em média 0,83 $\mathrm{m}^{3} / \mathrm{s}$ ao reservatório Taiaçupeba, enquanto que a transposição do Rio Grande 0,88 m³/s.

A Figura 27 a seguir apresenta os resultados do Índice de Sustentabilidade do Sistema Alto Tietê para os Cenários 1 e 2 . Como se observa, os novos aportes de água simulados no Cenário 2 provocaram um incremento de $82,5 \%$ na sustentabilidade global do sistema.

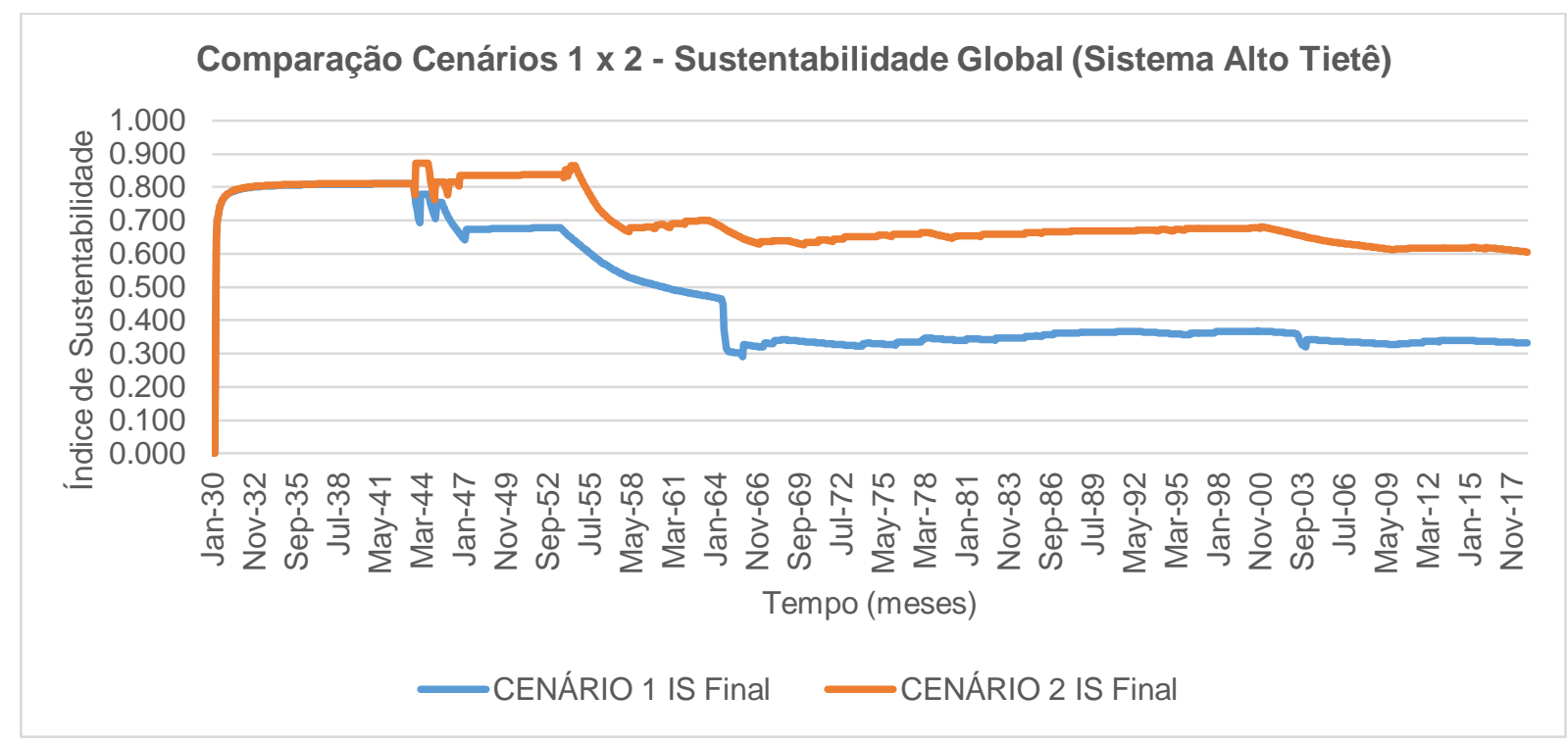

Figura 27: Acompanhamento do Índice de Sustentabilidade global do Sistema Alto Tietê. Comparação entre os Cenários 1 e 2.

Notadamente, o acréscimo de água no Alto Tietê e a consequente redução do número de falhas, tanto em termos de fornecimento de água na ETA quanto em termos das metas de reservação de água, fizeram com que a curva do Índice de Sustentabilidade para o Cenário 2 fosse suavizada principalmente nos períodos iniciais de condição insatisfatória da série: para o Cenário 1, em 1943-1947, o nível dos reservatórios oscilou frequentemente entre condições satisfatórias e insatisfatórias e, nos períodos de 1954-1955 e 1964, verificaram-se meses sucessivos de condições insatisfatórias provocadas por baixas afluências de vazões naturais.

\subsubsection{SISTEMA CANTAREIRA}

A Figura 28 demonstra o resumo dos resultados de desempenho do Sistema Cantareira para o Cenário 1, sem obras de aporte hídrico, e Cenário 2, com a inclusão 
da interligação Jaguari-Atibainha. De maneira geral, nota-se o acréscimo dos níveis de Confiabilidade, tanto para o fornecimento de água na ETA Guaraí, quanto em termos de reservação de água nos reservatórios do Cantareira.

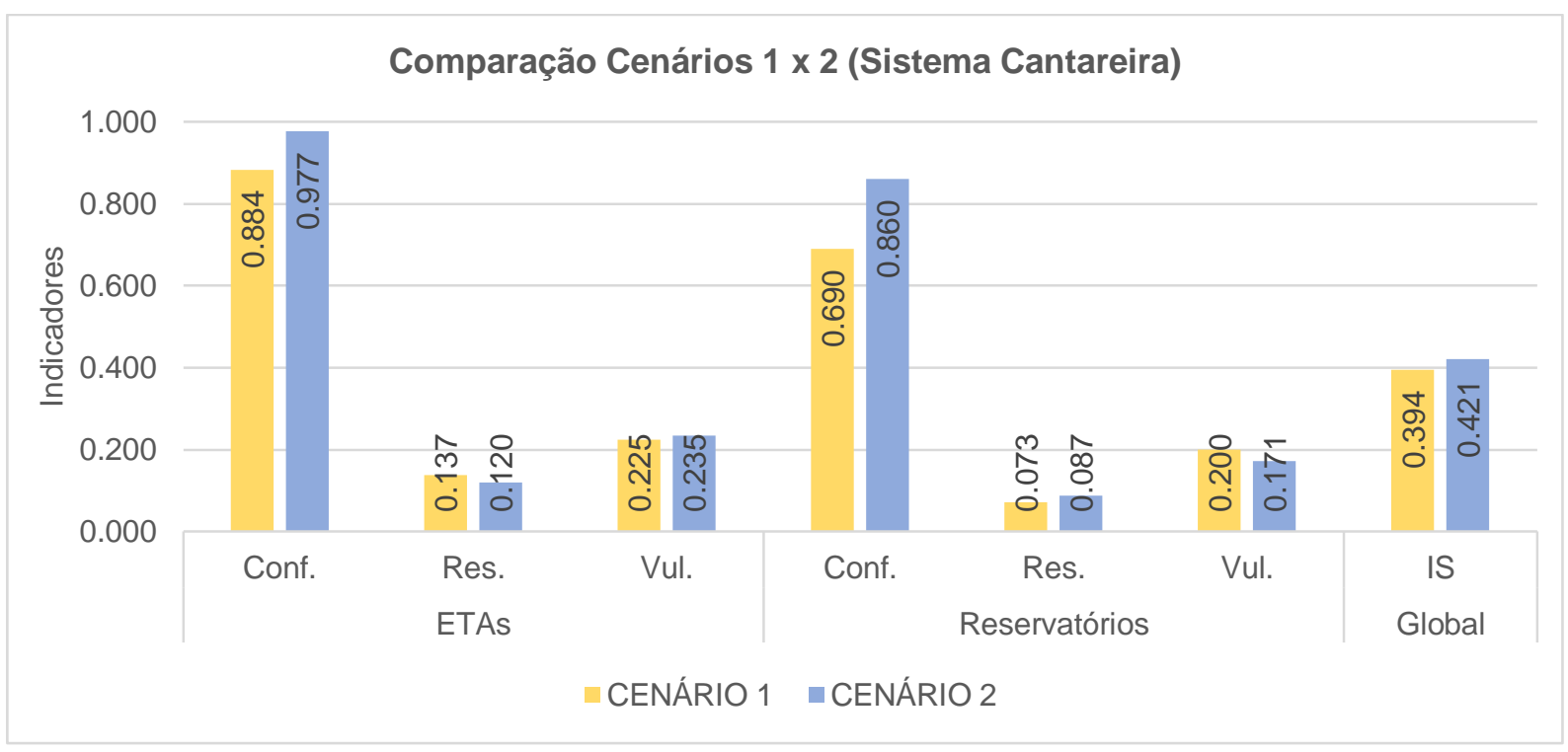

Figura 28: Resumo dos indicadores de desempenho e índice global de sustentabilidade para o Sistema Cantareira. Comparação Cenários 1 e 2.

A Figura 29 a seguir demonstra os resultados do fornecimento de água na ETA Guaraú nos Cenários 1 e 2.

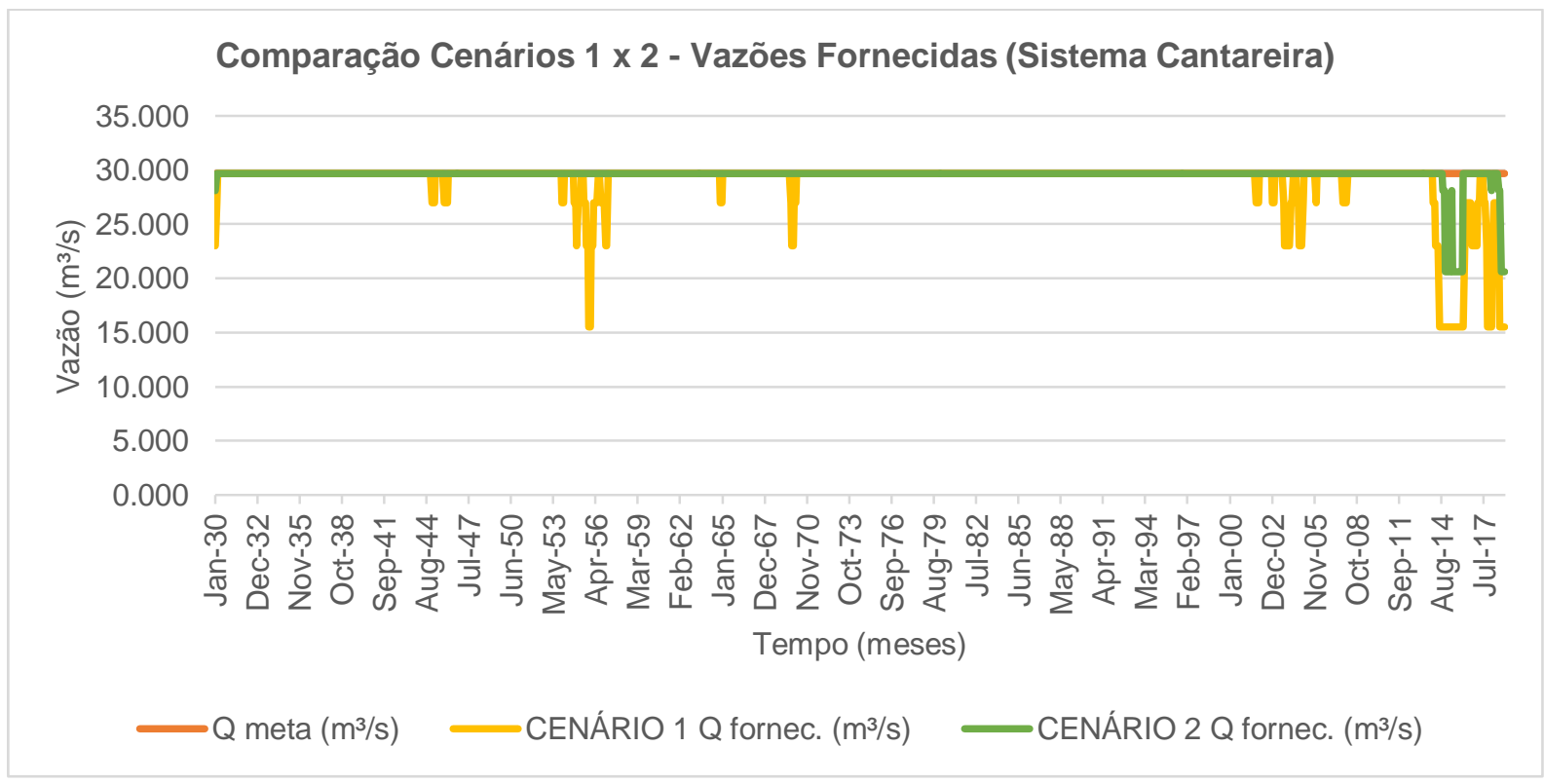

Figura 29: Vazões fornecidas e Vazão-meta no ponto de demanda "ETA Guaraú" nos Cenários 1 e 2. 
Diferentemente do Cenário 1, em que falhas de fornecimento de água na ETA são verificadas de forma distribuída ao longo da série, o Cenário 2 concentra falhas de atendimento de menor magnitude, se comparado ao Cenário 1, no período da Crise Hídrica de 2014-2015. Esta condição resulta em um ganho de 10,5\% de Confiabilidade, que passa de 0,884 no Cenário 1 para 0,977 no Cenário 2 (Figura 30). Para os demais indicadores, todavia, a redução do número de falhas não gerou os mesmos resultados positivos. Se em um primeiro momento, os indicadores de Resiliência e Vulnerabilidade comportaram-se próximos aos seus respectivos valores ideais (1,000 e 0,000) ao longo de quase toda a série, a Crise Hídrica de 2014-2015 provocou uma concentração de falhas sucessivas que resultaram em uma perda de desempenho, mesmo que de escala reduzida, em ambos os indicadores. A Resiliência passou de 0,137 no Cenário 1 para 0,120 no Cenário 2, e a Vulnerabilidade de 0,225 para 0,235 .

Uma vez que o cálculo da Resiliência é inversamente proporcional ao número de falhas da série, quando ocorre uma concentração de períodos sucessivos de falha sem que haja um rápido retorno à condição satisfatória do sistema, não aumentando assim o numerador da sua fórmula de cálculo (observar seção 5), mesmo que o sistema ganhe em Confiabilidade, pode-se constatar uma redução de sua capacidade de Resiliência. Este mesmo raciocínio é aplicável ao critério de Vulnerabilidade. Sendo este indicador também inversamente proporcional ao número de falhas da série, a ocorrência um número menor de falhas resulta em um menor denominador para divisão pelo somatório dos déficits das falhas verificadas. Esta condição, evidentemente, também dependerá da magnitude destas falhas. Como para o Cenário 2, no período da Crise Hídrica, observa-se a concentração da ocorrência de falhas sucessivas de elevada magnitude (aproximadamente $31 \%$ da vazão-meta), a curva de Vulnerabilidade do sistema acaba sofrendo um maior impacto (perda de desempenho) se comparada com este mesmo período no Cenário 1, ficando ao final da série sensivelmente superior à calculada quando o Cantareira ainda não contava com os aportes da interligação Jaguari-Atibainha (Figura 30). 




Figura 30: Acompanhamento dos indicadores de desempenho no ponto de demanda "ETA Guaraú". Comparação entre os Cenários 1 e 2.

O acompanhamento dos dados de volume armazenado no Sistema Cantareira para os Cenários 1 e 2 é apresentado na Figura 31 abaixo.

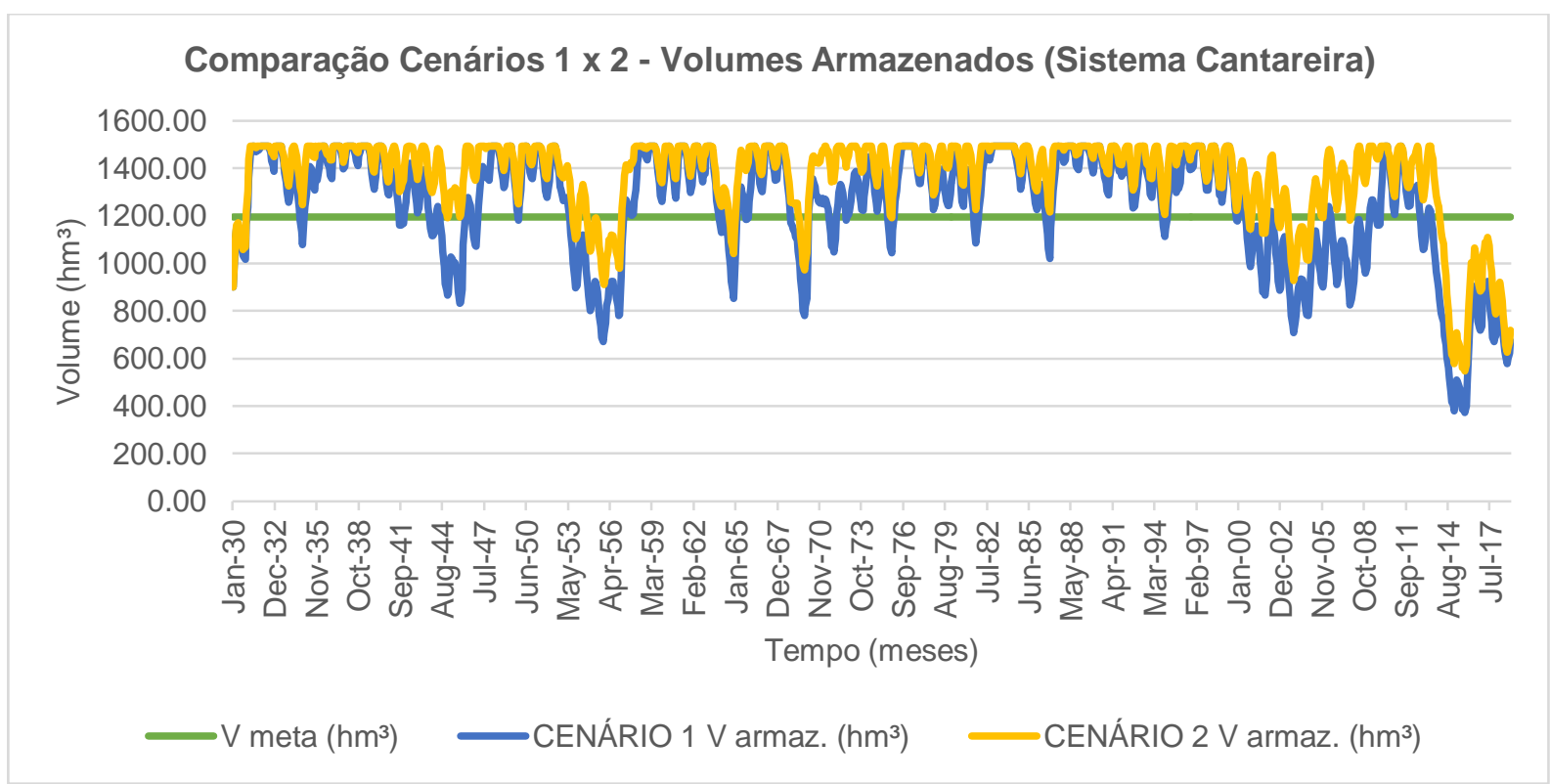

Figura 31: Volumes armazenados e Volume-meta para o Sistema Cantareira nos Cenários 1 e 2.

É notório que o aporte médio mensal de $3,20 \mathrm{~m} / \mathrm{s}$ faz com que o armazenamento do Sistema Canteira esteja menos susceptível a condições 
insatisfatórias de operação. Em mais de 53\% do tempo, a interligação com a bacia do Paraíba do Sul fornece a vazão máxima de $5,13 \mathrm{~m}^{3} / \mathrm{s}$, conforme pode ser verificado na curva de permanência da Figura 32.

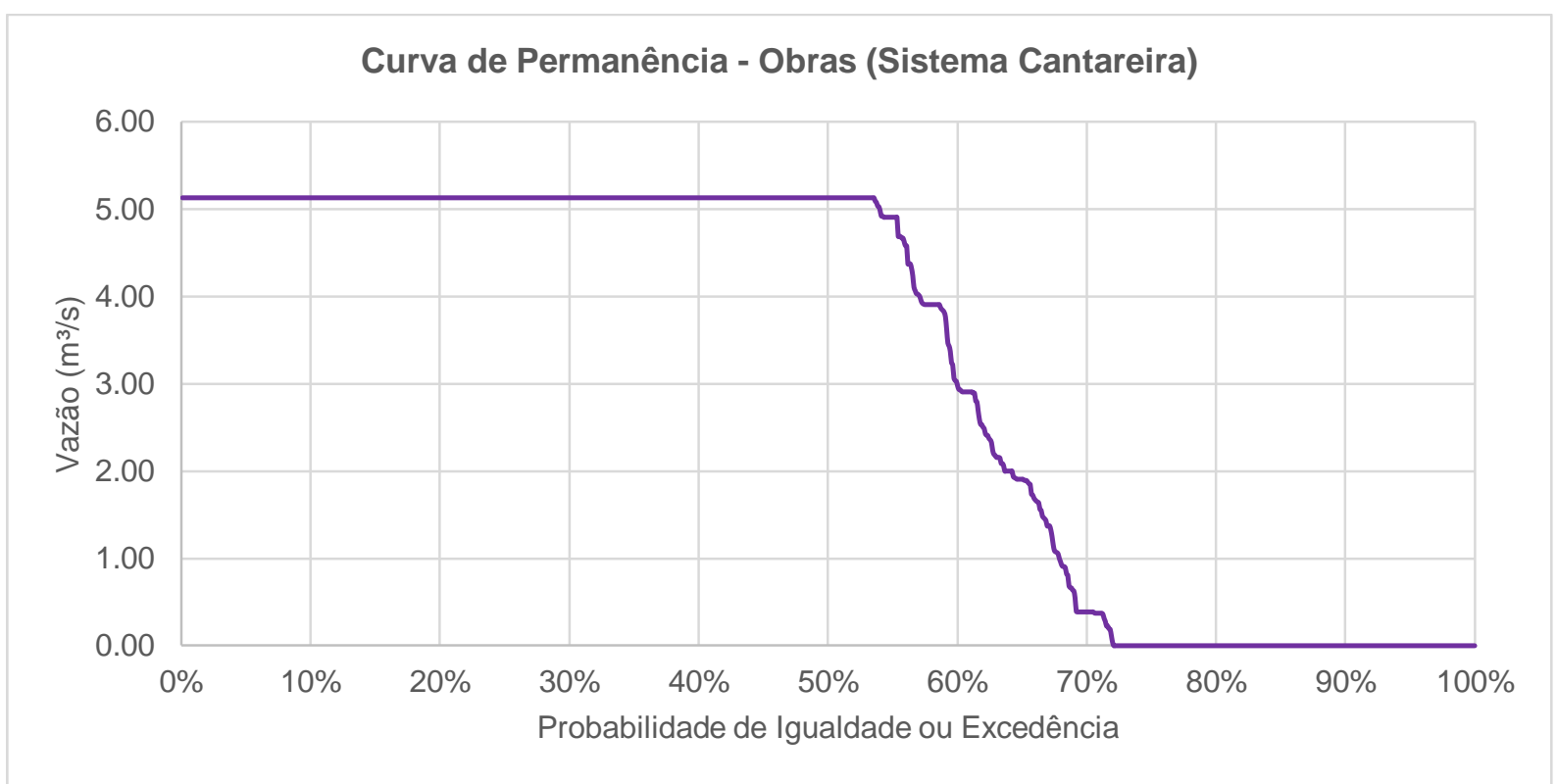

Figura 32: Curva de permanência dos dados de vazão da interligação Jaguari - Atibainha.

Apesar de ainda ocorrerem falhas em períodos marcados por baixas afluências, como nos períodos de 1954-1955 e início dos anos 2000, o número absoluto de falhas nestes períodos em reduzida, o que faz elevar principalmente o desempenho dos reservatórios em termos de Confiabilidade, que passa de 0,690 (Cenário 1) para 0,860 (Cenário 2). Registrou-se ganhos de 24,7\% neste indicador (Figura 33).

A Crise Hídrica de 2014-2015, por sua vez, ainda trouxe impactos claramente perceptíveis na condição de armazenamento do sistema. De janeiro/14 em diante, os níveis de armazenamento do Cantareira sempre figuraram abaixo da condição satisfatória de $80 \%$, resultando na observação de 60 eventos sequenciais de falha, 0 que gerou comportamentos negativos para os 3 indicadores. 


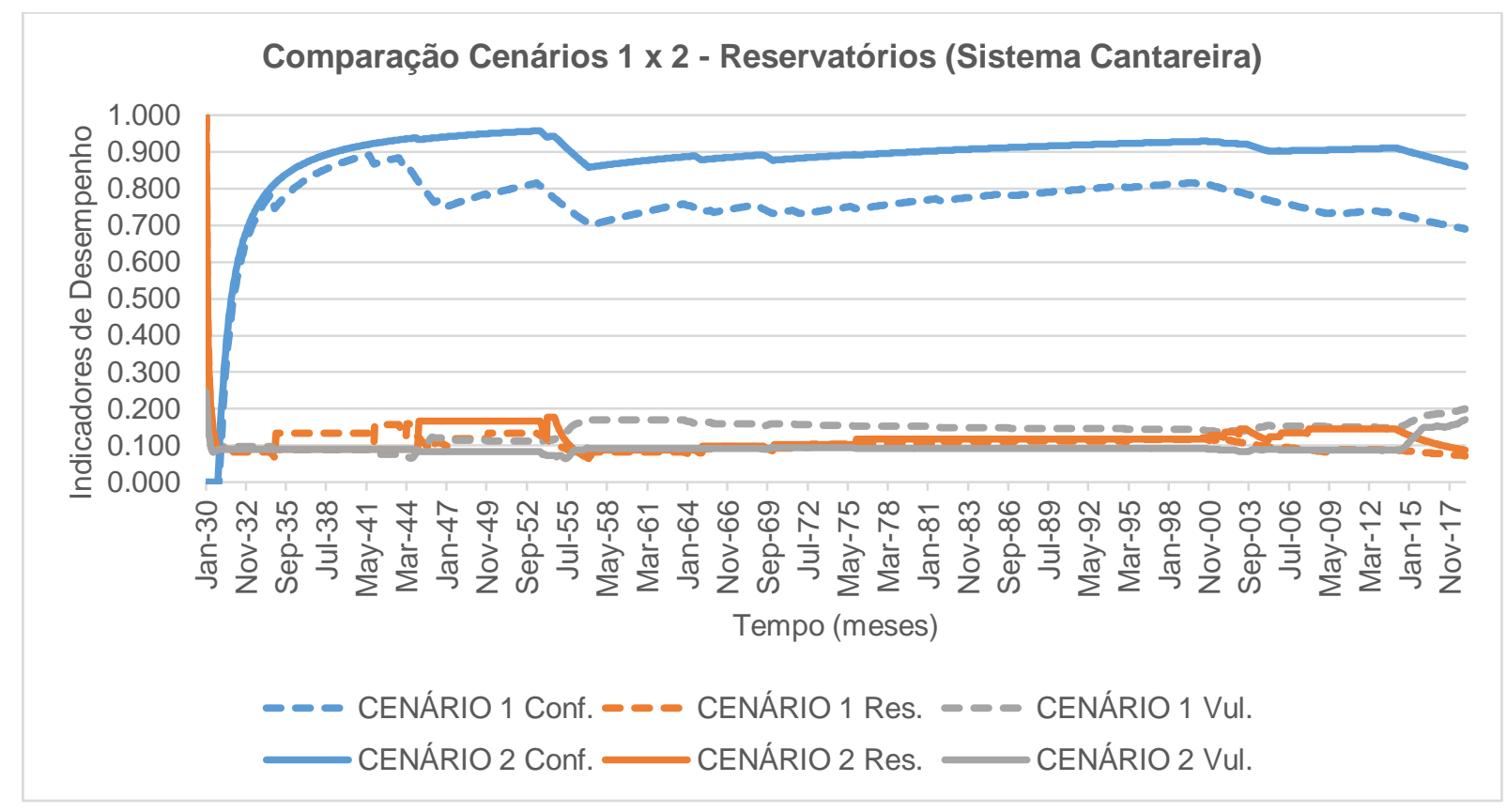

Figura 33: Acompanhamento dos indicadores de desempenho para os reservatórios do Sistema Cantareira. Comparação entre os Cenários 1 e 2.

Diferentemente do que ocorreu para o desempenho na ETA Guaraú, houve sensíveis ganhos nos critérios de Resiliência e Vulnerabilidade para os reservatórios do Sistema Cantareira. A Resiliência teve um ligeiro acréscimo de 0,073 no Cenário 1, para 0,087 no Cenário 2, enquanto a Vulnerabilidade diminuiu de 0,200 para 0,171. Verifica-se que a Resiliência é fortemente impactada pela condição inicial de simulação para ambos os Cenários (volume inicial dos reservatórios igual a $50 \%$ do volume útil). Tanto no Cenário 1 quanto no Cenário 2, a queda brusca no comportamento da Resiliência não consegue ser contornada tendo em vista que as condições insatisfatórias posteriores verificadas no Cantareira não são rapidamente revertidas. Ou seja, mesmo considerando os aportes constantes da interligação Jaguari-Atibainha simulados no Cenário 2, o armazenamento do Sistema Cantareira, uma vez que atinge uma condição de falha operacional, demora mais que um passo de tempo para se recuperar.

A Figura 34 a seguir demonstra os resultados da sustentabilidade global do Sistema Cantareira calculados para os Cenários 1 e 2. 


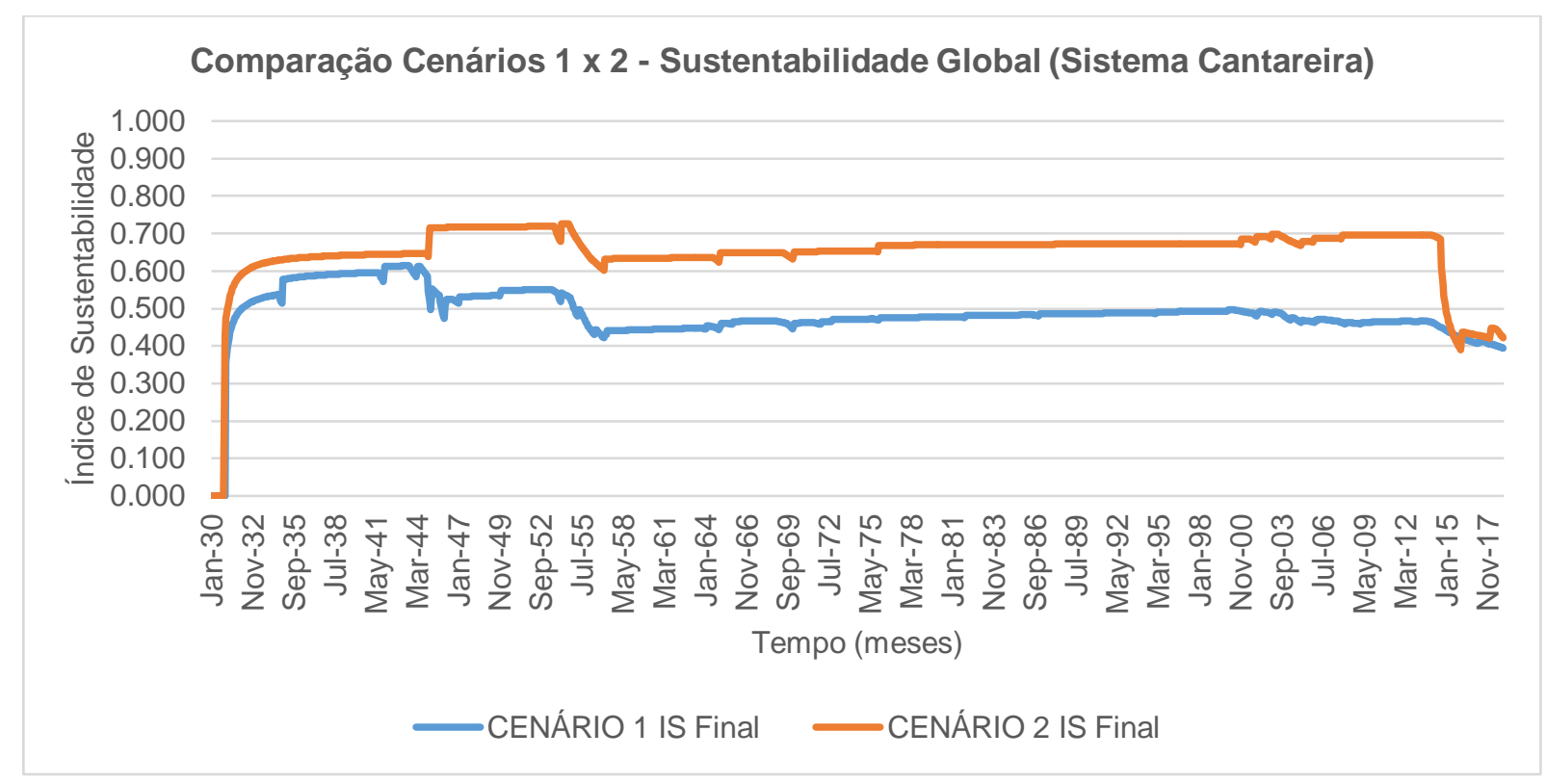

Figura 34: Acompanhamento do Índice de Sustentabilidade global do Sistema Cantareira. Comparação entre os Cenários 1 e 2.

Como se verifica, em quase toda a extensão da série, o Índice de Sustentabilidade para o Cantareira no Cenário 2 se comportou claramente superior ao verificado para o Cenário 1. Entre os anos de 1945 e 2013, os ganhos médios de sustentabilidade global do Cenário 2 foram de aproximadamente $40 \%$. A Crise Hídrica de 2014-2015, entretanto, causou um severo impacto principalmente no desempenho da Resiliência na ETA Guaraú neste período, o que fez o benefício final do Cenário 2 ficar na ordem de $6,8 \%$.

\subsubsection{SISTEMA RIO CLARO}

O Sistema Rio Claro não é diretamente beneficiado pela entrada em operação de obras de segurança hídrica no seu arranjo inicialmente simulado no Cenário1. Entretanto, as obras que trouxeram novos aportes de água para o Sistema Alto Tietê indiretamente provocaram alterações no desempenho do Rio Claro, tanto do ponto de vista de atendimento à demanda da ETA Casa Grande, quanto do armazenamento de água no reservatório Ribeirão do Campo, conforme se verifica na Figura 35 . Esta influência é exercida pelo comportamento do Rio Claro, que é um dos principais contribuintes da represa Ponte Nova, no Sistema Alto Tietê. 


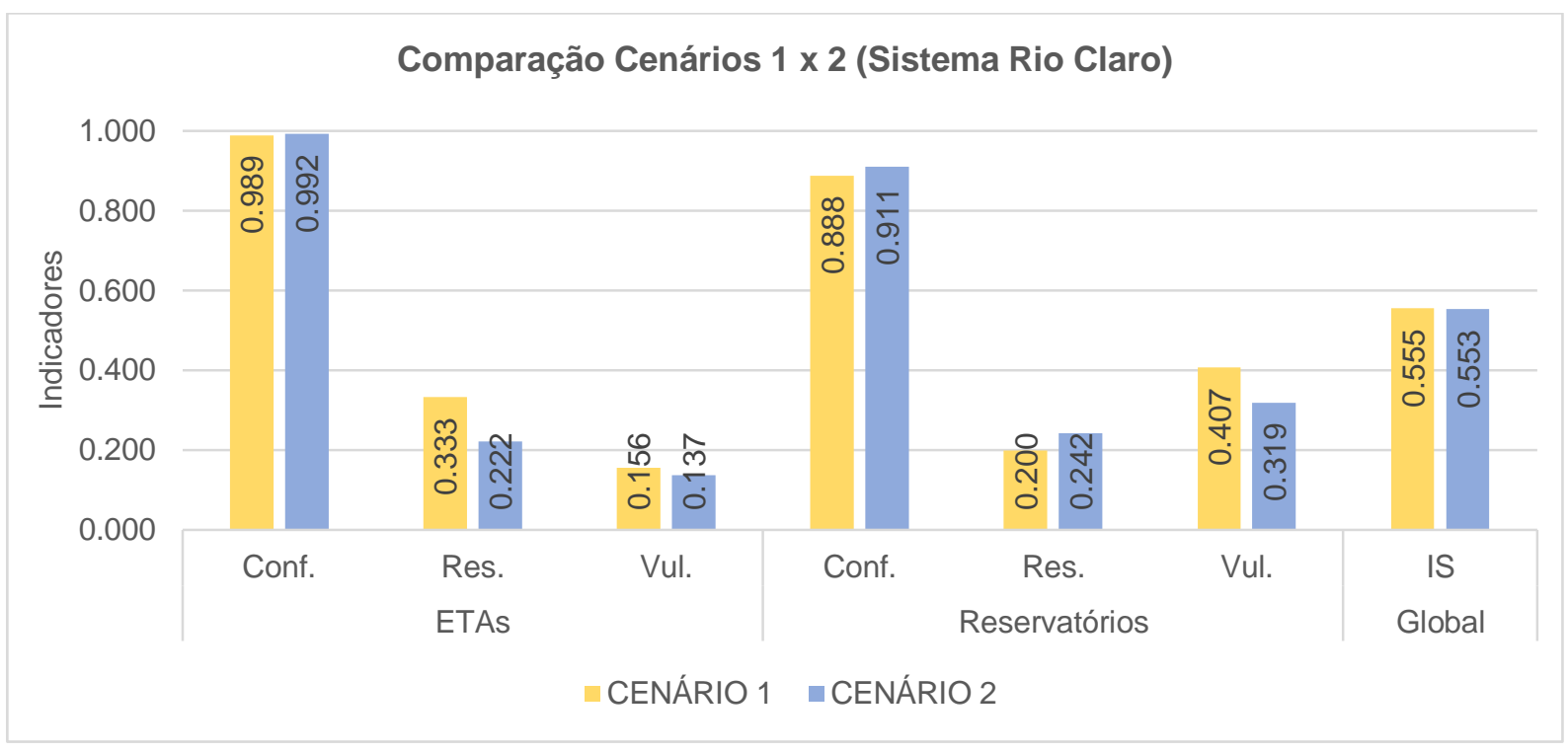

Figura 35: Resumo dos indicadores de desempenho e índice global de sustentabilidade para o Sistema Rio Claro. Comparação Cenários 1 e 2.

A Figura 36 a seguir demonstra o acompanhamento no tempo das vazões fornecidas no ponto de demanda "ETA Casa Grande". No Cenário 1, as falhas ocorrem basicamente em 3 momentos, nos anos de 1964, 2001 e 2003. Tendo sido período de 2001 o de maior estiagem, que provocou o esvaziamento total do Ribeirão do Campo, também tendo sido este um evento de falha perceptível no Cenário 2.

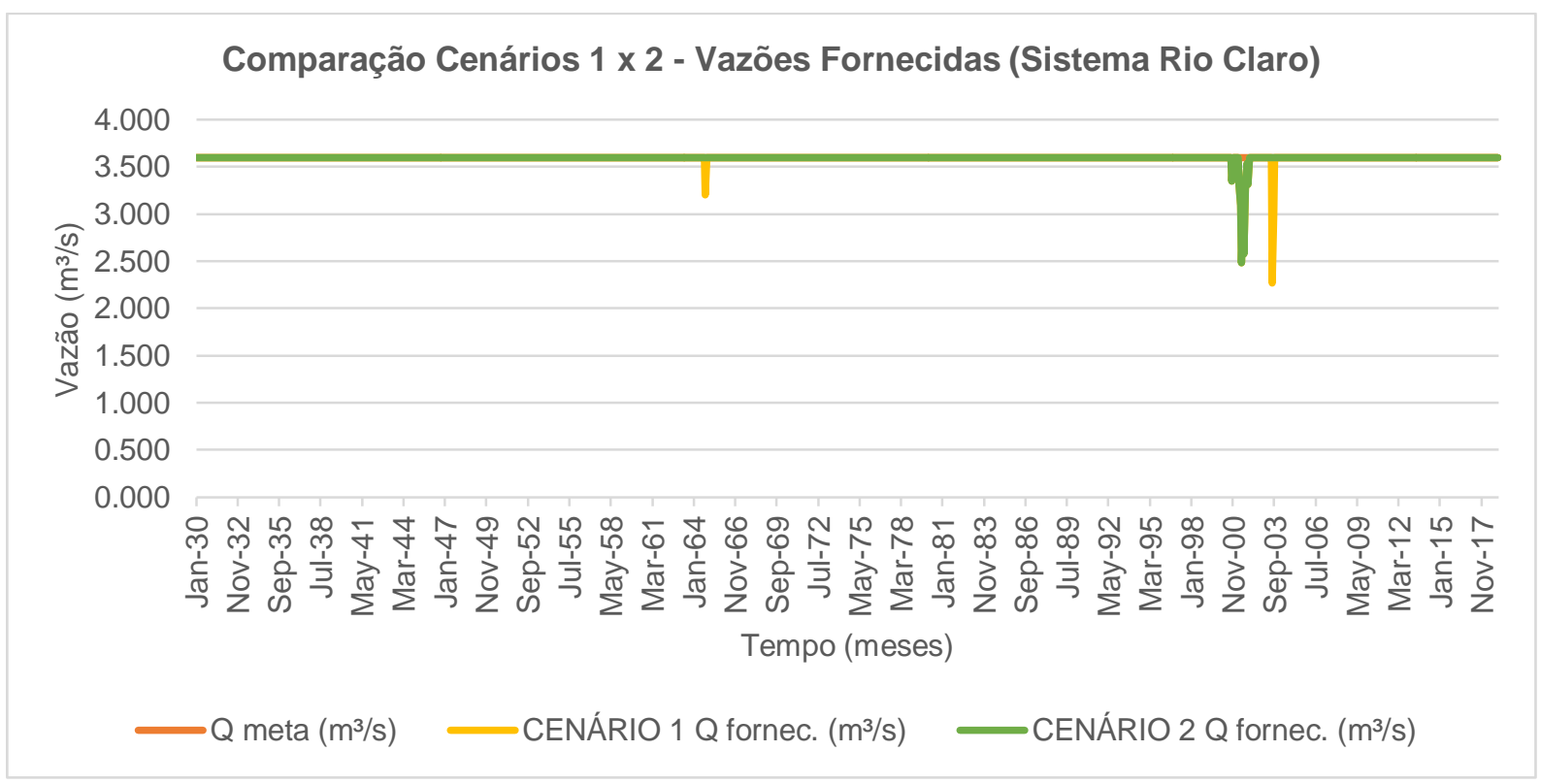

Figura 36: Vazões fornecidas e Vazão-meta no ponto de demanda "ETA Casa Grande" nos Cenários 1 e 2. 
O fornecimento de água na ETA Casa Grande se mostrou confiável para ambos os Cenários, com indicadores de desempenho mensurados em 0,989 no Cenário 1 e 0,992 no Cenário 2. Entretanto as falhas concentradas que ocorreram no ano de 2001 impactaram severamente a Resiliência do sistema. O Cenário 2 demonstrou uma perda de 33,3\% de Resiliência em relação ao Cenário 1, passando de 0,333 para 0,222 . As falhas sequencias ocorridas neste período provocarão esta redução. 0 somatório da magnitude das falhas se manteve proporcional ao número falhas registradas, de forma que Vulnerabilidade ficou muito próxima para os dois cenários, 0,156 no Cenário 1 e 0,137 no Cenário 2.

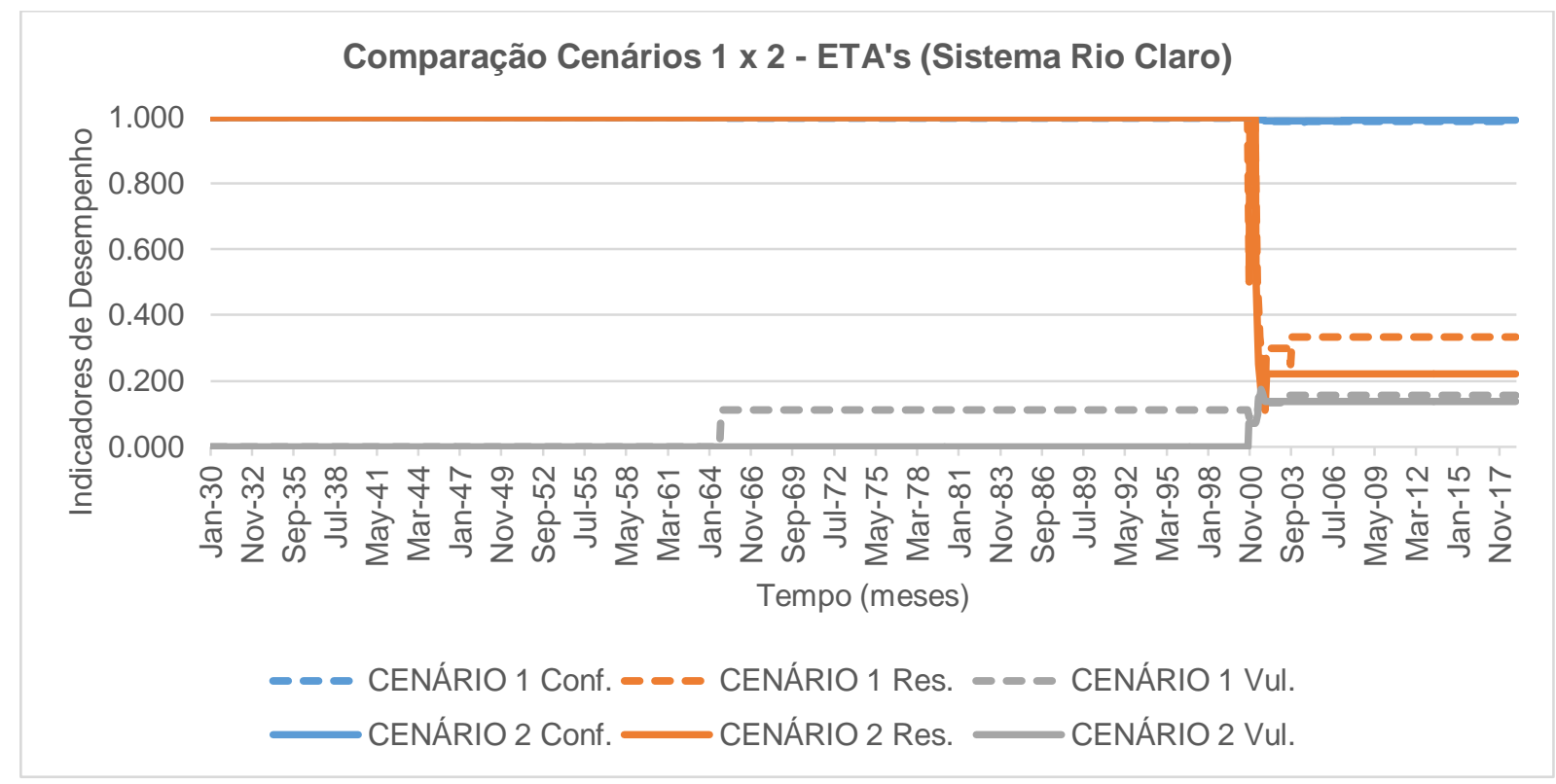

Figura 37: Acompanhamento dos indicadores de desempenho no ponto de demanda "ETA Casa Grande". Comparação entre os Cenários 1 e 2.

No Cenário 1, notadamente nos anos em que o Sistema Alto Tietê passou por eventos de escassez hídrica, que resultaram em rebaixamento acentuado dos níveis de água armazenada em seus reservatórios (1964-1965, 2001-2003 e 2018), o Sistema Rio Claro aumentou os despachos do Ribeirão do Campo para suprir as perdas do Alto Tietê, que resultaram no seu esvaziamento (Figura 38). 


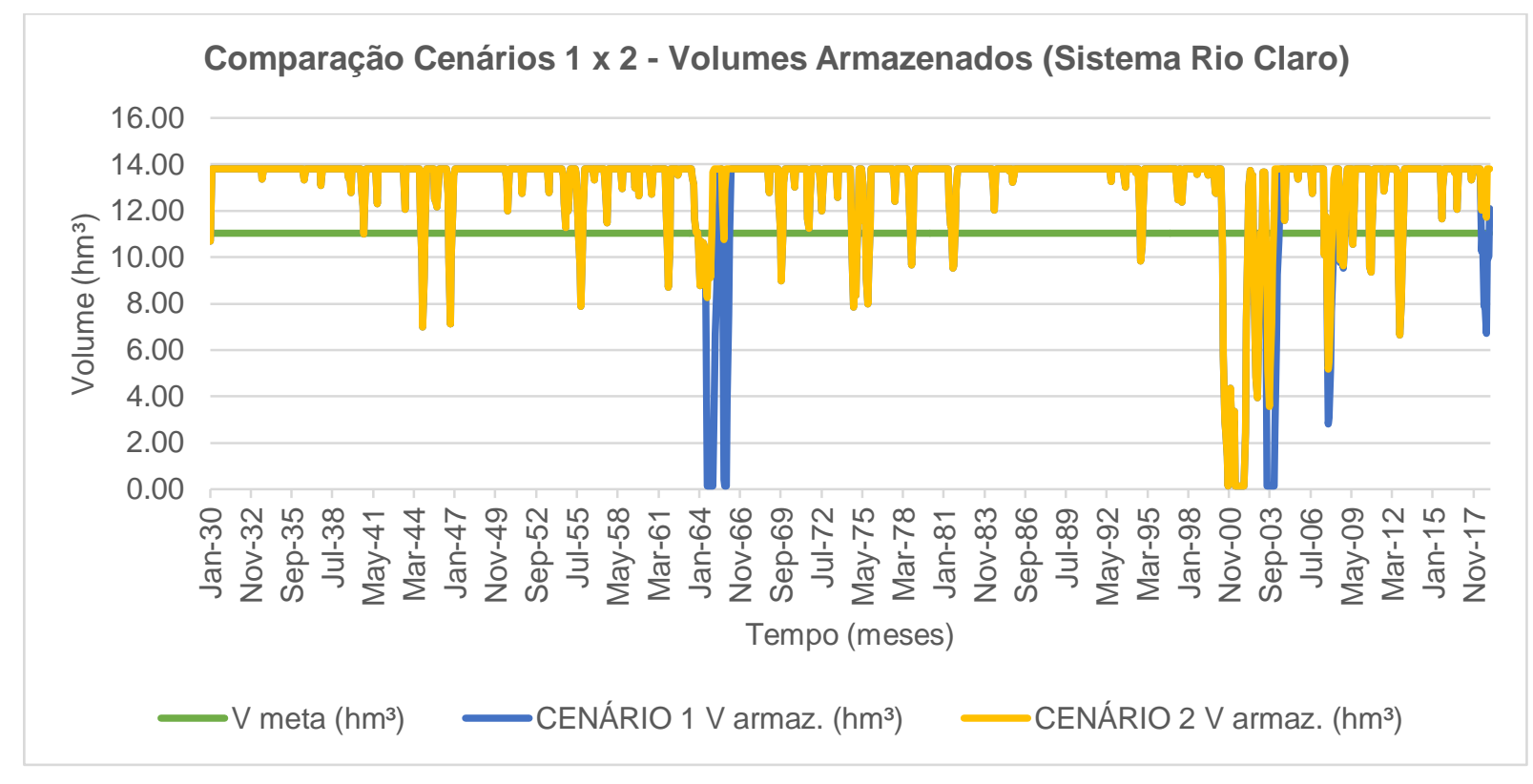

Figura 38: Volumes armazenados e Volume-meta para o Sistema Rio Claro nos Cenários 1 e 2.

Os novos aportes que garantiram uma atenuação dos eventos de crise para o Alto Tietê, por consequência, também surtiram este efeito atenuador na reservação de água no Sistema Rio Claro, com exceção do período do início dos anos 2000 que, devido à sua magnitude e afetação direta das afluências naturais do Ribeirão do Campo, mantiveram perdas importantes de desempenho principalmente para os indicadores de Resiliência e Vulnerabilidade também para o Cenário 2.

Para ambos os Cenários, a Confiabilidade do reservatório Ribeirão do Campo manteve-se em patamares elevados: 0,888 (Cenário 1) e 0,911 (Cenário 2). A Resiliência também foi incrementada, passando de 0,200 para 0,242. Os ganhos de desempenho, todavia, foram verificados mais acentuadamente em termos de Vulnerabilidade, com a uma redução de $21,7 \%$, passando de 0,407 no Cenário 1 para 0,319 no Cenário 2 (Figura 39). 


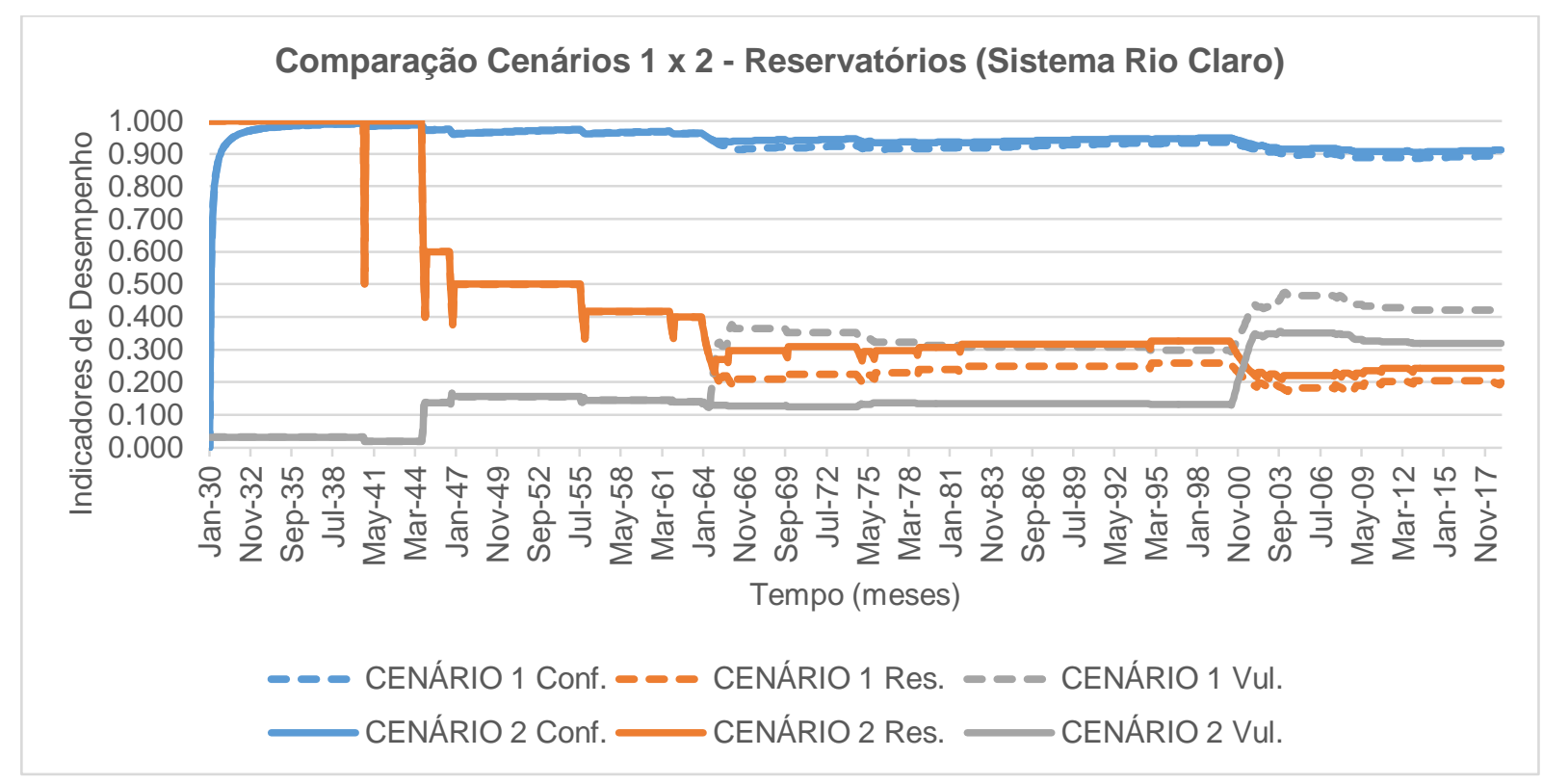

Figura 39: Acompanhamento dos indicadores de desempenho para os reservatórios do Sistema Rio Claro. Comparação entre os Cenários 1 e 2.

Por fim, a Figura 40 demonstra o resultado do desempenho global em termos de sustentabilidade para ambos os cenários. Entre os anos de 1964 e 2000, o Cenário 2 registrou ganhos médios de $11,4 \%$ em relação ao Cenário 1, principalmente por conta da redução da Vulnerabilidade na ETA Casa Grande e acréscimo de Resiliência na reservação de água no Ribeirão do Campo. Entretanto, a queda brusca de Resiliência na ETA, decorrente das falhas sequenciais observadas em 2001, equalizaram os ganhos obtidos até então e praticamente igualaram a sustentabilidade global para ambos os cenários simulados ao final da série, que ficou em 0,555 no Cenário 1 e 0,553 no Cenário 2. 


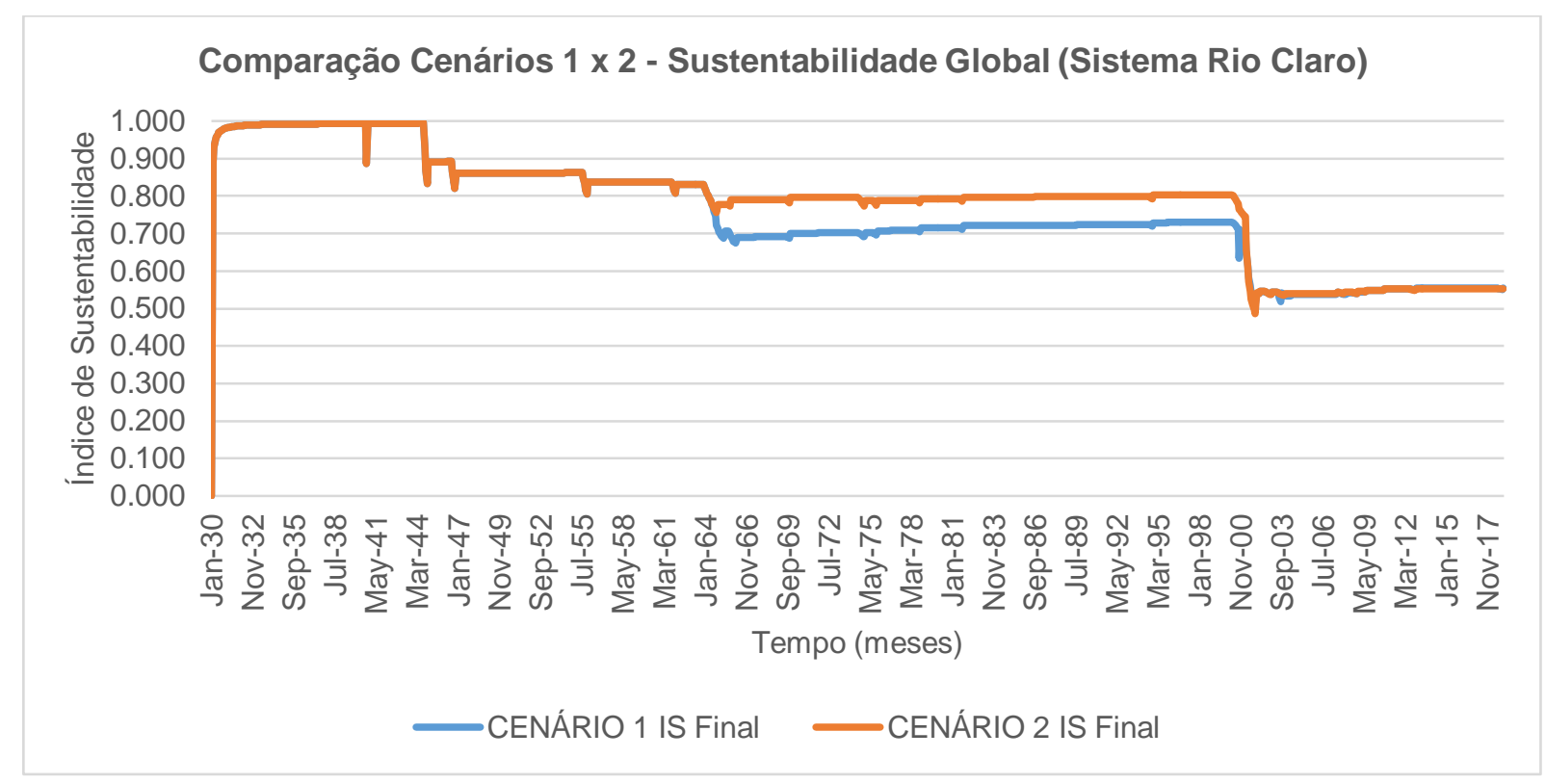

Figura 40: Acompanhamento do Índice de Sustentabilidade global do Sistema Rio Claro. Comparação entre os Cenários 1 e 2.

\subsubsection{SISTEMA RIO GRANDE}

O Sistema Rio Grande conta com a inclusão da obra de transferência do Braço do Rio Pequeno para o reservatório Rio Grande (braço isolado da represa Billings). A avaliação comparativa entre os Cenários 1 e 2, além de analisar os resultados desta transferência, presta-se ainda a realizar uma análise do impacto que a obra de transposição do Rio Grande para o reservatório Taiaçupeba (Sistema Alto Tietê) provoca em termos de desempenho operacional do Sistema Rio Grande.

O resumo dos resultados de desempenho do Sistema Rio Grande para os Cenários 1 e 2 encontra-se apresentado na Figura 41.

Conforme se pode notar, o desempenho no fornecimento de água em ambas as ETA's do sistema, ETA Rio Grande e ETA Ribeirão da Estiva, não é impactado pela inclusão das obras do Cenário 2. Enquanto a ETA Rio Grande não apresentou falhas em seu fornecimento, ficando assim com os 3 indicadores nos seus devidos valores ideais, a ETA Ribeirão da Estiva incorreu em falhas pontuais distribuídas ao longo do tempo, que resultaram nos seguintes resultados de desempenho: Confiabilidade $=0,984$; Resiliência $=0,882$ e Vulnerabilidade $=0,267$. Estes eventos de falha serão melhor discutidos na seção 7.2.6 adiante. 


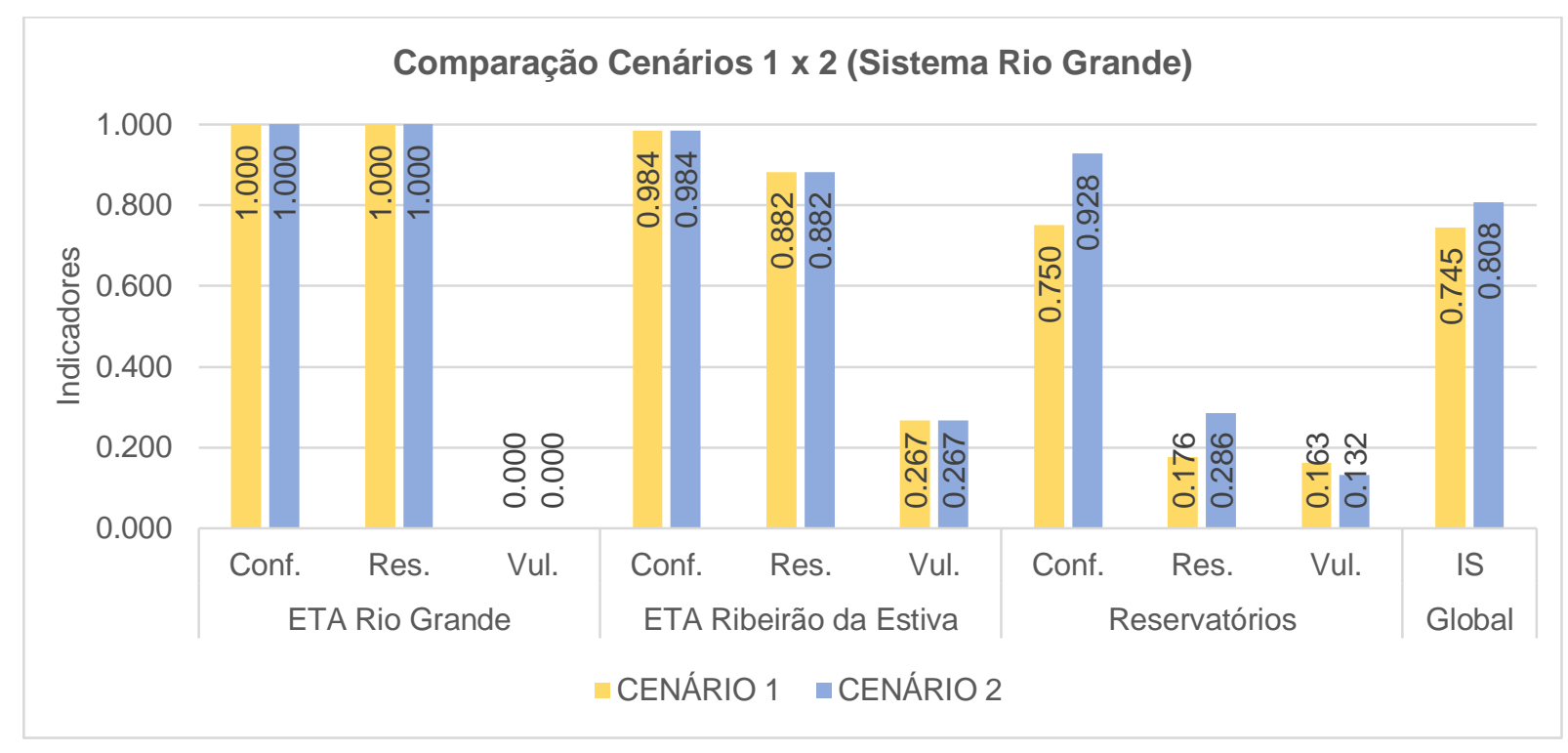

Figura 41: Resumo dos indicadores de desempenho e índice global de sustentabilidade para o Sistema Rio Grande. Comparação Cenários 1 e 2.

A transferência do Braço do Rio Pequeno aportou em média 1,50 m³/s ao Rio Grande. De acordo com a Figura 42, em mais de 90\% do tempo foram observadas vazões de ao menos de 0,60 $\mathrm{m}^{3} / \mathrm{s}$, o que resultou em um perceptível acréscimo dos níveis de armazenamento no sistema ao longo da série (Figura 43). Destaca-se ainda que estes ganhos não foram impactados pelas vazões médias de saída (transposição Rio Grande-Taiaçupeba) da ordem de 0,88 $\mathrm{m}^{3} / \mathrm{s}$, tendo em vista que a transposição somente ocorreu nos meses em que o reservatório Rio Grande estava vertendo.

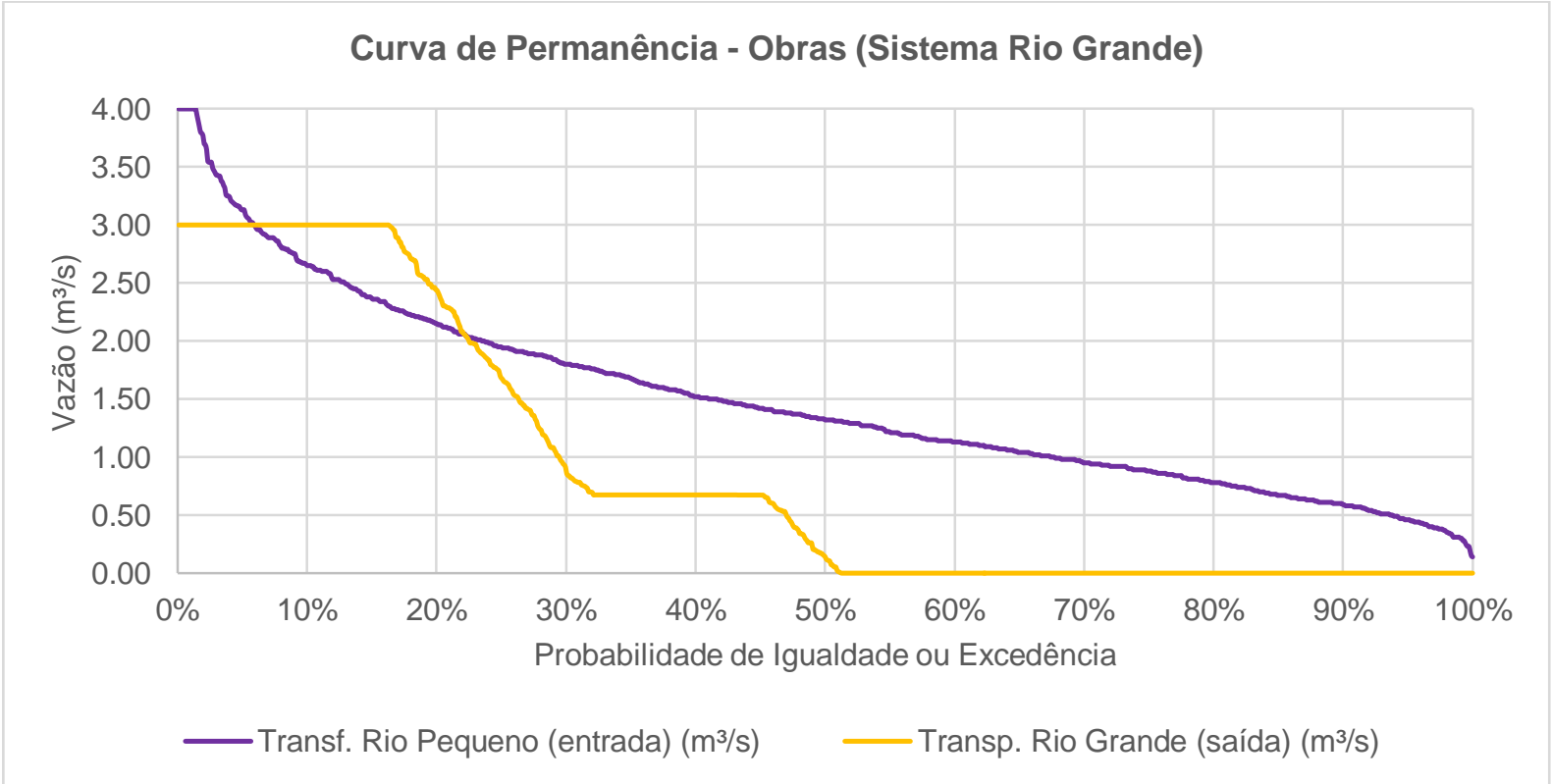

Figura 42: Curva de permanência dos dados de vazão da transferência do Rio Pequeno. 
Conforme mencionado, os aportes médios de $1,50 \mathrm{~m} 3 / \mathrm{s}$ ao Rio Grande simulados no Cenário 2 resultaram em um ganho distribuído nos níveis de armazenamento do reservatório. O acompanhamento do volume reservado no Rio Grande ao longo do tempo pode ser verificado na Figura 43.

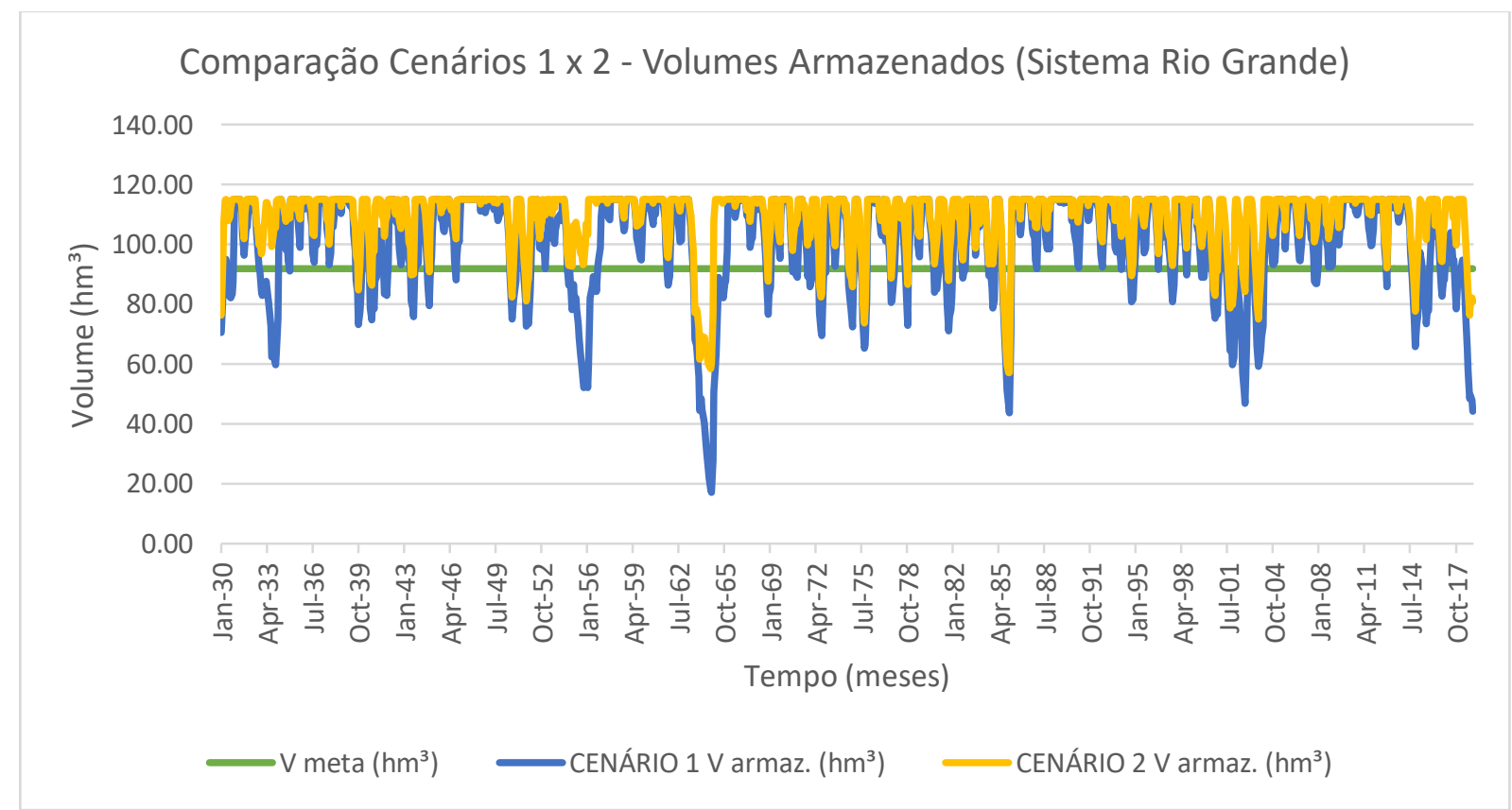

Figura 43: Volumes armazenados e Volume-meta para o Sistema Rio Claro nos Cenários 1 e 2.

A elevação geral do volume armazenado gerou como consequência uma redução das condições insatisfatórias na operação do reservatório, assim, verificouse um incremento de $23,7 \%$ no grau de Confiabilidade do reservatório, passando de 0,750 no Cenário 1 para 0,928 no Cenário 2. A Vulnerabilidade do sistema mantevese reduzida durante toda a série; 0,163 no Cenário 1 e 0,132 no Cenário 2, demonstrando que as condições insatisfatórias na reservação do Rio Grande, quando ocorrem, são de baixa magnitude média. A Resiliência, por sua vez, apesar de ter subido de 0,176 no Cenário1 para 0,286 no Cenário 2, ainda foi significativamente impactada por eventos de falhas sucessivas que ocorreram nos períodos de 1943, 1951 e 1963-1964, mesmo considerando os aportes decorrentes da transferência do Rio Pequeno. Neste último período, principalmente, registraram-se 17 meses consecutivos de condição insatisfatória de armazenamento, que fez a Resiliência sair do patamar de 0,500 para um mínimo de 0,226. 


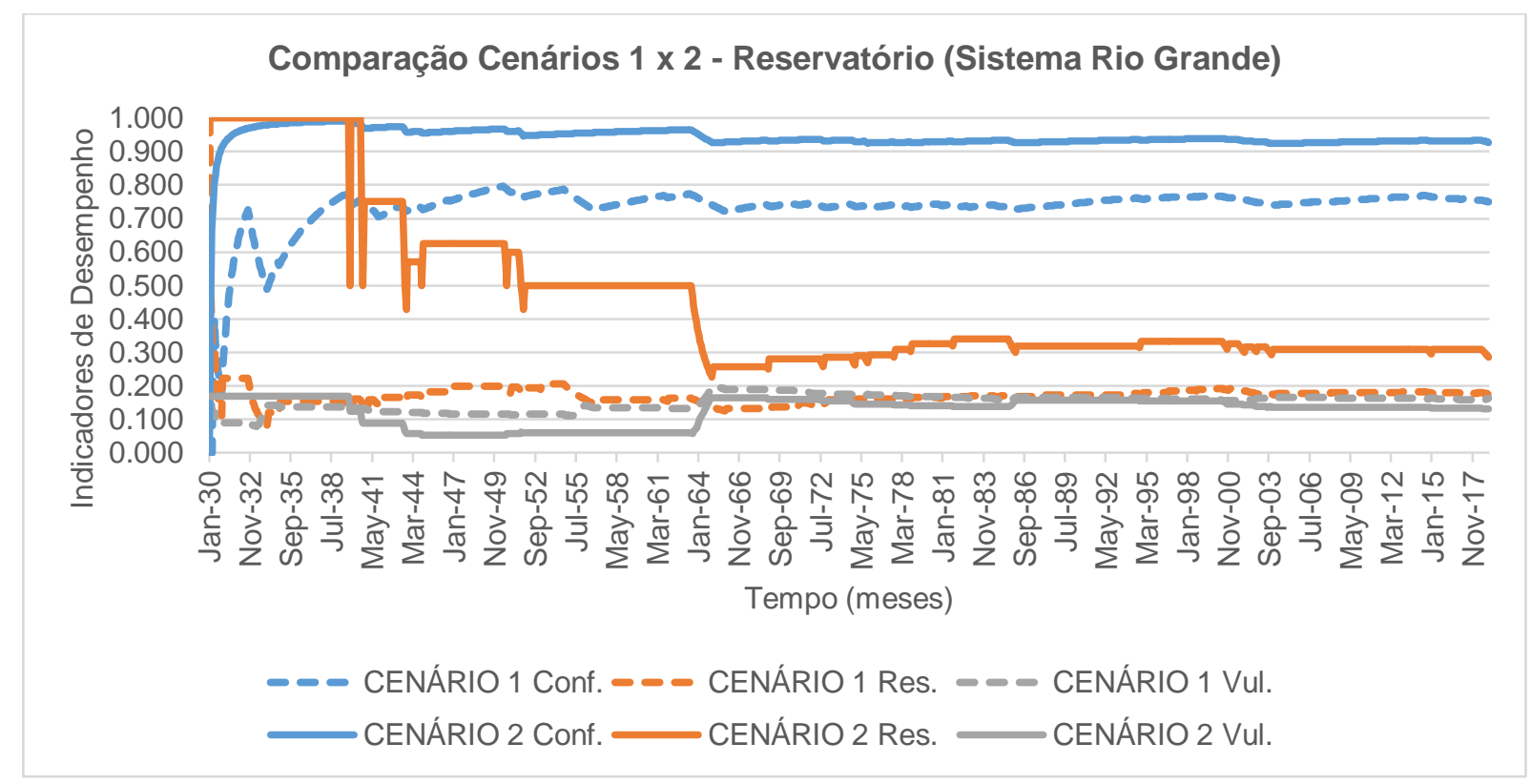

Figura 44: Acompanhamento dos indicadores de desempenho para o reservatório Rio Grande. Comparação entre os Cenários 1 e 2.

Influenciado exclusivamente pelos ganhos de desempenho obtidos na reservação de água para o Cenário 2, a sustentabilidade global do Sistema Rio Grande saiu de 0,745 no Cenário 1 para 0,808 no Cenário 2. Os ganhos foram da ordem de $8,5 \%$ (Figura 45).

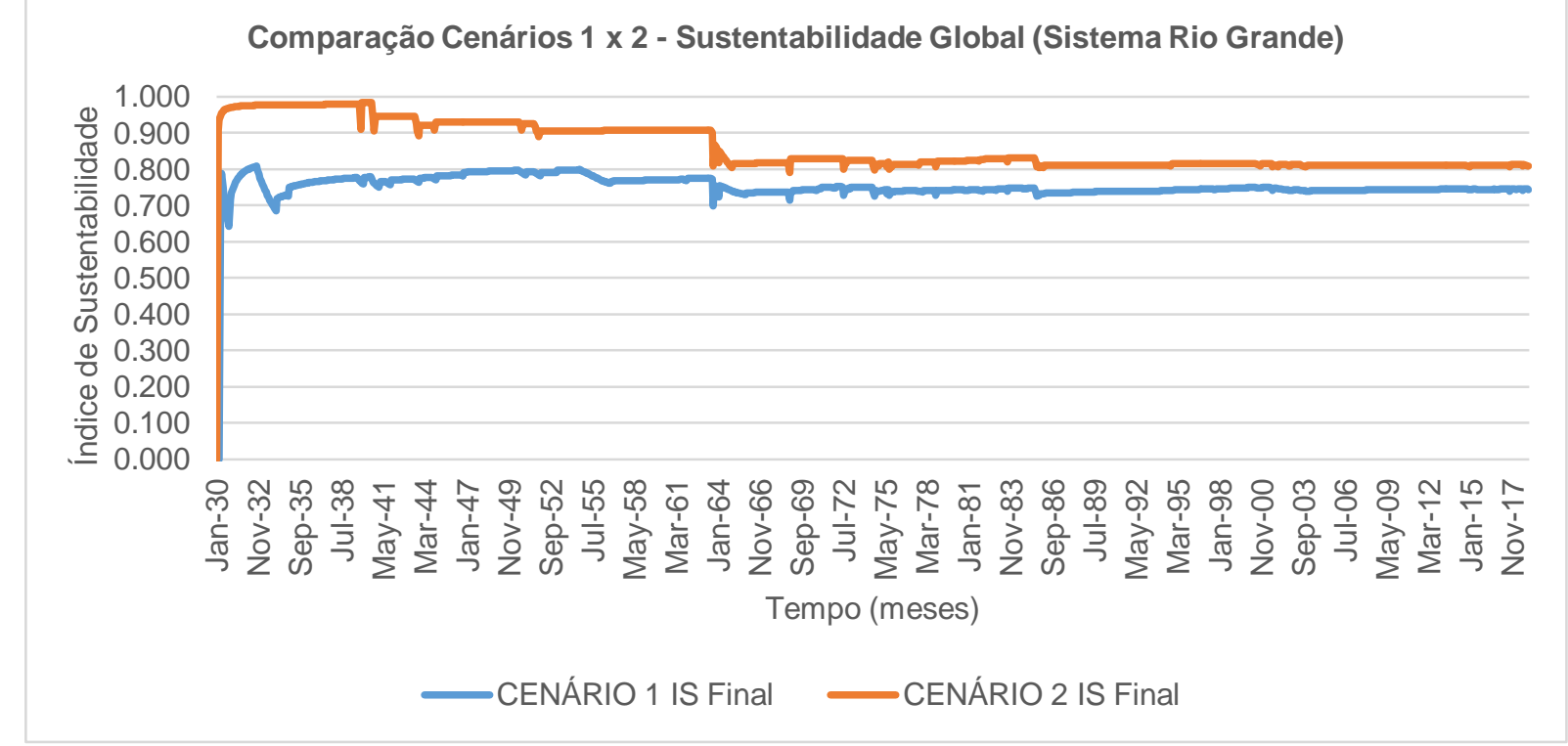

Figura 45: Acompanhamento do Índice de Sustentabilidade global do Sistema Rio Grande. Comparação entre os Cenários 1 e 2. 


\subsubsection{SISTEMA INTEGRADO METROPOLITANO}

A presente seção tem o intuito de apresentar comparativamente os resultados globais de desempenho dos Cenários 1 e 2 para o Sistema Integrado Metropolitano como um todo. A Figura 46 a seguir resume os resultados obtidos em ambos os cenários de simulação.

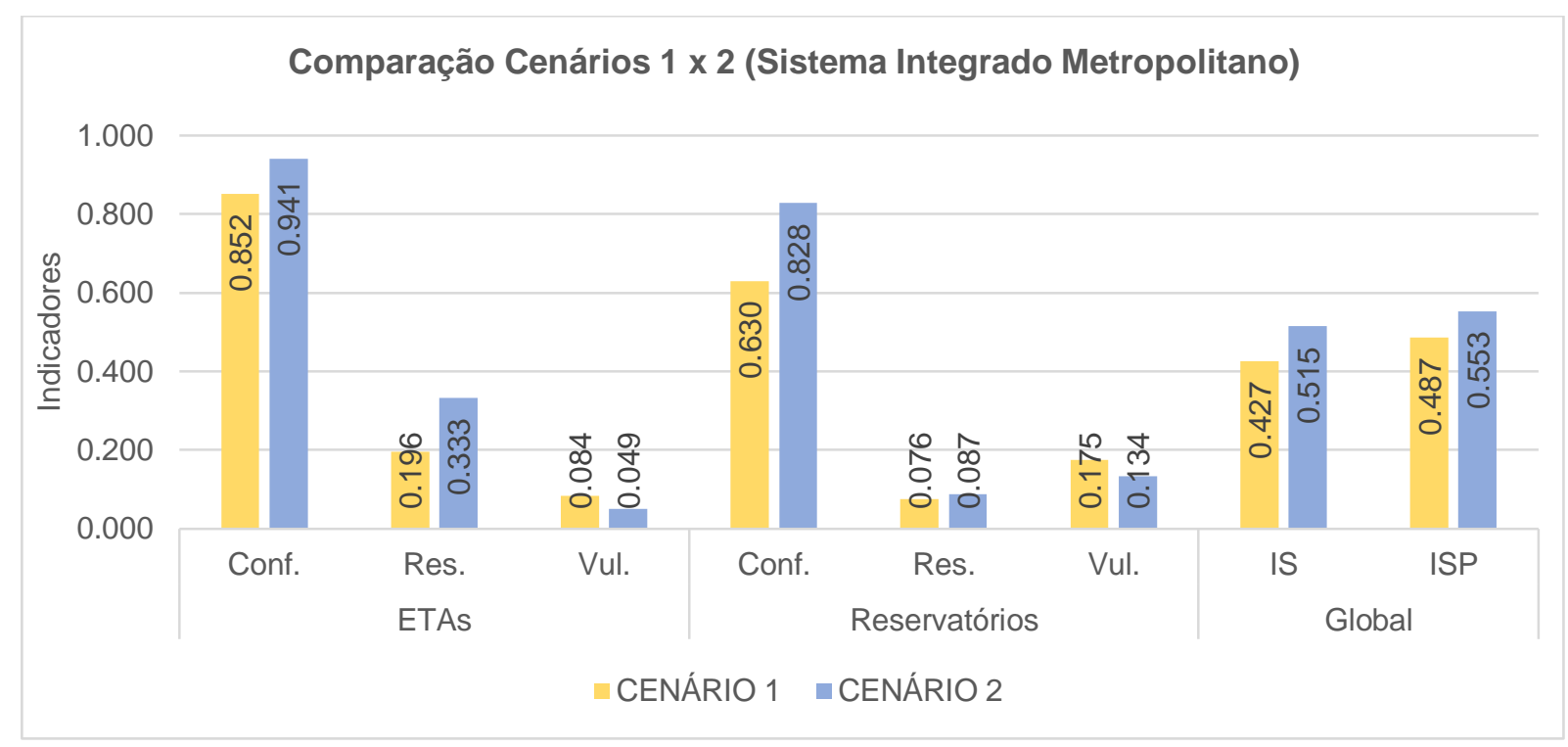

Figura 46: Resumo dos indicadores de desempenho e índice global de sustentabilidade para o Sistema Integrado Metropolitano. Comparação Cenários 1 e 2.

As séries de vazões totais fornecidas às ETA's do Sistema Integrado Metropolitano, bem como a vazão-meta de fornecimento, podem ser verificadas na Figura 47 abaixo, para os Cenários 1 e 2 . 


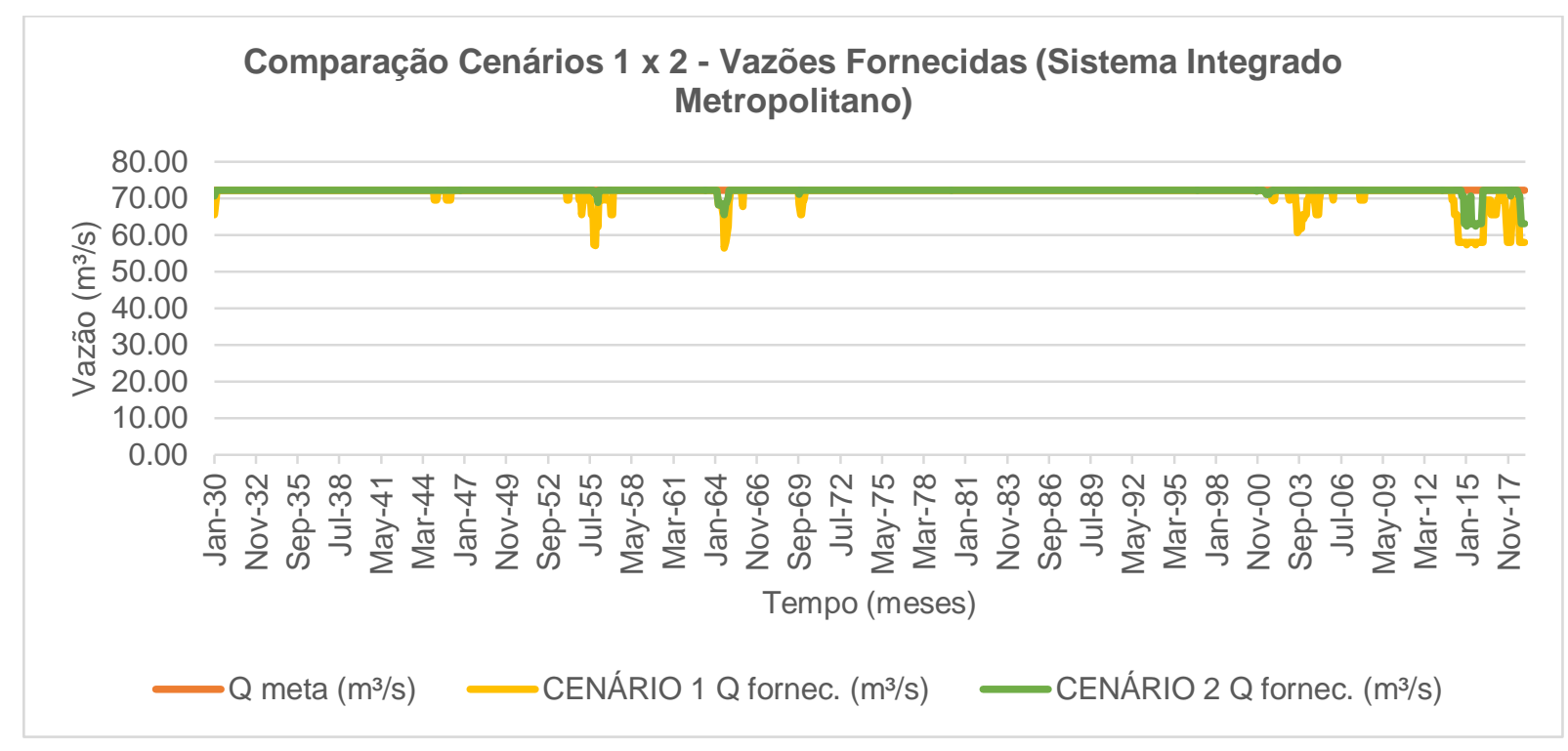

Figura 47: Somatório das vazões fornecidas e vazão-meta para o total das ETA's do Sistema Integrado Metropolitano nos Cenários 1 e 2.

A redução geral do número de falhas no atendimento às vazões requeridas nas ETA's elava diretamente a Confiabilidade do fornecimento, que passa de 0,852 no Cenário 1 para 0,941 no Cenário 2, conforme se verifica na Figura 48. Os ganhos neste critério foram da ordem de $10,4 \%$.

A Vulnerabilidade no abastecimento se manteve em patamares reduzidos, sofrendo acréscimos sensíveis após os eventos de crise hídrica de 1954-1955 e 20142015 que pouco afetaram o comportamento geral das curvas. Ao final da série, a Vulnerabilidade esteve em 0,084 para o Cenário 1 e 0,049 para o Cenário 2, demonstrando a baixa Vulnerabilidade global do SIM para ambos os cenários.

A Resiliência, por sua vez, é o indicador que apresenta maior variação ao longo da série analisada, em ambos os cenários. Apesar dos ganhos obtidos ao final da série, passando de 0,196 no Cenário 1 para 0,333 no Cenário 2, este representa um critério de desempenho que o SIM apresenta significativa susceptibilidade. Mesmo com os novos aportes de água oriundos das obras de segurança hídrica, o sistema apresenta perdas importantes de Resiliência em períodos de escassez, como em 1954-1955 e 1964-1965, devido a falhas sequenciais de fornecimento. A recuperação demonstrada após este segundo período é interrompida quando da ocorrência da crise hídrica do início dos anos 2000 e, novamente, em 2014-2015, quando a Resiliência sofre mais um decréscimo importante, não conseguindo recobrar um comportamento ascendente desde então, para ambos os cenários. Principalmente 
para o Cenário 2, a Crise Hídrica 2014-2015 impõe uma variação negativa da Resiliência de maior magnitude, isto por conta do menor número de falhas acumuladas deste cenário em relação ao Cenário 1.

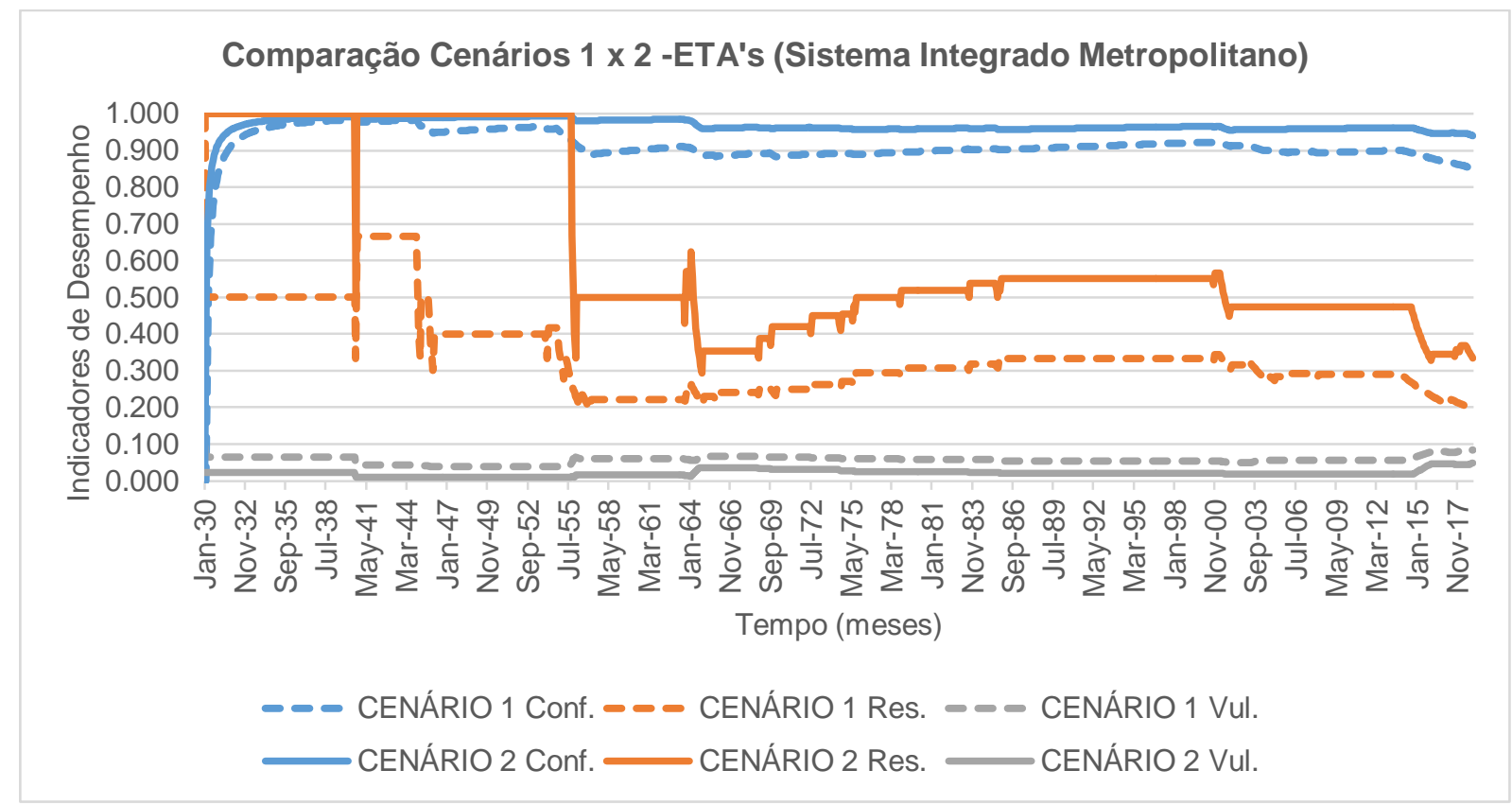

Figura 48: Acompanhamento dos indicadores de desempenho para o fornecimento global de água das ETA's do Sistema Integrado Metropolitano. Comparação entre os Cenários 1 e 2.

De maneira geral, os novos aportes de água decorrentes das obras de segurança hídrica provocaram um acréscimo do armazenamento global de água nos reservatórios do SIM, como se verifica na Figura 49. 


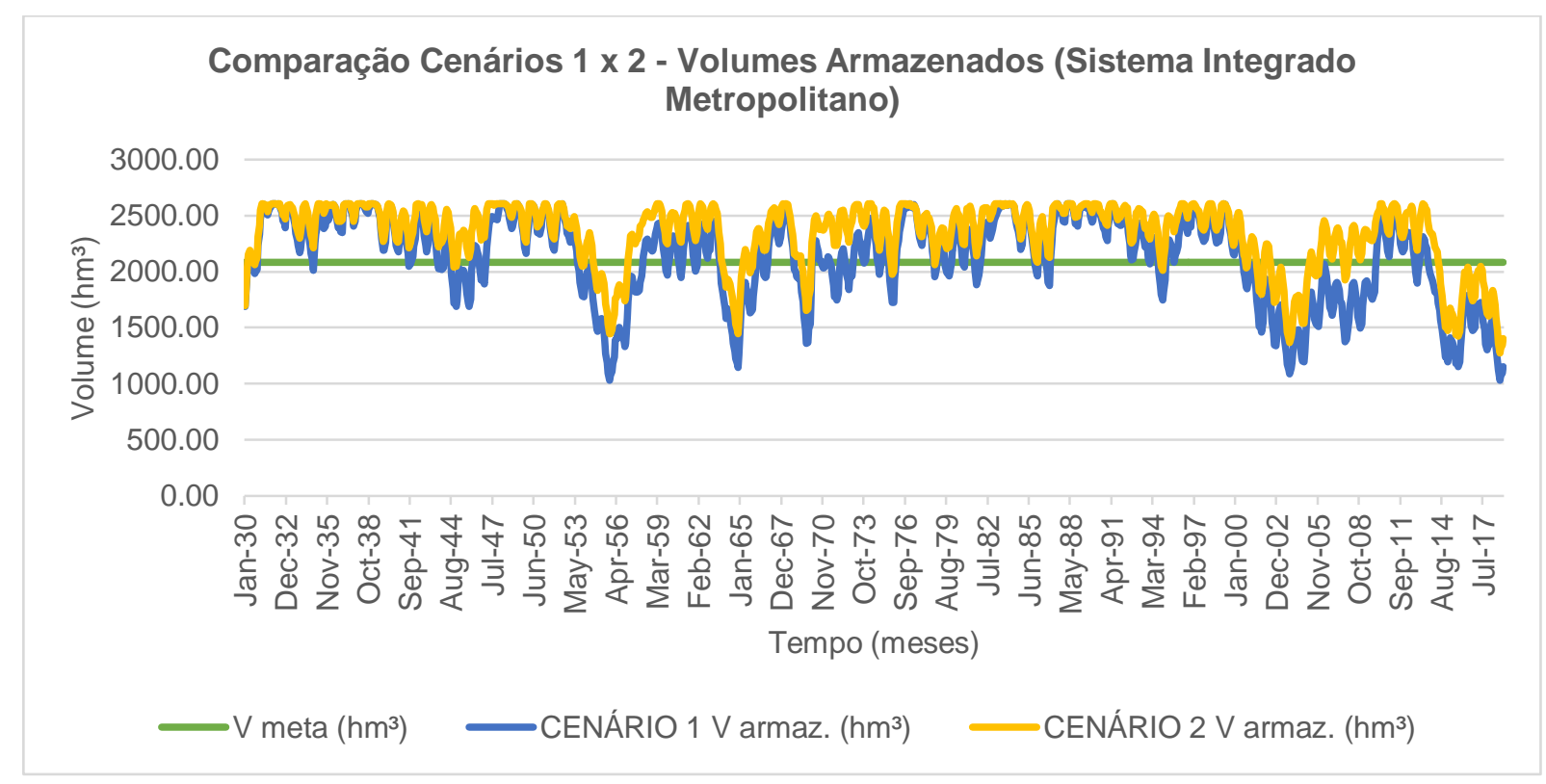

Figura 49: Volumes armazenados totais e Volume-meta para o Sistema Integrado Metropolitano nos Cenários 1 e 2.

O aumento do volume médio armazenado no sistema como um todo reduziu principalmente o número de condições insatisfatórias de armazenamento e, assim, gerou resultados positivos diretos notadamente em termos de Confiabilidade. Neste critério, os ganhos foram mensurados em $31,4 \%$ a favor do Cenário 2 (Figura 50). À exceção dos 25 primeiros anos da série, os resultados de Resiliência dos reservatórios do SIM pouco se diferenciaram ao final da série, ficando em 0,076 no Cenário 1 e 0,087 no Cenário 2. Novamente a primeira crise importante da série, em 1954-1955, provocou a perda de Resiliência do Cenário 2 a patamares próximo do Cenário 1. Após este evento, o sistema não passou por eventos de rápida recuperação de condições insatisfatórias que resultassem na elevação do desempenho em Resiliência.

Assim como no desempenho geral das ETA's em termos de abastecimento, a Vulnerabilidade dos reservatórios do SIM se manteve em patamares reduzidos, sofrendo acréscimos sensíveis após eventos de crise hídrica, mas que pouco afetaram o comportamento geral das curvas. Ao final da série, a Vulnerabilidade dos reservatórios foi de 0,175 para o Cenário 1 e 0,134 para o Cenário 2, demonstrando a baixa Vulnerabilidade global do SIM para ambos os cenários. Os déficits médios esperados de armazenamento em relação ao volume-meta ( $80 \%$ do volume útil), para os Cenários 1 e 2, são da ordem de 17,5\% e 13,4\%, respectivamente. 


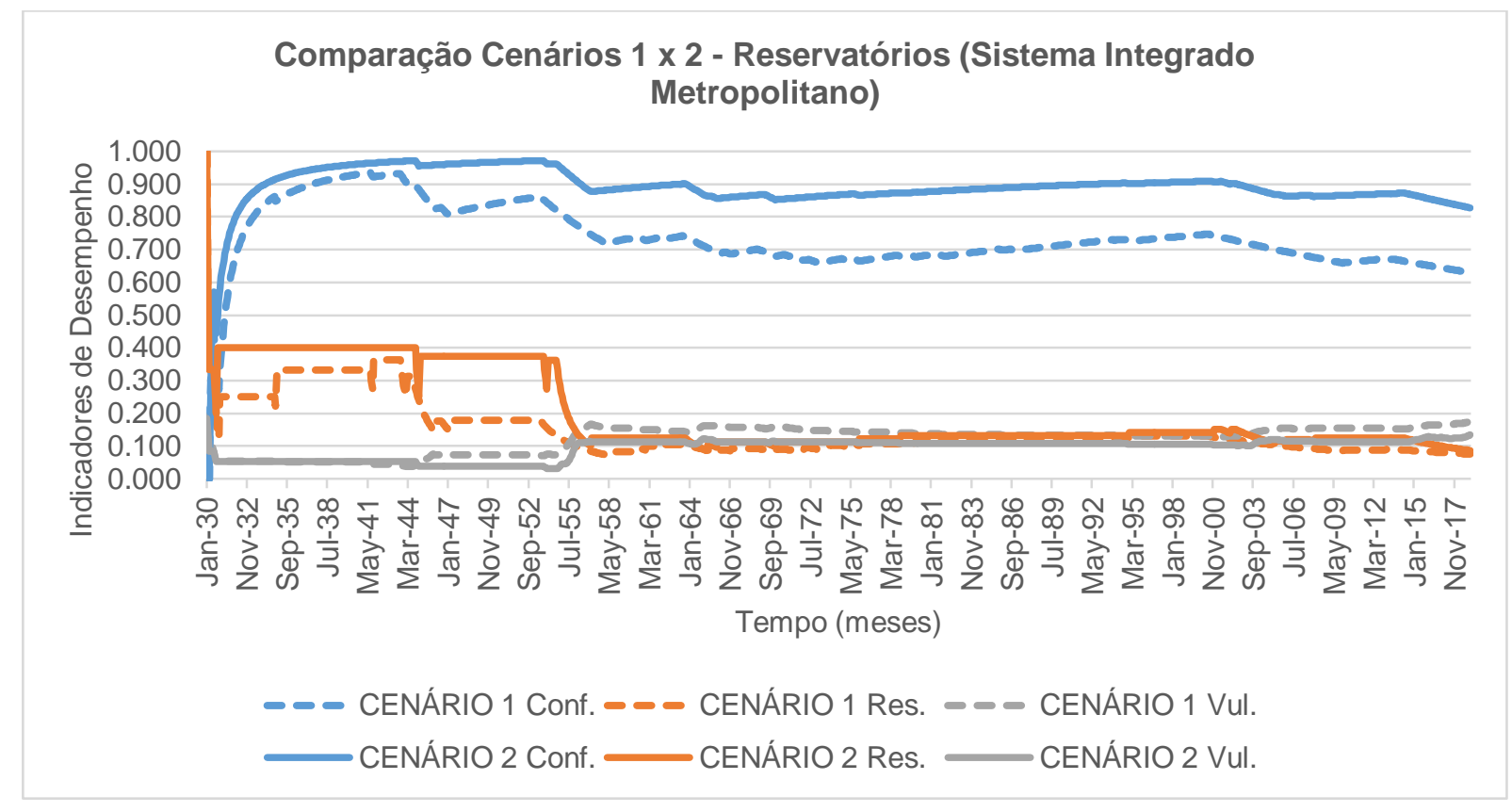

Figura 50: Acompanhamento dos indicadores de desempenho para o armazenamento global dos reservatórios do Sistema Integrado Metropolitano. Comparação entre os Cenários 1 e 2.

A Figura 51 abaixo demonstra a evolução dos Índices de Sustentabilidade global do Sistema Integrado Metropolitano ao longo do tempo para os Cenários 1 e 2.

Verificou-se que a combinação das 4 (quatro) obras de incremento de segurança hídrica: interligação Jaguari-Atibainha, reversão do Rio Guaió para o Reservatório Taiaçupeba, transposição Rio Grande para o Reservatório Taiaçupeba e transferência do Braço do Rio Pequeno para o Rio Grande, resultaram em um ganho global de desempenho para o SIM de 20,6\%. O Índice de Sustentabilidade subiu de 0,427 no Cenário 1 para 0,515 no Cenário 2. O Índice de Sustentabilidade Ponderado (ISP) também demonstrou o ganho global que as 4 (quatro) obras trouxeram ao SIM. Para este índice, os ganhos registrados foram da ordem de 13,6\%, o ISP passou de 0,487 no Cenário 1 para 0,553 para o Cenário 2.

Principalmente os ganhos de desempenho anotados para os Sistemas Alto Tietê e Cantareira, que em conjunto correspondem a aproximadamente $60 \%$ do desempenho do SIM, fizeram com que os valores do ISP ficassem superiores aos calculados diretamente para pelo IS. 


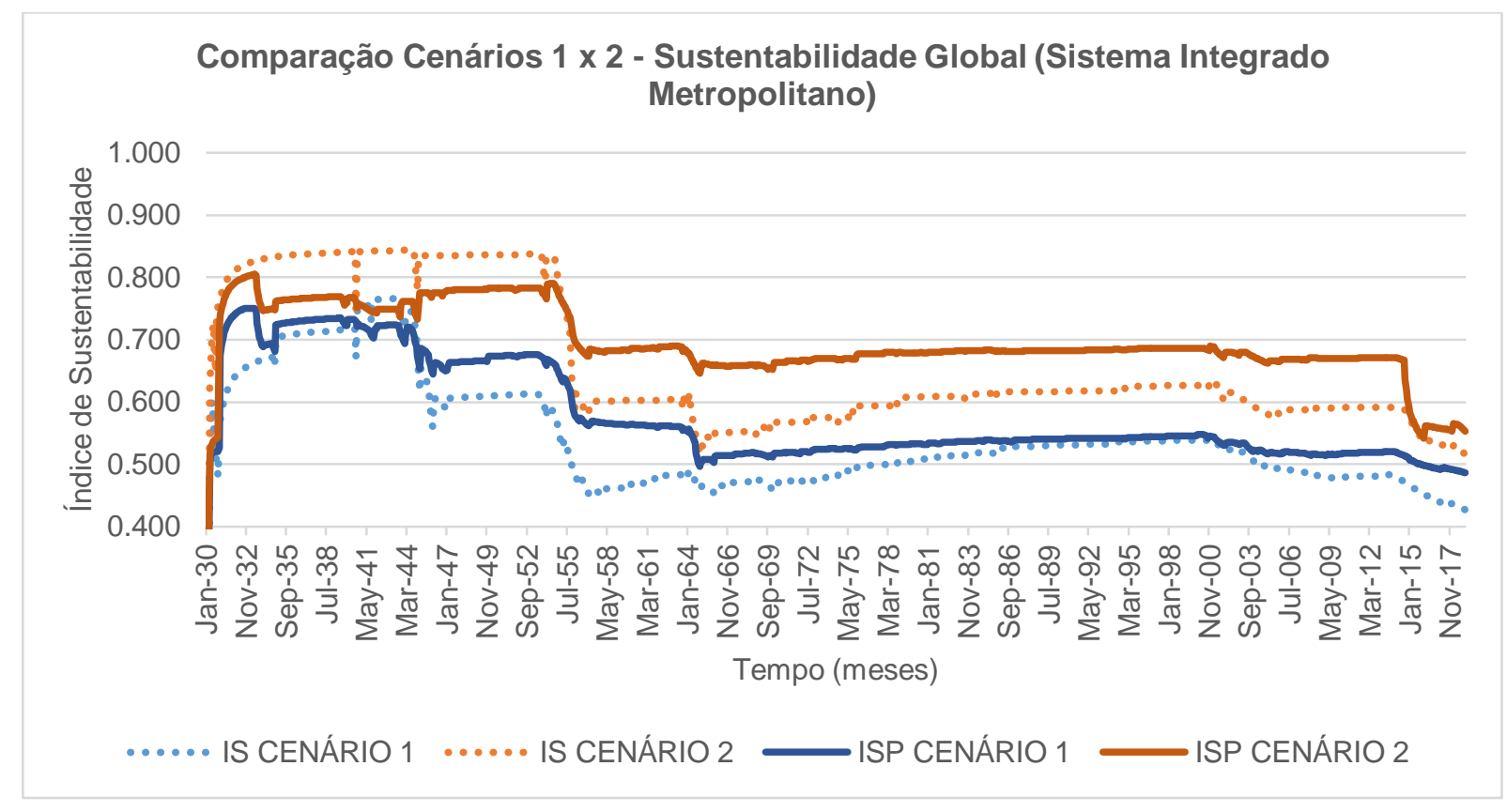

Figura 51: Acompanhamento do Índice de Sustentabilidade global do Sistema Integrado Metropolitano. Comparação entre os Cenários 1 e 2.

Ressalta-se, por fim, que mesmo que não tenham sido afetados diretamente pelas obras de novos aportes de água, os resultados de desempenho dos Sistemas Guarapiranga, Cotia e São Lourenço, fizeram parte dos cálculos dos Índices de Sustentabilidade global do SIM.

\subsection{BLOCO 2 - COMPARAÇÃO DOS CENÁRIOS 2 E 3}

O Bloco 2 de resultados tem como intuito a avaliação dos ganhos e perdas de desempenho de cada um dos sistemas produtores de água do SIM a partir da integração de suas demandas de abastecimento, conforme apresentado na Matriz de Integração da seção 6 deste trabalho.

Como forma de respaldar a análise de desempenho individual de cada sistema nas seções adiante, apresenta-se abaixo na Tabela 16 os resultados da integração da rede simulada no Cenário 3 . As curvas de permanência das vazões de entrada e saída de cada sistema, decorrentes da integração das demandas, também serão apresentadas individualmente por sistema nas seções adiante.

A matriz dos resultados de integração revela que o sistema produtor que mais se beneficiou do aporte das vazões de interligação, em termos absolutos, foi o Sistema 
Cantareira, com média de $1,653 \mathrm{~m} 3 / \mathrm{s}$, presentando $68,8 \%$ do total das vazões recebidas pelos sistemas. Em termos relativos, o Cantareira também foi sistema que recebeu as vazões médias mais altas em comparação à sua capacidade máxima de recepção, 13,3\%.

O Sistema Alto Tietê, por outro lado, foi o sistema que mais realizou empréstimos de água, com média de $0,712 \mathrm{~m} 3 / \mathrm{s}, 29,6 \%$ do total fornecido pelo conjunto dos sistemas, tendo como principal alvo o próprio Sistema Cantareira, com vazões médias recebidas de $0,705 \mathrm{~m}^{3} / \mathrm{s}$.

Em termos relativos à vazão máxima de transferência, por pequena margem, o sistema que mais forneceu água no período simulado foi o Sistema São Lourenço, com média de $2,88 \mathrm{~m}^{3} / \mathrm{s} ; 16,1 \%$ de sua capacidade máxima compartilhamento, contra $15,3 \%$ do Sistema Alto Tietê. 
Tabela 16: Matriz de Interligação do Sistema Integrado Metropolitano - Resultados (Cenário 3)

\begin{tabular}{|c|c|c|c|c|c|c|c|c|c|c|}
\hline \multirow{2}{*}{ Origem } & \multicolumn{9}{|c|}{ Destino } & \multirow{2}{*}{ Médias } \\
\hline & Cantareira & Alto Tietê & Guarapiranga & S. Lourenço & Rio Grande & Rib. Estiva & Rio Claro & Alto Cotia & Baixo Cotia & \\
\hline Cantareira & & 0,216 & 0,252 & 0,000 & - & - & 0,024 & - & 0,000 & 0,492 \\
\hline Guarapiranga & 0,175 & - & & - & - & - & & 0,001 & - & 0,176 \\
\hline São Lourenço & 0,433 & - & - & . & . & & & 0,030 & - & 0,463 \\
\hline Rio Grande & - & - & - & - & & & 0,073 & - & 0,027 & 0,099 \\
\hline Rio Claro & 0,224 & 0,006 & - & & 0,054 & 0,007 & & - & - & 0,290 \\
\hline Alto Cotia & - & - & 0,031 & 0,008 & - & - & - & & - & 0,039 \\
\hline Baixo Cotia & 0,117 & - & - & 0,015 & - & - & - & - & & 0,132 \\
\hline Médias & 1,653 & 0,222 & 0,283 & 0,023 & 0,054 & 0,007 & 0,104 & 0,031 & 0,027 & - \\
\hline
\end{tabular}




\subsubsection{SISTEMA ALTO TIETÊ}

Do Cenário 2 para o Cenário 3, não foram verificadas alterações de desempenho no fornecimento de água para o Sistema Alto Tietê. Em ambos os cenários, não foram verificadas falhas de atendimento, de forma que os indicadores de Confiabilidade, Resiliência e Vulnerabilidade mantiveram seus valores máximos ideais, conforme apresentado na Figura 52 abaixo.

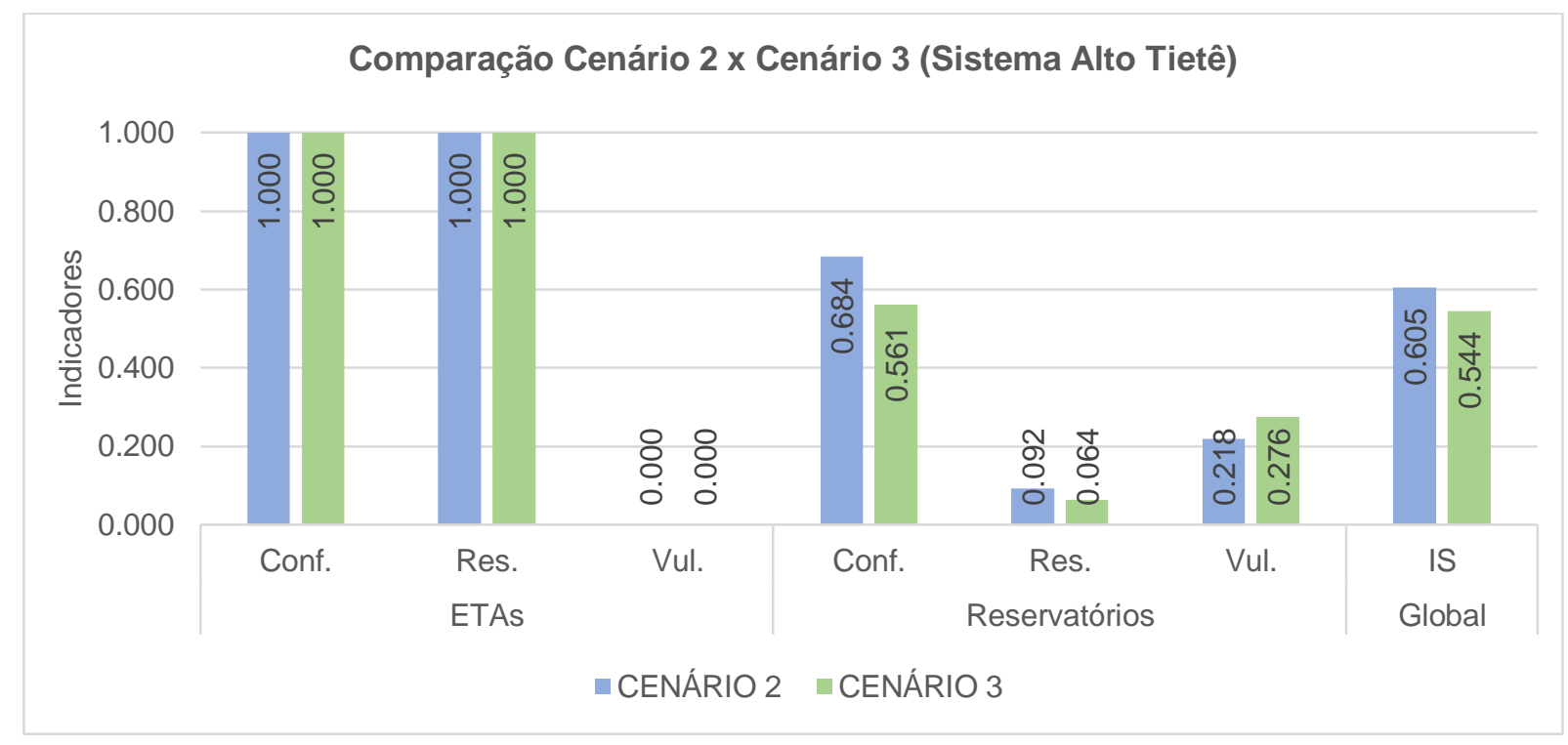

Figura 52: Resumo dos indicadores de desempenho e índice global de sustentabilidade para o Sistema Alto Tietê. Comparação Cenários 2 e 3.

O desempenho do Alto Tietê em relação ao seu armazenamento, por outro lado, foi claramente afetado pelo fato de que este foi o sistema que mais compartilhou água para os demais sistemas na rede integrada simulada no Cenário 3.

Conforme se verifica na Figura 53 abaixo, o Alto Tietê em menos de 10\% do tempo recebeu alguma vazão de contribuição dos demais sistemas do SIM. Ou seja, na quase totalidade do tempo, as demandas da ETA Taiaçupeba foram atendidas pela abstração da própria água armazenada no sistema. Em média, o Alto Tietê recebeu contribuições de 0,222 m³/s dos Sistemas Cantareira e Rio Claro. 


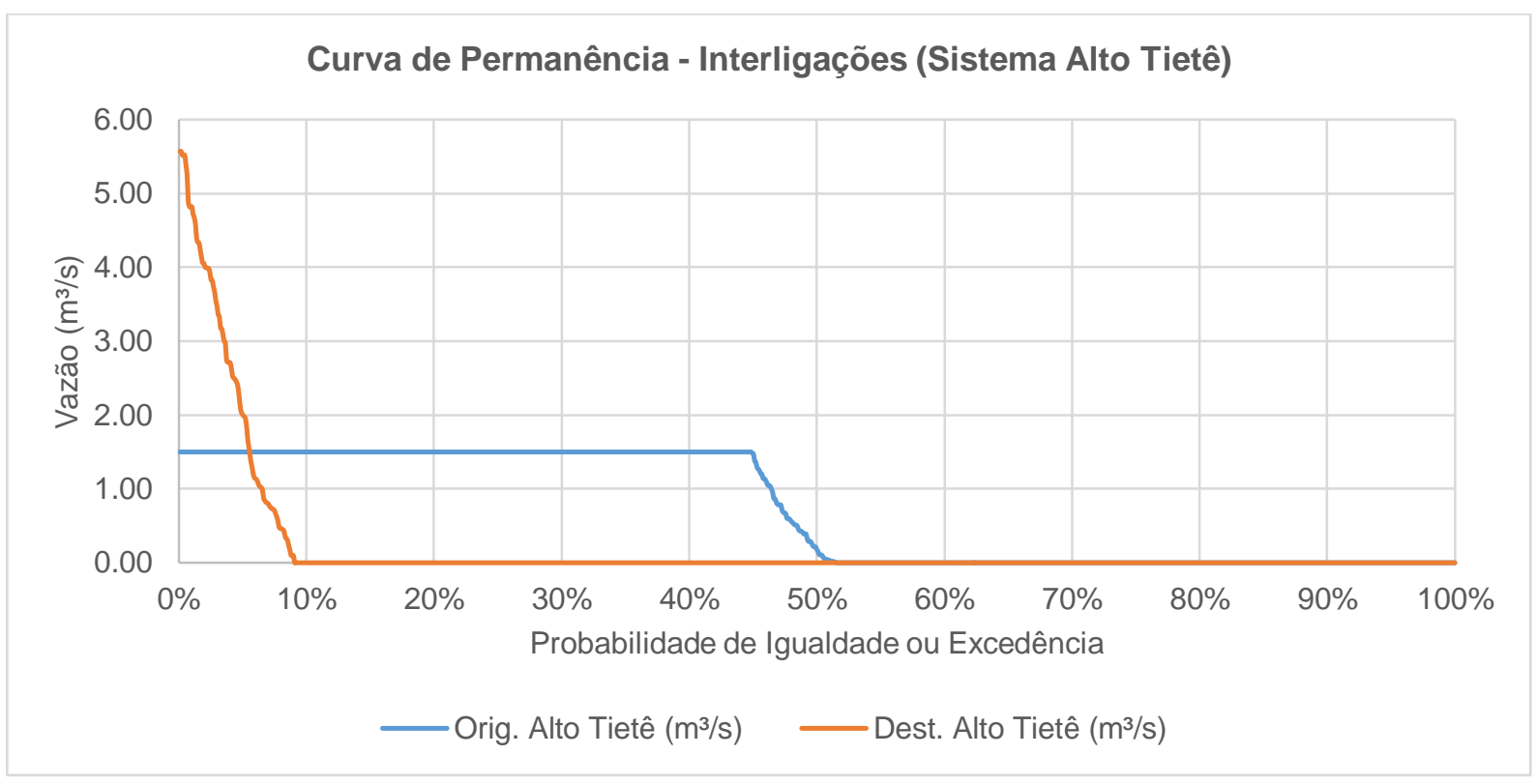

Figura 53: Curvas de permanência das vazões de interligação do Sistema Alto Tietê.

Em aproximadamente 45\% do tempo, o Sistema Alto Tietê forneceu uma vazão de $1,50 \mathrm{~m}^{3} / \mathrm{s}$ para 0 atendimento das demandas compartilhadas com os Sistemas Cantareira e Rio Claro, o que resultou na redução do nível médio de armazenamento de seus reservatórios no Cenário 3 em comparação com o Cenário 2, conforme observado abaixo na Figura 54.

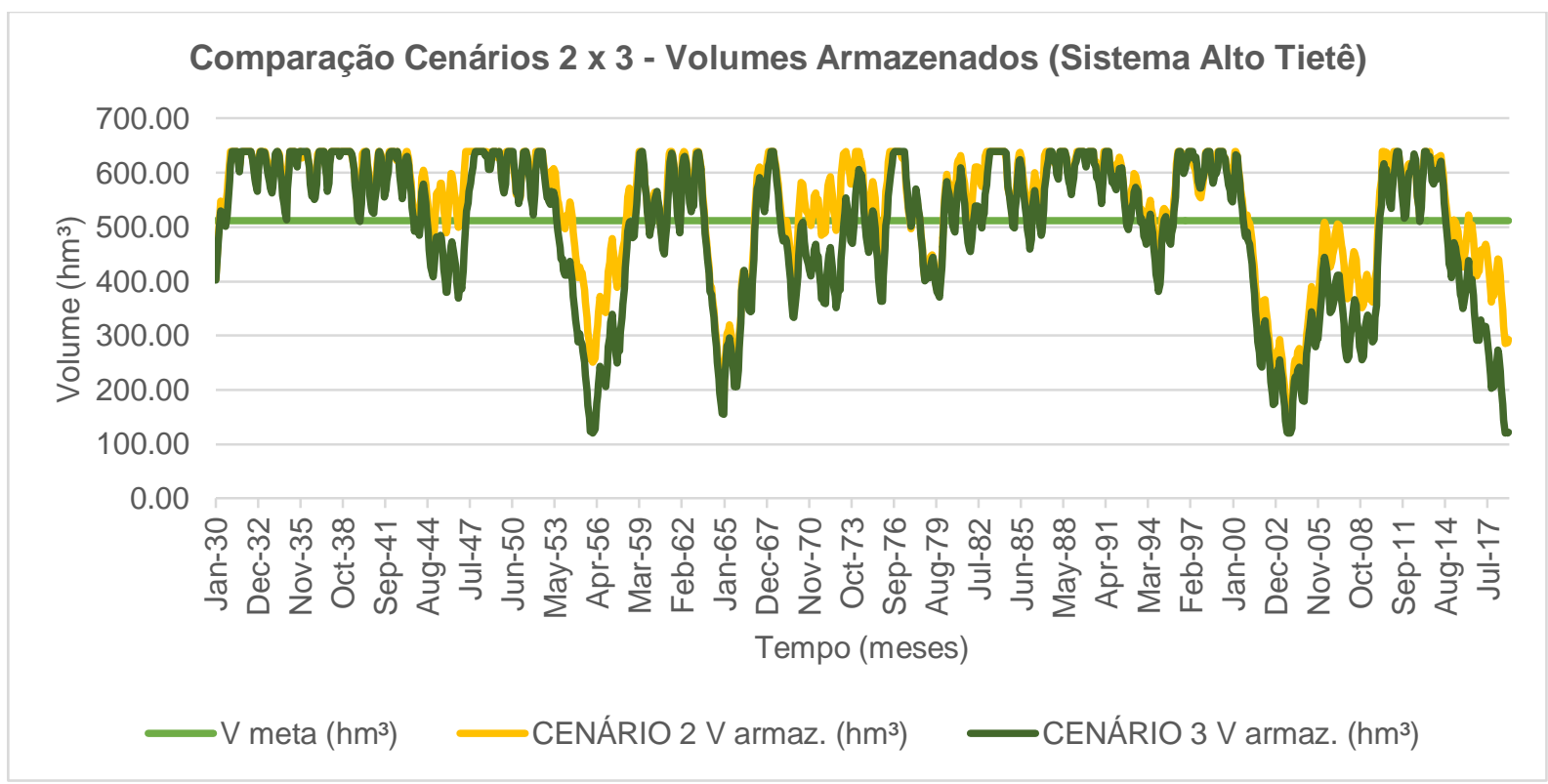

Figura 54: Volumes armazenados e Volume-meta para o Sistema Alto Tietê nos Cenários 2 e 3. 
A menor reservação do Alto Tietê ao longo da série resultou em um aumento das condições insatisfatórias de armazenamento, o que provocou a queda da Confiabilidade dos reservatórios de 0,684 no Cenário 2 para 0,561 no Cenário 3. Esta mesma perda de desempenho também foi verificada nos indicadores de Resiliência e Vulnerabilidade. Enquanto no Cenário 2, queda na Resiliência ocorreu no período de baixas afluências do Alto Tietê em 1954-1955, no Cenário 3 este comportamento foi antecipado para o período de 1944 a 1947, em que o sistema registrou 32 meses consecutivos de condições insatisfatórias. Neste período, o Alto Tietê compartilhou uma vazão média de $1,0 \mathrm{~m}$ 3/s com os Sistemas Rio Claro e Cantareira. Ao final da série, a Resiliência ficou em 0,092 para o Cenário 2 e 0,064 para o Cenário 3 .

$O$ indicador de Vulnerabilidade também sofreu uma pequena perda de desempenho, devido ao aumento dos déficits médios de armazenamento do Sistema Alto Tietê em relação à meta de $80 \%$. No Cenário 2 a Vulnerabilidade ao final da série foi de 0,218 , enquanto para o Cenário 3 , de 0,276 . O perceptível descolamento das curvas de Vulnerabilidade, e o consequente aumento deste indicador no Cenário 3 , ocorre justamente após períodos em que o Sistema Alto Tietê mais precisou compartilhar água para atendimento das necessidades dos demais sistemas: em 1944-1947, 1954-1955 e do início dos anos 2000 em diante (Figura 55).

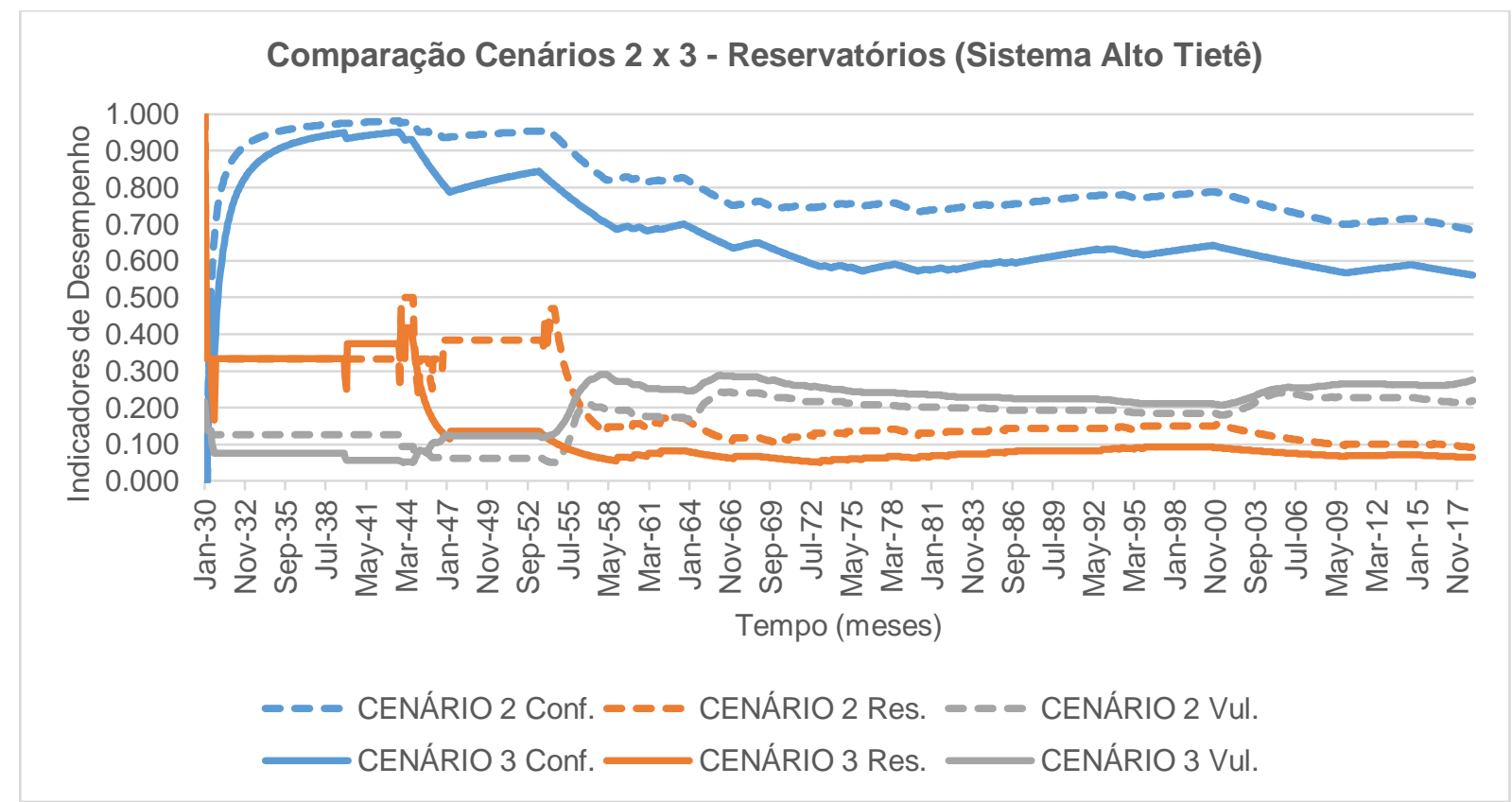

Figura 55: Acompanhamento dos indicadores de desempenho para os reservatórios do Sistema Alto Tietê. Comparação entre os Cenários 2 e 3. 
Por fim, a Figura 56 a seguir apresenta os resultados do Índice de Sustentabilidade do Sistema Alto Tietê para os Cenários 2 e 3. Como há de se notar, apesar dos valores máximos de desempenho de fornecimento para ambos os cenários, o Cenário 3 foi afetado pelo aumento das condições insatisfatórias de armazenamento, fazendo com que ao final da série, a sustentabilidade global do Alto Tietê caísse em $10 \%$ se comparada ao Cenário 2, saindo de 0,605 para 0,544 .

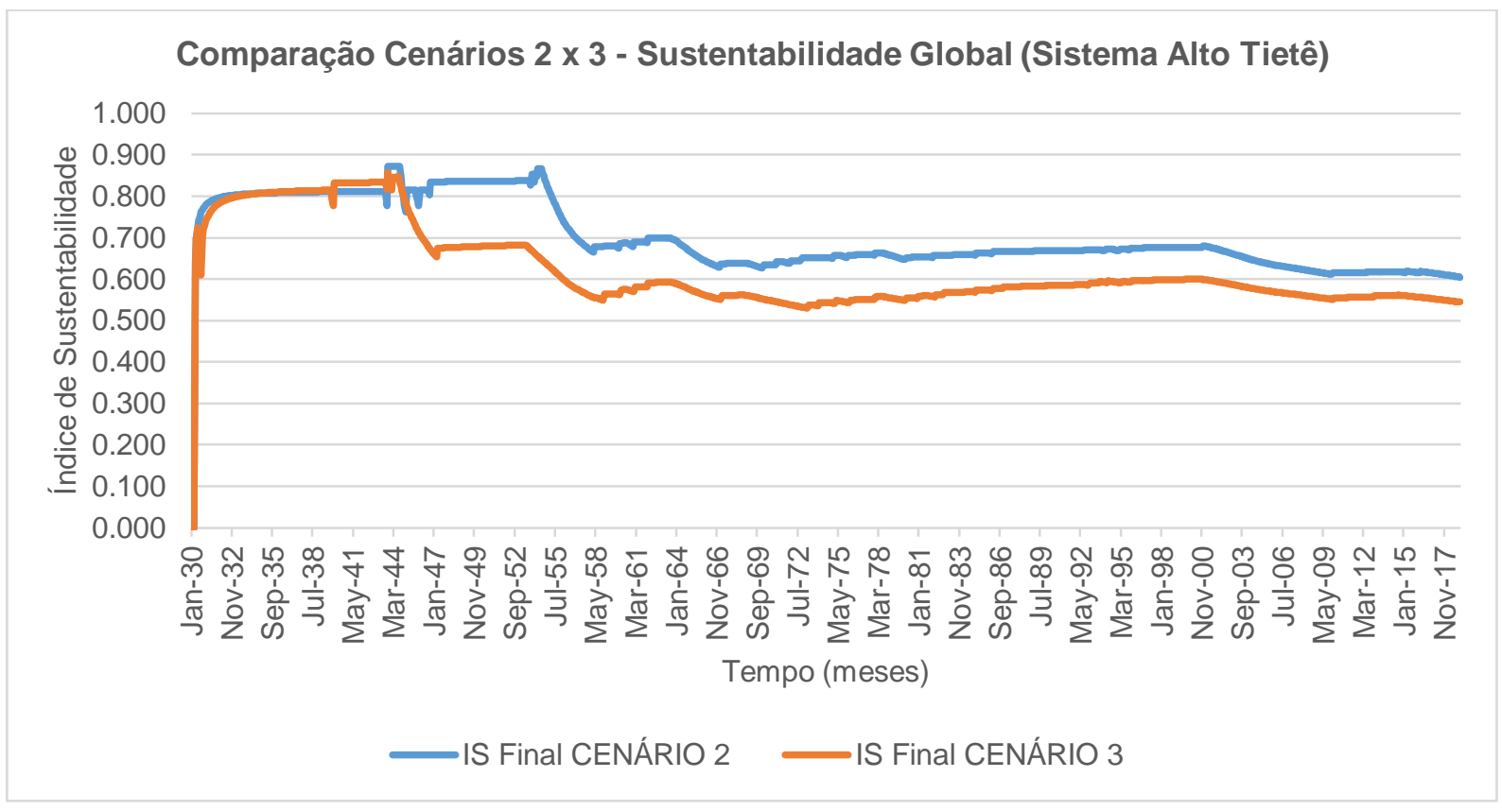

Figura 56: Acompanhamento do Índice de Sustentabilidade global do Sistema Alto Tietê. Comparação entre os Cenários 2 e 3.

\subsubsection{SISTEMA COTIA}

O Sistema Cotia é subdividido entre Alto e Baixo Cotia, tendo cada uma destas subdivisões um ponto de fornecimento de água específico para a avaliação de desempenho. Conforme se apresenta no resumo dos resultados de desempenho na Figura 57, a ETA Baixo Cotia não apresentou falhas de atendimento no período avaliado em nenhum dos 2 cenários de simulação, assim, seus respectivos indicadores mantiveram-se em seus valores máximos ideais. 


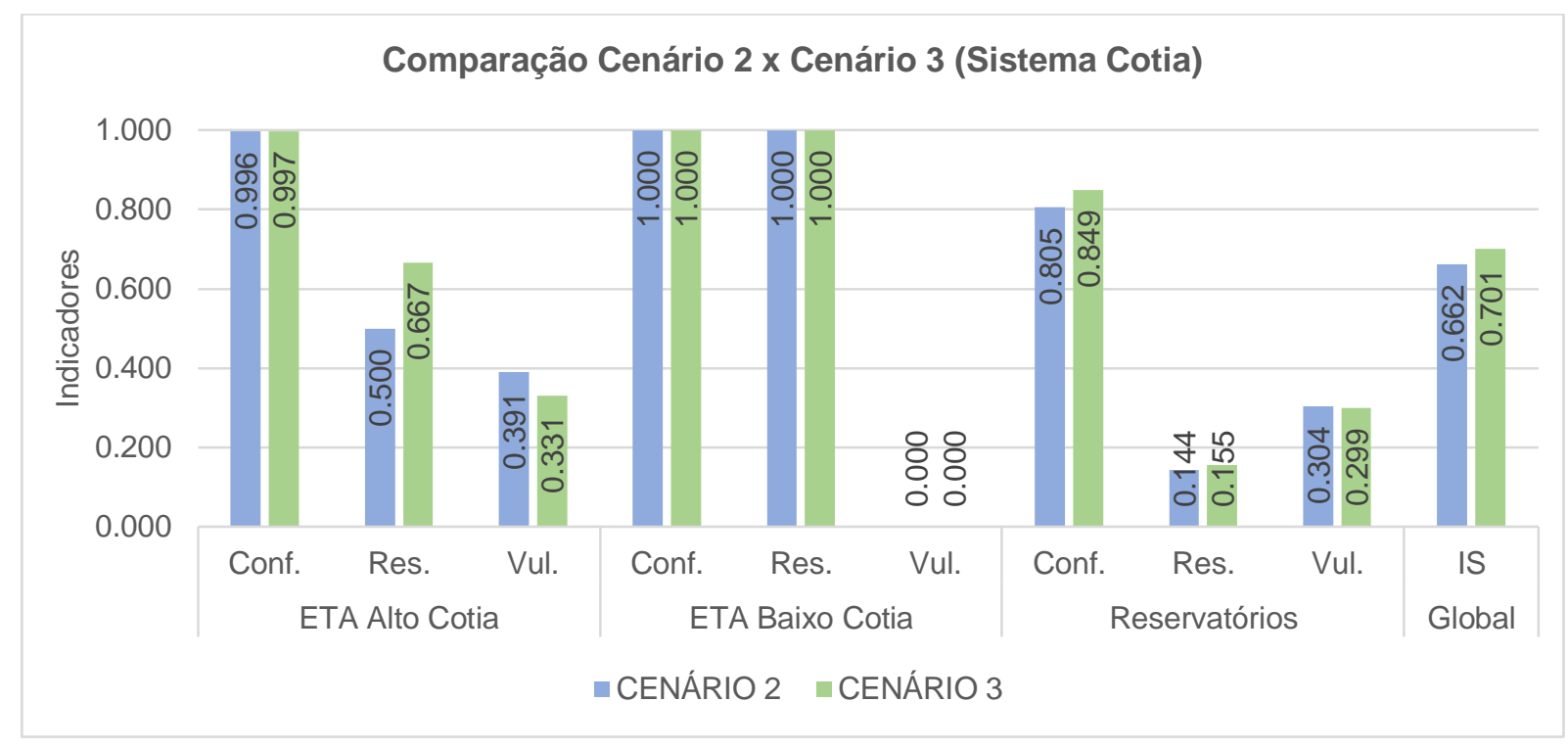

Figura 57: Resumo dos indicadores de desempenho e índice global de sustentabilidade para o Sistema Cotia. Comparação Cenários 2 e 3.

$\mathrm{Na}$ simulação da rede integrada (Cenário 3), em média o Alto Cotia compartilhou uma vazão de $0,039 \mathrm{~m} / \mathrm{s}$ com os Sistemas Guarapiranga e São Lourenço. E recebeu $0,222 \mathrm{~m} 3 / \mathrm{s}$, sendo aproximadamente $98 \%$ desta vazão oriunda do Cantareira. Enquanto isto, o Baixo Cotia forneceu em 100\% do período simulado vazões iguais ou superiores a $0,10 \mathrm{~m}^{3} / \mathrm{s}$ para os Sistemas São Lourenço e Cantareira (Figura 58).

Apesar de já no Cenário 2 o Baixo Cotia registrar o desempenho máximo nos indicadores avaliados, o sistema também registra o recebimento de vazões de compartilhamento. O Baixo Cotia recebe a transferência do Sistema Rio Grande quando há a necessidade de fornecer vazões superiores a $0,105 \mathrm{~m}^{3} / \mathrm{s}$. Nestes casos, o sistema opta por fornecer a máxima vazão, obedecendo sua outorga, e o atendimento ao seu próprio ponto de demanda compartilhada é complementado pelas vazões que chegam do Rio Grande. 


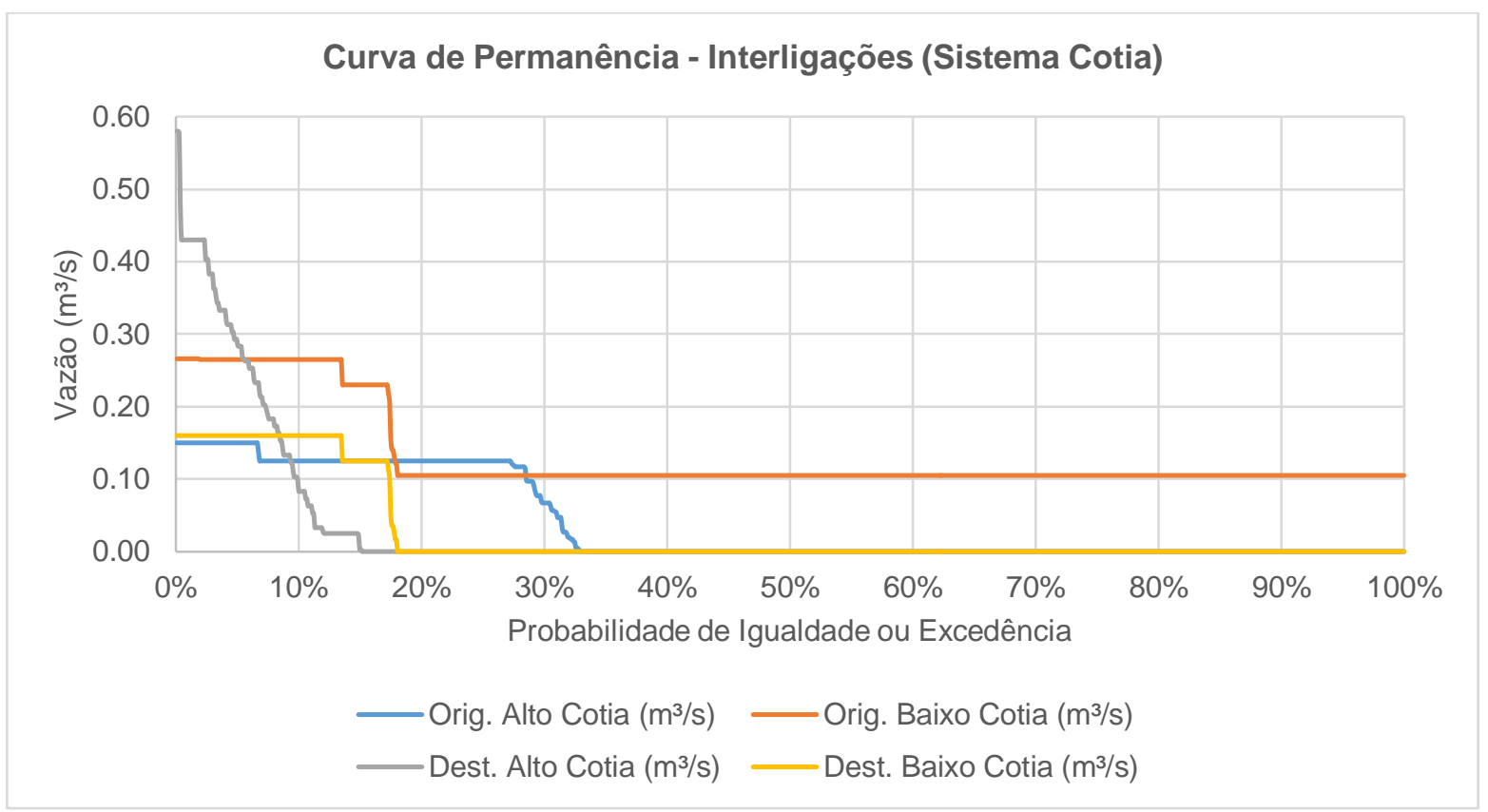

Figura 58: Curvas de permanência das vazões de interligação do Sistema Cotia.

A integração proposta no Cenário 3 resultou na diminuição pontual das falhas de fornecimento no Alto Tietê, notadamente retardando em 1 mês as falhas verificadas na Crise de 2014-2015, como pode ser visto na Figura 59 abaixo.

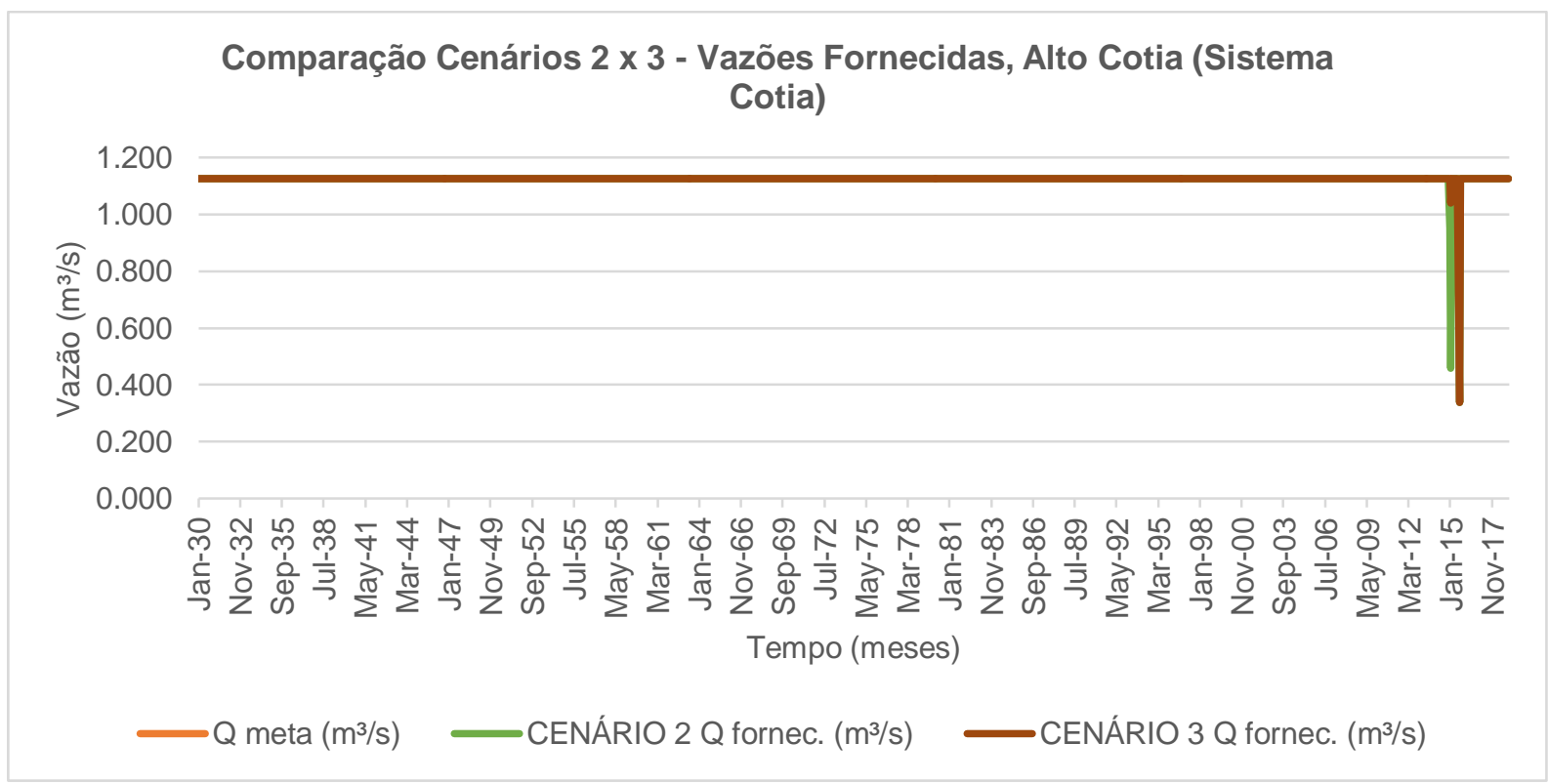

Figura 59: Vazões fornecidas e Vazão-meta no ponto de demanda "ETA Alto Cotia" nos Cenários 2 e 3. 
A Confiabilidade já elevada no Cenário 2 de 0,996 sofreu um ligeiro aumento para 0,997 no Cenário 3. A ligeira redução do número de falhas afetou em maior escala a Resiliência, que subiu de 0,500 no Cenário 2 para 0,667 no Cenário 3, e a Vulnerabilidade que reduziu de 0,391 para 0,331.

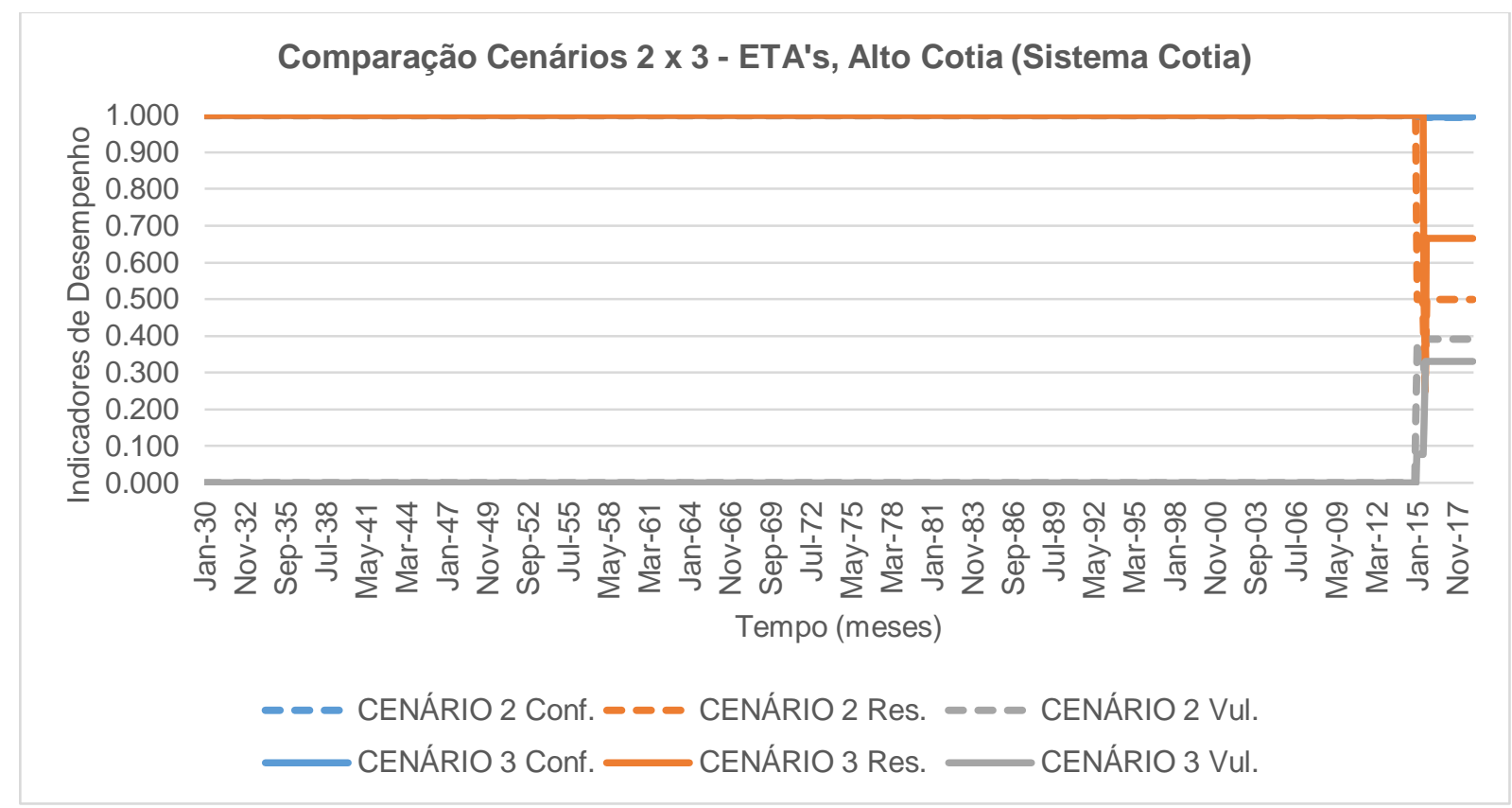

Figura 60: Acompanhamento dos indicadores de desempenho no ponto de demanda "ETA Alto Cotia". Comparação entre os Cenários 2 e 3.

As integrações da rede do Cenário 3 foram benéficas para o armazenamento de água do Sistema Cotia. O maior volume de compartilhamento de água ocorreu através da ETA Baixo Cotia, que capta água da barragem Isolina. Como esta não possui função de reservação, este fato não gera influência no armazenamento de água do sistema como um todo. Por outro lado, as vazões que o Sistema Cotia recebeu das interligações foi superior no ponto de demanda compartilhada da ETA Alto Cotia que, por sua vez, reduziu ligeiramente sua captação das represas em série Cachoeira da Graça e Pedro Breicht e, assim, permitiu o sensível aumento do armazenamento global de água no Cenário 3 em comparação ao Cenário 2 (Figura $61)$. 


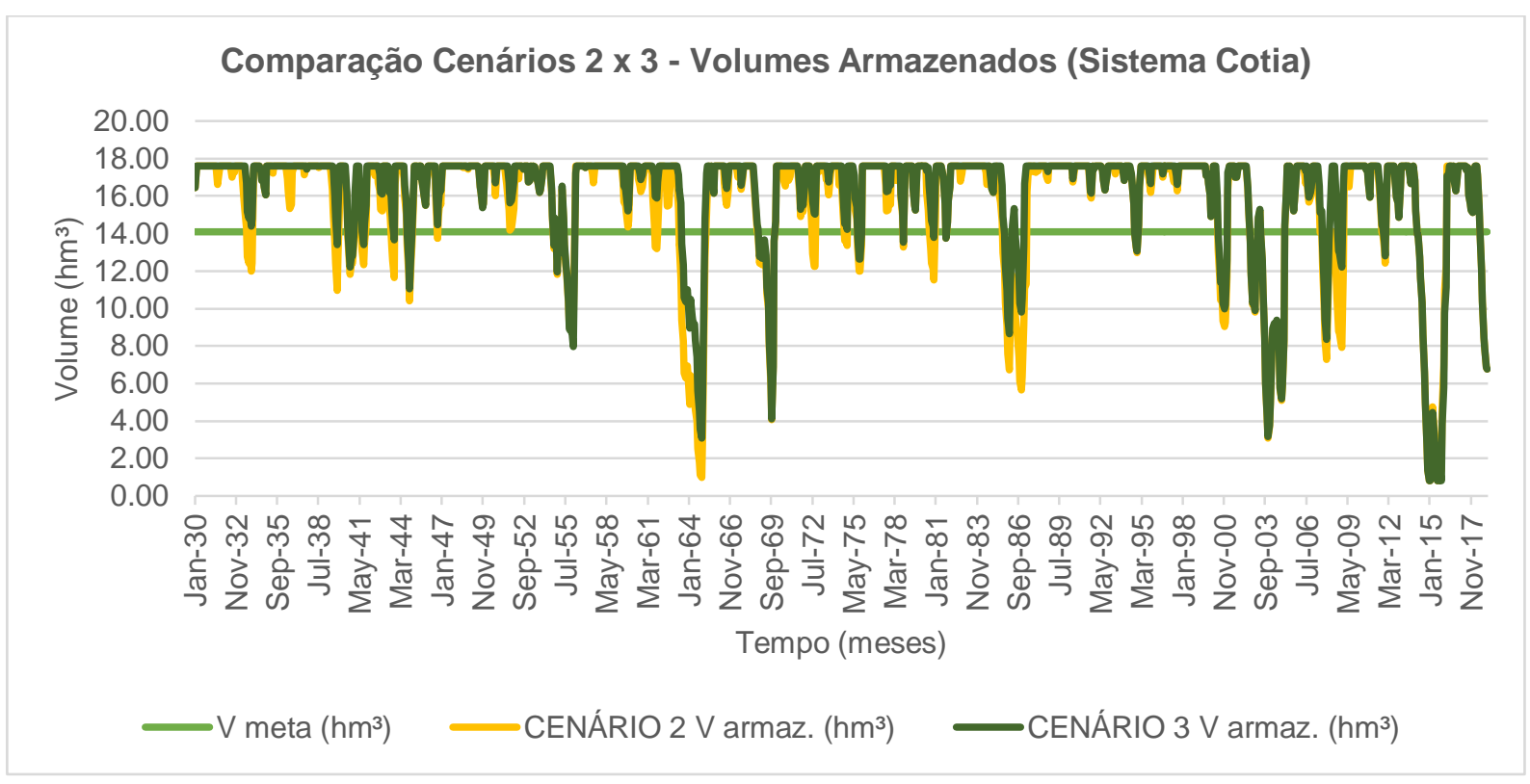

Figura 61: Volumes armazenados e Volume-meta para o Sistema Cotia nos Cenários 2 e 3.

Conforme se observa na Figura 62, mesmo que pequeno, o aumento médio da reservação do Sistema Cotia trouxe um ganho de desempenho dos indicadores. A Confiabilidade passou de 0,805 no Cenário 2 para 0,849 no Cenário 3. A Resiliência subiu de 0,144 para 0,155, e a Vulnerabilidade foi reduzida de 0,304 para 0,299.

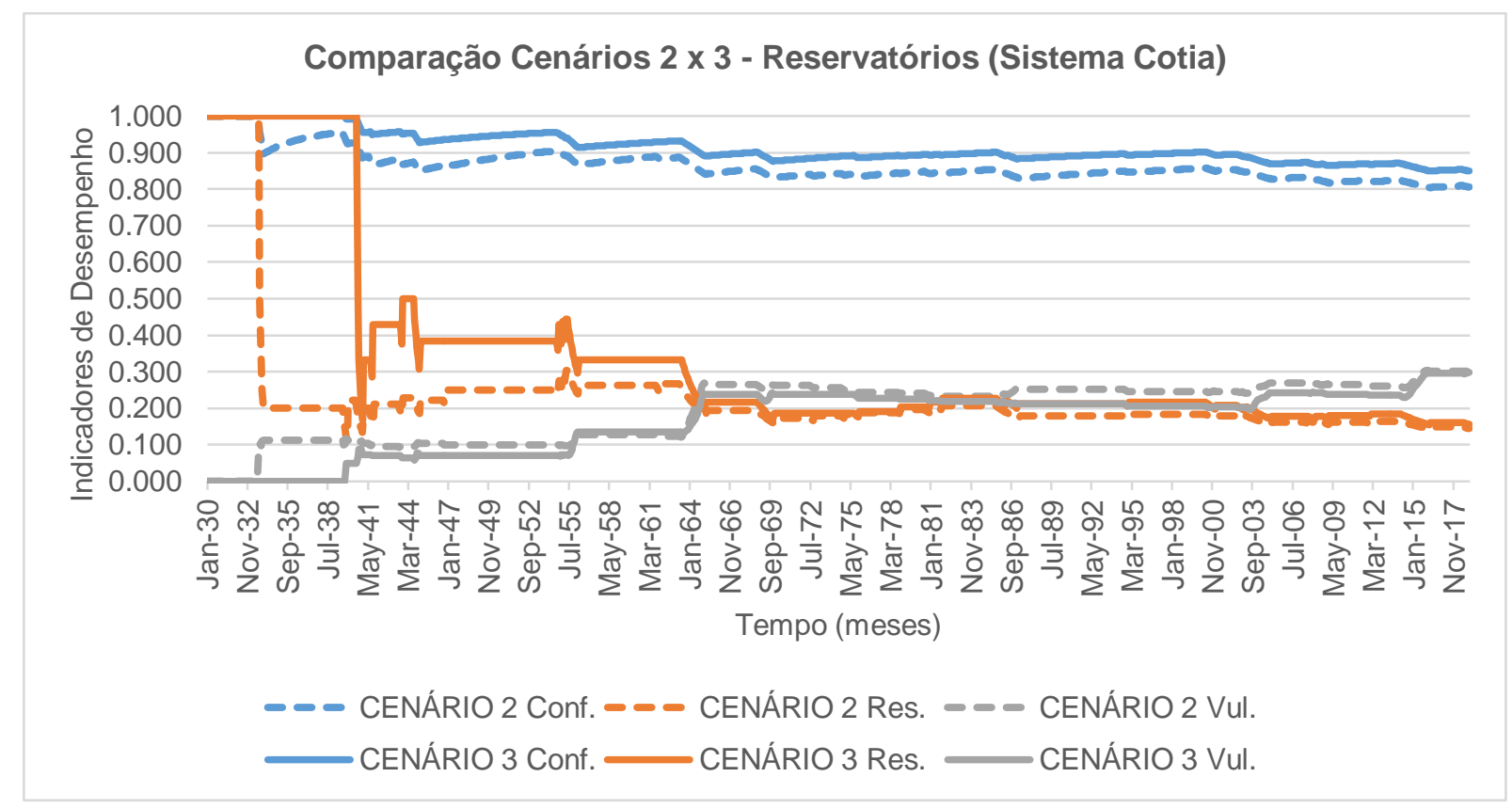

Figura 62: Acompanhamento dos indicadores de desempenho para os reservatórios do Sistema Cotia. Comparação entre os Cenários 2 e 3. 
A Figura 63 a seguir apresenta os resultados do Índice de Sustentabilidade do Sistema Cotia para os Cenários 2 e 3 . A sustentabilidade global do sistema foi principalmente influenciada de maneira positiva pelos ganhos de desempenho da Resiliência e Vulnerabilidade no atendimento às demandas da ETA Alto Cotia. Ao final da série, os índices foram de 0,662 para o Cenário 2 e 0,701 para o Cenário 3. Os ganhos globais da integração da rede foram anotados em aproximadamente $6 \%$.

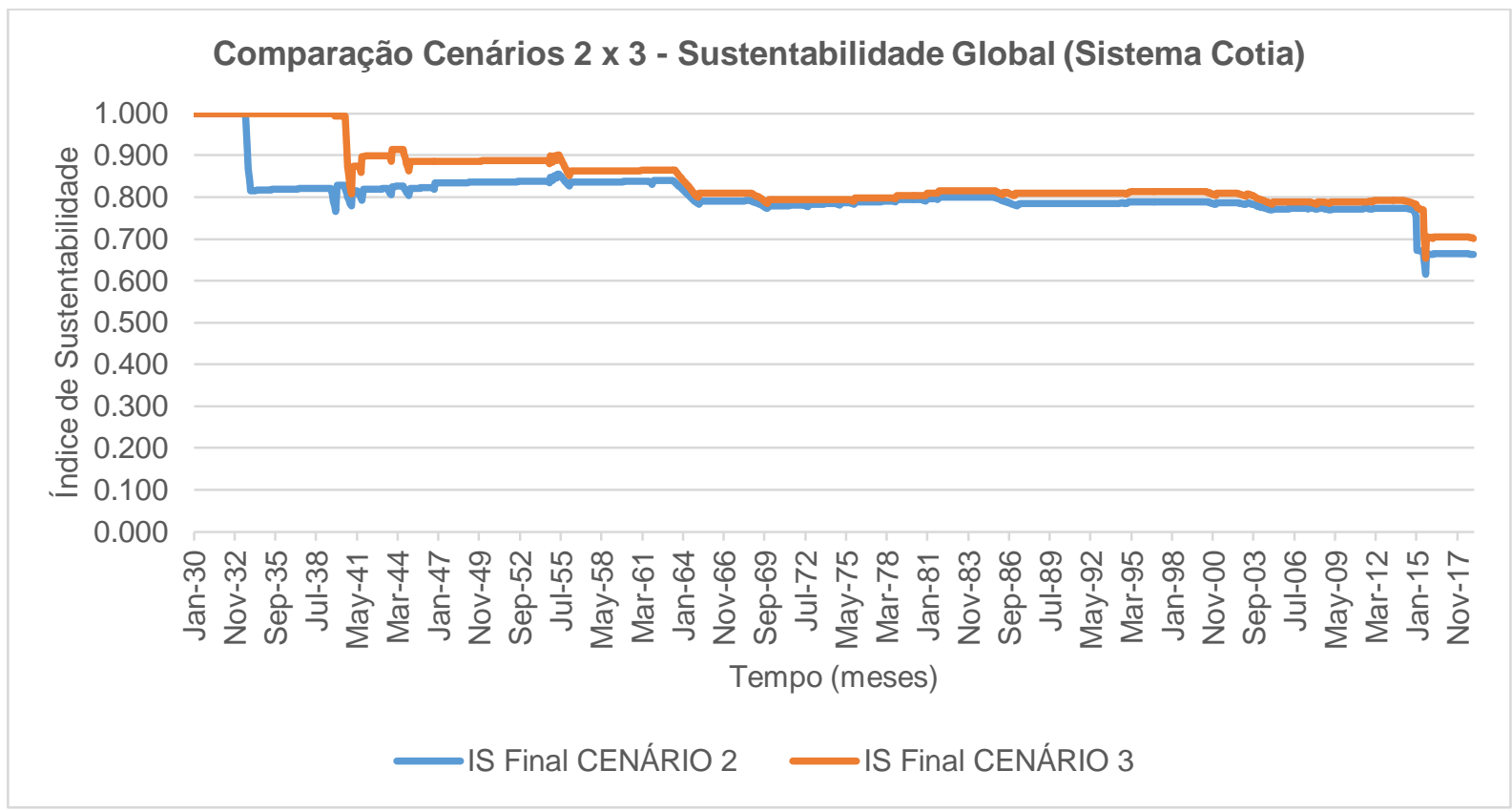

Figura 63: Acompanhamento do Índice de Sustentabilidade global do Sistema Cotia. Comparação entre os Cenários 2 e 3.

\subsubsection{SISTEMA CANTAREIRA}

A rede integrada simulada no Cenário 3 trouxe para o Sistema Cantareira ganhos de desempenho nos indicadores de Confiabilidade, Resiliência e Vulnerabilidade em relação ao Cenário 2, tanto sob o ponto de atendimento às demandas da ETA Guaraú, quanto dos níveis de armazenamento de água dos reservatórios. Os ganhos de desempenho consequentemente resultaram na melhora do Índice de Sustentabilidade global do Cantareira, conforme resumo apresentado na Figura 64 a seguir. 


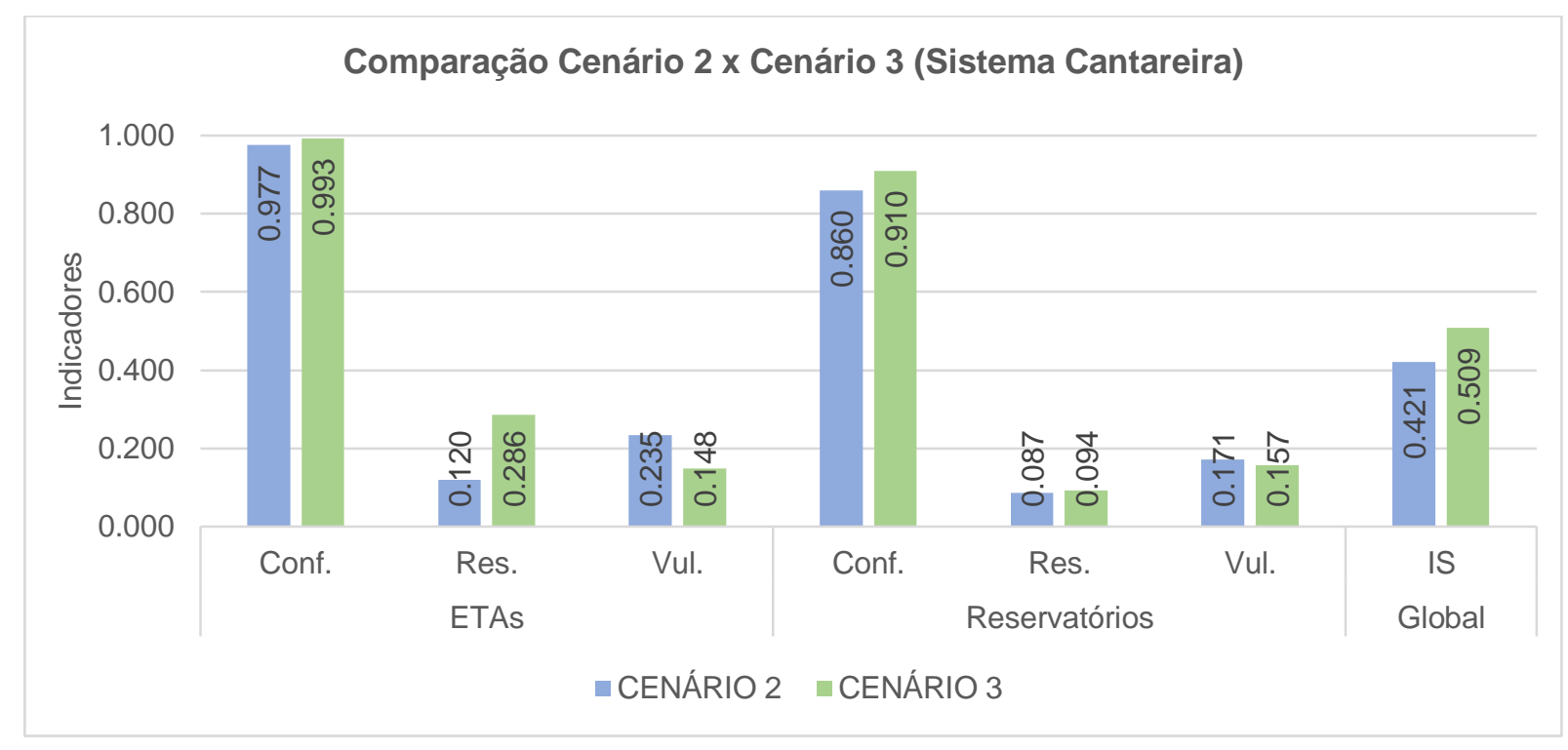

Figura 64: Resumo dos indicadores de desempenho e índice global de sustentabilidade para o Sistema Cantareira. Comparação Cenários 2 e 3.

A integração da rede por meio do compartilhamento de demandas gerou ao Cantareira o recebimento de vazões médias de $1,65 \mathrm{~m} 3 / \mathrm{s}$, tendo sido este o sistema que mais foi beneficiado pela integração. Em aproximadamente $45 \%$ do tempo, o sistema recebeu uma contribuição maior que $2,00 \mathrm{~m} / \mathrm{s}$ dos demais sistemas produtores do SIM (Alto Tietê, Guarapiranga, São Lourenço, Rio Claro e Cotia) para atendimento do seu ponto de demanda compartilhada (Figura 65).

No período, o Sistema Cantareira ainda foi capaz de contribuir com o fornecimento de vazões médias de aproximadamente $0,50 \mathrm{~m} / \mathrm{s}$ para 0 atendimento de demandas compartilhadas com outros sistemas, notadamente para o Alto Tietê e Guarapiranga. 


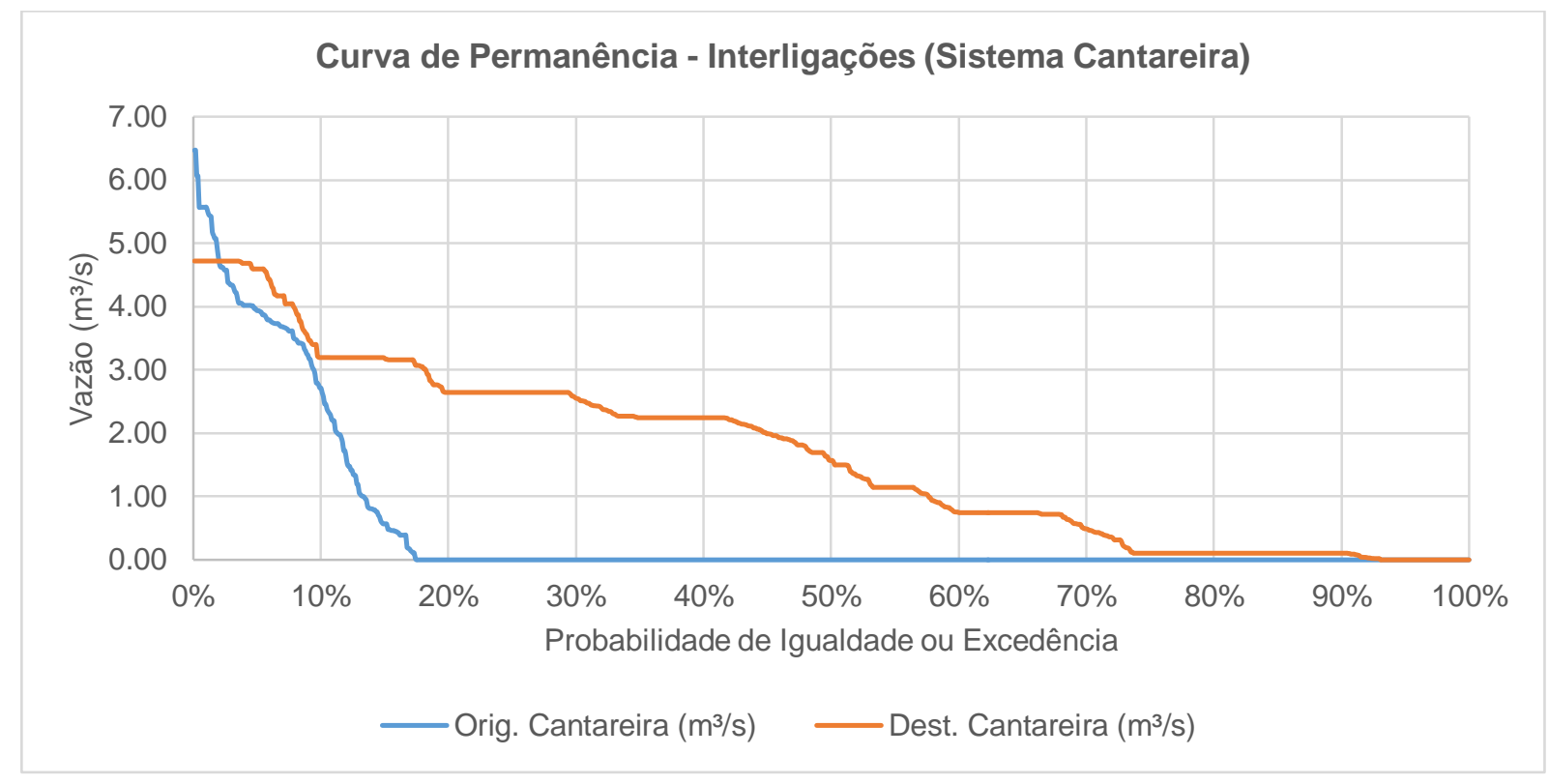

Figura 65: Curvas de permanência das vazões de interligação do Sistema Cantareira.

A integração da rede trouxe uma redução ainda maior no número de falhas de atendimento da ETA Guaraú, que ficaram restritas ao período da Crise Hídrica de 2014-2015, porém com uma menor magnitude de déficits de comparado ao Cenário 2 (Figura 66).

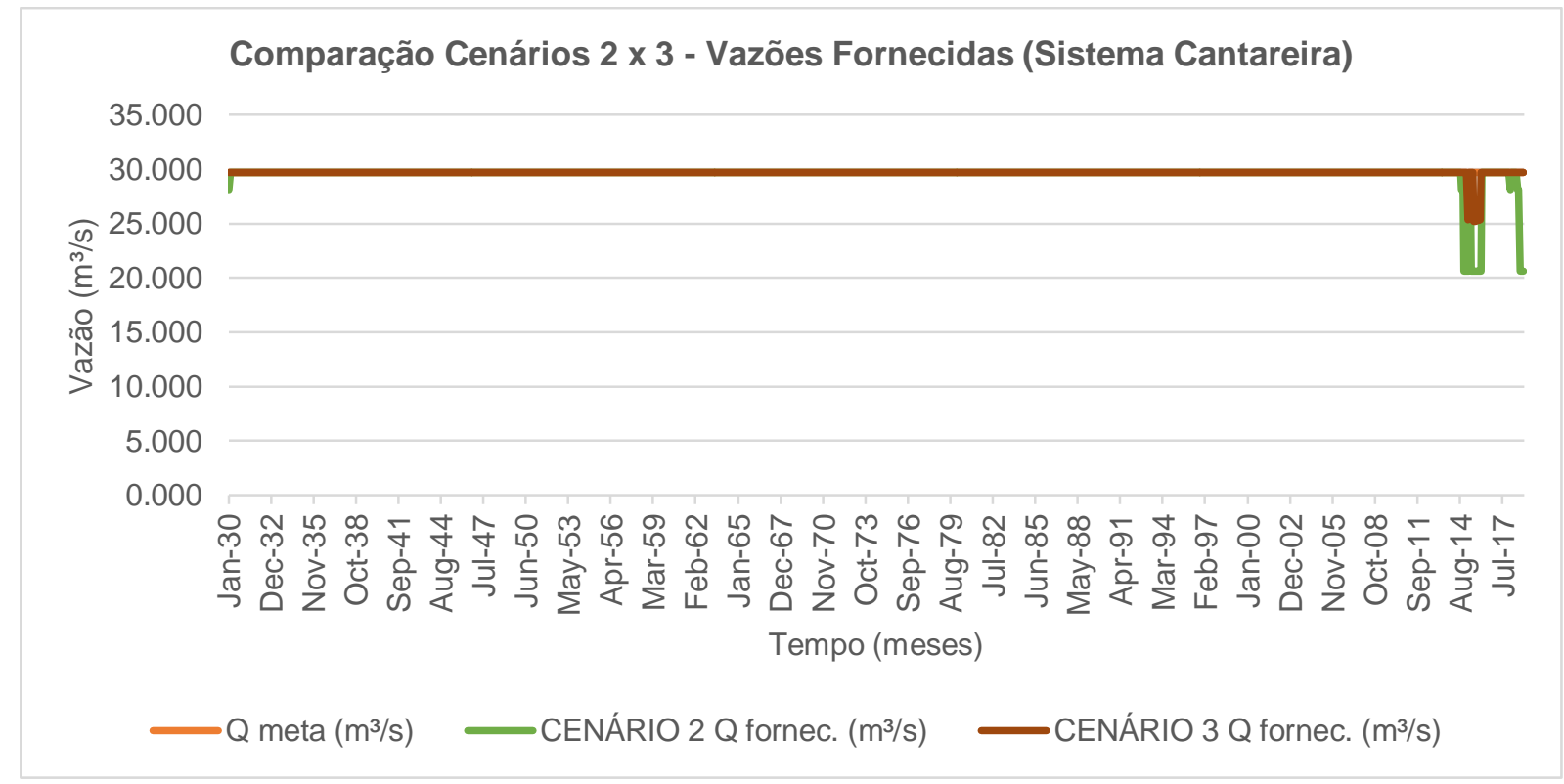

Figura 66: Vazões fornecidas e Vazão-meta no ponto de demanda "ETA Guaraú" nos Cenários 2 e 3. 
O acréscimo do número de sucessos no fornecimento de água gerou um sensível aumento na Confiabilidade, que passou de 0,977 para 0,993. A redução da magnitude dos déficits de fornecimento trouxe principalmente um ganho na Vulnerabilidade do sistema, que reduziu de 0,235 no Cenário 2 para 0,148 no Cenário 3. Embora também tenha havido ganhos no critério de Resiliência, que passou de 0,120 para 0,286 com a integração da rede, este foi um indicador que manteve um patamar reduzido em relação aos demais, muito por conta do período de 6 meses de falhas sequenciais que ainda ocorreram durante a Crise de 2014-2015 (Figura 67).

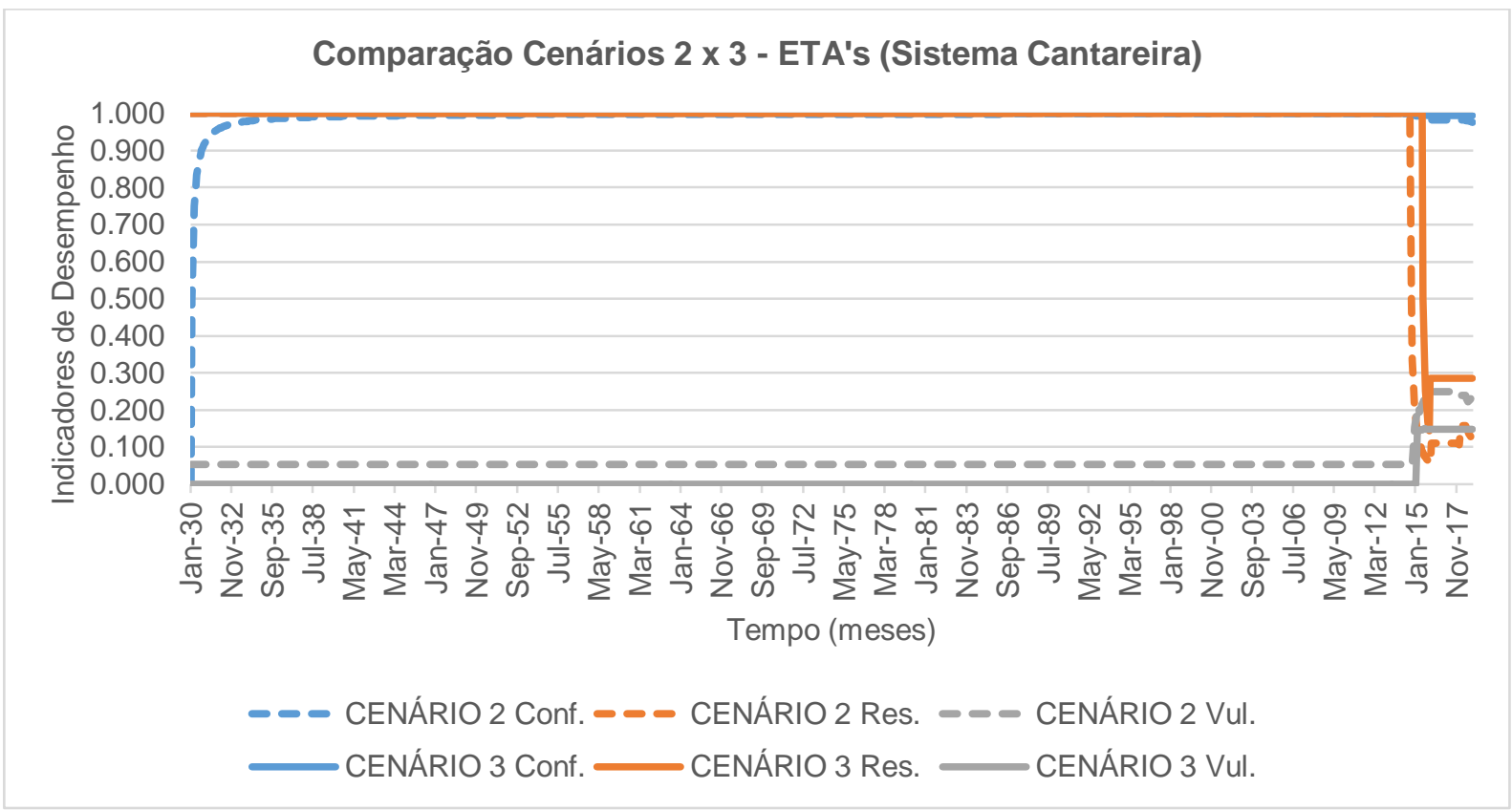

Figura 67: Acompanhamento dos indicadores de desempenho no ponto de demanda "ETA Guaraú". Comparação entre os Cenários 2 e 3.

A contribuição dos aportes da interligação (Cenário 3) indiretamente provoca um aumento médio nos níveis de armazenamento do Cantareira, mais perceptível nos períodos de maior depleção observados no Cenário 2, já que minimizam as necessidades de abstração de água dos reservatórios do sistema (Figura 68). 


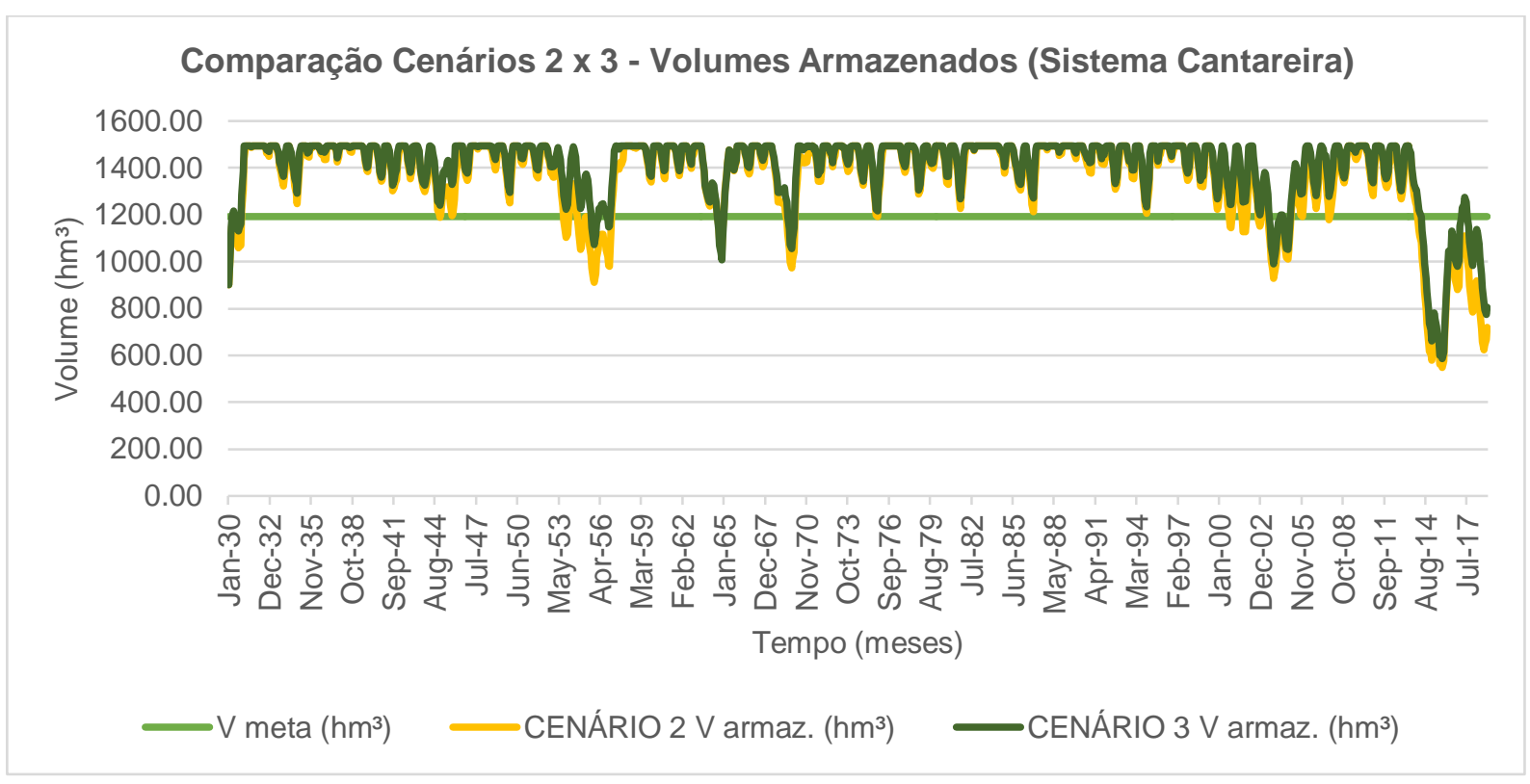

Figura 68: Volumes armazenados e Volume-meta para o Sistema Cotia nos Cenários 2 e 3.

O aumento do armazenamento médio gera, por consequência, a redução do número de condições insatisfatórias de reservação. A Figura 69 a seguir demonstra os ligeiros ganhos de desempenho obtidos com a integração da rede. A Confiabilidade aumenta de 0,860 no Cenário 2 para 0,910 no Cenário 3, assim como a Resiliência, de 0,087 para 0,094. A Vulnerabilidade registra uma redução de 0,171 para 0,157.

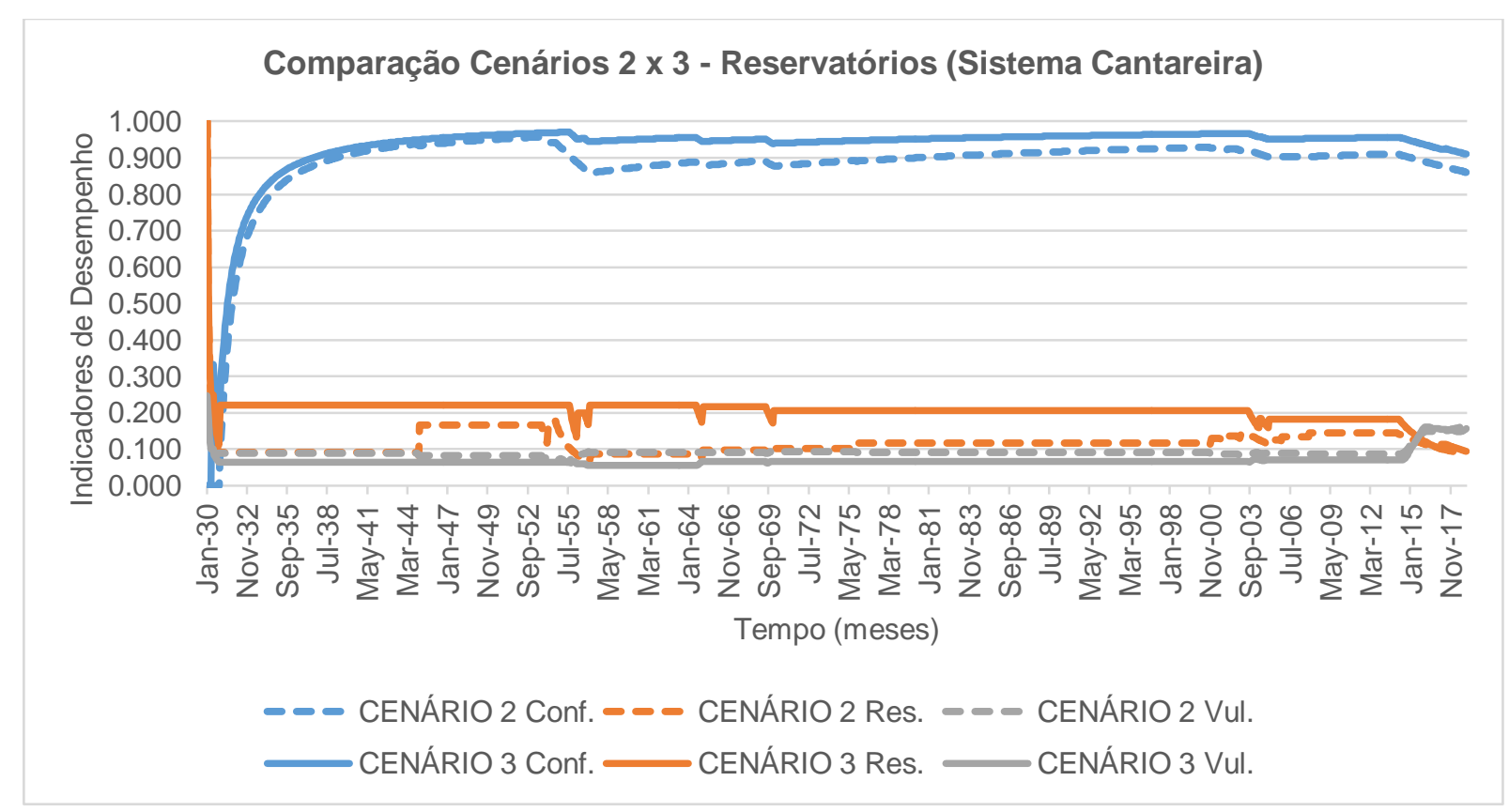

Figura 69: Acompanhamento dos indicadores de desempenho para os reservatórios do Sistema Cantareira. Comparação entre os Cenários 2 e 3. 
Por fim, a Figura 70 a seguir demonstra a evolução das curvas de sustentabilidade global do Cantareira para ambos os cenários simulados. Apesar de ainda impactado notoriamente pela Crise de 2014-2015, o Cenário 3 demonstra que a integração da rede através do compartilhamento de demandas gera um ganho de 17,3\% no Índice de Sustentabilidade global do Sistema Cantareira em comparação ao Cenário 2, que simulou as redes isoladamente.



Figura 70: Acompanhamento do Índice de Sustentabilidade global do Sistema Cantareira. Comparação entre os Cenários 2 e 3.

\subsubsection{SISTEMA GUARAPIRANGA}

Uma vez que o Sistema Guarapiranga não foi incrementado com nenhuma obra de segurança hídrica no Cenário 2, a comparação com o Cenário 3 demonstra exclusivamente os ganhos e/ou perdas de desempenho que foram gerados pela integração da rede por meio do compartilhamento de uma parcela das demandas a serem atendidas pelo sistema. $O$ resumo dos resultados de desempenho para 0 Sistema Guarapiranga é apresentado na Figura 71 abaixo. 


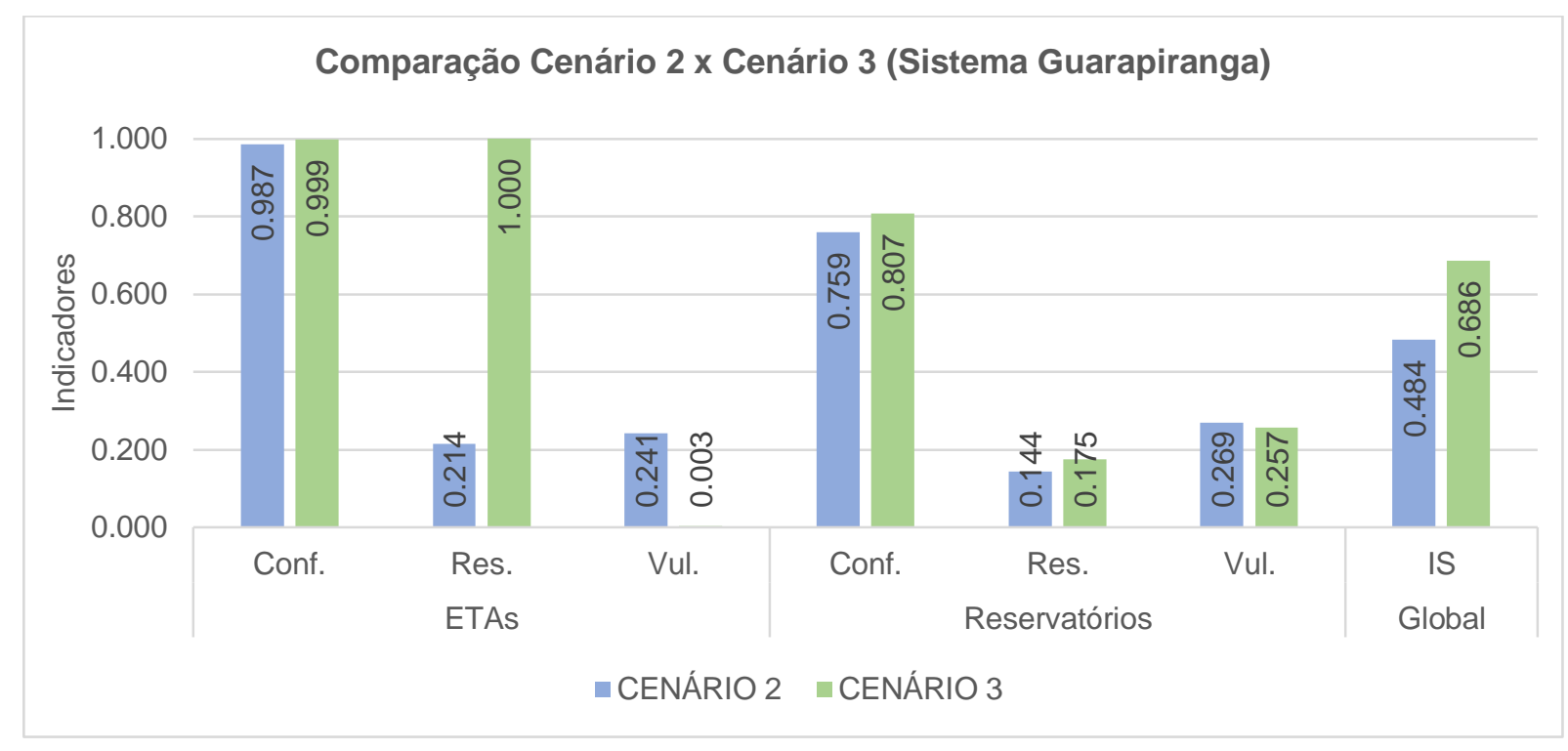

Figura 71: Resumo dos indicadores de desempenho e índice global de sustentabilidade para o Sistema Guarapiranga. Comparação Cenários 2 e 3.

Nota-se que os indicadores de Confiabilidade, Resiliência e Vulnerabilidade, assim como o Índice de Sustentabilidade global do sistema registraram ganhos de desempenho no Cenário 3 em comparação ao Cenário 2.

O Guarapiranga foi o principal destino das vazões de compartilhamento do Sistema Cantareira, apesar destas transferências terem ocorrido com vazões superiores a $1,0 \mathrm{~m}^{3} / \mathrm{s}$ em pouco menos de $9 \%$ do tempo, como demonstrado na Figura 72. As transferências do Sistema Cantareira mitigaram principalmente as falhas de fornecimento do Cenário 2 (Figura 73), nos anos de 1955, 1964 e 1969, e contribuíram para a atenuação da depleção acentuada do Guarapiranga em 1933, 1941, 1986 e 2003-2004. Nestes períodos, as vazões de compartilhamento do Cantareira ficaram próximas da máxima capacidade de transferência de $6,62 \mathrm{~m} / \mathrm{s}$.

O Sistema Guarapiranga forneceu água para atendimento de demandas compartilhadas em pouco mais de $15 \%$ do tempo, tendo sido o principal beneficiado o próprio Sistema Cantareira, com vazões médias recebidas de $0,175 \mathrm{~m}^{3} / \mathrm{s}$. 


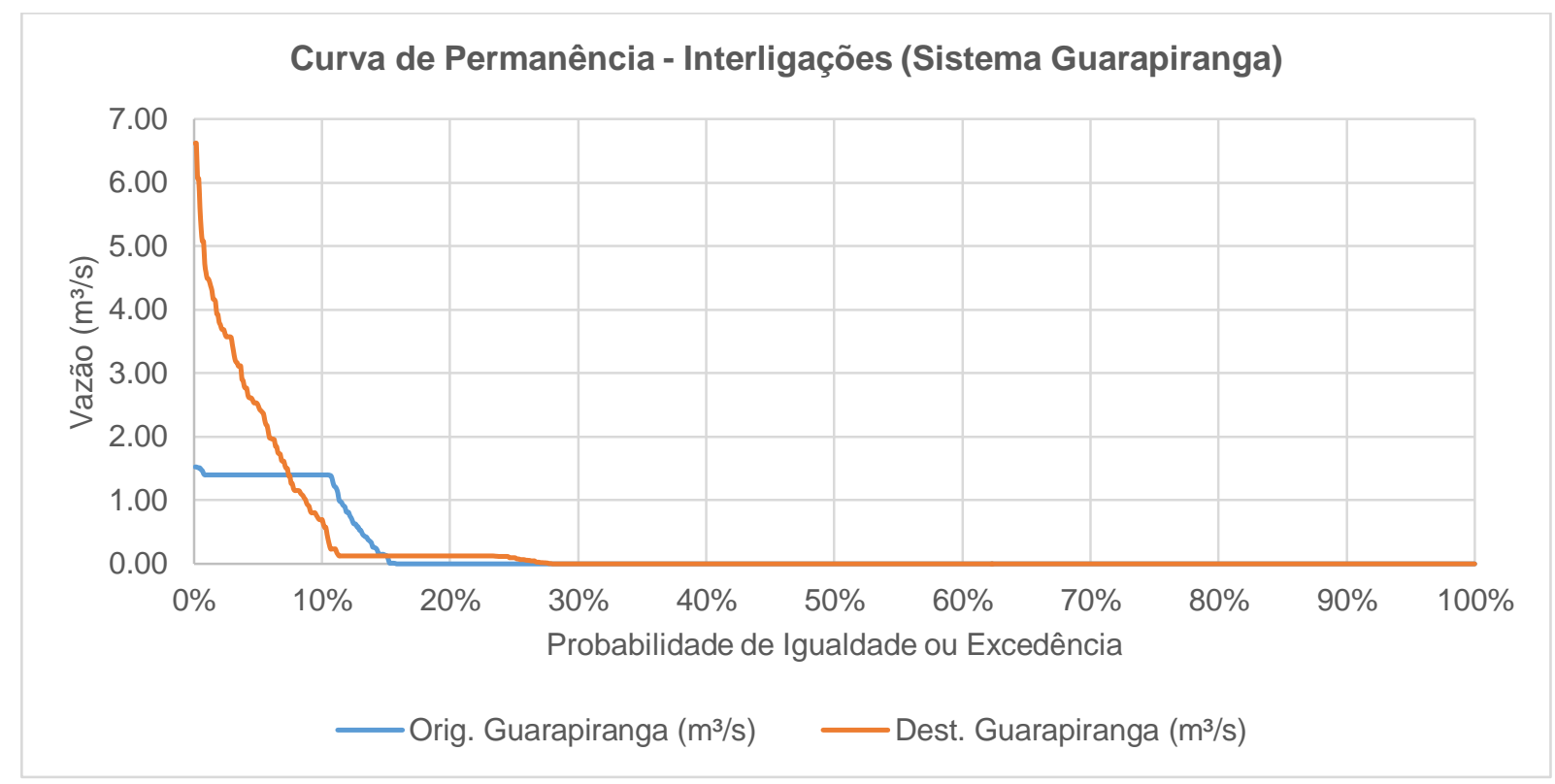

Figura 72: Curvas de permanência das vazões de interligação do Sistema Guarapiranga.

Para o Cenário 3, o fornecimento de água na ETA ABV apresentou apenas uma única falha em toda a série. Como já no Cenário 2 o número de falhas era muito baixo (14 eventos), houve apenas um ligeiro acréscimo de Confiabilidade de 0,987 para 0,999 .

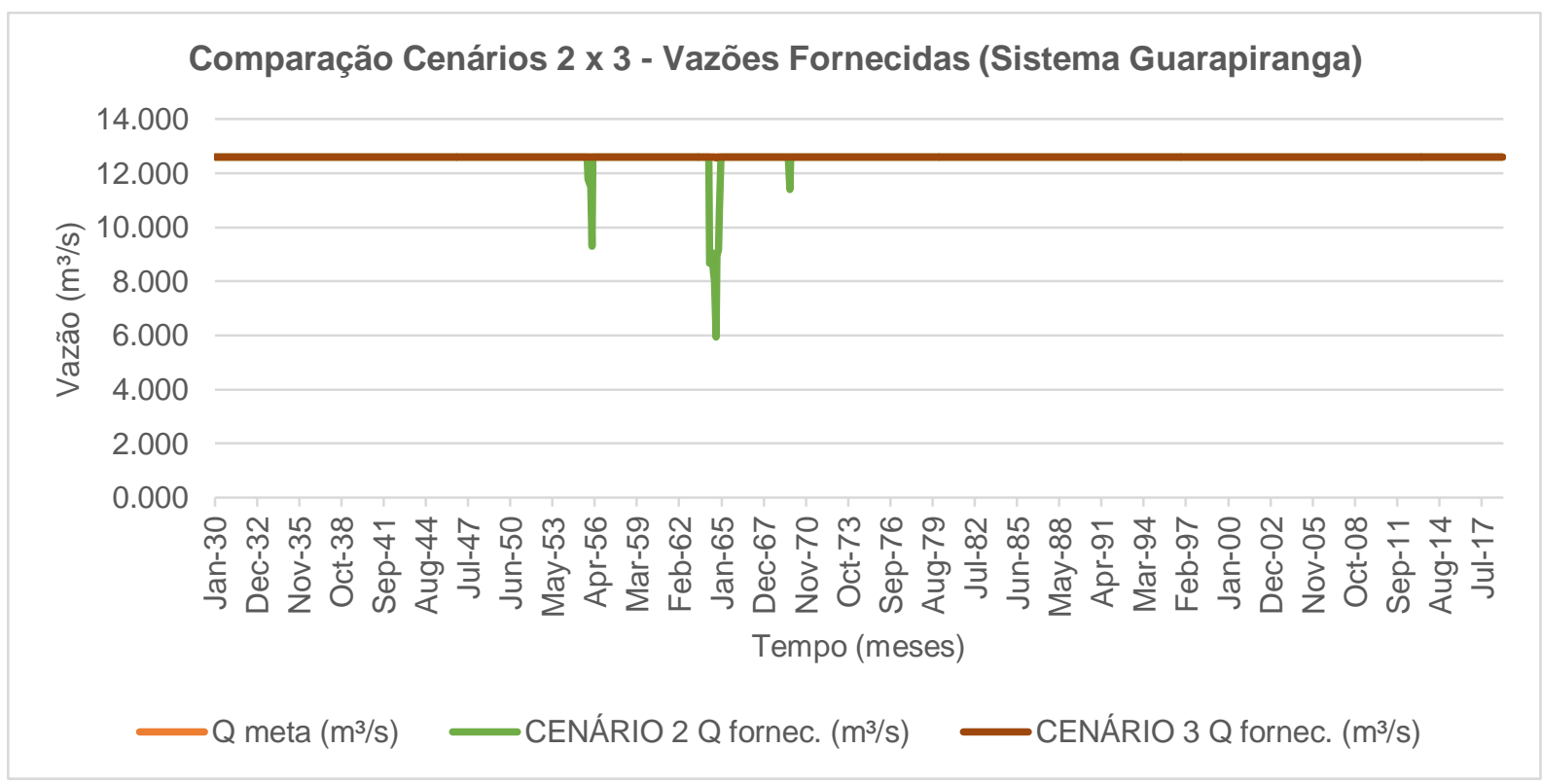

Figura 73: Vazões fornecidas e Vazão-meta no ponto de demanda "ETA ABV" nos Cenários 2 e 3. 
Tendo em vista a falha no abastecimento de água no Cenário 3 foi rapidamente recuperada no mês posterior, a Resiliência do sistema não sofreu alterações e manteve-se no seu valor máximo. A baixa magnitude desta falha isolada também não foi capaz de gerar perdas significativas em termos de Vulnerabilidade. Este indicador foi reduzido de 0,241 no Cenário 2 para 0,003 no Cenário 3 .

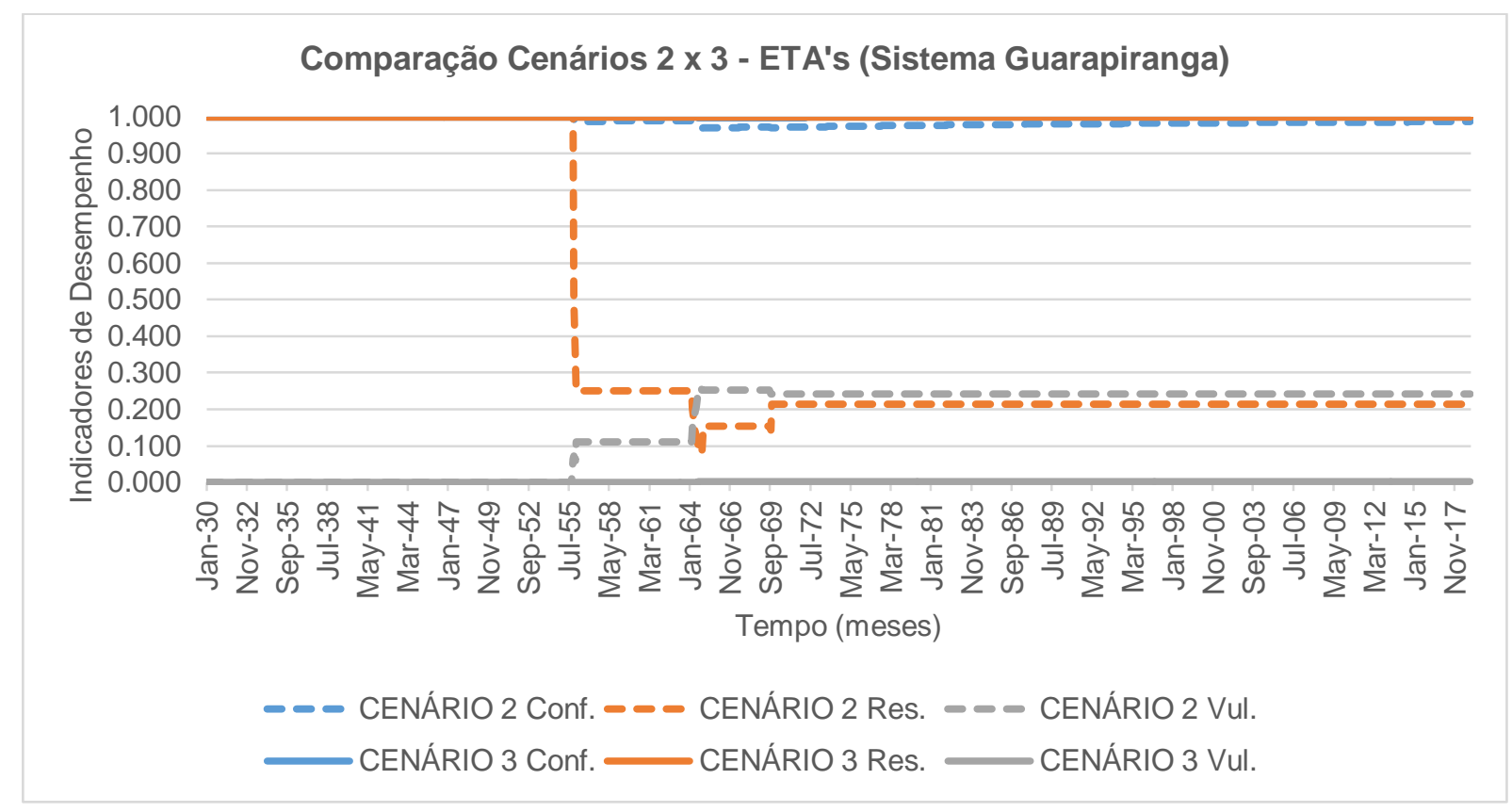

Figura 74: Acompanhamento dos indicadores de desempenho no ponto de demanda "ETA ABV". Comparação entre os Cenários 2 e 3.

A Figura 75 a seguir apresenta o acompanhamento dos volumes reservados no Sistema Guarapiranga nos Cenários 2 e 3. De maneira geral, foi observada uma elevação dos níveis de armazenamento médio do sistema. Conforme mencionado nos parágrafos acima, a integração da rede trouxe como um dos benefícios ao Guarapiranga o efeito de mitigação do esvaziamento do reservatório, mais notadamente nos períodos de 1933, 1941, 1986 e 2003-2004. 


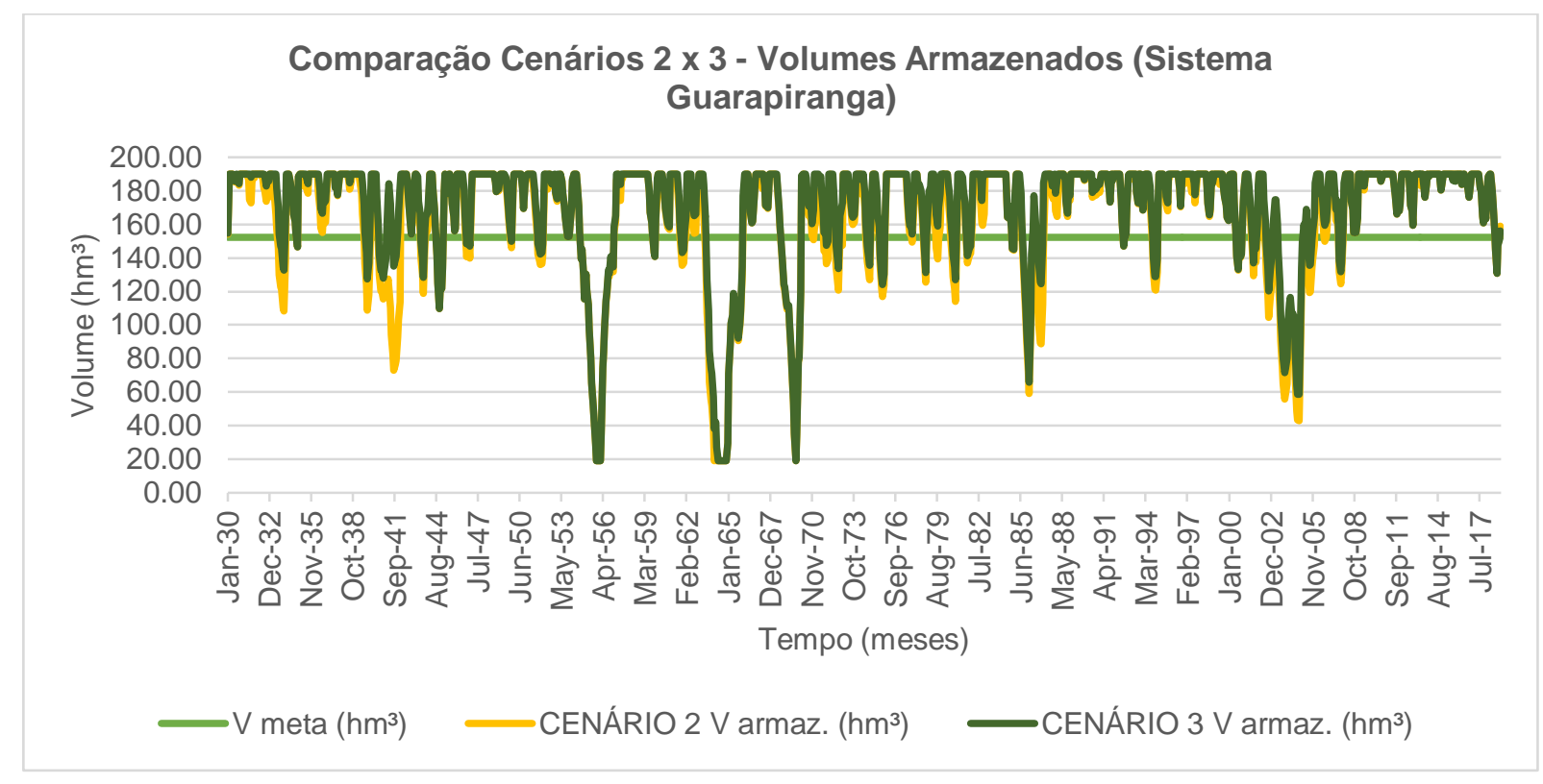

Figura 75: Volumes armazenados e Volume-meta para o Sistema Guarapiranga nos Cenários 2 e 3.

A elevação dos níveis médios de armazenamento gerou a redução do número de condições insatisfatórias do reservatório. Esta condição resultou em ganhos de desempenho para a Confiabilidade, que subiu de 0,759 no Cenário 2 para 0,807 no Cenário 3. Apesar de terem sido atenuadas, as 2 condições de não atendimento à meta de reservação no início da série (1933 e 1941) foram marcantes para a perda de Resiliência em ambos os cenários. Ainda assim, foram registrados ganhos sensíveis para Cenário 3, com Resiliência de 0,175 , ao final da série, contra 0,144 no Cenário 2 (Figura 76).

Tanto no Cenário 2 quanto no 3, a Vulnerabilidade do reservatório Guarapiranga foi claramente afetada pelos esvaziamentos acentuados do reservatório que ocorreram nos anos de 1955, 1964 e 1969. Da mesma forma que para a Resiliência, ao final da série também foi registrado um pequeno ganho de desempenho; a Vulnerabilidade caiu de 0,269 no Cenário 2 para 0,257 no Cenário 3. 


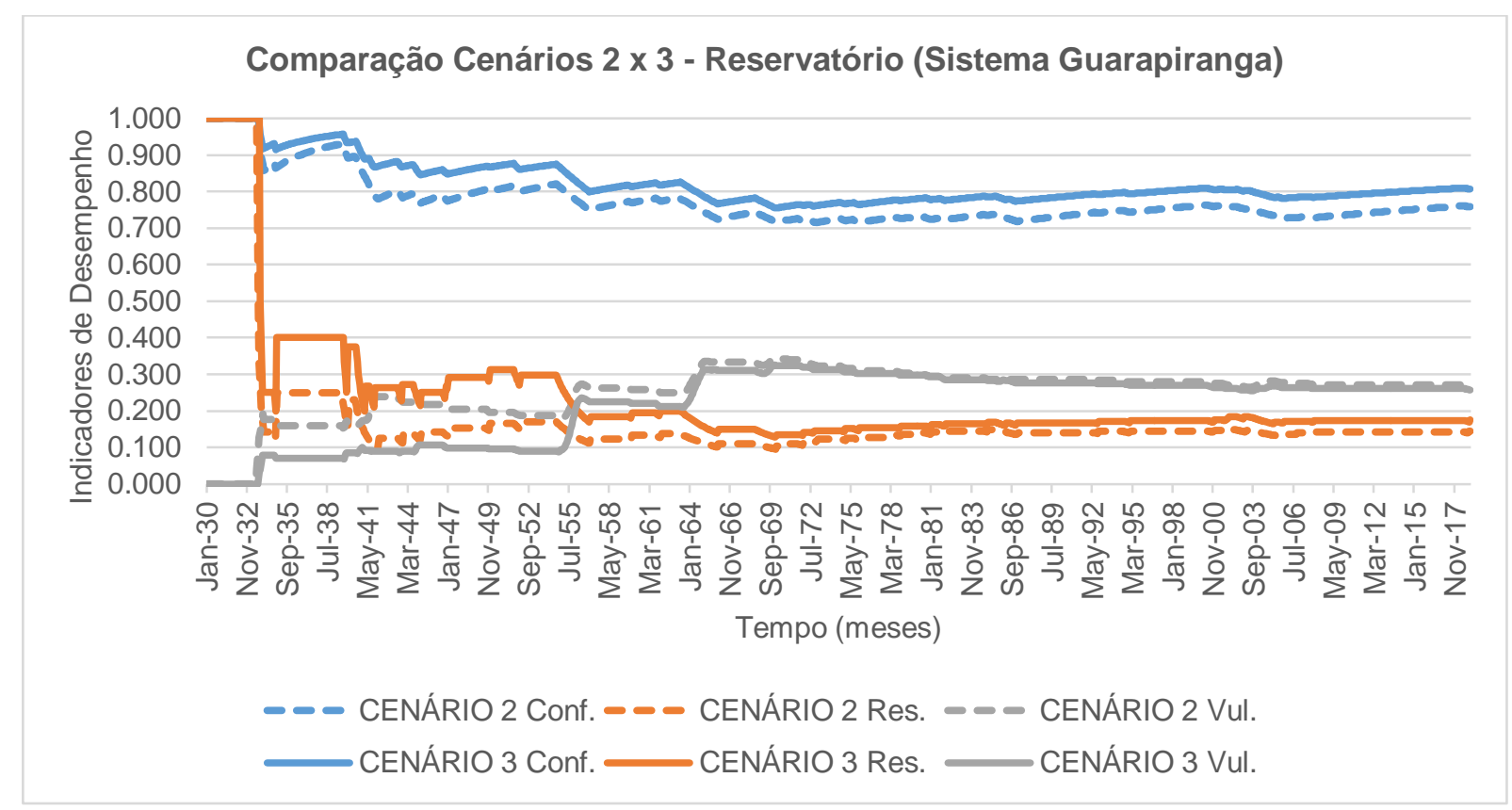

Figura 76: Acompanhamento dos indicadores de desempenho para os reservatórios do Sistema Guarapiranga. Comparação entre os Cenários 2 e 3.

A sustentabilidade global do Sistema Guarapiranga no Cenário 3 registrou um aumento de aproximadamente $42 \%$ em relação ao Cenário 2. Como se observa na Figura 77, desde o final do período de 1954-1955, a curva do Índice de Sustentabilidade da rede integrada manteve constante o desempenho superior que foi verificado no final da série. Em dezembro/2018, a sustentabilidade global do sistema foi calculada em 0,686 para o Cenário 3 e 0,484 para o Cenário 2. Esta diferença de desempenho se deveu principalmente aos ganhos da integração obtidos para os indicadores de Resiliência e Vulnerabilidade na ETA ABV. 


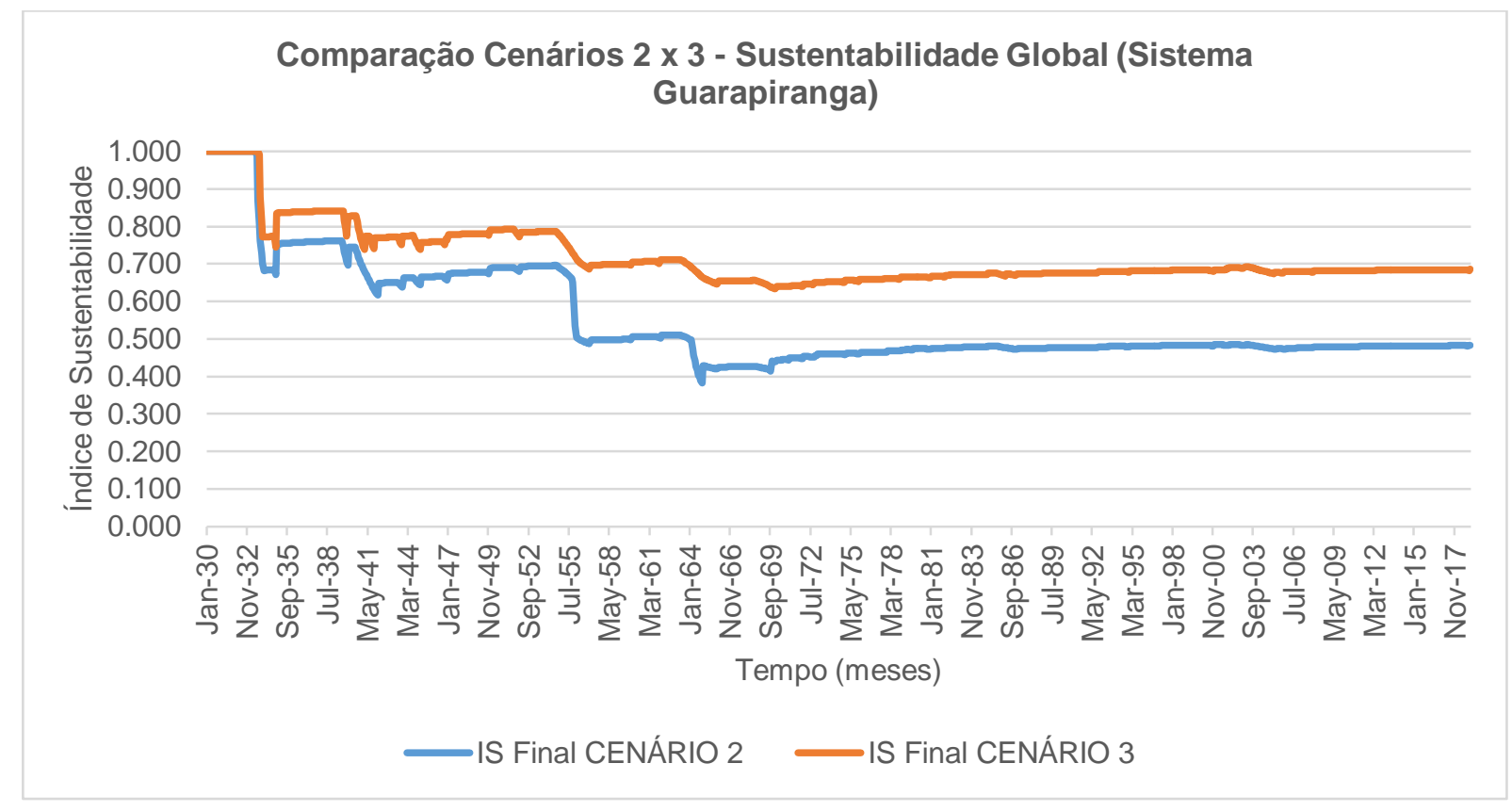

Figura 77: Acompanhamento do Índice de Sustentabilidade global do Sistema Guarapiranga. Comparação entre os Cenários 2 e 3.

\subsubsection{SISTEMA RIO CLARO}

Conforme apresentado na seção 7.1.3 deste trabalho, o Sistema Rio Claro sofreu influências indiretas decorrentes das obras de segurança hídricas no Cenário 2 para o Sistema Alto Tietê. A integração da rede simulada no Cenário 3 trouxe, por sua vez, benefícios diretos ao desempenho do Rio Claro, notadamente trazendo os indicadores da ETA Casa Grande para seus valores máximos ideais. O resumo dos resultados de desempenho do Sistema Rio Claro, para as simulações dos Cenários 2 e 3, é apresentado na Figura 78. 


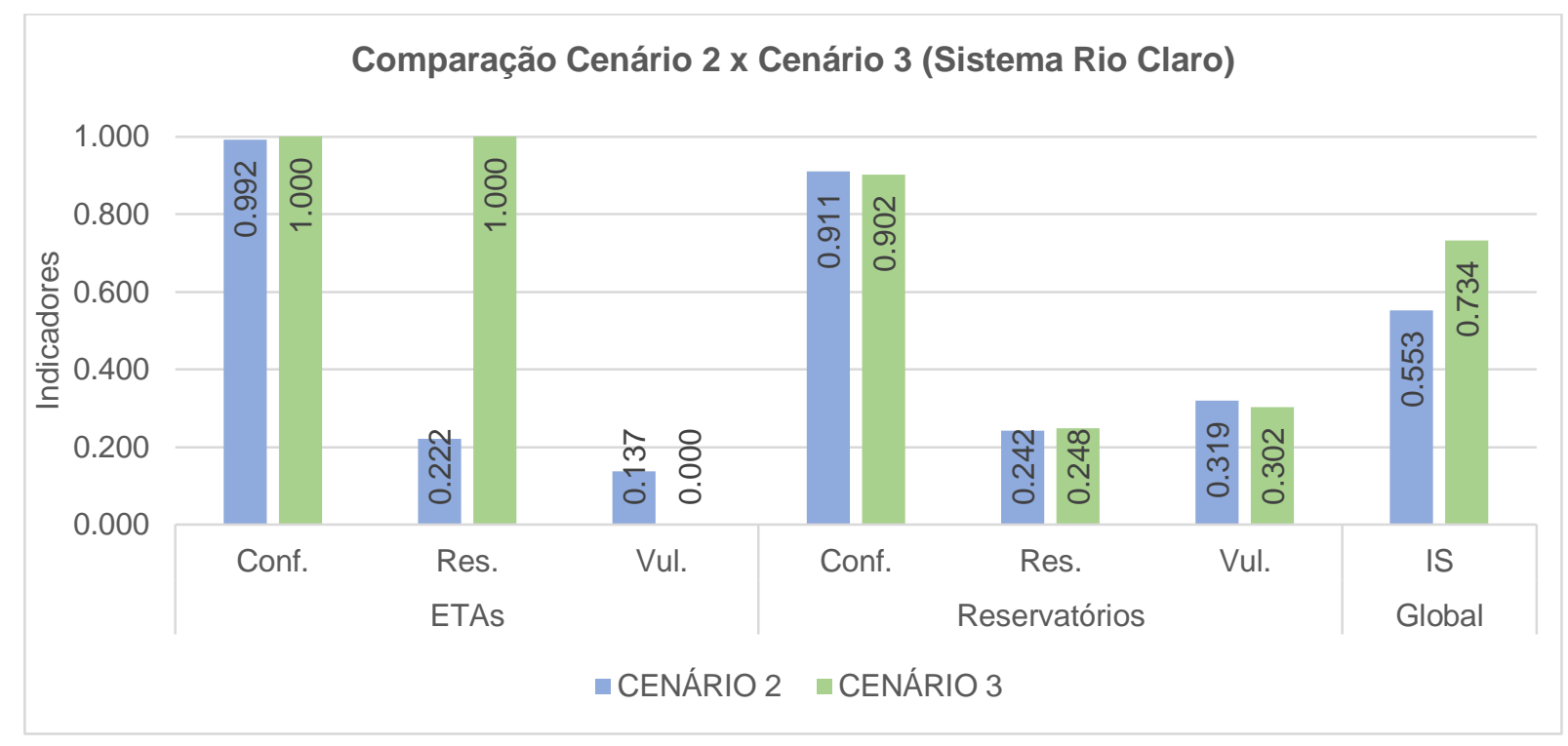

Figura 78: Resumo dos indicadores de desempenho e índice global de sustentabilidade para 0 Sistema Rio Claro. Comparação Cenários 2 e 3.

A Figura 79 demonstra a permanência das vazões de compartilhamento do Sistema Rio Claro. As vazões médias recebidas para atendimento das demandas compartilhadas foram da ordem de $0,104 \mathrm{~m}^{3} / \mathrm{s}$, tendo sido próximas a $0,400 \mathrm{~m}^{3} / \mathrm{s}$ em mais de $20 \%$ dos meses simulados.

Em mais de 45\% do tempo, o Sistema Rio Claro contribuiu com vazões médias de $0,40 \mathrm{~m}^{3} / \mathrm{s}$ para o atendimento dos pontos de demanda compartilhada dos Sistemas Alto Tietê, Rio Grande e Cantareira, sendo este último o que mais se beneficiou dos compartilhamentos; $77 \%$ do volume compartilhado teve como destino o Cantareira. 


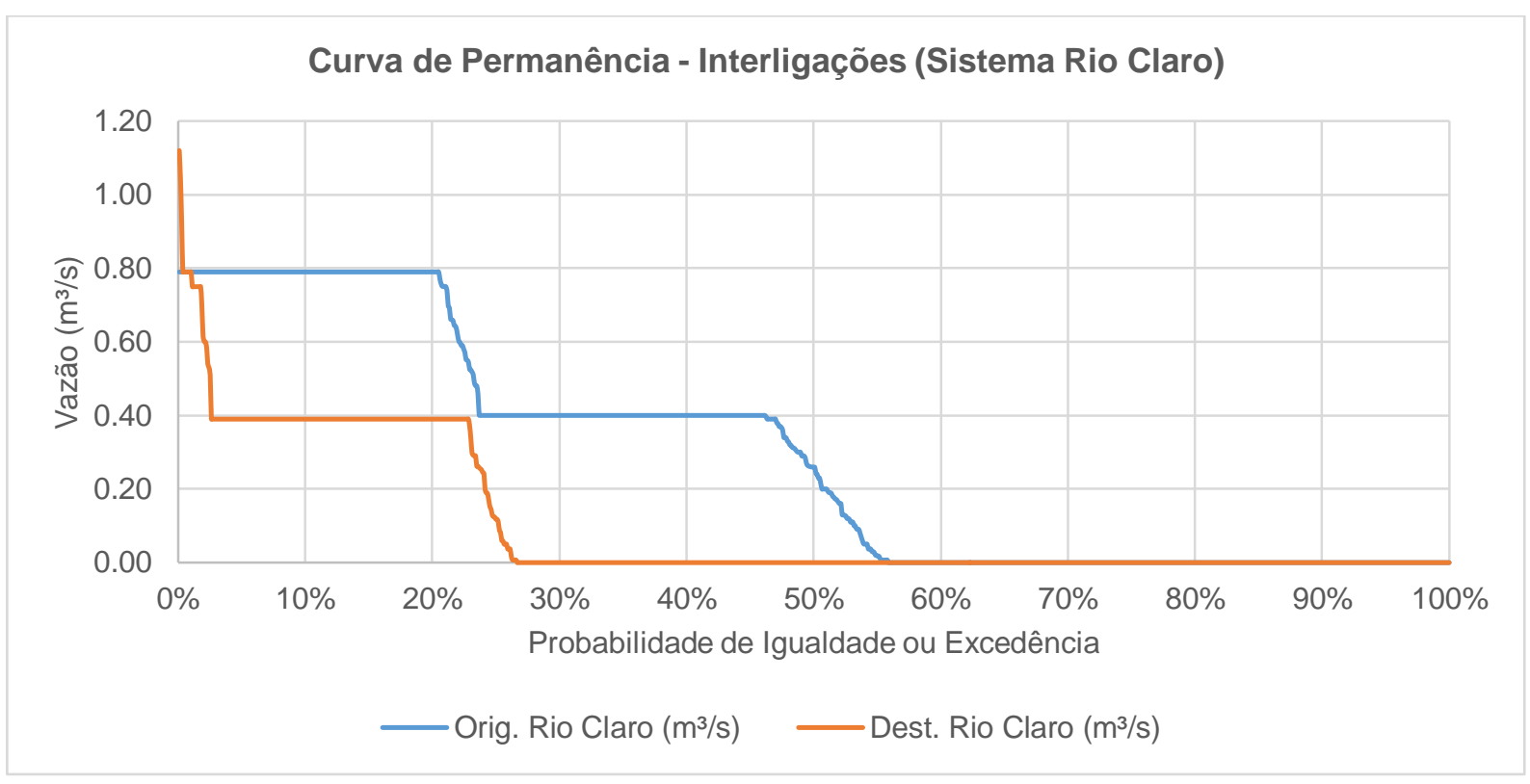

Figura 79: Curvas de permanência das vazões de interligação do Sistema Rio Claro.

Os aportes recebidos pelo Sistema Rio Claro foram suficientes para a eliminação do número de falhas de atendimento na ETA Casa Grande, como mostra a Figura 80.

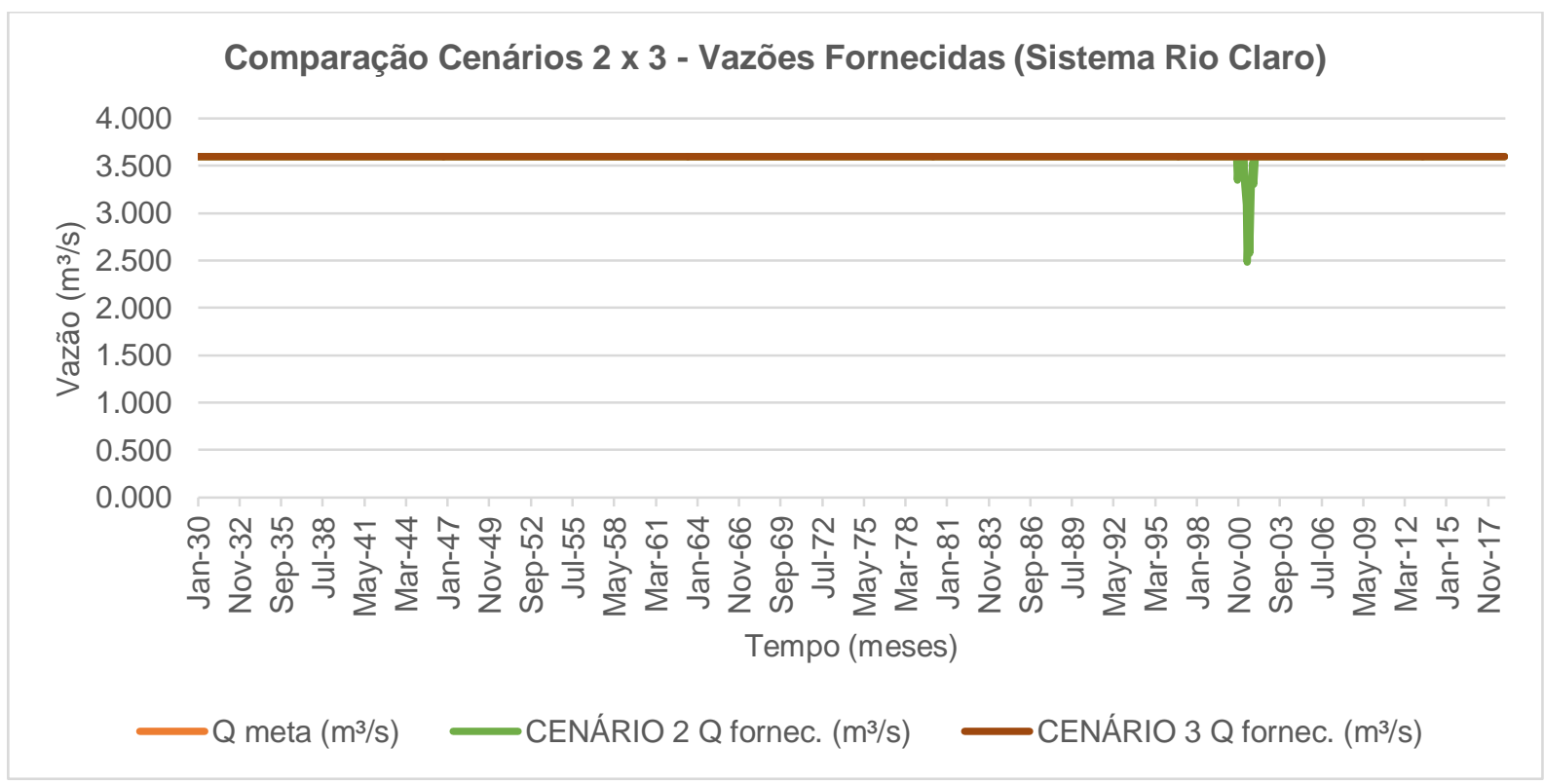

Figura 80: Vazões fornecidas e Vazão-meta no ponto de demanda "ETA Casa Grande" nos Cenários 2 e 3.

A eliminação das falhas de fornecimento mitigou principalmente os efeitos da queda brusca de Resiliência demonstrada no Cenário 2. Neste cenário, as 8 falhas 
sequenciais que ocorreram no ano de 2001 provocaram a perda de desempenho não só da Resiliência, mas também da Vulnerabilidade. Ao final da série, estes indicadores foram 0,222 e 0,137 , respectivamente.

A Confiabilidade da rede isolada (Cenário 2) registrou um valor de elevado de 0,992, devido ao baixo número de falhas registados nesta simulação. Para o Cenário 3 , a inexistência de falhas de atendimento na série elevou ainda mais a Confiabilidade, trazendo também os indicadores de Resiliência e Vulnerabilidade para seus valores máximos ideais. Conforme se observa na Figura 81, ao final da série no Cenário 3, registraram-se os seguintes resultados: Confiabilidade $=1,000$; Resiliência $=1,000$, e; Vulnerabilidade $=0,000$.

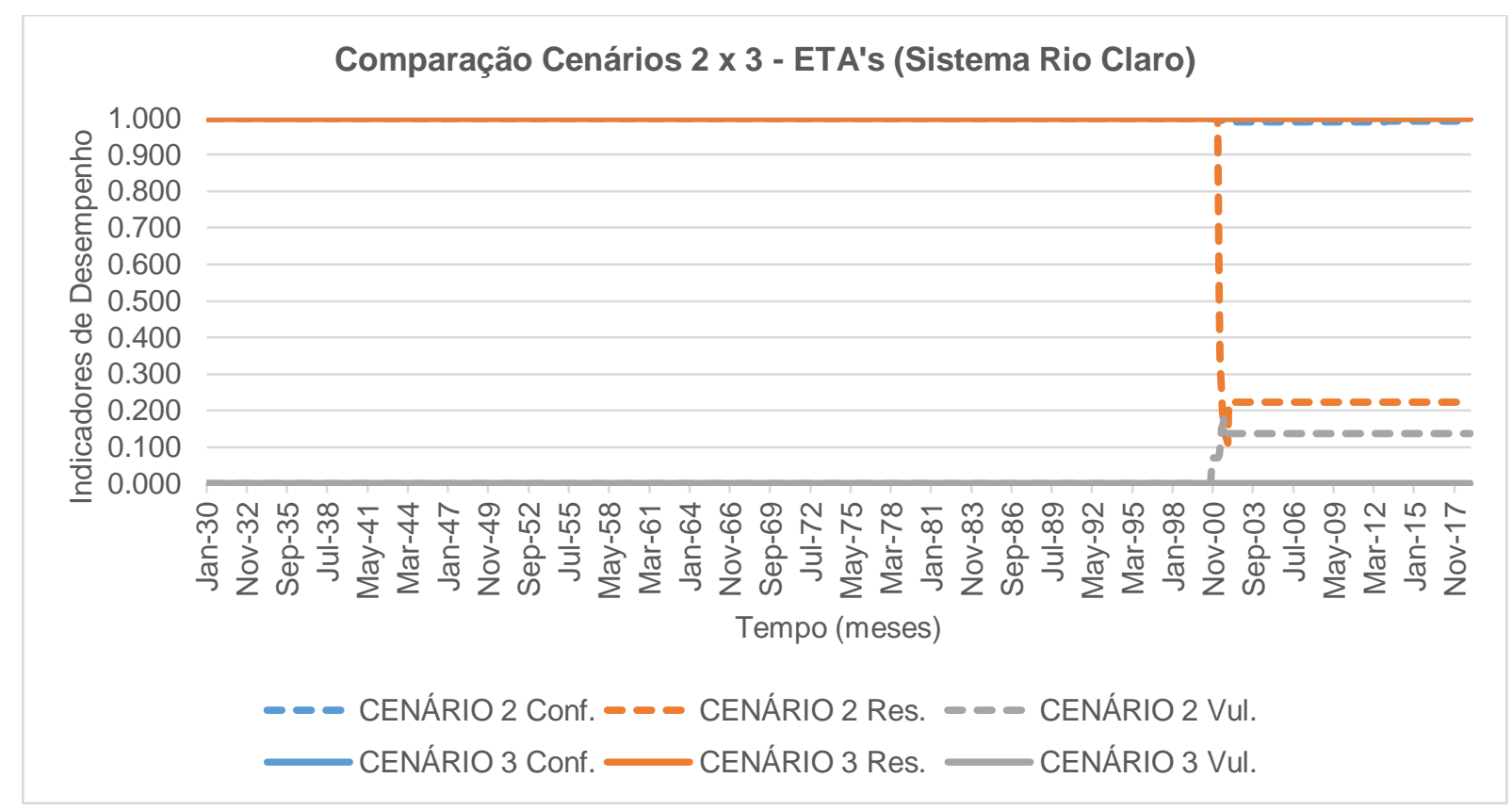

Figura 81: Acompanhamento dos indicadores de desempenho no ponto de demanda "ETA Casa Grande". Comparação entre os Cenários 2 e 3.

Os ganhos de desempenho decorrentes da integração da rede no atendimento das demandas da ETA Casa Grande não foram alcançados na mesma proporção em termos de armazenamento de água para o reservatório Ribeirão do Campo. A Figura 82 a seguir demonstra como, especificamente após a crise dos anos 2014 e 2015, os níveis de armazenamento registrados no Cenário 3 foram inferiores aos do Cenário 2 . 


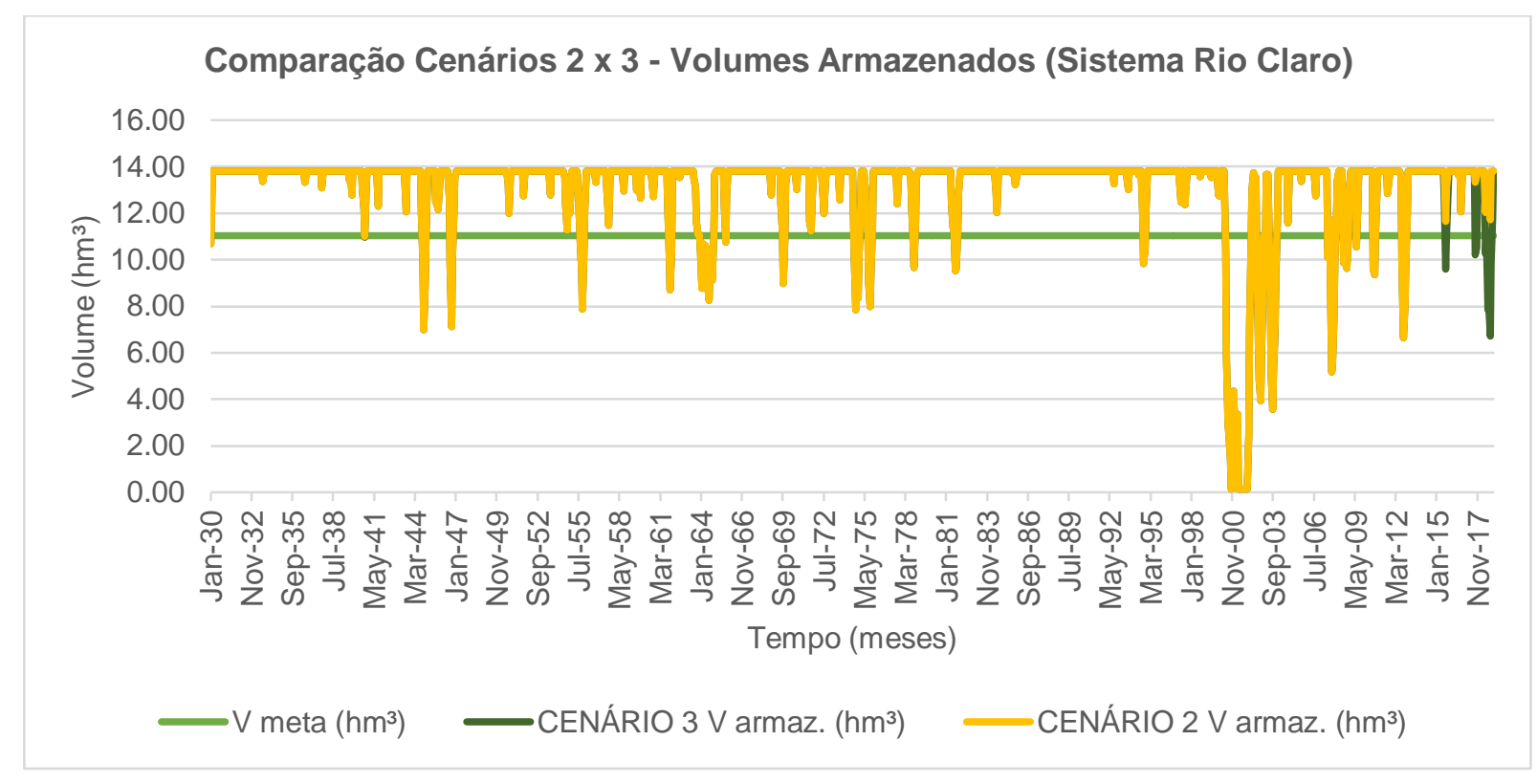

Figura 82: Volumes armazenados e Volume-meta para o Sistema Rio Claro nos Cenários 2 e 3.

As diferenças de armazenamento ao final da série, porém, não foram suficientes para alterar de forma significativa o desempenho da reservação de água do Rio Claro no Cenário 3 em comparação ao Cenário 2, conforme se observa na Figura 83.

A Confiabilidade em ambos os cenários se manteve elevada; 0,911 no Cenário 2 e 0,902 no Cenário 3.

As condições insatisfatórias de armazenamento que ocorreram entre os anos de 1944 e 1965 foram determinantes para a perda de desempenho em termos de Resiliência nos 2 cenários. A Resiliência foi ainda claramente afetada pelas condições insatisfatórias sequenciais do Ribeirão do Campo verificadas no início dos anos 2000. Ao final da série, a Resiliência foi de 0,242 no Cenário 2 e 0,248 no Cenário 3.

Para ambos os cenários simulados, as perdas notáveis de desempenho em Vulnerabilidade ocorreram em 2 momentos: na primeira depleção acentuada do Ribeirão do Campo, ocorrido no ano de 1944, e entre os anos 2000 e 2003, no principal evento que provocou o esvaziamento do reservatório. Ao final da série, a Vulnerabilidade ficou em 0,319 para a rede isolada (Cenário 2), e 0,302 para a rede integrada (Cenário 3). 


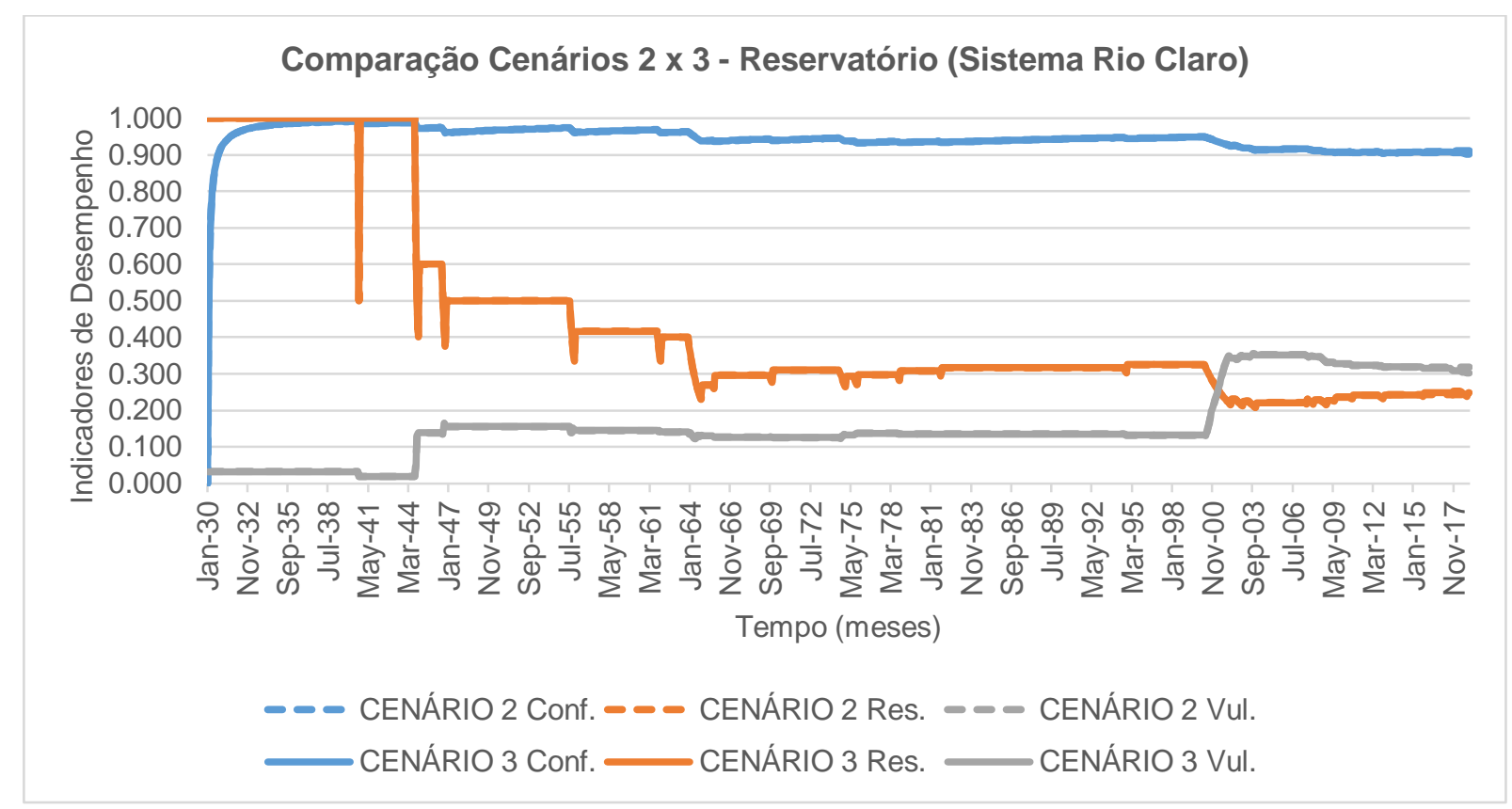

Figura 83: Acompanhamento dos indicadores de desempenho para os reservatórios do Sistema Rio Claro. Comparação entre os Cenários 2 e 3.

Na sequência, a Figura 84 apresenta a evolução ao longo do tempo do Índice de Sustentabilidade global do Sistema Rio Claro, para ambos os cenários.

Uma vez que o desempenho do Cenário 2 e 3 para a reservação do Ribeirão do Campo foi muito similar, os ganhos de aproximadamente 33\% do Cenário $3 \mathrm{em}$ relação ao 2 são atribuídos principalmente aos incrementos anotados nos indicadores de Resiliência e Vulnerabilidade da ETA Casa Grande. Os efeitos da integração da rede no Cenário 3 foram especificamente importantes na atenuação dos impactos da crise hídrica que afetou o Sistema Rio Claro no início dos anos 2000. 


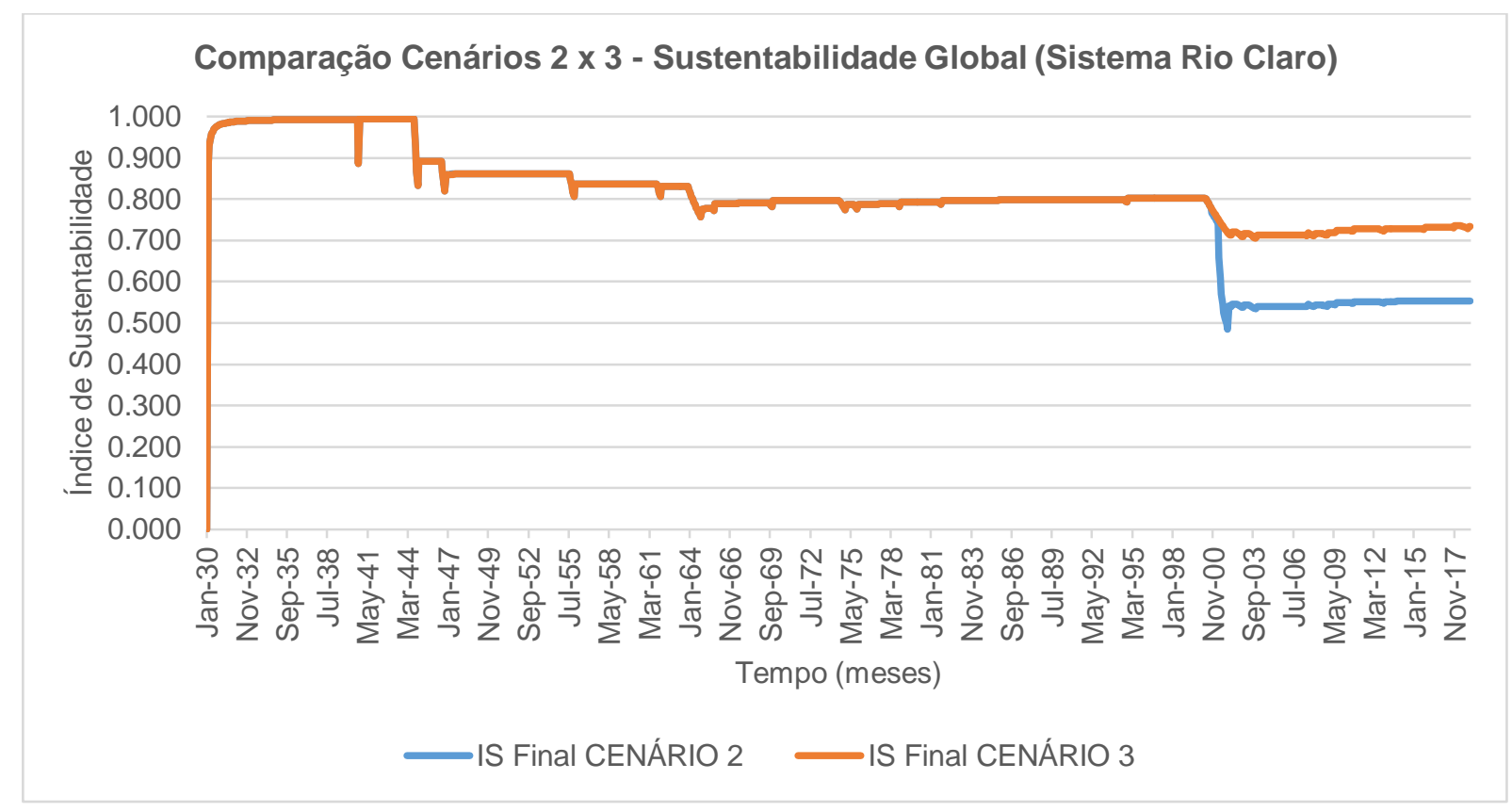

Figura 84: Acompanhamento do Índice de Sustentabilidade global do Sistema Rio Claro. Comparação entre os Cenários 2 e 3.

\subsubsection{SISTEMA RIO GRANDE}

No Cenário 2, as transferências do Braço do Rio Pequeno para o reservatório Rio Grande já trouxeram um importante fator de segurança hídrica que resultou em ganhos de desempenho para o sistema. A integração da rede proposta no Cenário 3 foi capaz de contribuir ainda mais para a melhoria de desempenho da ETA Ribeirão da Estiva e do reservatório Rio Grande e, assim, para a sustentabilidade global do sistema, conforme será discutido nesta seção.

A Figura 85 a seguir demonstra o resumo dos resultados de desempenho do Sistema Rio Grande para ambos os cenários simulados. Nota-se que os valores máximos de desempenho da ETA Rio Grande já verificados no Cenário 2 (rede isolada) foram mantidos para o Cenário 3 (rede integrada). 


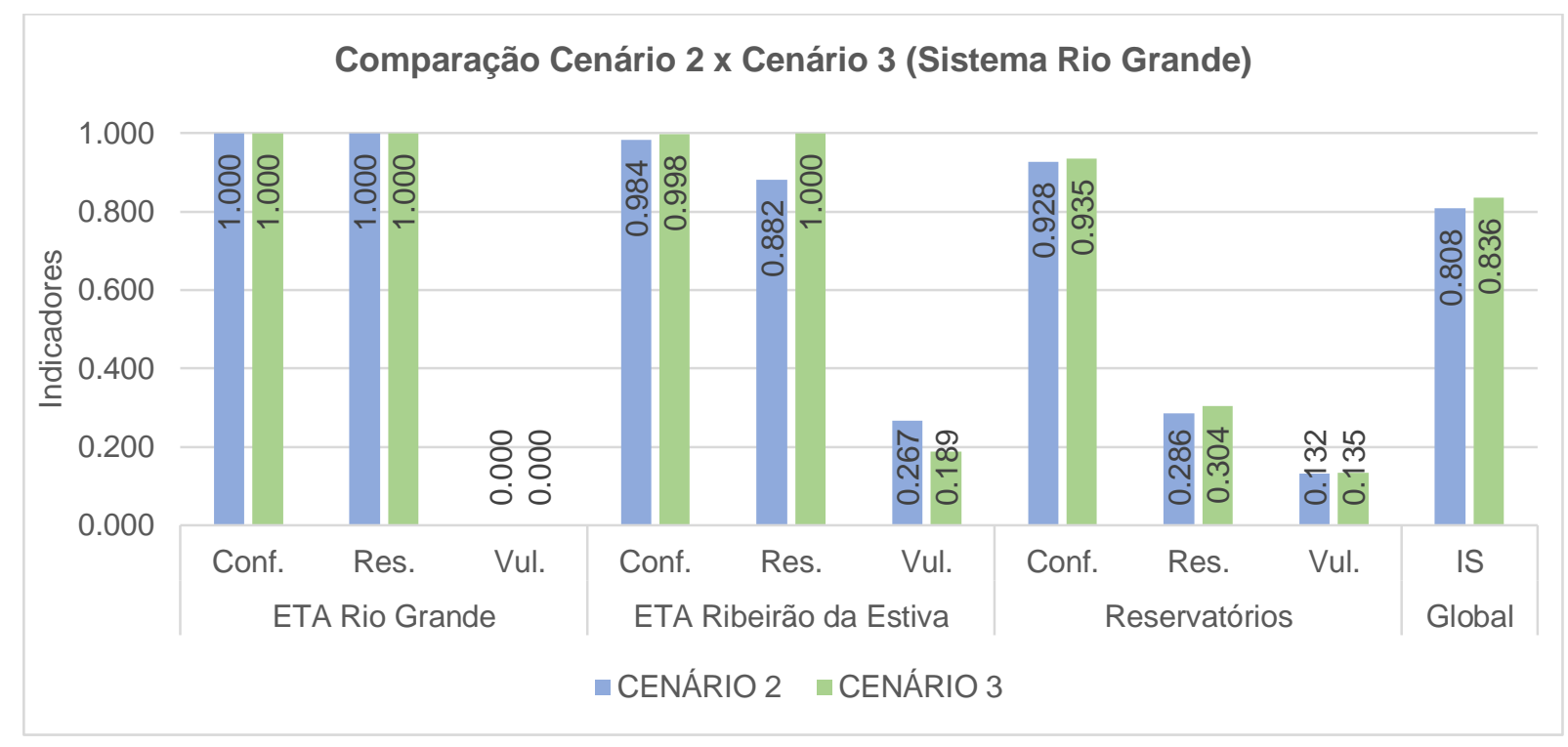

Figura 85: Resumo dos indicadores de desempenho e índice global de sustentabilidade para o Sistema Rio Grande. Comparação Cenários 2 e 3.

As permanências das vazões de compartilhamento do Sistema Rio Grande são apresentadas na Figura 86. A ETA Rio Grande, como se pode observar, tanto forneceu quanto recebeu vazões para atendimento das demandas compartilhadas. Enquanto isto, a ETA Ribeirão da Estiva apenas recebeu estas vazões de compartilhamento.

As vazões destinadas ao Sistema Rio Grande foram oriundas do Sistema Rio Claro, com as seguintes médias: 0,054 m³/s para a demanda compartilhada da ETA Rio Grande e 0,007 m³/s para o Ribeirão da Estiva. A ETA Rio Grande, por sua vez, contribuiu para o atendimento das demandas dos Sistemas Rio Claro e Cotia com médias de transferência de 0,073 e $0,027 \mathrm{~m}^{3} / \mathrm{s}$, respectivamente. 


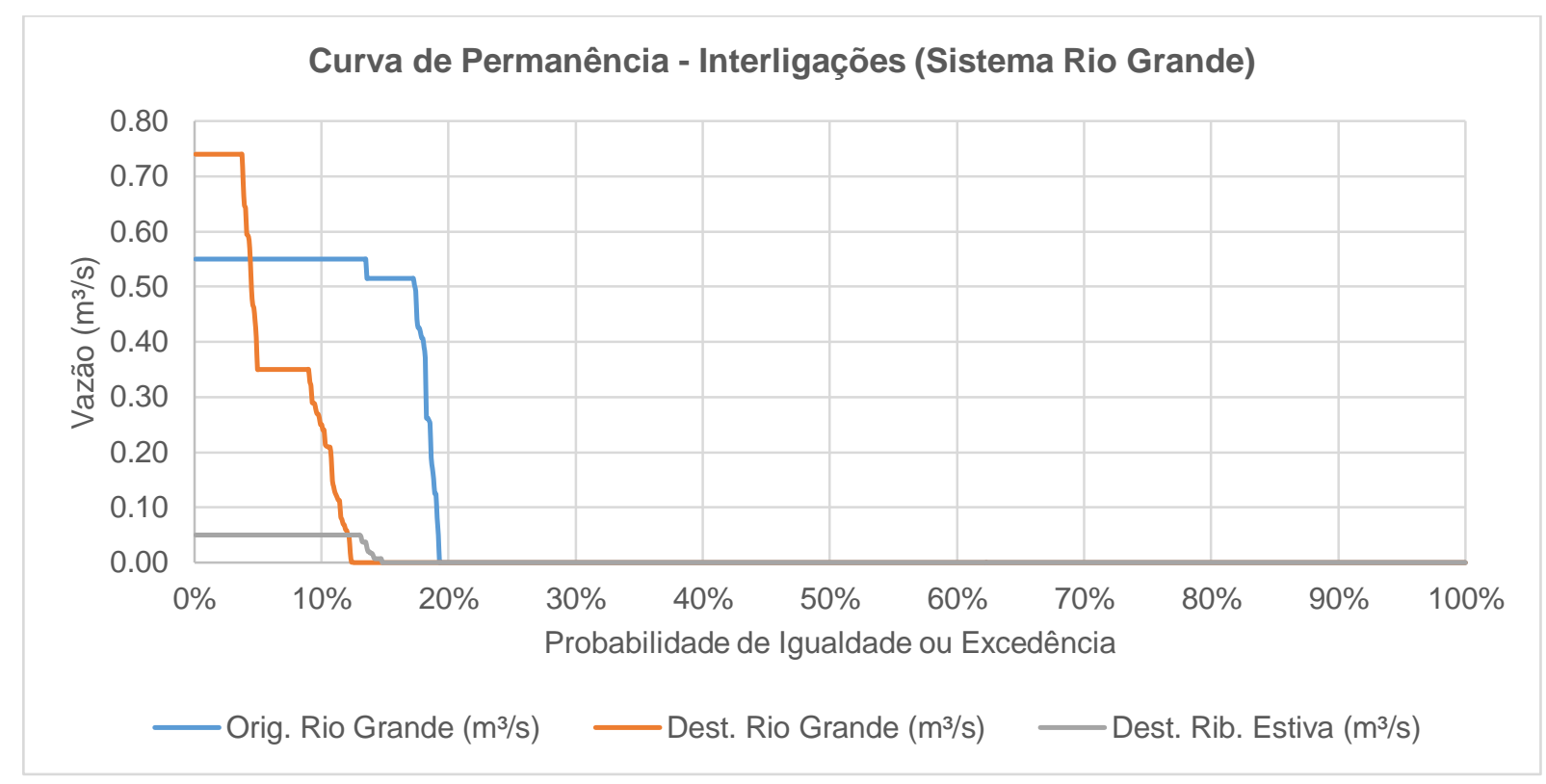

Figura 86: Curvas de permanência das vazões de interligação do Sistema Rio Grande.

No Cenário 3, as vazões de transferência aportadas ao ponto de demanda compartilhada do Ribeirão da Estiva trouxeram uma redução absoluta do número e da magnitude das falhas de atendimento, conforme verificado na Figura 87.

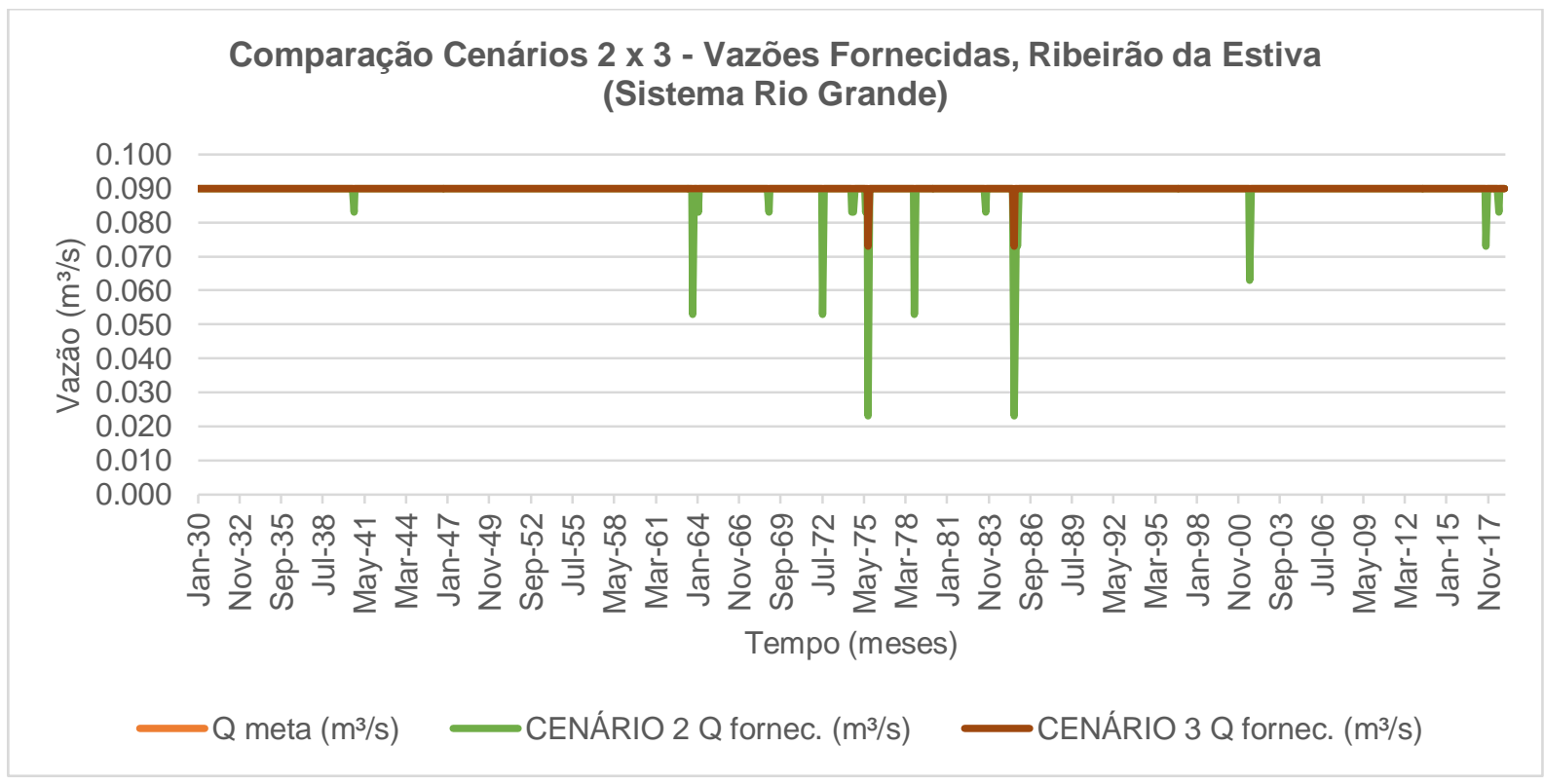

Figura 87: Vazões fornecidas e Vazão-meta no ponto de demanda "ETA Ribeirão da Estiva" nos Cenários 2 e 3.

Os ganhos de desempenho na operação da ETA Ribeirão da Estiva a partir da integração da rede podem ser observados na Figura 88 abaixo. A Confiabilidade teve 
um ligeiro acréscimo de 0,984 no Cenário 2 para 0,998 no Cenário 3. Neste último cenário, as duas únicas falhas registradas foram rapidamente recuperadas nos meses seguintes que estas ocorreram, fazendo com que a Resiliência da ETA fosse mantida em seu valor máximo de 1,000. No Cenário 2, a Resiliência foi de 0,882.

As duas falhas verificadas no Cenário 3 também registraram menores valores de déficits em relação às ocorridas no Cenário 2, assim, o indicador de Vulnerabilidade foi reduzido de 0,267 para 0,189 .

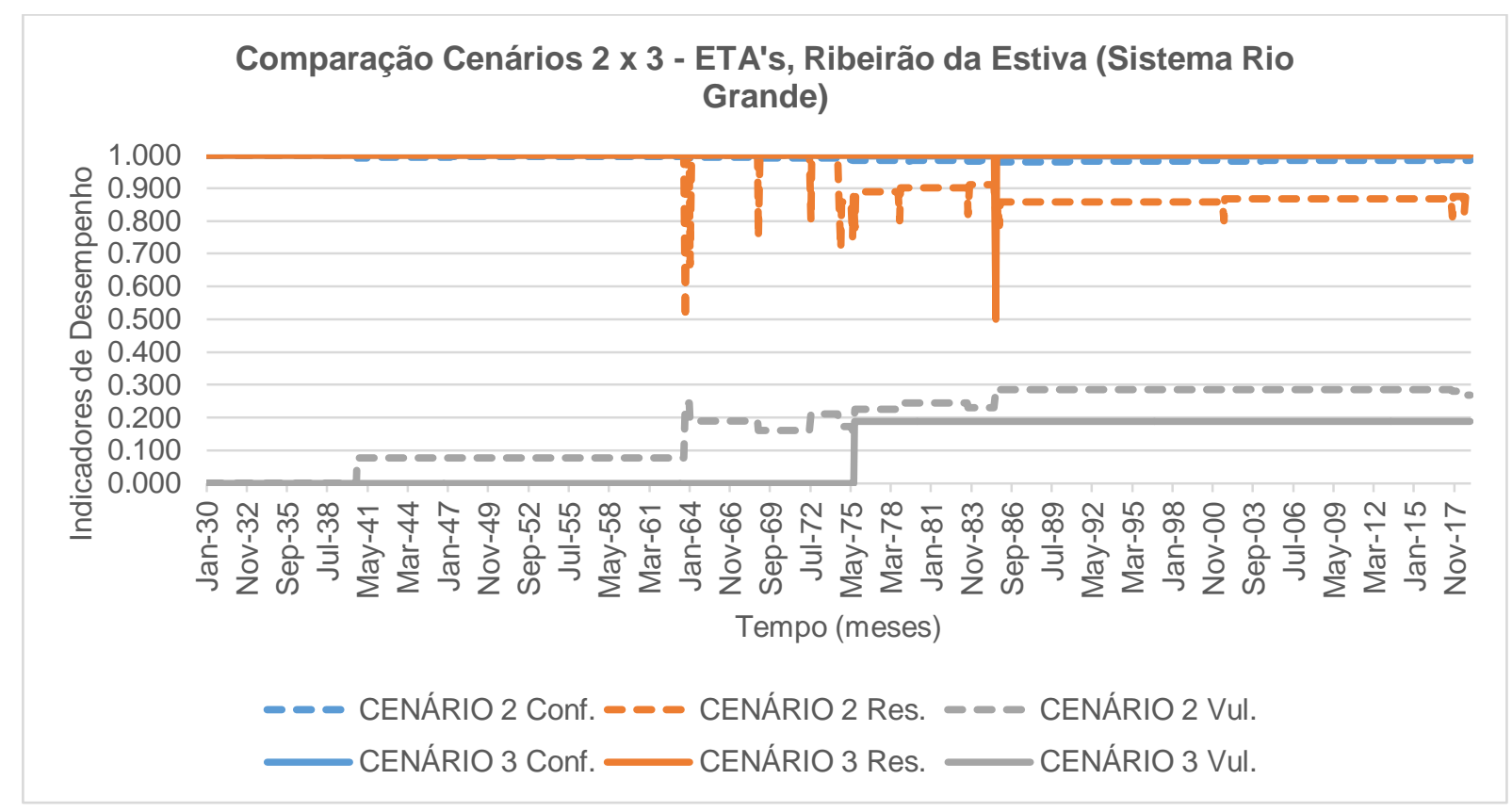

Figura 88: Acompanhamento dos indicadores de desempenho no ponto de demanda "ETA Ribeirão da Estiva”. Comparação entre os Cenários 2 e 3.

A Figura 89 demonstra que, de maneira geral, o armazenamento médio do reservatório Rio Grande foi ligeiramente superior no Cenário 3 em comparação ao Cenário 2. Não foi possível a identificação de nenhum ponto específico de descolamento mais acentuado entre as curvas de volume armazenado do reservatório. 


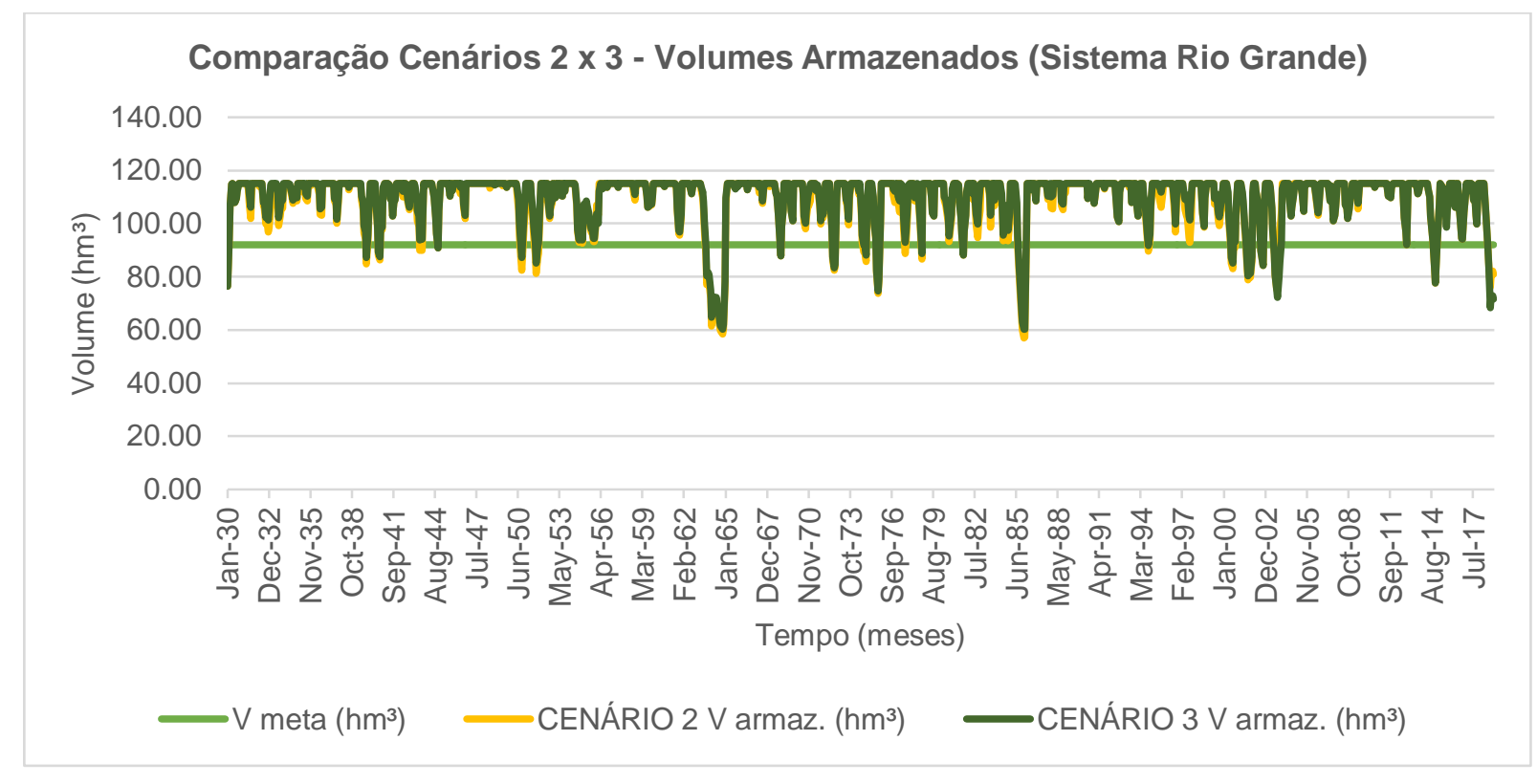

Figura 89: Volumes armazenados e Volume-meta para o Sistema Rio Grande nos Cenários 2 e 3.

A diferença do número de condições insatisfatórias de armazenamento entre os 2 cenários simulados foi de apenas 8 eventos ( 77 no Cenário 2 e 69 no Cenário 3 ). Este fato foi determinante para que ao final da série os indicadores de desempenho das redes isoladas e integradas ficassem muito próximos. Os desempenhos do reservatório em Confiabilidade e Vulnerabilidade foram de 0,928 e 0,132 no Cenário 2, e 0,935 e 0,13 no Cenário 3. A Resiliência teve um comportamento mais atenuado no início da série do Cenário 3, entretanto, o acúmulo de 17 períodos sequenciais de condições insatisfatórias entre 1964 e 1965 reduziram significativamente o desempenho neste critério. Ao final da série, a Resiliência do reservatório Rio Grande foi de 0,286 para o Cenário 2, e 0,304 para o Cenário 3. 


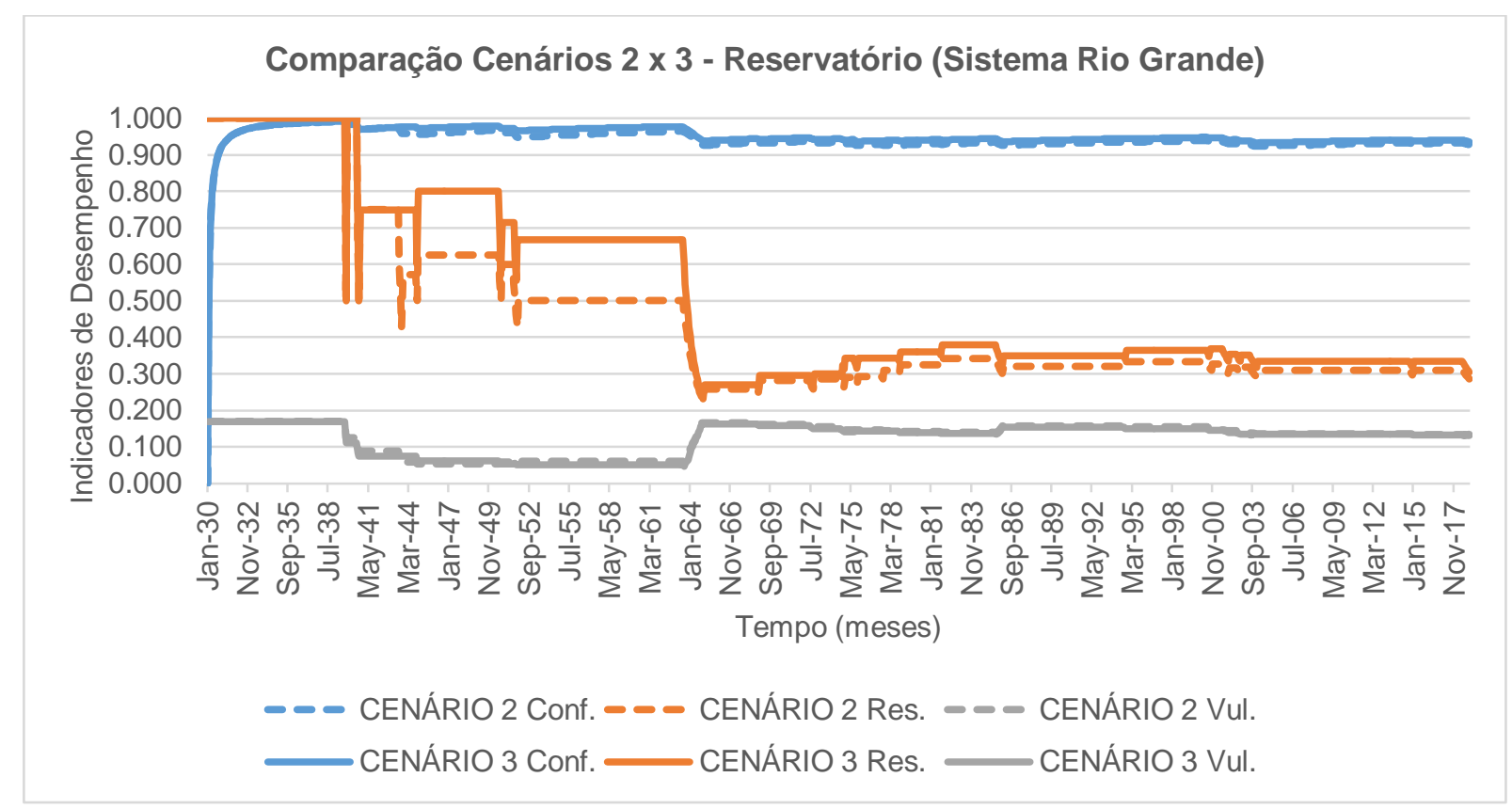

Figura 90: Acompanhamento dos indicadores de desempenho para os reservatórios do Sistema Rio Grande. Comparação entre os Cenários 2 e 3.

Por fim, a Figura 91 apresenta os resultados do Índice de Sustentabilidade global do Sistema Rio Grande para ambos os cenários simulados. Verificou-se um pequeno ganho de $3,5 \%$ na sustentabilidade global do Sistema Rio Grande a favor do Cenário 3. Ao final da série, o Índice de Sustentabilidade ficou em 0,808 para o Cenário 2 e 0,836 para o Cenário 3. 
Comparação Cenários 2 × 3 - Sustentabilidade Global (Sistema Rio Grande)

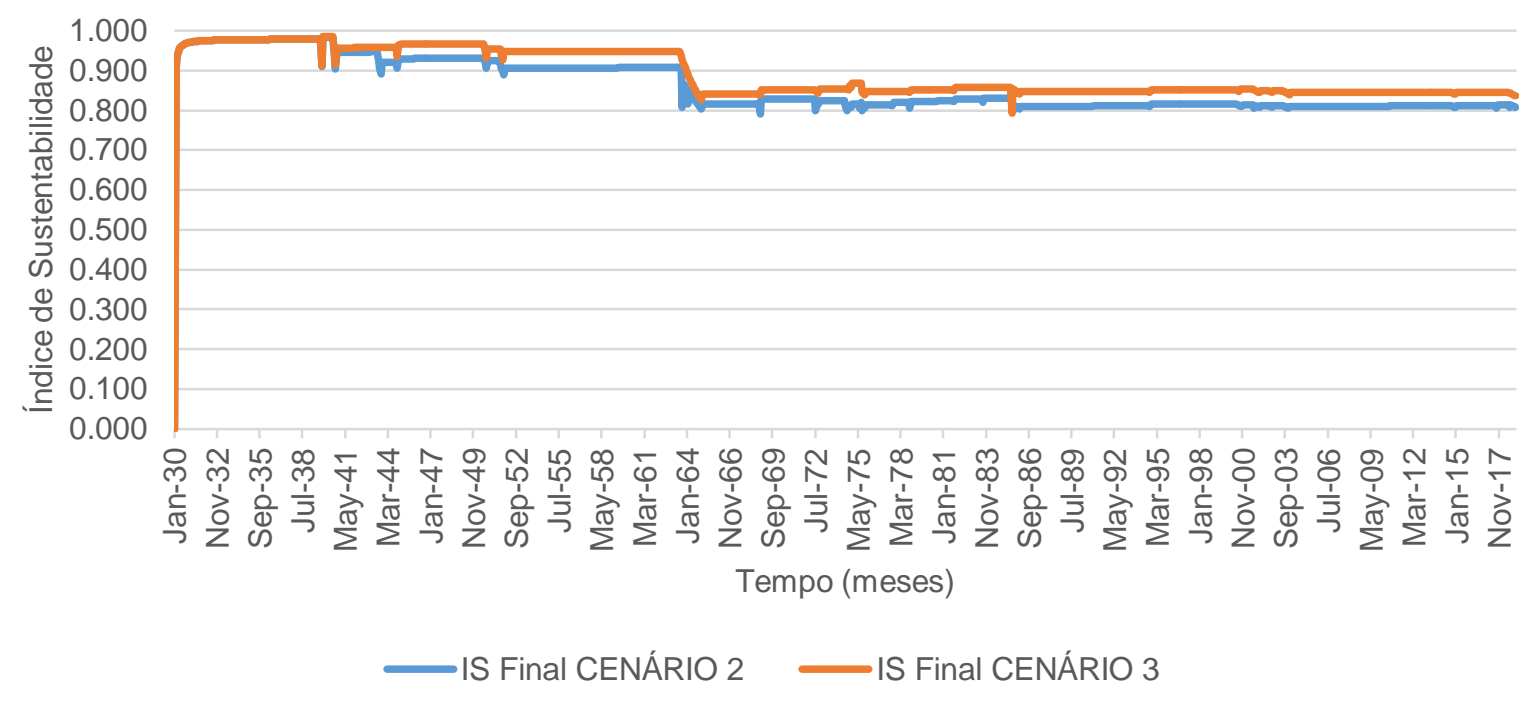

Figura 91: Acompanhamento do Índice de Sustentabilidade global do Sistema Rio Grande. Comparação entre os Cenários 2 e 3.

\subsubsection{SISTEMA SÃO LOURENÇO}

Nos 2 cenários de simulação, o Sistema São Lourenço não registrou falhas de fornecimento, nem tampouco condições insatisfatórias de armazenamento de água no reservatório Cachoeira do França, assim, todos os indicadores de desempenho e, por consequência, o Índice de Sustentabilidade global mantiveram-se nos seus respectivos valores máximos ideais, como observado na Figura 92. 


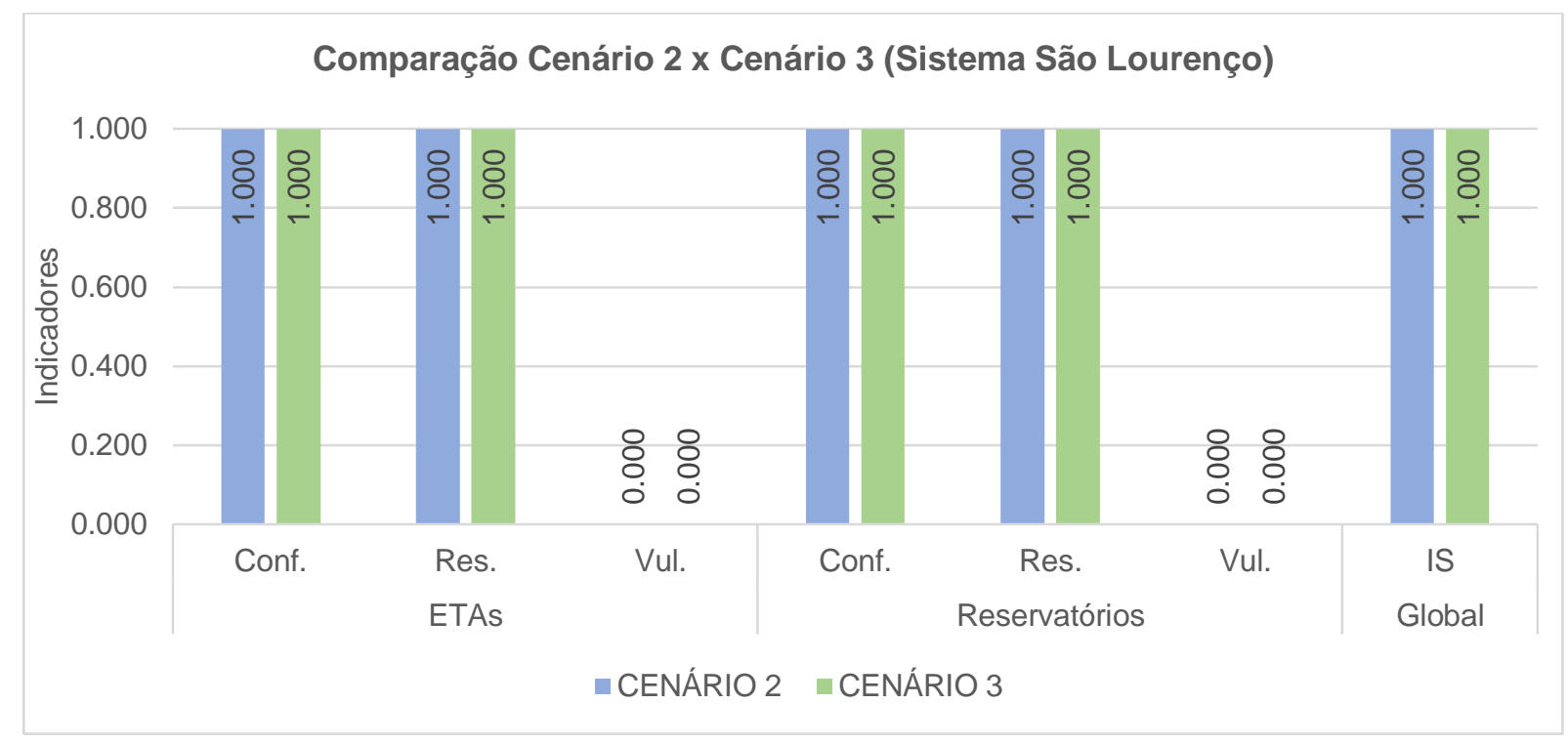

Figura 92: Resumo dos indicadores de desempenho e índice global de sustentabilidade para o Sistema São Lourenço. Comparação Cenários 2 e 3.

Apesar do fato mencionado acima, é interessante ressaltar que as interligações propostas para o Sistema São Lourenço registraram um funcionamento ativo, tanto do ponto de vista do recebimento de água quanto do fornecimento para os demais sistemas do SIM, conforme demonstrado na Figura 93 abaixo.

Em relação à capacidade máxima de compartilhamento, o São Lourenço foi o sistema que mais compartilhou água com os demais sistemas do SIM. Em média, o São Lourenço forneceu $0,463 \mathrm{~m}^{3} / \mathrm{s}$ aos pontos de demanda compartilhada com os Sistemas Cantareira e Cotia, o que representa $16,1 \%$ de sua capacidade máxima de transferência de $2,88 \mathrm{~m}^{3} / \mathrm{s}$.

Embora com valores absolutos bem menores, por questões de arranjo operacional da rede, o São Lourenço também recebeu água do Sistema Cotia para atendimento de suas demandas compartilhadas. Nota-se que quando o São Lourenço necessita aumentar as vazões fornecidas ao Cantareira a valores superiores a 0,640 $\mathrm{m}^{3} / \mathrm{s}$, o sistema opta por primeiramente atender suas demandas isoladas e ceder $\mathrm{o}$ máximo de água possível (dentro dos limites de sua outorga) para atender às demandas compartilhadas. Os déficits que, em um primeiro momento, deveriam ocorrer demanda compartilhada do próprio São Lourenço são equalizados mediante as transferências oriundas do Alto e Baixo Cotia. Estas vazões foram registradas em ao menos $27 \%$ dos meses simulados. 


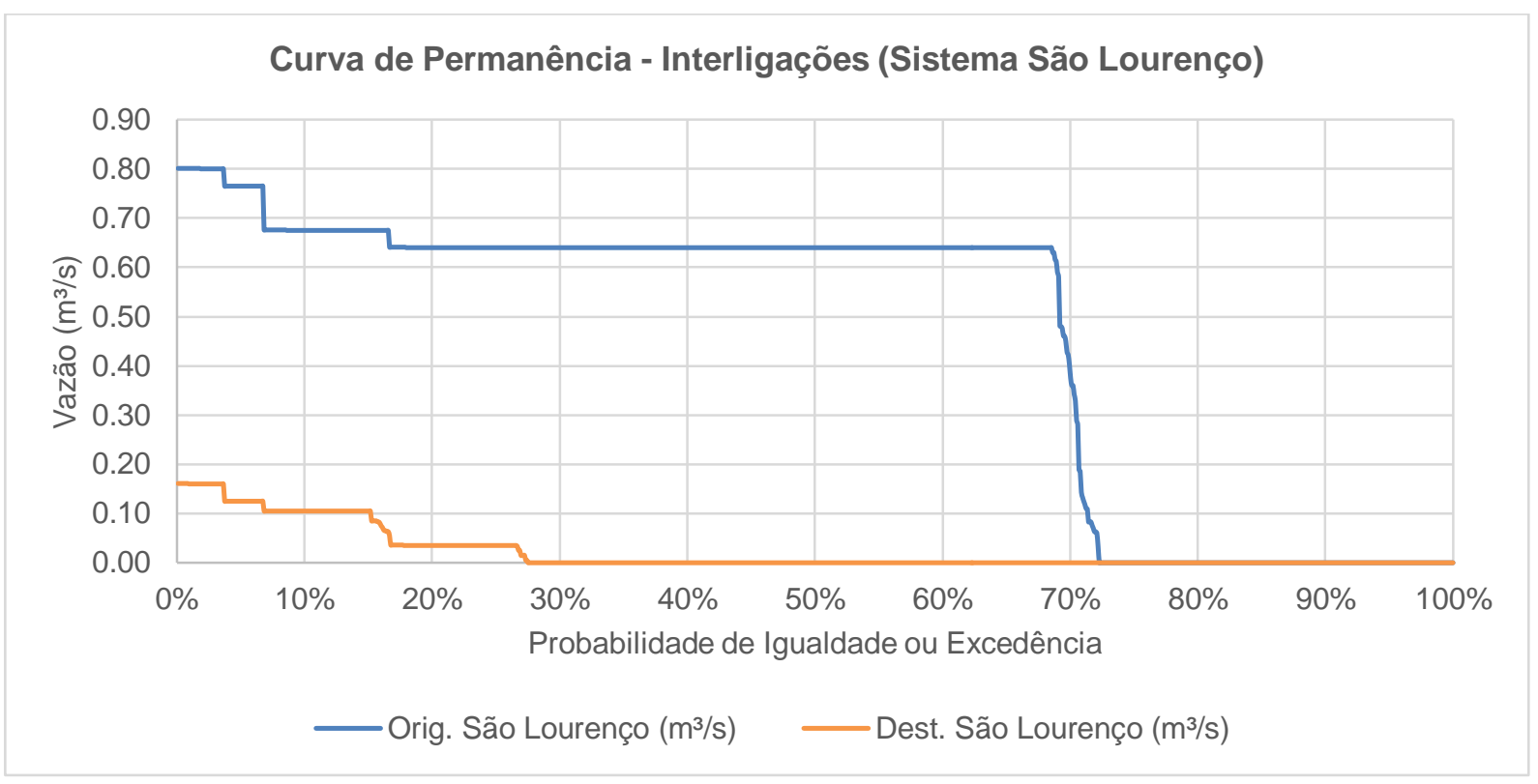

Figura 93: Curvas de permanência das vazões de interligação do Sistema São Lourenço.

\subsubsection{SISTEMA INTEGRADO METROPOLITANO}

A comparação do desempenho global do Sistema Integrado Metropolitano para as simulações realizadas nos Cenários 2 e 3 demonstra que a integração da rede trouxe ganhos de desempenho mais perceptíveis em termos de atendimento às demandas de fornecimento das ETA's do SIM, do que propriamente na reservação global de água do sistema. O resumo destes resultados é apresentado na Figura 94 a seguir. 


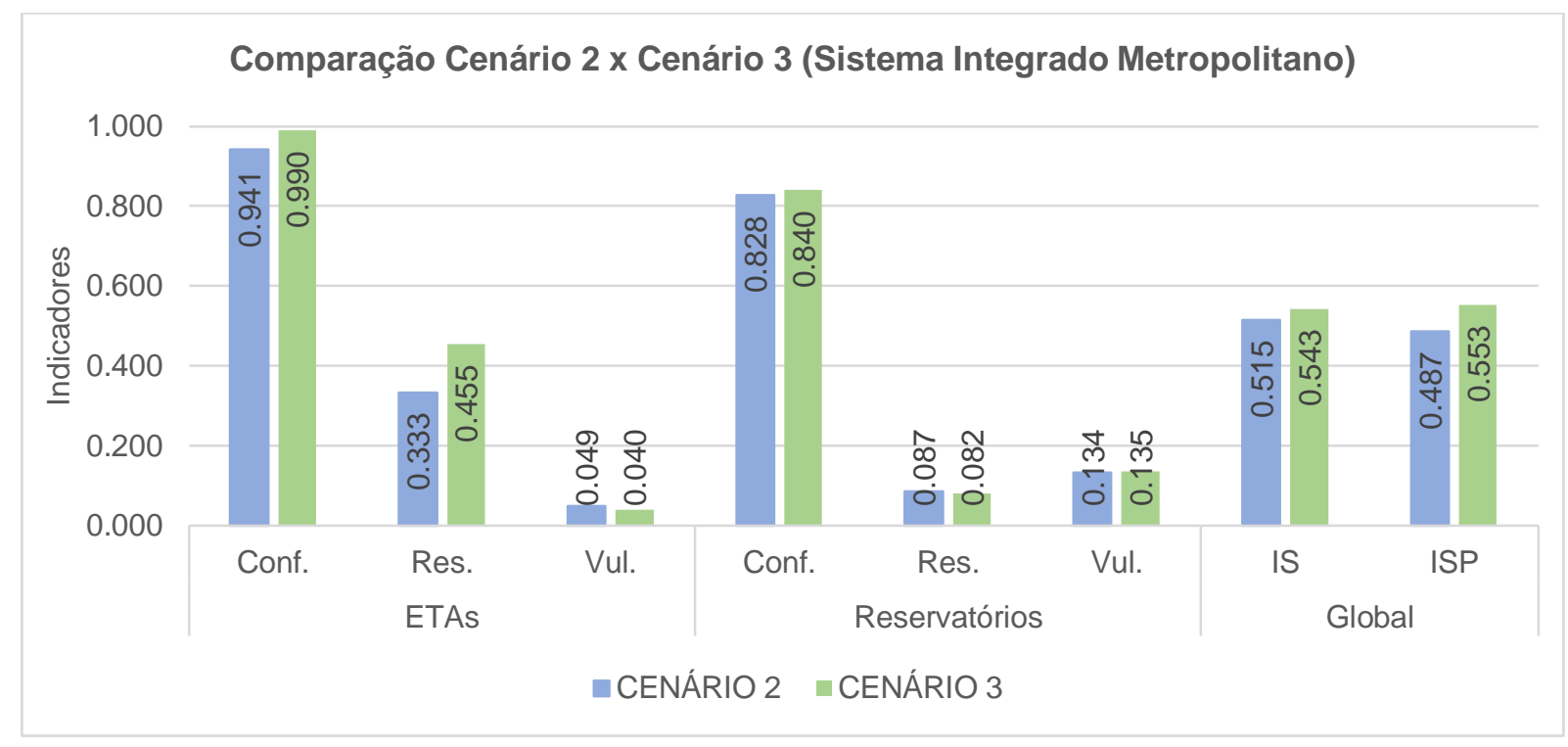

Figura 94: Resumo dos indicadores de desempenho e índice global de sustentabilidade para o Sistema Integrado Metropolitano. Comparação Cenários 2 e 3.

A Figura 95 abaixo demonstra o somatório das vazões fornecidas às ETA's do SIM nas simulações dos Cenários 2 e 3. Nota-se que a integração da rede resultou na redução do número absoluto de eventos de falha de atendimento, concentrando as falhas principalmente no período da Crise Hídrica de 2014-2015. Os déficits verificados no período, porém, foram reduzidos em termos de magnitude na comparação com as falhas deste mesmo período no Cenário 2.

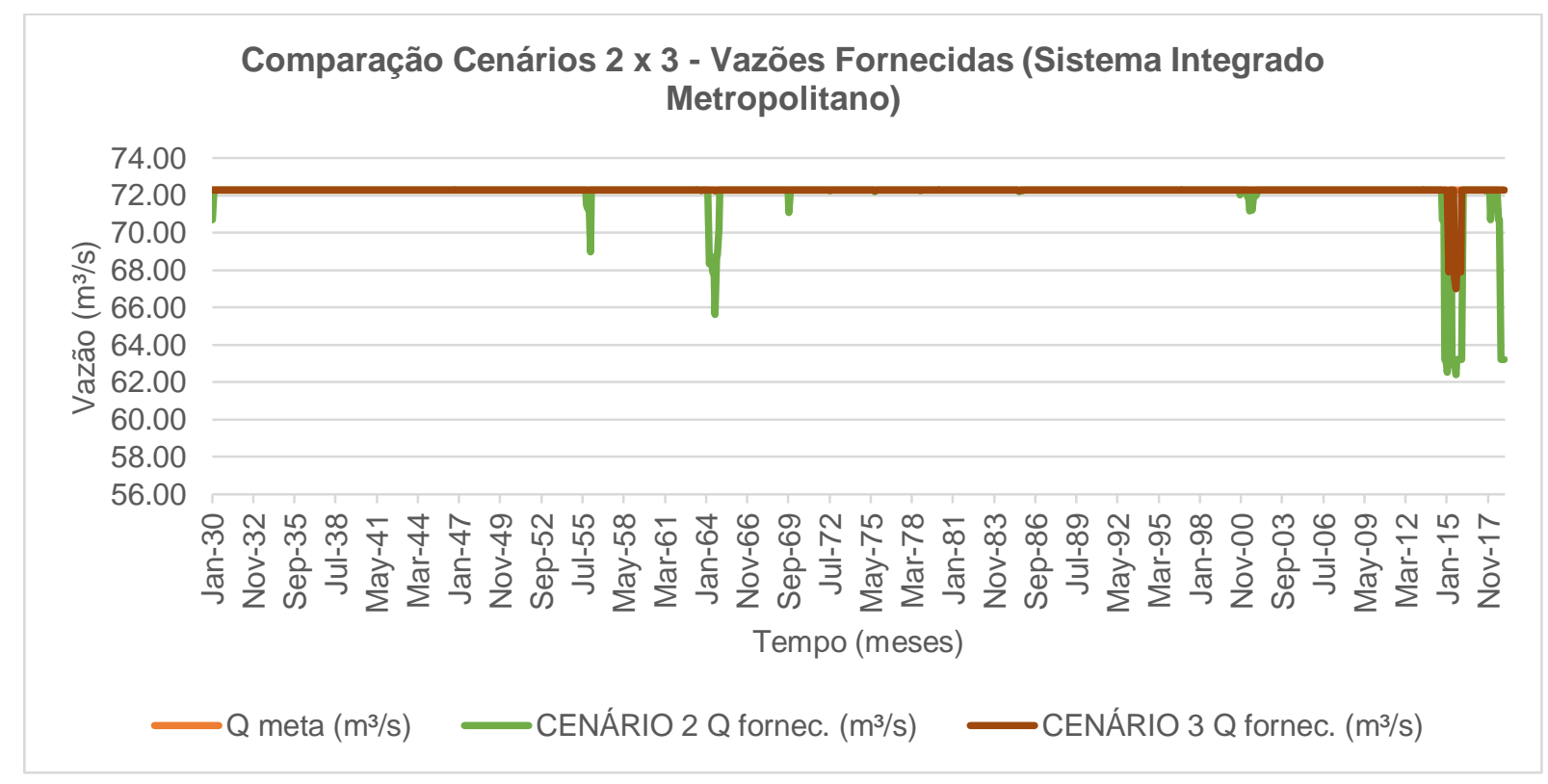

Figura 95: Somatório das vazões fornecidas e vazão-meta para o total das ETA's do Sistema Integrado Metropolitano nos Cenários 2 e 3. 
Os indicadores de desempenho global de fornecimento de água do SIM registraram pequenos ganhos em Confiabilidade e Vulnerabilidade. No Cenário 2, tais indicadores foram registrados em 0,941 e 0,049, respectivamente. Já no Cenário 3, a Confiabilidade foi de 0,990 e a Vulnerabilidade, 0,040.

Conforme pode ser observado na Figura 96, a Resiliência do sistema, embora mantida em um patamar intermediário, foi o critério de desempenho que apresentou melhoras mais notáveis, passando de 0,333 no Cenário 2 para 0,455 no Cenário 3 . Apesar de não perceptível na Figura 95, destaca-se que também foram registradas pontualmente 3 falhas de fornecimento no SIM nos anos de 1964, 1975 e 1985, entretanto, como a recuperação da condição satisfatória ocorreu logo nos meses posteriores às falhas, rapidamente a Resiliência retornou ao seu valor máximo. Como também observado individualmente para alguns sistemas, a redução para um número mínimo de falhas na série faz com que qualquer período de falhas sequenciais de operação gerem uma perda importante de Resiliência. Mesmo que tenham sido atenuadas em quantidade e magnitude, as falhas que ainda ocorreram no Cenário 3 no período da Crise de 2014-2015 foram determinantes para a perda de desempenho no indicador de Resiliência das ETA's.

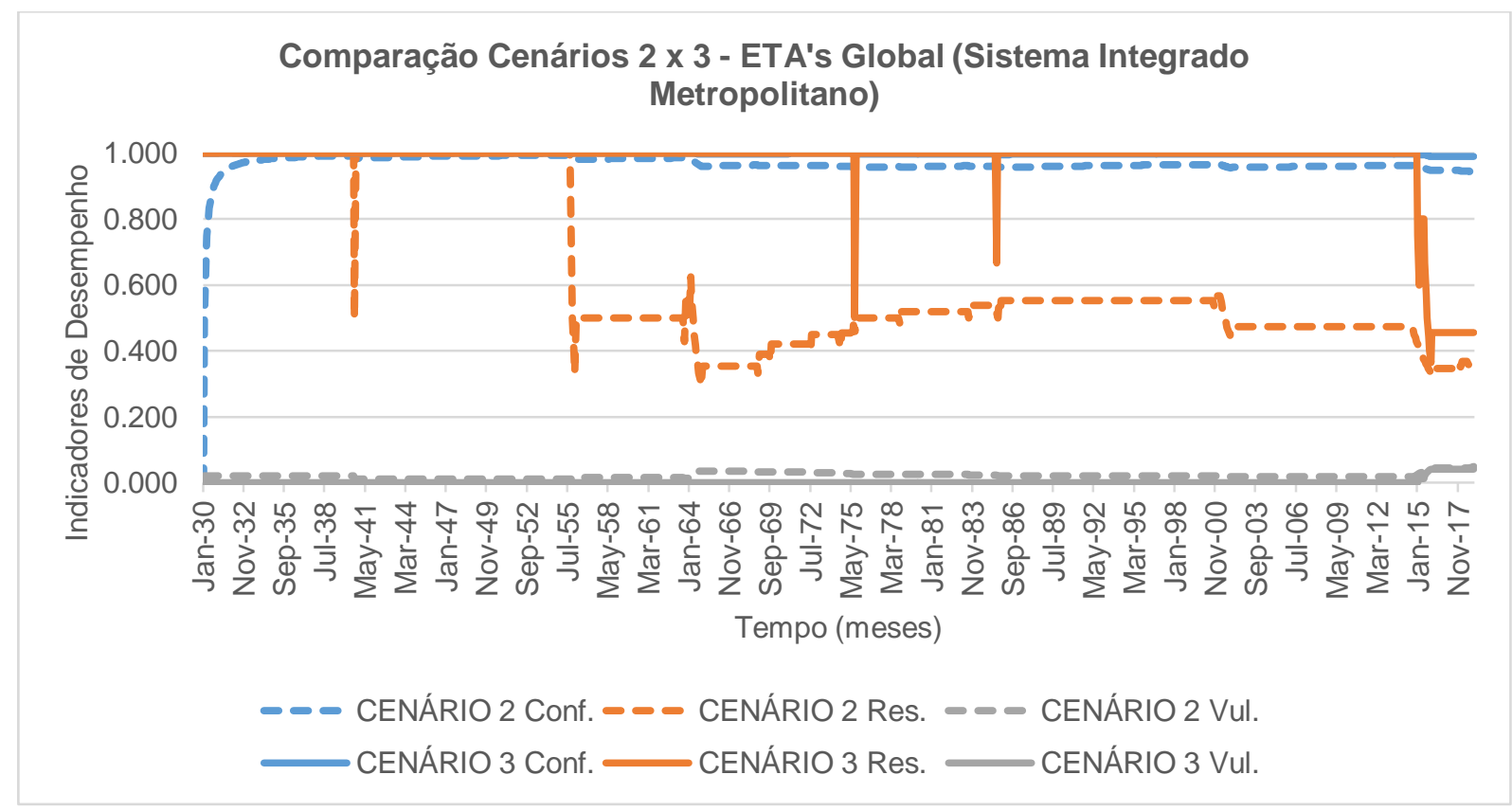

Figura 96: Acompanhamento dos indicadores de desempenho para o fornecimento global de água das ETA's do Sistema Integrado Metropolitano. Comparação entre os Cenários 2 e 3. 
Os volumes totais armazenados nos reservatórios do SIM, para os Cenários 2 e 3, são apresentados na Figura 97. A integração das redes através de pontos de demandas compartilhadas não gerou ganhos notáveis no armazenamento médio do sistema.

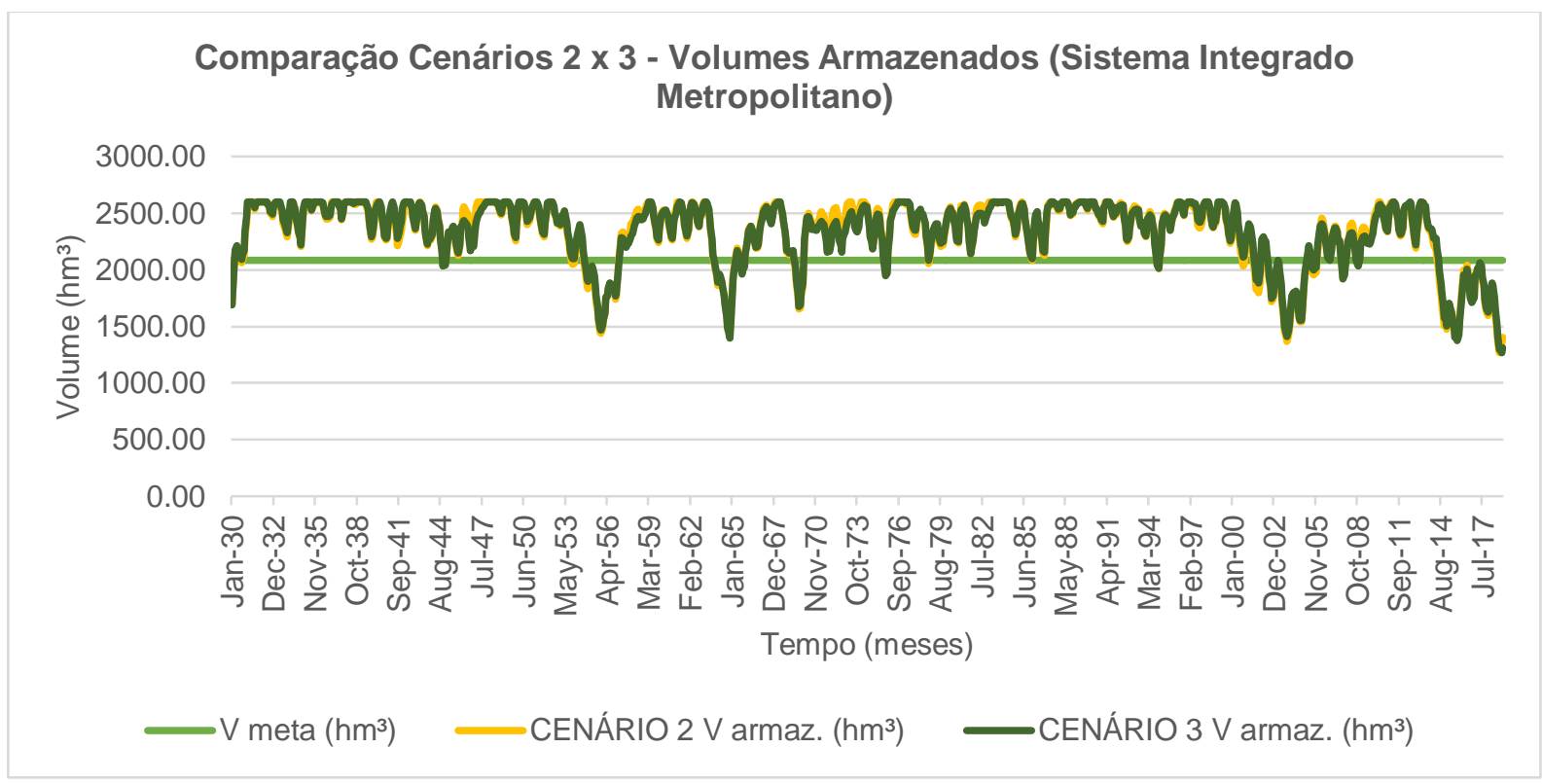

Figura 97: Volumes armazenados totais e Volume-meta para o Sistema Integrado Metropolitano nos Cenários 2 e 3.

As condições insatisfatórias de armazenamento foram reduzidas de 184 no Cenário 2 para 171 no Cenário 3. Na prática, as diferenças de desempenho entre os Cenários 2 e 3 foram mínimas em termos de armazenamento de água. A Confiabilidade passou de 0,828 no Cenário 2 para 0,840 no Cenário 3 , a Resiliência de 0,087 para 0,082 e, por fim, a Vulnerabilidade passou de 0,134 para 0,135 . 


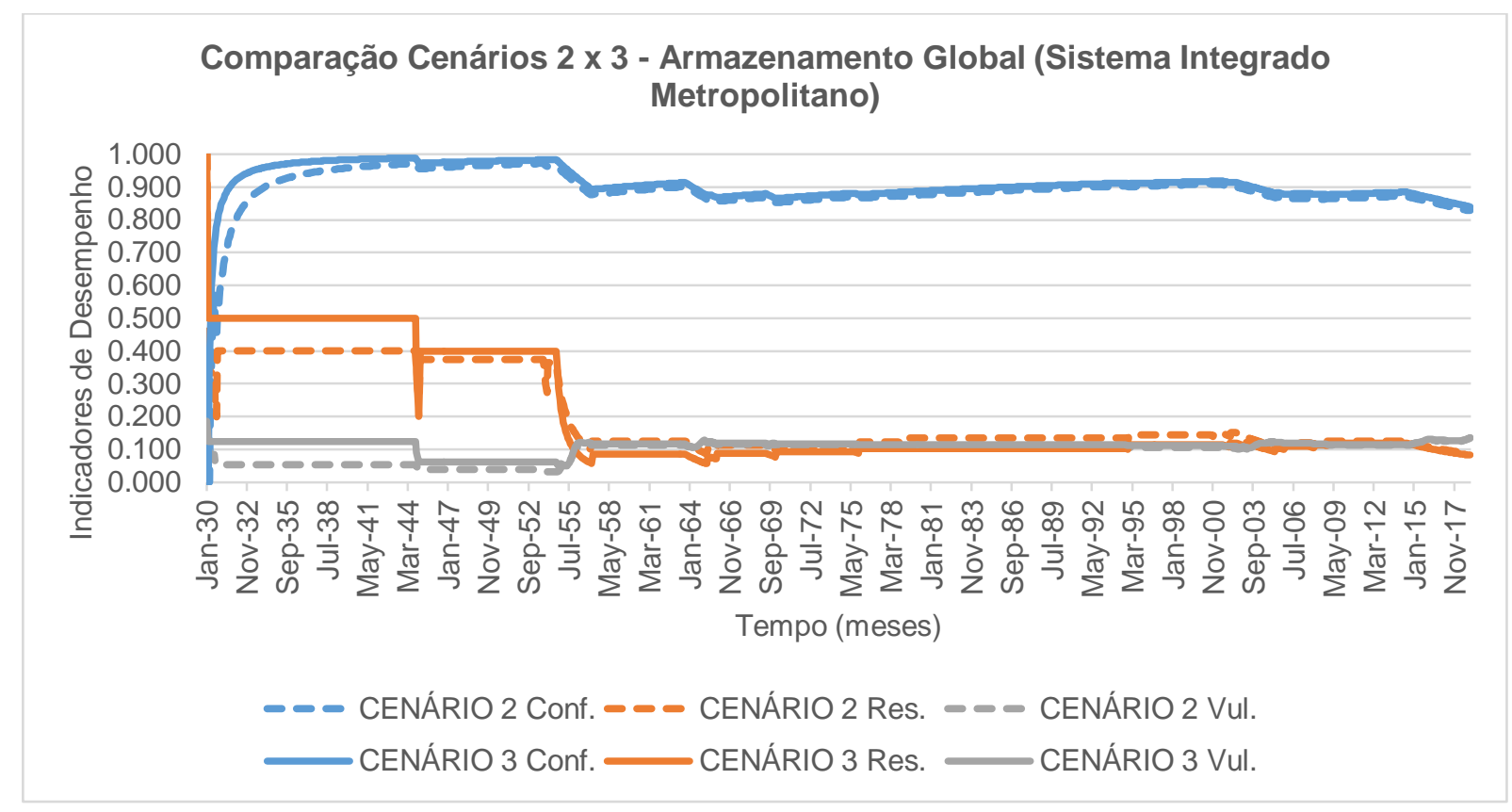

Figura 98: Acompanhamento dos indicadores de desempenho para o armazenamento global dos reservatórios do Sistema Integrado Metropolitano. Comparação entre os Cenários 2 e 3.

A Figura 99 abaixo apresenta os resultados dos Índices de Sustentabilidade global do Sistema Integrado Metropolitano, para os Cenários 2 e 3.

A rede isolada do SIM com os aportes das obras (Cenário 2) e a rede integrada (Cenário 3) apresentaram resultados de desempenho muito similares para Confiabilidade e Vulnerabilidade nas ETA's e nos 3 (três) indicadores para o armazenamento global de água.

Os ganhos anotados na Resiliência das ETA's do SIM foram determinantes para a sensível melhora na sustentabilidade global do Cenário 3 em comparação do Cenário 2. Ao final da série, o índice global para a rede integrada foi de 0,543 contra 0,515 da rede isolada. O compartilhamento de demandas do Cenário 3 resultou em ganhos globais de aproximadamente 5,5\% de desempenho. Já para o Índice de Sustentabilidade Ponderado (ISP), os ganhos anotados com a integração da rede foram maiores, ficando na ordem de 13\%, passando de 0,553 no Cenário 2 para 0,625 no Cenário 3. Os ganhos de desempenho anotados principalmente para os Sistemas Cantareira, Guarapiranga, Rio Claro e Rio Grande, que juntos correspondem a aproximadamente $70 \%$ do desempenho do SIM, resultaram nos ganhos mais elevados para o Índice de Sustentabilidade Ponderado (ISP) em relação ao IS. 


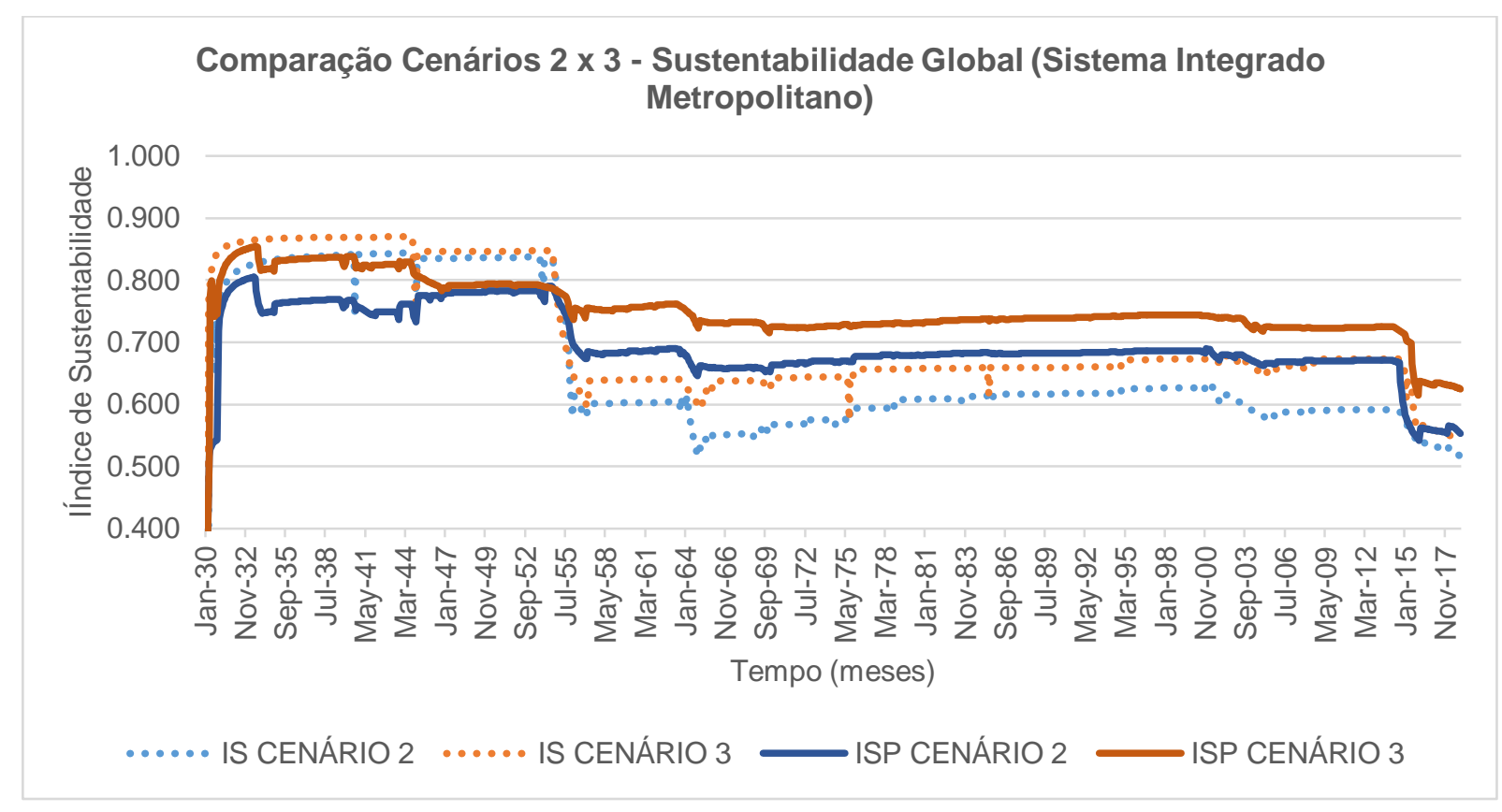

Figura 99: Acompanhamento do Índice de Sustentabilidade global do Sistema Integrado Metropolitano. Comparação entre os Cenários 2 e 3.

\subsection{BLOCO 3 - DESEMPENHO GLOBAL DO SIM NOS CENÁRIOS 1, 2 E 3}

O Bloco 3 de resultados apresenta uma análise conjunta dos 3 cenários de simulação sob o ponto de vista do desempenho global do Sistema Integrado Metropolitano.

O intuito deste bloco é de ressaltar pontos importantes comentados nos blocos anteriores, assim como apresentar uma análise comparativa da evolução da configuração da rede do SIM nos 3 cenários propostos, apontando as devidas consequências que estas configurações trouxeram para o desempenho global do sistema.

No Cenário 1, a rede do SIM demonstrava sua configuração básica inicial, que serviu de condição-base de desempenho para a comparação os demais cenários desenhados. A configuração da rede proposta no Cenário 2 contou com a inclusão das ditas obras de incremento de segurança hídrica, implementadas no âmbito da Crise Hídrica de 2014-2015 da Região Metropolitana de São Paulo. Estas obras trouxeram novos aportes de água para os Sistemas Alto Tietê, Cantareira e Rio Grande. 
No cômputo geral, os novos aportes do Cenário 2 reduziram as falhas de fornecimento nos pontos de demanda das ETA's e diminuíram as condições insatisfatórias de armazenamento de água nos sistemas diretamente beneficiados. Os ganhos afetaram o desempenho global do SIM e foram verificados principalmente na elevação do desempenho das ETA's em Confiabilidade e Resiliência, que passaram de 0,852 e 0,196 no Cenário 1 para 0,941 e 0,333 no Cenário 2, respectivamente. Nos reservatórios, a Confiabilidade também demonstrou um ganho importante, passando de 0,630 no Cenário 1 para 0,828 no Cenário 2. A Vulnerabilidade manteve-se em patamares reduzidos, apresentando sensíveis reduções do Cenário 1 para o Cenário 2; nas ETA's o indicador reduziu de 0,084 para 0,049; e nos reservatórios 0,175 para 0,134 .

O Cenário 3 proposto neste trabalho avaliou os ganhos e perdas de desempenho resultantes da integração da rede do SIM através da criação de pontos de demandas compartilhadas entre os sistemas produtores de água. Neste cenário, de forma positiva ou negativa, em maior ou menor escala, todos os sistemas integrantes do SIM apresentaram variações de desempenho nos quesitos de Confiabilidade, Resiliência e Vulnerabilidade. Em termos globais, o compartilhamento de demandas resultou em ganhos de desempenho mais acentuados no atendimento às demandas totais das ETA's. A Confiabilidade passou de 0,941 no Cenário 2 para 0,990 no Cenário 3 , enquanto a Resiliência subiu de 0,333 para 0,455 ; e a Vulnerabilidade reduziu sensivelmente de 0,049 para 0,040.

Sob o ponto de vista do armazenamento global de água, os Cenários 2 e 3 não apresentaram diferenças significativas. Menciona-se apenas o pequeno incremento de Confiabilidade que passou de 0,828 para 0,840 , resultante da diminuição das condições insatisfatórias de armazenamento no Cenário 3. Os ganhos em termos de reservação conseguidos pelo SIM com os aportes simulados no Cenário 2 foram mantidos. No Cenário 3, mesmo que um sistema produtor tenha apresentado incrementos nos volumes médios armazenados nos seus reservatórios, como por exemplo no caso do Cantareira, estes ganhos foram praticamente equalizados pela depleção mais acentuada de outro sistema, como por exemplo o Alto Tietê, fazendo com que no cômputo global o SIM apresentasse volumes reservados muito próximos entre os Cenários 2 e 3 . Os ganhos de fornecimento observados na rede integrada (Cenário 3) foram decorrentes principalmente dos arranjos operacionais de compartilhamento de vazões que esta configuração da rede possibilitou. 
A Figura 100 a seguir demonstra o resumo dos resultados de desempenho do Sistema Integrado Metropolitano para os 3 (três) cenários analisados.

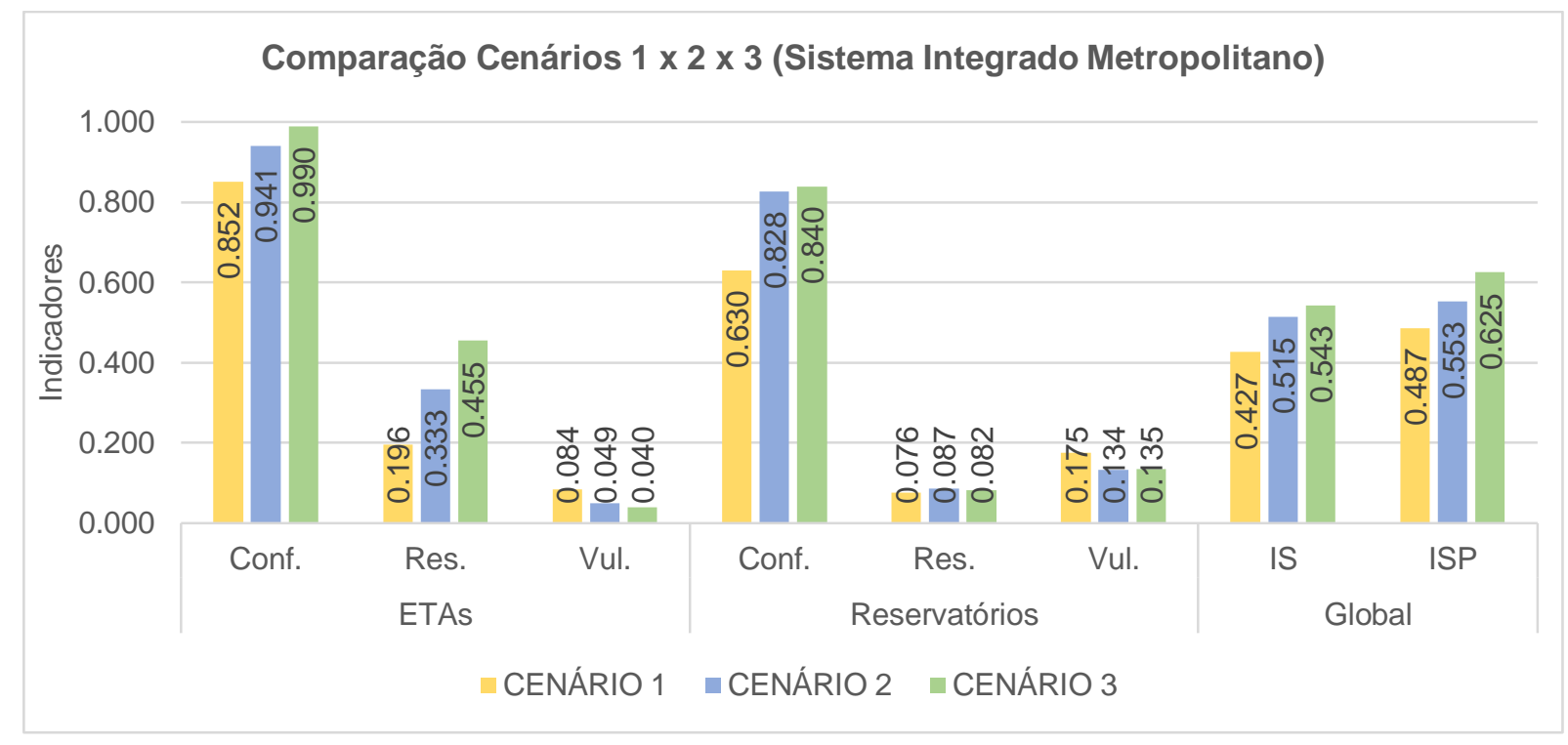

Figura 100: Resumo dos indicadores de desempenho e índice global de sustentabilidade para o Sistema Integrado Metropolitano. Comparação Cenários 1, 2 e 3.

Analisando o contexto dos 3 (três) cenários de simulação, verifica-se que a Resiliência é o principal fator que afeta a sustentabilidade global do Sistema Integrado Metropolitano. Enquanto que o conjunto das ETA's do SIM apresentou notáveis ganhos de Resiliência a cada configuração da rede, para a reservação de água do SIM, nos Cenários 1, 2 e 3 este indicador manteve-se praticamente constante, em um patamar muito próximo de seu valor mínimo. Na prática, isto demonstra que, uma vez que atinge uma condição insatisfatória de armazenamento, o SIM tem baixa capacidade de se recuperar em um pequeno período de tempo. Ou seja, é característico do sistema uma elevada inércia para recobrar uma situação satisfatória de armazenamento global de água em seus reservatórios.

O acompanhamento dos Índices de Sustentabilidade global do Sistema Integrado Metropolitano nos 3 (três) cenários encontra-se apresentado abaixo na Figura 101. Por meio do IS, do Cenário 1 para Cenário 2, os ganhos globais foram registrados em aproximadamente $20,6 \%$, passando de 0,427 para 0,515 ; enquanto que do Cenário 2 para o 3, o acréscimo relativo do Índice de Sustentabilidade foi menor, da ordem de $5,5 \%$, passando de 0,515 para 0,543 . 
Por outro lado, em termos ponderados, os ganhos progressivos de cada Cenário de Simulação foram similares. Do Cenário 1 para $\circ 2$, os ganhos de desempenho foram registrados em $13,6 \%$, passando de 0,487 para 0,553 . E do Cenário 2 para o 3, o acréscimo de desempenho foi de $13,0 \%$, tendo o ISP passado de 0,553 para 0,625 .

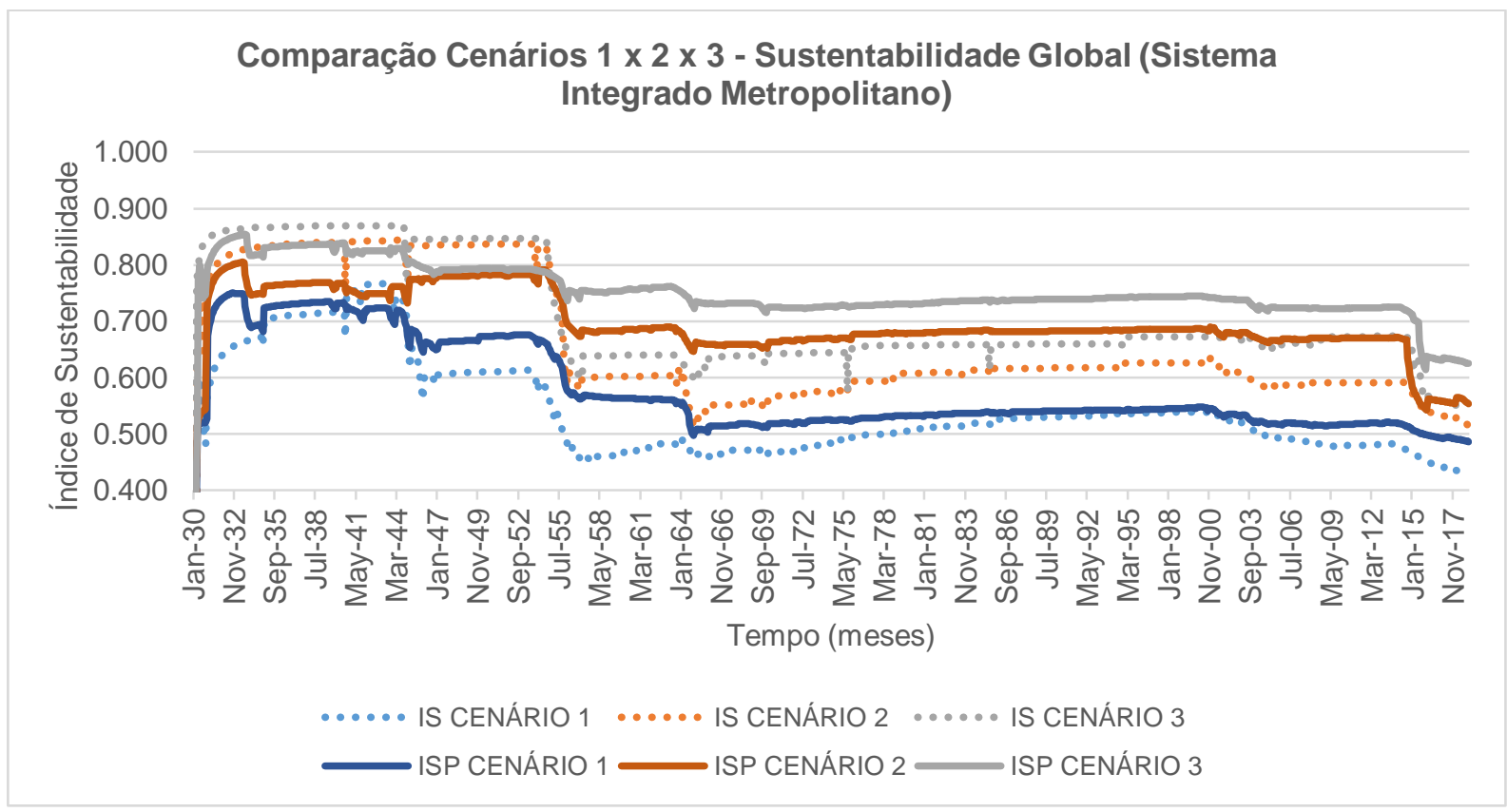

Figura 101: Acompanhamento do Índice de Sustentabilidade global do Sistema Integrado Metropolitano. Comparação entre os Cenários 1, 2 e 3.

Há de se ressaltar que os resultados obtidos com a integração do SIM através de pontos de demandas compartilhada possuem o potencial de apresentarem ganhos ainda mais significativos, desde que outras premissas operacionais sejam adotadas na simulação da rede. Tendo em vista que foi uma deliberação do autor deste trabalho a adoção das vazões outorgadas como fator limitante à captação de água dos reservatórios, eventuais rearranjos nestes valores poderão propiciar um incremento dos atendimentos globais da rede. Nesta mesma linha, a definição das metas de fornecimento nas ETA's, bem como das metas de armazenamento dos reservatórios também são variáveis que podem ser melhor ajustadas no intuito de gerar um maior desempenho de cada sistema e, por conseguinte, do Sistema Integrado Metropolitano como um todo.

A partir dos resultados de Confiabilidade, Resiliência e Vulnerabilidade de cada sistema produtor, em cada um 3 (três) dos Cenários de Simulação, procurou-se 
entender o perfil de correlação entre cada dupla de indicadores. Este exercício teve como intuito identificar o comportamento específico dos sistemas componentes do SIM, bem como verificar perfis de correção já mencionados na literatura.

Em termos de Confiabilidade e Resiliência, aparentemente os resultados dos sistemas produtores do SIM sugerem que os sistemas de elevada Confiabilidade não possuem igualmente elevadas Resiliências, principalmente em termos de reservação de água, como pode ser observado abaixo na Figura 102. Sob o ponto de vista das ETA's, os resultados foram mais distribuídos, os resultados abaixo de 0,500 de Resiliência foram anotados pelos Sistemas Guarapiranga e Rio Claro nos Cenários 1 e 2. E Cotia e Cantareira, nos 3 Cenários. Nas demais operações, a elevada Confiabilidade também sugeriu uma elevada Resiliência de abastecimento.

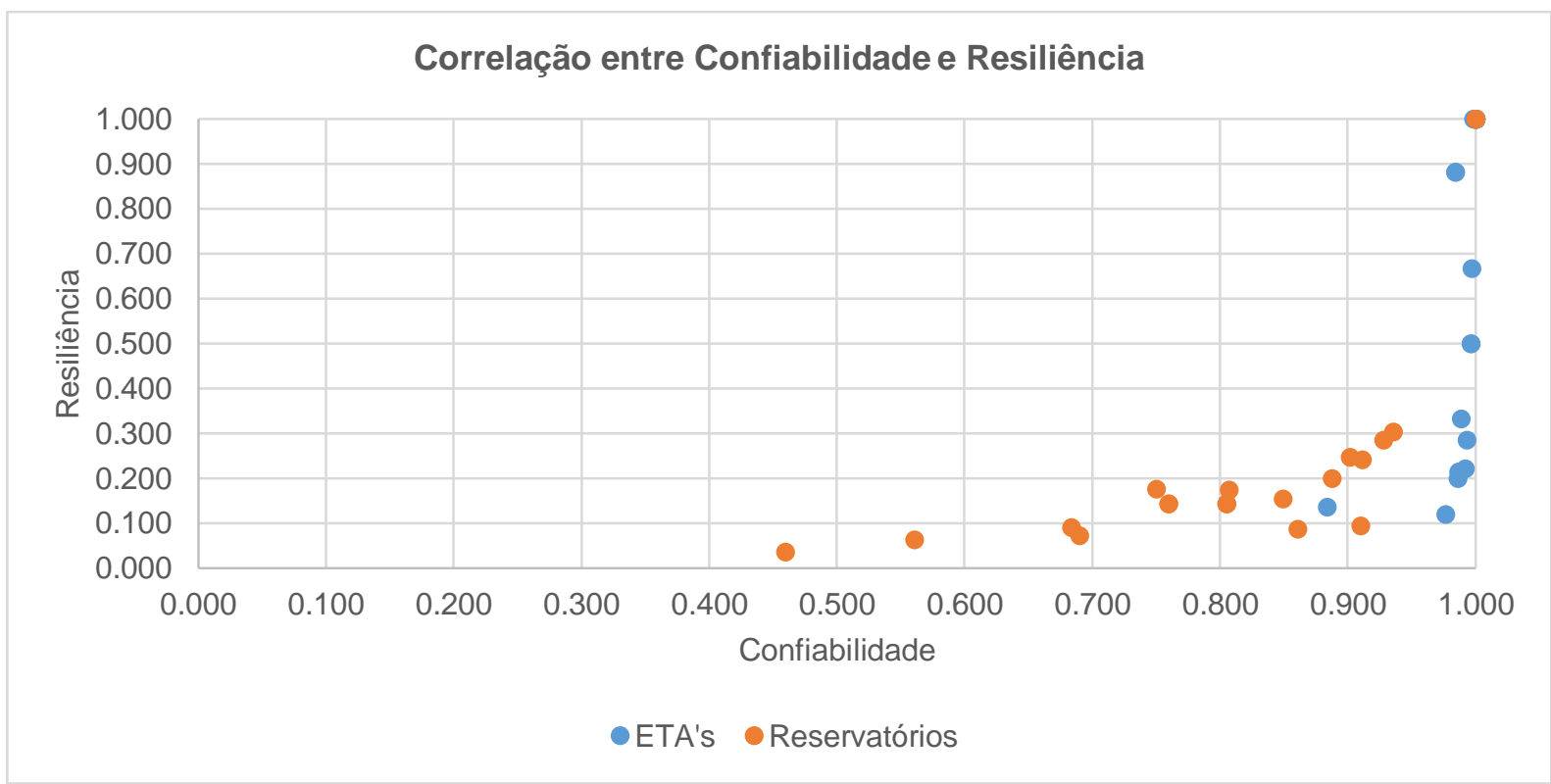

Figura 102: Correlação dos resultados de Confiabilidade e Resiliência, calculados em dezembro/18, para os sistemas produtores do SIM nos 3 (três) cenários de simulação.

Na Figura 103 a seguir, a correlação entre os indicadores de Confiabilidade e Vulnerabilidade sugere que, na maioria dos casos, os sistemas mais confiáveis $(\mathrm{C}>$ $0,800)$ também demonstraram uma mediana a baixa Vulnerabilidade às falhas $(\mathrm{V}<$ $0,400)$. Apesar de demonstrar um comportamento de Vulnerabilidade similar aos demais Sistemas, o Sistema Alto Tietê apresentou os menores resultados em termos de Confiabilidade na reservação de água. 


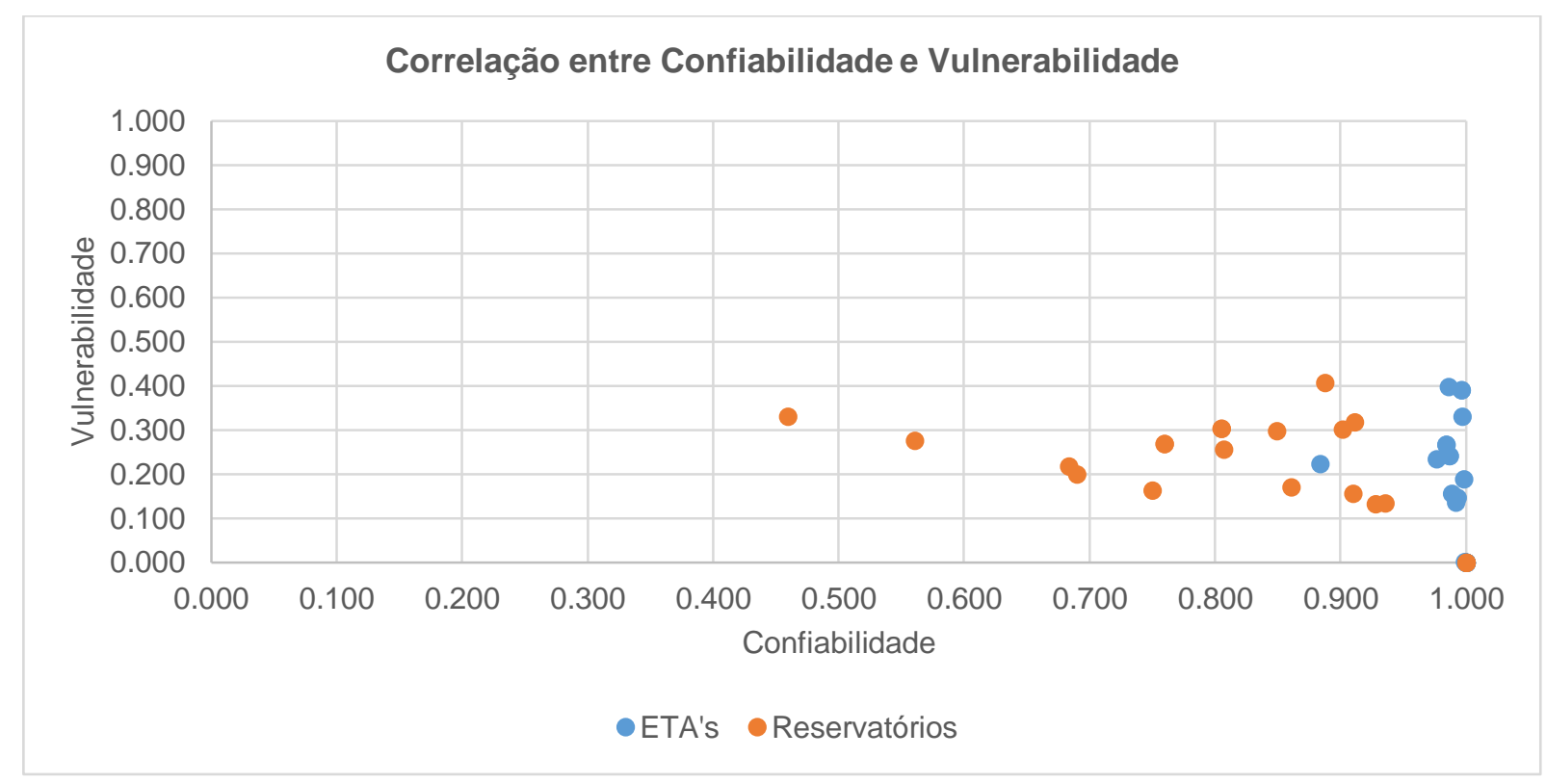

Figura 103: Correlação dos resultados de Confiabilidade e Vulnerabilidade, calculados em dezembro/18, para os sistemas produtores do SIM nos 3 (três) cenários de simulação.

A Figura 104 demonstra a correlação entre os indicadores de Resiliência e Vulnerabilidade. A disposição dos dados sugere uma tendência dos sistemas produtores do SIM de demonstrarem baixas Resiliências, frente a Vulnerabilidades de mediana a baixa, principalmente sob o ponto de vista dos reservatórios.

Por outro lado, em termos de abastecimento de água nas ETA's, os resultados da correlação entre Resiliência e Vulnerabilidade foram mais dispersos. Enquanto os Sistemas Alto Tietê, Cotia (ETA Baixo Cotia), Guarapiranga (Cenário 3) Rio Claro, Rio Grande (ETA Rio Grande) tiveram os desempenhos máximos de cada indicador ( $\mathrm{R}=$ 1,000 e V $=0,000$ ), os Sistemas Cotia (ETA Alto Cotia), Cantareira, Guarapiranga (nos Cenários 1 e 2) e Rio Grande (ETA Ribeirão da Estiva) apresentaram baixas Vulnerabilidades e baixas Resiliências, de forma similar ao comportamento dos reservatórios. 


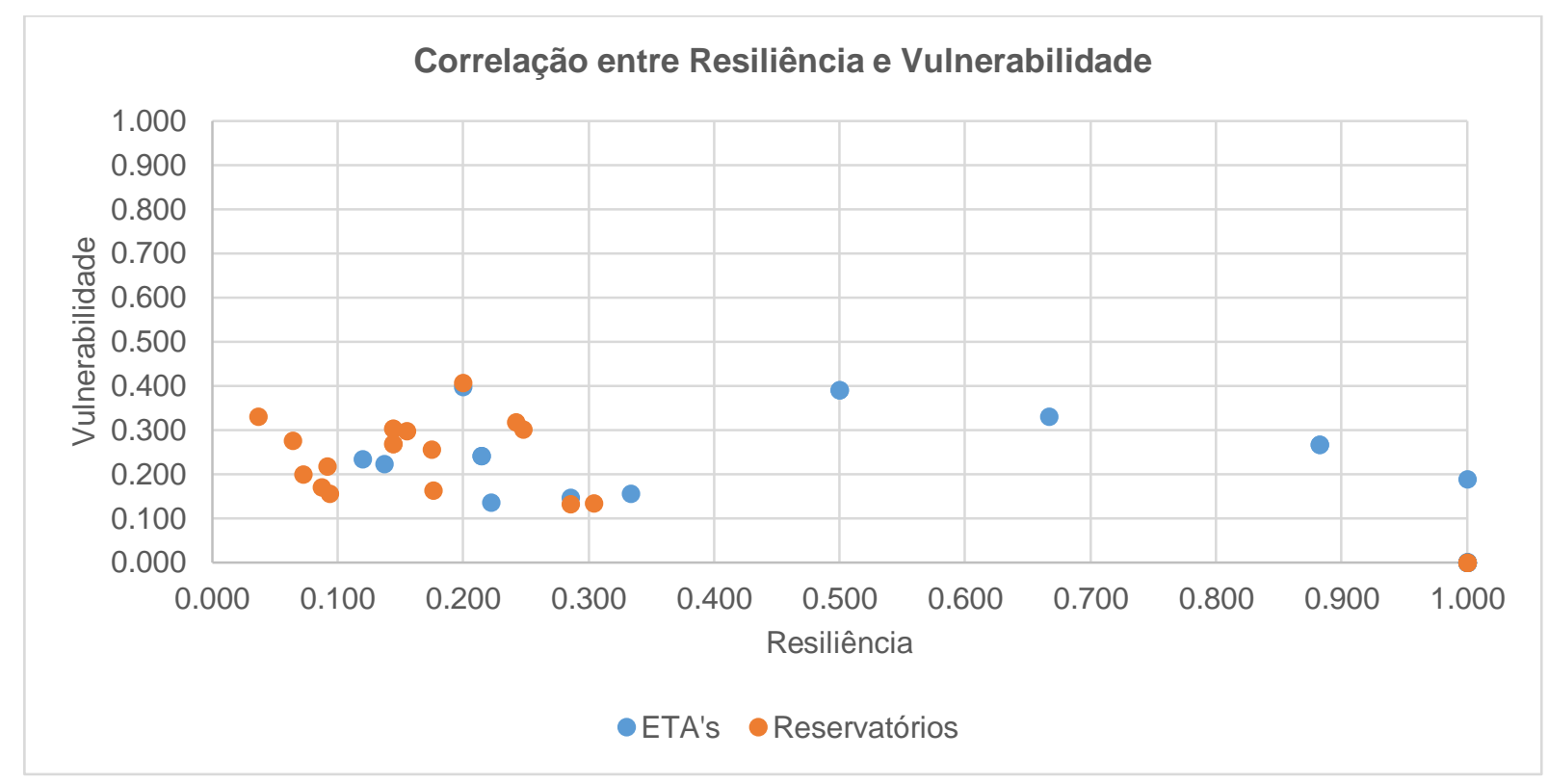

Figura 104: Correlação dos resultados de Resiliência e Vulnerabilidade, calculados em dezembro/18, para os sistemas produtores do SIM nos 3 (três) cenários de simulação.

Por fim, pretende-se ressaltar que a apresentação dos resultados de desempenho deste trabalho não pretende, em nenhuma instância, substituir métodos mais corriqueiros de demonstração de resultados de análises hidrológicas, como por exemplo a demonstração das garantias de vazões através de "curvas de permanência", muito utilizada nos estudos e relatórios técnicos da área. De fato, ambos os métodos guardam relação entre si, como pode ser verificado no exemplo do Sistema Cantareira abaixo (Figura 105). 


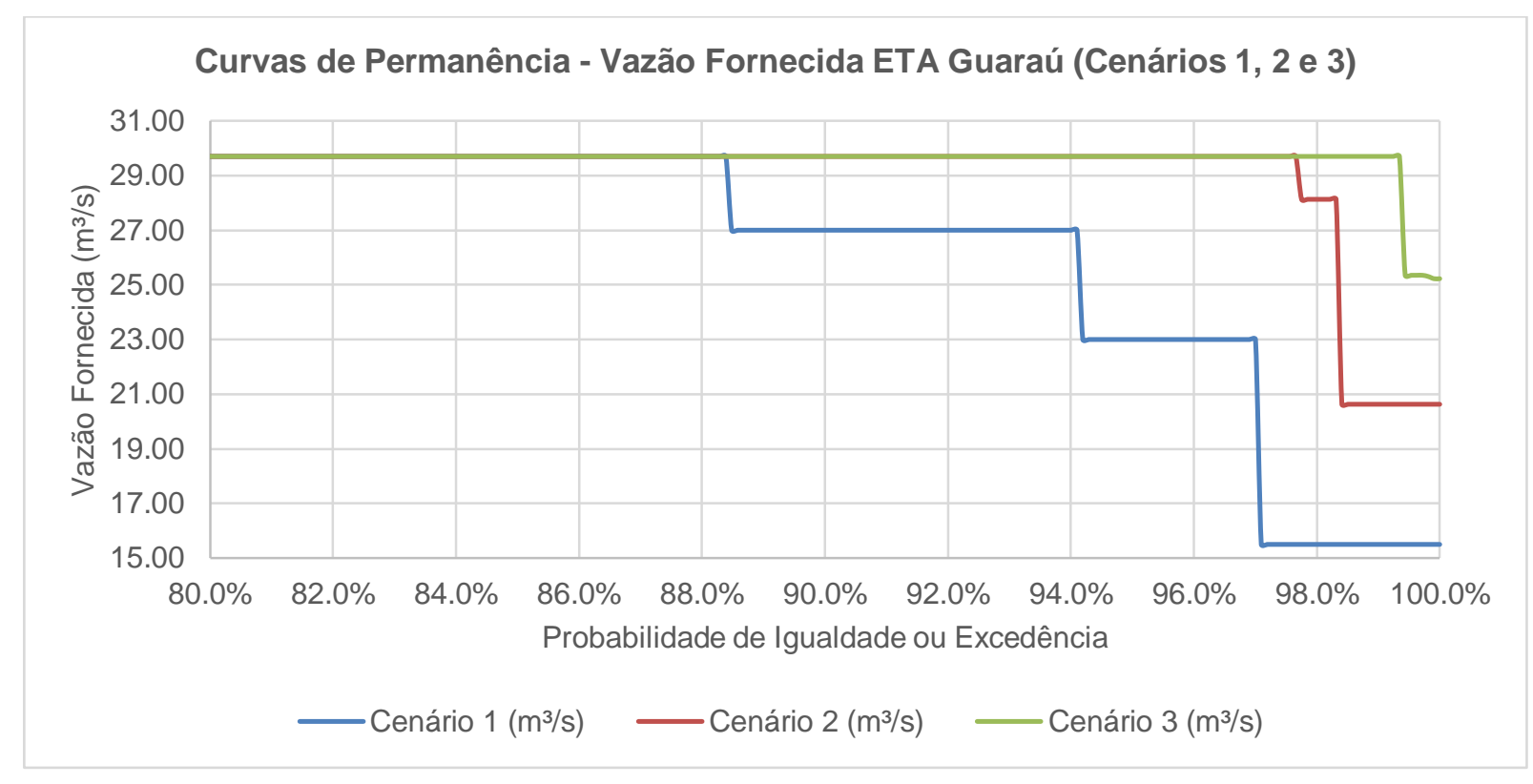

Figura 105: Curvas de permanência das vazões fornecidas na ETA Guaraú (Sistema Cantareira) nos Cenários 1, 2 e 3.

A Figura 105 apresenta as curvas de permanência para as vazões fornecidas na ETA Guaraú nos 3 (três) Cenários de Simulação. Observa-se que as garantias de fornecimento das vazões-meta de $29,70 \mathrm{~m}^{3} / \mathrm{s}$ são, respectivamente, $88,4 \%$ (Cenário 1); $97,7 \%$ (Cenário 2) e 99,3\% (Cenário 3), que correspondem exatamente aos valores dos indicadores de Confiabilidade da ETA. Os trechos finais das curvas de permanência, em que se situam os eventos de "falhas de atendimento" a uma determinada meta estabelecida, constituem-se justamente no ponto central em que o uso dos indicadores de desempenho complementam os métodos tradicionais de apresentação de resultados. Por meio da Resiliência e Vulnerabilidade, consegue-se avaliar com mais detalhes os impactos que os eventos de falha geram para um determinado sistema. Estes indicadores aportam informações relevantes, por exemplo, acerca da capacidade de recuperação do sistema, uma vez que a falha ocorre, assim como da magnitude médias das falhas. 


\section{CONCLUSÕES}

O presente trabalho apresentou e discutiu a utilização dos indicadores de desempenho Confiabilidade, Resiliência e Vulnerabilidade, propostos por Hashimoto, Stedinger e Loucks (1982), a partir do estudo de caso do Sistema Integrado Metropolitano (SIM), responsável pelo abastecimento da Região Metropolitana de São Paulo (RMSP). Neste estudo de caso, foram analisados os ganhos e perdas de desempenho na operação do SIM, de forma comparativa, a partir de 3 (três) cenários de operação do sistema. As análises também foram realizadas a partir do Índice de Sustentabilidade proposto por Sandoval-Solis, Mckinney e Loucks (2011), que realiza a agregação dos 3 (três) indicadores de desempenho em um único índice compreensivo.

Cada um dos 3 (três) cenários propostos representou uma configuração diferente da rede estrutural do SIM: Cenário 1, a rede-base de comparação, com todos os sistemas produtores operando isoladamente; Cenário 2 , rede isolada acrescida de novos aportes de água oriundos das obras de segurança hídrica, e; Cenário 3, a rede integrada através do estabelecimento de pontos de demandas compartilhadas entre mais de um sistema produtor.

Neste trabalho, os Índices de Sustentabilidade para o Sistema Integrado Metropolitano foram demonstrados em termos diretos, calculados de forma direta a partir dos indicadores de desempenho globais do SIM, e ponderados, considerando o peso relativo de cada sistema produtor no contexto global de produção de água do SIM. Ressalta-se principalmente a importância desta segunda abordagem, que demonstram mais assertivamente a sustentabilidade global de sistemas de recursos hídricos complexos, uma vez que considera o peso relativo de cada um de seus componentes individuais.

A partir da análise comparativa entre os cenários foi possível mensurar os efetivos ganhos de desempenho obtidos com a evolução na configuração da rede. $A$ inclusão das obras da crise hídrica elevou a sustentabilidade global do SIM (ISP) em $13,6 \%$, enquanto a integração da rede, após a consideração das obras, produziu um ganho global de $13,0 \%$ para o sistema.

Nesta questão, conforme apontado por Loucks (1997), é importante ponderar que ao se estabelecer que uma alternativa se apresenta "mais sustentável" que outra, deve-se ressaltar que esta atribuição foi feita considerando: os critérios de avaliação 
selecionados, os valores de cada critério que são considerados satisfatórios e insatisfatórios, e o relativo peso entre eles. Ainda assim, se o grupo de critérios utilizados é compreensivo e identifica as principais preocupações e objetivos atuais das partes interessadas, considerando cenários futuros, se possível, a sustentabilidade de um sistema medida através do Índice de Sustentabilidade pode ser utilizada nos processos de gestão e tomada de decisão em recursos hídricos.

No estudo de caso analisado neste trabalho, nota-se que os dados de vazão apresentaram um comportamento mais estável ao longo do tempo, justamente pelo fato de terem sido avaliados nos pontos de fornecimento (ETA's) que captam água de sistemas de armazenamento (reservatórios) de para regularização de vazões. Por outro lado, os dados de volume dos reservatórios demonstraram um comportamento com maior variabilidade temporal, resultando assim em indicadores de desempenho mais instáveis e variáveis ao longo das séries analisadas.

Conforme exposto, neste trabalho realizou-se a avaliação dos indicadores de desempenho de forma desagregada, ou seja, por meio do comportamento individual de cada um deles, e agregada, através do Índice de Sustentabilidade, sendo estas duas abordagens distintas que aportam informações importantes para a gestão de sistemas de recursos hídricos complexos, como foi o caso do Sistema Integrado Metropolitano.

A avaliação individualizada de cada um dos indicadores contribui de forma importante no âmbito do reconhecimento e da compreensão dos múltiplos impactos que os eventos de falha infringem à operação de um determinado sistema, uma vez que cada indicador está ligado a um aspecto fundamental de sua operação. Permitindo ainda a avaliação da troca de benefícios (trade-offs) entre cada um deles.

Os indicadores de Confiabilidade, Resiliência e Vulnerabilidade ligam-se diretamente aos fatores probabilísticos da operação do sistema, na medida em que, a partir de uma amostra extensa de dados, demonstram a tendência de como o sistema deverá reagir a eventos de falha, oferecendo, assim, aos gestores um melhor entendimento sobre os riscos aos quais os sistemas de recursos hídricos estão expostos, seja por eventos naturais, como períodos de baixas afluências naturais, seja por questões decisórias, como a ampliação da captação de uma Estação de Tratamento de Água.

Por outro lado, a avaliação de desempenho dos sistemas de recursos hídricos de forma agregada, por meio do Índice de Sustentabilidade, oferece uma visão global 
do desempenho do sistema nos parâmetros determinados, que se traduz em uma ferramenta prática, compreensiva e objetiva para a orientação do processo de tomada de decisões, principalmente quando trocas complexas de benefícios entre os indicadores individualizados podem dificultar uma visão holística do tomador de decisão, necessária no processo de tomada de decisão multi-objetivo.

Quando na identificação, comparação e análise de alternativas em que os resultados dos critérios estabelecidos podem não convergir para uma definição objetiva, devido às divergências de resultados de desempenho, os processos de negociação e tomada de decisão podem ser facilitados pelo uso do Índice de Sustentabilidade, conforme apontam Sandoval-Solis, Mckinney e Loucks (2011).

$\mathrm{O}$ uso dos indicadores de desempenho e índices de sustentabilidade assume ainda importante função frente à possibilidade de sua aplicação às análises de impactos dos cenários de mudanças climáticas. Conforme visto neste trabalho, a utilização destas ferramentas possui elevada aplicabilidade aos problemas que envolvem análises comparativas e mensuração de benefícios entre múltiplos cenários.

O presente trabalho sugeriu ainda que a avaliação de sistemas de recursos hídricos, frente a diversos cenários operacionais, por meio dos índices e indicadores de desempenho complementa abordagens e métodos tradicionais de análise de resultados, como por exemplo, a avaliação de garantias através de curvas de permanência.

Por fim, retomando o exposto por Hashimoto, Stedinger e Loucks (1982), dadas as devidas ponderações, o uso dos critérios de desempenho para avaliação do risco de sistemas de recursos hídricos incrementa a habilidade dos gestores e tomadores de decisão para, de forma objetiva, descrever qual a frequência que as falhas podem ocorrer, qual a duração estimada dos eventos de falhas, em quanto tempo o sistema deve recobrar sua condição satisfatória de operação e quão severas as falhas deverão ser, uma vez que elas ocorram. Informações estas que são de elevado valor estratégico na gestão integrada de sistemas complexos de recursos hídricos. 


\section{SUGESTÕES PARA TRABALHOS FUTUROS}

Apesar de aportarem informações relevantes sobre o desempenho de sistemas de recursos hídricos complexos, os indicadores utilizados neste trabalho ainda dependem da sensibilidade dos gestores, analistas e tomadores de decisões quanto ao estabelecimento das metas para cada variável a ser analisada.

A definição do que são consideradas as condições satisfatórias (sucesso) e insatisfatórias (falha) de uma determinada variável do sistema avaliado tem um razoável grau de subjetividade e, quase sempre, são embasadas no julgamento humano sobre objetivos específicos esperadas do sistema, e não sobre bases científicas.

Em certos casos, as condições podem ser baseadas em padrões bem definidos, como planos de gestão e outorgas, mas as condições satisfatórias e insatisfatórias não se encontram pré-definidas, muito menos publicadas, para as diversas variáveis da gestão de recursos hídricos (LOUCKS, 1997).

Neste contexto, deve-se avançar nos processos de definição do que realmente são condições satisfatórias e insatisfatórias de cada sistema a ser analisado, procurando-se minimizar o grau de subjetividade destas escolhas. Deve-se ainda considerar a utilização de metas dinâmicas, adaptativas, variáveis ao longo do tempo, que podem, porventura, melhor representar as condições reais de operação dos sistemas de recursos hídricos avaliados.

Conforme apontado por Asefa et al. (2014), na avaliação da performance de sistemas, não há forma clara de se agregar as métricas de desempenho em um único índice sem introduzir um fator de ponderação subjetiva, uma vez que cada métrica avalia um aspecto diferente do sistema. A própria média geométrica utilizada no Índice de Sustentabilidade já implicitamente considera uma ponderação igual entre todos os indicadores, o que pode não ser necessariamente aplicável a todos os sistemas, tendo em vista que cada problema em recursos hídricos é uma situação única, e é pouco provável que a mesma abordagem sobre desempenho de um sistema seja diretamente aplicável aos demais.

Devido às especificidades de cada problema formulado, bem como das próprias características dos sistemas a serem estudados, os critérios de desempenho podem se comportar de forma aleatória, como se viu, por exemplo, neste mesmo trabalho. Em certos casos, observou-se a melhora de todos os indicadores, enquanto 
em outros, um indicador melhorava, ao passo que os outros pioravam. Nestes casos, deve-se discutir sobre importância de se definirem pesos relativos na avaliação dos critérios. Nesta linha, deve-se avançar nos estudos das características que são mais efetivamente importantes para cada sistema, de forma a se poder priorizar um determinado indicador em relação ao outro, quando da otimização dos resultados de um determinado cenário de avaliação.

Estudos futuros para a análise de desempenho do Sistema Integrado Metropolitano devem ainda considerar a utilização de indicadores de desempenho de base dinâmica, como a Resiliência Dinâmica, proposta por Simonovic e Arunkumar (2016), que integra não só a mensuração da performance do sistema em um dado critério, mas também a sua capacidade adaptativa aos eventos de falhas, considerando as características específicas dos reservatórios, como: robustez, redundância, desenvoltura e celeridade (do inglês, Robustness, Redundancy, Resourcefulness, Rapidity). Segundo estes autores, a Resiliência Dinâmica constitui uma importante ferramenta na seleção de medidas pró-ativas e reativas-adaptativas como resposta de eventos de falhas na operação de sistemas de recursos hídricos de múltiplos usos, somando assim ao rol de ferramentas de avaliação de desempenho como as utilizadas neste trabalho.

Conforme verificado por Kjeldsen e Rosbjerb (2004), a métrica de Confiabilidade apresenta um comportamento monotônico (do inglês, monotonic behavior) em relação ao número de eventos de falha de uma determinada operação, ou seja, reduz-se a Confiabilidade à medida em que se aumentam o número de falhas, e vice-versa. A Resiliência e Vulnerabilidade, por outro lado, não apresenta esse mesmo comportamento. Apesar das séries históricas de dados serem utilizadas em diversos estudos na área, segundo os autores, o cálculo da Resiliência e Vulnerabilidade tende a ser melhorado em robustez com a utilização de longas séries sintéticas, de ao menos 1000 anos, obtidas a partir de modelos estocásticos. Isto ocorre devido ao aumento do número de falhas, muitas vezes limitadas nas séries de duração histórica, conforme pôde ser verificado para alguns sistemas nos cenários simulados neste trabalho.

Portanto, para estudos futuros, recomenda-se também a consideração de séries temporais mais longas, que possibilitem a ocorrência de um maior número de falhas na série, e assim, possibilite também o avanço nos estudos de troca de benefícios (trade-offs) entre indicadores. É preferível a ocorrência de falhas mais 
frequentes de baixa magnitude ou falhas pouco frequentes, mas de elevado déficit? Deve-se priorizar cenários com menos falhas e pequenos déficits? Mas a que custo? Perguntas como estas devem poder ser respondidas nos futuros estudos da área. 
ANA, Agência Nacional De Águas. Conjuntura dos recursos hídricos no Brasil 2017: relatório pleno / Agência Nacional de Águas. Brasília, 169p, 2017.

ANA, Agência Nacional De Águas. SAR - Sistema de Acompanhamento de Reservatórios. Dados de operação dos reservatórios SIN, 2019. Disponivel em: <https://www.ana.gov.br/sar0/MedicaoSin>. Acesso em: 15 agosto 2019.

AJAMI, N. K.; HORNBERGER, G. M.; SUNDING, D. L. Sustainable water resource management under hydrological uncertainty. Water Resources Research, v. 44, n. $11,2008$.

ASEFA, T. et al. Performance evaluation of a water resources system under varying climatic conditions: Reliability, Resilience, Vulnerability and beyond. Journal of Hydrology, n. 508, 53-65, 2014.

BROWN, A.; MATLOCK, M. D. A Review of Water Scarcity Indices and Methodologies. White Paper \#106. The Sustainability Consortium. [S.I.], p. 19. 2011.

daee, departamento de ÁGuas e energia elÉtricA. Portaria daee no 2104, de 16 de setembro de 2010. Secretaria de Saneamento e Recursos Hídricos do Estado de São Paulo. São Paulo. 2010.

DAEe, departamento de ÁGuas e energia elÉtricA. Portaria Daee no 2792, de 17 de novembro de 2014. Secretaria de Saneamento e Recursos Hídricos do Estado de São Paulo. São Paulo. 2014.

daee, departamento de ÁGuas e energia elÉtricA. Portaria daee no 350, 11 de fevereiro de 2014. Secretaria do Estado de Saneamento e Recursos Hídricos do Estado de São Paulo. São Paulo. 2014. 
daee, departamento de ÁGuas e energia elÉtricA. Portaria daee no 3975, de 21 de dezembro de 2016. Secretaria de Saneamento e Recursos Hídricos do Estado de São Paulo. São Paulo. 2016.

DAEe, Departamento de ÁGuas e energia ElÉtricA. Portaria DaEe no 2443, de 02 de agosto de 2017. Secretaria de Saneamento e Recursos Hídricos do Estado de São Paulo. São Paulo. 2017.

DAEe, departamento de ÁGuas e energia elÉtricA. Portaria daEe no 3062, de 21 de setembro de 2017. Secretaria de Saneamento e Recursos Hídricos do Estado de São Paulo. São Paulo. 2017.

DAEe, departamento de ÁGuas e energia elÉtricA. Portaria daee no 588, de 22 de fevereiro de 2017. Secretaria de Saneamento e Recursos Hídricos do Estado de São Paulo. São Paulo. 2017.

DAEE, Departamento de ÁGuAs e energia ElÉtricA. Portaria daee no 3373, de 26 de junho de 2018. Secretaria de Saneamento e Recursos Hídricos do Estado de São Paulo. São Paulo. 2018.

DAEE, DEPARTAMENTO DE ÁGUAS E ENERGIA ELÉTRICA; ANA, AGÊNCIA NACIONAL DE ÁGUAS. Resolução Conjunta ANA/DAEE no 926, de 29 de maio de 2017. São Paulo. 2017.

DOOGE, J. Linear theory of hydrologic systems. Agricultural Research Service, US Department of Agriculture, 1973.

FARIAS, E. E. V.; CURI, W. F.; DINIZ, L. S. São Francisco river Integration Project, Eastern Axis: losses analysis and performance indicators. RBRH, v. 22, 2017.

FOWLER, H. J.; KILSBY, C. G.; O'CONNELL, P. E. Modeling the impacts of climatic change and variability on the reliability, resilience, and vulnerability of a water resource system. Water Resources Research, v. 39, n. 8, 2003. 
GARCIA, J. I. B. Sistema de suporte a decisão para o lançamento de efluentes. Tese de Doutorado. Universidade de São Paulo. 2011.

HASHIMOTO, T.; STEDINGER, J. R.; LOUCKS, D. P. Reliability, Resiliency and Vulnerability Criteria for Water Resource System Performance Evaluation. Water Resources Research, 18, № 1, 14-20, Fevereiro 1982.

JUNIOR, W. P. V.; LANNA, A. E. L. Simulação e Otimização da Operação de um Sistema de Reservatórios: Bacia do Rio Curu. RBRH - Revista Brasileira de Recursos Hídricos Volume 7 n.3, 63-83, Jul/Set 2002.

KARAMOUZ, M. et al. Water resources systems analysis. Boca Raton, FL: Lewis Publishers, 2003.

KJELDSEN, T. R.; ROSBJERG, D. Choice of reliability, resilience and vulnerability estimators for risk assessments of water resources systems. Hydrological Sciences Journal, 5, 755-767, 2004.

LABADIE, J. W., Dynamic Programming with the Microcomputer in Encyclopedia of microcomputers, Vol. 5, A. Kent and J. Williams, eds., Marcel Dekker Inc., New York, 1990.

LABADIE, J. W. Descision support systems applied to water resources engineering, Curso promovido pela SABESP_EPUSP, São Paulo, 1998.

LOBATO DA COSTA, F. J. Água Brasil serie: estratégias de gerenciamento dos recursos hídricos no Brasil, áreas de cooperação com o banco mundial. BANCO MUNDIAL, 2003.

LOUCKS, D. P. Quantifying trends in system sustainability. Hydrological Sciences Journal, n. 42:4, 513-530, 1997. 
LOUCKS, D. P.; GLADWELL, John S. Sustainability criteria for water resource systems. Cambridge University Press, 1999.

LOUCKS, D. P.; VAN BEEK, E. Water Resources Systems Planning and Management: An Introduction to Methods, Models and Applications. UNESCO. Paris, p. 690. 2005.

PAIXÃO, M. P.; et al. Aplicação de indicadores de performance na avaliação de sistemas hídricos: um estudo de caso. 2002.

PEIXOTO, L. S.; MAUAD, F. F. Estudo de conflitos de usos múltiplos da água utilizando simulação computacional. Revista Brasileira de Recursos Hídricos, Porto Alegre, v. 8, p. 209-215, 2003.

PORTO, M. Recursos hídricos e saneamento na Região Metropolitana de São Paulo: um desafio do tamanho da cidade. In: Serie Água Brasil. Banco Mundial, 2003.

PORTO, R. L. L. (Ed.). Fundamentos para a Gestão da Água. FEHIDRO, Governo do Estado de São Paulo, Secretaria de Saneamento e Recursos Hídricos, 2012.

PORTO, R. L; AZEVEDO, L. G. T. Sistema de Suporte a Decisão Aplicado a Problemas de Recursos Hídricos. In: Técnicas quantitativas para o gerenciamento de recursos hídricos. Org. por Porto, R. L., ABRH, ed. UFRGS, Porto Alegre - RS, pp. $43-95 p, 1997$.

PORTO, R. L. L., MELLO JR, A. V., ROBERTO A. N., R. B., Plataforma Generalizada para Análise de Outorga para Captação de Água e para Lançamento de Efluentes. In: I Simpósio de Recursos Hídricos do Sul-Sudeste, Curitiba - PR, 2006.

PORTO, R. L.; ROBERTO, A. N. Manual do Usuário - AcquaNet. (Versão 1). Laboratório de Sistemas de Suporte a Decisão - LabSid/USP. São Paulo, p. 72. 2015. 
SABESP. Crise Hídrica, Estratégia e Soluções da Sabesp para a Região Metropolitana de São Paulo. Companhia de Saneamento Básico do Estado de São Paulo - Sabesp. São Paulo, p. 95. 2015.

SABESP/ENCIBRA. Relatório Parcial RP06C Estudo de Modelagem Hídrica das Transferências entre os Sistemas Produtores para o Sistema Integrado - SIM. Companhia Estadual de Saneamento do Estado de São Paulo - Sabesp. São Paulo, p. 87. 2017.

SABESP/ENCIBRA. Revisão e Atualização do Plano Diretor de Abastecimento de Água da Região Metropolitana de São Paulo - RMSP / Relatório Final Volume II. Companhia de Saneamento Básico do Estado de São Paulo - Sabesp. São Paulo, p. 214. 2017.

SANDOVAL-SOLIS, S.; MCKINNEY, D. C.; LOUCKS, D. P. Sustainability Index for Water Resources Planning and Management. Journal of Water Resources Planning and Management, 381-390, Setembro/Outubro 2011.

SICHE, R. et al. Índices versus indicadores: Precisões conceituais na discussão da sustentabilidade de países. Ambiente \& Sociedade, Campinas, v. X, n. 2, p. 137148, jul-dez, 2007.

SIMONOVIC, S. P.; ARUNJUMAR, R. Comparison of static and dynamic resilience for a multipurpose. Water Resources Research, 8630-8649, 2016.

TUCCI, C. E. M. Hidrologia: Ciência e Aplicação. 4⿳亠丷. ed. Porto Alegre: UFRGS/ABRH, 2012.

TUCCI, C. E. M. et al. Modelos hidrológicos. Editora da Universidade Federal do Rio Grande do Sul (UFRGS). Porto Alegre, 1998.

WHITE, I. D.; MOTTERSHEAD, D. N.; HARRISON, S. J. Environmental systems: an introductory text. Psychology Press, 1998. 
ZONGXUE, X. et al. Performance risk analysis for Fukuoka water supply system.

Water Resources Management, v. 12, n. 1, p. 13-30, 1998. 